UNIVERSIDADE DE BRASÍLIA

FACULDADE DE TECNOLOGIA

DEPARTAMENTO DE ENGENHARIA CIVIL E AMBIENTAL

ESTUDO MICROESTRUTURAL DO COMPORTAMENTO HIDROMECÂNICO DO SOLO DE BRASÍLIA-DF

CAMILLA RODRIGUES BORGES

ORIENTADOR: MANOEL PORFÍRIO CORDÃO NETO, DSC.

TESE DE DOUTORADO EM GEOTECNIA

PUBLICAÇÃO: G.TD-102/14

BRASÍLIA/DF: OUTUBRO/2014 
UNIVERSIDADE DE BRASÍLIA

FACULDADE DE TECNOLOGIA

DEPARTAMENTO DE ENGENHARIA CIVIL E AMBIENTAL

\section{ESTUDO MICROESTRUTURAL DO COMPORTAMENTO \\ HIDROMECÂNICO DO SOLO DE BRASÍLIA-DF}

\section{CAMILLA RODRIGUES BORGES}

TESE DE DOUTORADO SUBMETIDA AO DEPARTAMENTO DE ENGENHARIA CIVIL E AMBIENTAL DA UNIVERSIDAdE DE BRASÍLIA COMO PARTE DOS REQUISITOS NECESSÁRIOS PARA A OBTENÇÃO DO GRAU DE DOUTOR.

APROVADA POR:

MANOEL PORFÍRIO CORDÃO NETO, DSc.(UnB)

ORIENTADOR

JOSÉ CAMAPUM DE CARVALHO, DSc.(UnB)

(EXAMINADOR INTERNO)

MÁRCIO MUNIZ DE FARIAS, PhD (UnB)

(EXAMINADOR INTERNO)

FERNANDO ANTÔNIO MEDEIROS MARINHO, PhD (USP) (EXAMINADOR EXTERNO)

MARCIA MARIA DOS ANJOS MASCARENHA, DSc.( (UFG) (EXAMINADOR EXTERNO)

DATA: BRASÍLIA/DF, 10 de OUTUBRO de 2014. 


\section{FICHA CATALOGRÁFICA}

\section{BORGES, CAMILLA RODRIGUES}

Estudo microestrutural do comportamento hidromecânico do solo de Brasília-DF, Distrito Federal, 2014. xxxii, 112p., 297 mm (ENC/FT/UnB, Doutor, Geotecnia, 2014)

Tese de Doutorado - Universidade de Brasília. Faculdade de Tecnologia. Departamento de Engenharia Civil e Ambiental

1. Solos não saturados $\quad$ 2. Comportamento hidromecânico

3. Estrutura 4. Distribuição do tamanho dos poros

I. ENC/FT/UnB II. Título (série)

\section{REFERÊNCIA BIBLIOGRÁFICA}

BORGES, C. R. (2014). Estudo microestrutural do comportamento hidromecânico do solo de Brasília-DF, Distrito Federal, 2014. Tese de Doutorado, Publicação G.TD-102/14, Departamento de Engenharia Civil e Ambiental, Universidade de Brasília, Brasília-DF, 112p.

\section{CESSÃO DE DIREITOS}

NOME DO AUTOR: Camilla Rodrigues Borges

TÍTULO DA TESE DE DOUTORADO: Estudo microestrutural do comportamento hidromecânico do solo de Brasília-DF

GRAU: Doutor ANO: 2014

É concedida à Universidade de Brasília a permissão para reproduzir cópias desta tese de doutorado e para emprestar ou vender tais cópias somente para propósitos acadêmicos e científicos. O autor reserva outros direitos de publicação e nenhuma parte desta tese de doutorado pode ser reproduzida sem a autorização por escrito do autor.

Camilla Rodrigues Borges

SEPS 712/912, BLOCO C, APTO. 423. EDIFÍCIO GRAND VILLE, ASA SUL

CEP: 70390-125 Brasília/DF - Brasil

camillarb@gmail.com 


\section{AGRADECIMENTOS}

A Deus, por todas as bênçãos que tem me concedido, por estar sempre comigo principalmente em meio às tempestades, guiando-me, iluminando meu caminho e me dando forças para seguir adiante em busca de novas conquistas.

A meus pais, João e Leusa, aos meus irmãos, Gustavo e Renan, à minha cunhada Sara e o meu sobrinho/afilhado Caê, pelo apoio, carinho, paciência, amor e compreensão nos momentos em que eu tanto precisei, pelo incentivo ao aprendizado contínuo e pela confiança depositada em mim, durante esta jornada da minha vida. Família que eu admiro, respeito e pela qual terei enorme gratidão por toda minha vida. Obrigada por compreenderem minha ausência nos momentos importantes!

A toda minha família, avós, tios, primos pelo apoio, carinho, paciência e atenção.

Ao professor Manoel Porfírio Cordão Neto pela orientação, paciência, pelo incentivo nos momentos de dificuldade e pela confiança depositada em mim. Obrigada por sua dedicação e por todo conhecimento que me foi transmitido ao longo da pesquisa. Esses quatro anos de convivência foram muito importantes para mim. Ao tê-lo como orientador adquiri ensinamentos preciosos. Obrigada por tudo!

Aos meus amigos: Rosely, Mariana, Bruna, Oisy, Angela, Marlon e Leonardo. Pelo carinho e apoio, por todos os momentos que passamos. Obrigada.

A todos os professores e colegas, pelos ensinamentos e companheirismo durante esta jornada.

À secretária Cida, pelo carinho e paciência, e por sempre atender cordialmente aos meus pedidos na secretaria.

Ao professor Bernardo Caicedo e ao Departamento de Engenharia Civil e Ambiental da Universidade dos Andes, Bogotá-Colombia, pela disponibilização do equipamento de intrusão de mercúrio.

Ao Laboratório de Mecânica dos Solos da Universidade de Brasília, pela disponibilização dos equipamentos laboratoriais para execução dos ensaios.

A CAPES e CNPq pelo auxílio financeiro na realização desta pesquisa.

Enfim, a todos que, direta ou indiretamente, contribuíram para realização deste trabalho. 


\section{RESUMO}

Nas últimas décadas houve uma evolução da análise da estrutura do solo, além disso, houve um aperfeiçoamento da avaliação e dos aspectos de determinação dessa estrutura e como ela se relaciona com o comportamento hidráulico e mecânico do solo. Devido à necessidade de compreensão do comportamento do solo tropical sobre diversas estruturas (natural, compactada e lama) o estudo desenvolvido foi realizado por meio dos ensaios de Porosimetria por Intrusão de Mercúrio (MIP), permitindo assim as análises da característica da estrutura desses solos. O principal objetivo desta pesquisa é avaliar como estas diversas estruturas são afetadas por solicitações externas e como a variação no tamanho destes diferentes poros afeta o comportamento hidromecânico do solo na condição saturada e não saturada. O estudo consiste em: ensaios de caracterização física e compactação, preparação das amostras, ensaios mecânicos (adensamento), ensaios hidráulicos (curva de retenção). Após estes ensaios foram preparados os corpos de prova para a realização de ensaios de porosimetria por intrusão de mercúrio, com o intuito de avaliar a estrutura do solo. Observou-se nos resultados de compressão que mesmo as amostras tendo estruturas iniciais diferentes, estas tendem a convergir. Os resultados demonstraram que a estrutura tem um efeito maior sobre o comportamento do solo para os carregamentos iniciais e que, depois de atingir certo nível de carregamento as diferentes amostras tendem a ter comportamento mecânico semelhante. Também mostraram que tanto a curva de retenção, como a curva de distribuição do tamanho dos poros, têm o comportamento bimodal e que, independente da trajetória hidromecânica utilizada, a microestrutura de todas as amostras analisadas permaneceu praticamente inalteradas. Além disso, com o aumento do carregamento mecânico houve uma diminuição dos macroporos, sendo que a aplicação de sucção desacelerou a destruição da macroestrutura das amostras. O trabalho mostra ainda que a modelagem da curva de distribuição do tamanho dos poros e da curva de retenção utilizadas apresentaram resultados satisfatórios. Por fim, a partir das análises de distribuição do tamanho de poros realizadas nesta pesquisa, foi proposta uma curva de distribuição de poros efetiva. Esta proposta simplifica a compreensão da evolução da macroestrutura, inclusive sendo possível perceber com mais nitidez o efeito da sucção na desaceleração da destruição da estrutura.

Palavras-chave: Solos não saturados, Comportamento hidromecânico, Estrutura, Distribuição do tamanho dos poros. 


\begin{abstract}
In the last decades there was an evolution in the analysis of the soil structure, most importantly, there was an improvement in the evaluation and in the ways of determinaning the mentioned structure and how it relates to the hydromechanical behaviour of soils. Due to the necessity of understanding the behaviour of tropical soils under different structures (natural, compacted and slurry) this study was developed by means of the Mercury Intrusion Porosimetry (MIP), enabling the analysis of the structural characteristics of these soils. The main objective of this thesis is to evaluate how the different strucutres are affected by external loading and how the changes in the pore sizes influences the hydromechanical behaviour of the soil in both, saturated and unsaturated conditions. This study consists of: physical characterisation and compaction tests, samples preparation, consolidation tests, and water retention curve tests. After that, soil specimens were prepared for the Mercury Intrusion Porosimetry test, in order to analyse the soil structure. Consolidation test results showed that even though the specimens have different initial structures, they all tend to converge. The results indicated that the structure has more effect over the soil behaviour in the initial load and after a certain level of loading the different specimens are likely to mechanically behave similarly. Furthermore, the results showed that both the water retention curve and the pore size destribution curve are bimodal curves. Regardless the hydromechanical path used, the microstructure of all specimens analysed remained virtually unchanged. Moreover, as the loading increased there was a reduction of the macropores, and the suction slowed the macrostructure evolution. This study also shows that the modelling of the pore size distribution curve and the water retention curve chosen were appropriate. From the pore size distribution analysis an effective pore size distribution curve was proposed based on the wellknown particle size distribution curve. This proposal simplifies the understanding of the macrostructure evolution, also helping in the visualization of the suction effect on the slowing down of the structure evolution.
\end{abstract}

Key words: Unsaturated soils, Hydromechanical behaviour, Structure, Pore size destribution. 


\section{SUMÁRIO}

1 - INTRODUÇÃ

1.1 - MOTIVAÇÃO _ 2

1.2 - OBJETIVOS _ 3

1.3 - ORGANIZAÇÃO DA TESE ___ 3

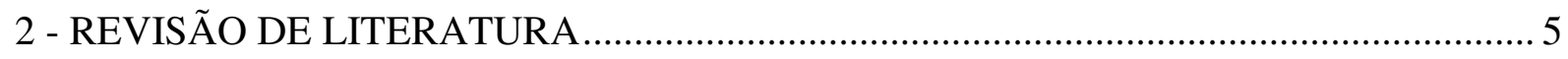

2.1 - CONCEITOS

2.2 - ANÁLISE MICROESTRUTURAL DO SOLO ___ 6

2.3 - COMPORTAMENTO HIDRÁULICO VERSUS POROSIMETRIA ___ 12

2.4 - COMPORTAMENTO MECÂNICO VERSUS POROSIMETRIA___ 19

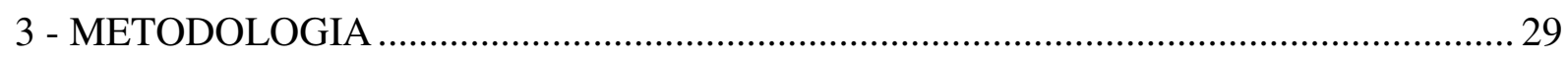

3.1 - PREPARAÇÃO E CARACTERIZAÇÃO FÍSICA DAS AMOSTRAS _ 30

3.2 - PREPARAÇÃO DAS AMOSTRAS COMPACTADAS ___ 31

3.3 - PREPARAÇÃO DAS AMOSTRAS DE LAMA _ 32

3.4 - ENSAIOS DE ADENSAMENTO __ 33

3.4.1 - CÉlula DE ADENSAMENTO COM CONTROLE DE SUCÇÃO TRANSLAÇÃO DE EIXO _ _ 34

3.4.2 - CÉLULA DE ADENSAMENTO COM CONTROLE DE SUCÇÃO OSMÓTICA 35

3.5 - DETERMINAÇÃO DA CURVA DE RETENÇÃO __ 37

3.5.1 - PAPEL FILTRO _ 38

3.5 .2 - TRANSLAÇÃO DE EIXO __ 39

3.5.3 - PSICRÔMETRO - WP4__ 40

3.6 - ENSAIO DE POROSIMETRIA POR INTRUSÃO DE MERCÚRIO___ 41

3.7 - PREPARAÇÃO DE CORPOS DE PROVA PARA ANÁLISE ESTRUTURAL _ 42

3.7.1 - CORPOS DE PROVA SATURADOS _ 43

3.7.2 - CORPOS DE PROVA NÃO SATURADOS $(\mathrm{s}=50 \mathrm{kPa}) \_45$ 
3.7.3 - CORPOS DE PROVA NÃO SATURADOS $(\mathrm{s}=1.000 \mathrm{kPa})$ 46

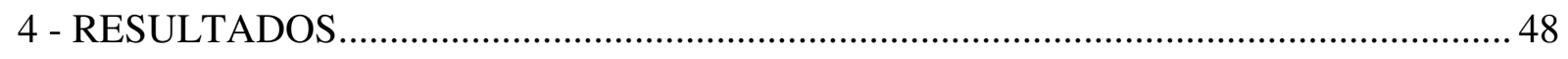

4.1 - CARACTERIZAÇÃO __ 48

4.2 - COMPORTAMENTO HIDRÁULICO

4.3 - COMPORTAMENTO MECÂNICO _ 53

4.4 - COMPORTAMENTO ESTRUTURAL _ 57

4.4.1 - PREPARAÇÃO DOS CORPOS DE PROVA__ 58

4.4.2 - ANÁLISE ESTRUTURAL _ _ 64

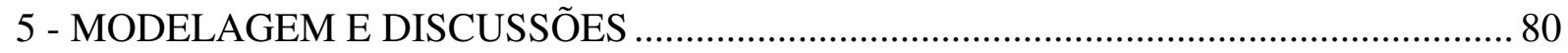

5.1 - ANÁLISE MICROESTRUTURAL DA CURVA DE RETENÇÃO__ 80

5.2 - MODELAGEM DA DISTRIBUIÇÃO DO TAMANHO DOS POROS __ 83

5.3 - ANÁLISE QUALITATIVA DA DISTRIBUIÇÃO DO TAMANHO DOS POROS 96

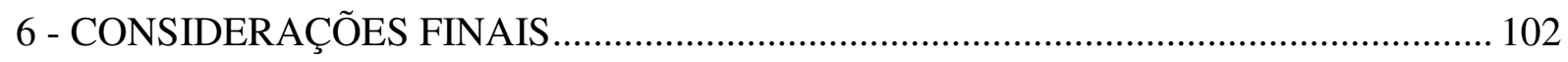

6.1 - CONCLUSÃO _ 102

6.2 - SUGESTÕES A TRABALHOS FUTUROS __ 105

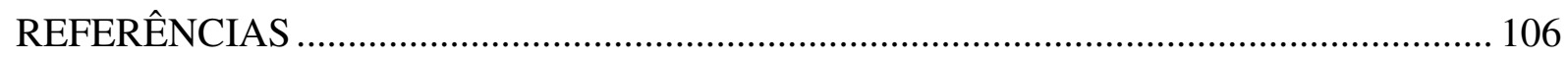




\section{LISTA DE FIGURAS}

Figura 2.1 - Interagregados (macroporos) e Intra-agregados (microporos) 5

Figura 2.2 - Estufa a vácuo para secar a amostra após o congelamento. 8

Figura 2.3 - Curvas de extrusão e intrusão da amostra no estado natural (Mascarenha, 2008).

Figura 2.4 - Relação entre o PSD e os diâmetros dos poros da amostra no estado natural (Mascarenha, 2008). 12

Figura 2.5 - Curvas de retenção do solo obtidas pelo MIP e outras técnicas:(a) e=0,62; (b) e=0,97 (modificada de Romero, 1999).

Figura 2.6 - Curvas de retenção do solo (equação e MIP) (a) em relação à umidade; (b) em relação aos grau de saturação (Mascarenha, 2008). 16

Figura 2.7 - Resultados obtidos a partir da curva de retenção do solo e resultados obtidos pelo MIP: (a) curva de retenção; (b) distribuição do tamanho dos poros (Mascarenha, 2008). _ 17

Figura 2.8 - Predição da PSD através da SAIC. 18

Figura 2.9 - PSD de dois solos tropicais naturais: a) Futai \& Almeida (2005), e b) Miguel \& Bonder (2012).

Figura 2.10 - Predição da PSD com a SAIC: a) com correção de volume, e b) com correção de adsorção (Otálvaro, 2014).

Figura 2.11 - Relação entre a PSD e os diâmetros dos poros das amostras no estado natural e colapsadas (Mascarenha, 2008). 20

Figura 2.12 - Distribuição de poros para amostras compactadas a distintas densidades: a) Romero (1999); b) Buenfil (2007).

Figura 2.13 -Distribuição do tamanho dos poros para amostras compactadas a distintas densidades (Romero et al., 2005).

Figura 2.14 - Evolução da função de PSD com o carregamento, em bentonita FEBEX com teor de umidade constante de 14\% (Romero et al., 2005). 22

Figura 2.15 - Evolução da função PSD na molhagem a uma tensão vertical constantes e volume constante (Lloret \& Villar, 2007).

Figura 2.16 -Distribuição do tamanho dos poros de solos não saturados (Sivakumar et al., 2010) .

Figura 2.17 - Distribuição do tamanho dos poros: (a) amostras levemente comprimidas IS(A); (b) amostras fortemente comprimidas IS(B) (Sivakumar et al., 2010). 24 
Figura 2.18 - Efeitos da anisotropia de tensão induzidas na distribuição do tamanho dos poros: (a) levemente comprimida; (b) fortemente comprimida (Sivakumar et al., 2010). _ 25 Figura 2.19 - Amostras de Silte Bioley ensaiados para a distribuição do tamanho dos poros (PSD) utilizando a técnica de porosimetria por intrusão de mercúrio (MIP) (Koliji et al., 2010). 26

Figura 2.20 - Comparação de resultados de porosimetria por intrusão de mercúrio: (a) efeito da compactação não saturado; (b) efeito da saturação; (c) efeito da compactação saturada; (df) efeito da estrutura (Koliji et al., 2010). 27

Figura 3.1 - Esquema do desenvolvimento da pesquisa. 29

Figura 3.2 - Curva de compactação. 32

Figura 3.3 - Processo de fabricação da lama: (a) lama homogeneizada em um misturador mecânico; (b) solo em forma de lama. 33

Figura 3.4 - Equipamento de adensamento com controle de sucção/pressão. 35

Figura 3.5 - Equipamento de medida de sucção pela técnica osmótica (Otálvaro, 2013) 36

Figura 3.6 - Equipamento WP4C (Dewpoint PotenciaMeter) 40

Figura 3.7 - Equipamento AutoPore IV 9500 Micromeritics Instrument Corporation da Universidade dos Andes. 42

Figura 3.8 - Trajetória mostrada no diagrama de fases da água. 43

Figura 3.9 - Exemplo do processo de amostragem dos corpos de prova para realização do MIP e curva de adensamento $(0,50,100,200,400$ e $800 \mathrm{kPa})$ 44

Figura 3.10 - Equipamento de adensamento com controle de sucção (Otálvaro, 2013) 45

Figura 3.11 - Preparação de corpos de prova por adensamento com variação de sucção para realização do MIP 46

Figura 3.12 - Preparação de corpos de prova por adensamento com sucção de $1000 \mathrm{kPa}$ realização do MIP 47

Figura 4.1 - Curva granulométrica do solo de Brasília-DF (1,7 a 2,30 m): ensaio convencional com o uso de defloculante e sem defloculante. 49

Figura 4.2 - Curva de retenção do solo (modificado - Mascarenha et al., 2014). 50

Figura 4.3 - Curva de retenção do solo Natural (modificado - Grau, 2014). 51

Figura 4.4 - Curva de retenção do solo para amostra Compactada $(e=1,20)$. 51

Figura 4.5 - Curva de retenção do solo para amostra de Lama. 52

Figura 4.6 - Resultados da curva de retenção do solo para amostra Natural, Compactada e Lama. 53 
Figura 4.7 - Curva de adensamento do solo de Compactada (modificado de Silva, 2009)._ 54

Figura 4.8 - Curva de adensamento do solo Compactado.

Figura 4.9 - Curva de adensamento do solo de Lama. __ 55

Figura 4.10 - Curva de adensamento do solo saturado, Natural, Compactado e Lama.__ 56

Figura 4.11 - Curva de adensamento do solo não saturado (s=1000 kPa), Compactado e

Lama.__ 57

Figura 4.12 - Estado da estrutura (modificado - Leroueil \& Vaughan, 1990). ___ 57

Figura 4.13 - Curvas de adensamento do solo Natural e os pontos de ensaio do MIP. __ 60

Figura 4.14 - Curvas de adensamento do solo Compactado saturados e com sucção de 1000 $\mathrm{kPa}$ e os pontos de ensaio do MIP. 60

Figura 4.15 - Curvas de adensamento da Lama, saturados e com sucção de $1.000 \mathrm{kPa}$ e os pontos de ensaio do MIP. 61

Figura 4.16 - Pontos do ensaio do MIP do solo Compactado e da Lama, não saturados com sucção de $50 \mathrm{kPa}$. 61

Figura 4.17 - Argila porosa de Brasília em diferentes estados: (a) Distribuição do tamanho dos poros; (b) Densidade do tamanho dos poros. 64

Figura 4.18 - Argila porosa de Brasília em diferentes estados com carregamento de $50 \mathrm{kPa}$ : (a) Distribuição do tamanho dos poros; (b) Densidade do tamanho dos poros. 66 Figura 4.19 - Argila porosa de Brasília em diferentes estados com carregamento de $100 \mathrm{kPa}$ : (a) Distribuição do tamanho dos poros; (b) Densidade do tamanho dos poros. 66 Figura 4.20 - Argila porosa de Brasília em diferentes estados com carregamento de $200 \mathrm{kPa}$ : (a) Distribuição do tamanho dos poros; (b) Densidade do tamanho dos poros. 67 Figura 4.21 - Argila porosa de Brasília em diferentes estados com carregamento de $400 \mathrm{kPa}$ : (a) Distribuição do tamanho dos poros; (b) Densidade do tamanho dos poros. 67 Figura 4.22 - Argila porosa de Brasília em diferentes estados com carregamento de $800 \mathrm{kPa}$ : (a) Distribuição do tamanho dos poros; (b) Densidade do tamanho dos poros. 68 Figura 4.23 - Argila porosa de Brasília, solo em estado Natural, na condição saturada, para diferentes carregamentos: (a) Distribuição do tamanho dos poros; (b) Densidade do tamanho dos poros. 68

Figura 4.24 - Argila porosa de Brasília, solo Compactado, na condição saturada para diferentes carregamentos: (a) Distribuição do tamanho dos poros; (b) Densidade do tamanho dos poros. 69 
Figura 4.25 - Argila porosa de Brasília, solo em estado de Lama em diferentes carregamentos para o solo saturado: (a) Distribuição do tamanho dos poros; (b) Densidade do tamanho dos poros.

Figura 4.26 - Argila porosa de Brasília, solo Compactado, na condição não saturada, com sucção de $50 \mathrm{kPa}$, para diferentes carregamentos: (a) Distribuição do tamanho dos poros; (b) Densidade do tamanho dos poros. 70

Figura 4.27 - Argila porosa de Brasília, solo em estado de Lama, na condição não saturada, sucção de $50 \mathrm{kPa}$ em diferentes carregamentos: (a) Distribuição do tamanho dos poros; (b) Densidade do tamanho dos poros. 71

Figura 4.28 - Argila porosa de Brasília, solo Compactado para diferentes carregamentos para o solo com sucção de 1.000 kPa: (a) Distribuição do tamanho dos poros; (b) Densidade do tamanho dos poros. 72

Figura 4.29 - Argila porosa de Brasília, solo em estado de Lama em diferentes carregamentos para o solo com sucção de $1.000 \mathrm{kPa}$ : (a) Distribuição do tamanho dos poros; (b) Densidade do tamanho dos poros. 73

Figura 4.30 - Argila porosa de Brasília, solo Compactado com tensão vertical de $50 \mathrm{kPa}$ em diferentes estados para diferentes sucções: (a) Distribuição do tamanho dos poros; (b) Densidade do tamanho dos poros. 74

Figura 4.31 - Argila porosa de Brasília, solo Compactado com tensão vertical de $100 \mathrm{kPa}$ de tensão vertical em diferentes estados para diferentes sucções: (a) Distribuição do tamanho dos poros; (b) Densidade do tamanho dos poros. 74

Figura 4.32 - Argila porosa de Brasília, solo em estado de Lama com tensão vertical de 50 kPa em diferentes estados para diferentes sucções: (a) Distribuição do tamanho dos poros; (b) Densidade do tamanho dos poros. 75

Figura 4.33 - Argila porosa de Brasília, solo em estado de Lama com tensão vertical de 100 $\mathrm{kPa}$ de tensão vertical em diferentes estados, para diferentes sucções: (a) Distribuição do tamanho dos poros; (b) Densidade do tamanho dos poros. 75 Figura 4.34 - Argila porosa de Brasília, solo Compactado com tensão vertical de $200 \mathrm{kPa}$ de tensão vertical em diferentes estados, para diferentes sucções: (a) Distribuição do tamanho dos poros; (b) Densidade do tamanho dos poros. 76

Figura 5.1 - Curva de retenção do solo do compactado de Brasília.

Figura 5.2 - Curva de retenção do solo de Brasília no estado Natural, Compactado e Lama. 82 
Figura 5.3 - Forma da curva de retenção de água do solo, segundo a distribuição do tamanho dos poros (Marinho, 2005).

Figura 5.4 - Ajuste completo das curvas para o solo saturado: (a) Natural, com carregamento de $800 \mathrm{kPa}\left(\mathrm{R}^{2}=0,985\right)$; (b) Natural, com carregamento de $100 \mathrm{kPa}\left(\mathrm{R}^{2}=0,997\right)$. 85 Figura 5.5 - Ajuste completo das curvas do solo Compactado: (a) Saturado, com carregamento de $100 \mathrm{kPa}\left(\mathrm{R}^{2}=0,976\right)$; (b) Saturado, com carregamento de $800 \mathrm{kPa}\left(\mathrm{R}^{2}=\right.$ 0,998). 86

Figura 5.6 - Ajuste completo das curvas para a Lama: (a) Saturado, com carregamento de 100 $\mathrm{kPa}(\mathrm{R} 2=0,990)$; (b) Sucção de $1.000 \mathrm{kPa}$, com carregamento de $100 \mathrm{kPa}(\mathrm{R} 2=0,999)$ _ 87 Figura 5.7 - Ajuste da macro das curvas para o solo Compactado: (a) saturado, sem carregamento $\left(\mathrm{R}^{2}=0,978\right)$; (b) saturado, com carregamento de $800 \mathrm{kPa}\left(\mathrm{R}^{2}=0,999\right)$. 89 Figura 5.8 - Ajuste da macro das curvas para o solo Compactado: (a) saturado, sem carregamento $\left(\mathrm{R}^{2}=0,975\right)$; (b) Saturado, com carregamento de $800 \mathrm{kPa}\left(\mathrm{R}^{2}=0,998\right)$. 89 Figura 5.9 - Ajuste da macro das curvas para a Lama(a) saturada, sem carregamento $\left(\mathrm{R}^{2}=\right.$ 0,992) (b) sucção de $50 \mathrm{kPa}$, com carregamento de $100 \mathrm{kPa}\left(\mathrm{R}^{2}=0,998\right)$. 90 Figura 5.10 - Variação dos parâmetros de ajuste do solo saturado no estado Natural: (a) Poro dominante - $\alpha_{M}$; (b) Coeficiente de uniformidade - $\mathrm{n}_{M}$. 92 Figura 5.11 - Variação dos parâmetros de ajuste do solo saturado no estado Compactado: (a) Poro dominante - $\alpha_{M}$; (b) Coeficiente de uniformidade - $\mathrm{n}_{M}$. 92 Figura 5.12 - Variação dos parâmetros de ajuste do solo saturado no estado de Lama: (a) Poro dominante - $\alpha_{M}$; (b) Coeficiente de uniformidade - $\mathrm{n}_{M}$. 93 Figura 5.13 - Variação dos parâmetros de ajuste do solo não saturado com sucção de $50 \mathrm{kPa}$ no estado Compactado: (a) Poro dominante - $\alpha_{M}$; (b) Coeficiente de uniformidade $-\mathrm{n}_{M}$. 94 Figura 5.14 - Variação dos parâmetros de ajuste do solo não saturado com sucção de $50 \mathrm{kPa}$ no estado de Lama: (a) Poro dominante - $\alpha_{M}$; (b) Coeficiente de uniformidade - $\mathrm{n}_{\mathrm{M}}$. 94 Figura 5.15 - Variação dos parâmetros de ajuste do solo não saturado com sucção de 1.000 kPa no estado Compactado: (a) Poro dominante - $\alpha_{M}$; (b) Coeficiente de uniformidade - $\mathrm{n}_{M} .95$ Figura 5.16 - Variação dos parâmetros de ajuste do solo não saturado com sucção de 1.000 kPa no estado de Lama: (a) Poro dominante - $\alpha_{M}$; (b) Coeficiente de uniformidade - $n_{M}$ ___ 95 Figura 5.17 - Relação do índice de vazios relativo versus Diâmetro aparente dos poros para o solo Natural na condição saturada. 97 Figura 5.18 - Relação do índice de vazios relativo versus Diâmetro aparente dos poros para o solo Compactado na condição saturada. 98 
Figura 5.19 - Relação do índice de vazios relativo versus Diâmetro aparente dos poros para a Lama na condição saturada.

Figura 5.20 - Relação do índice de vazios relativo versus Diâmetro aparente dos poros para o solo Compactado com sucção de $1.000 \mathrm{kPa}$. 100

Figura 5.21 - Relação do índice de vazios relativo versus Diâmetro aparente dos poros para a Lama com sucção de $1.000 \mathrm{kPa}$. 101 


\section{LISTA DE TABELAS}

Tabela 3.1 - Ensaios de caracterização física. 31

Tabela 3.2 - Curvas de calibração do papel filtro Whatman $n^{0} 42$ 39

Tabela 3.3 - Nomenclatura dos corpos de prova saturados utilizada no MIP 44

Tabela 3.4 - Nomenclatura dos corpos de prova não saturados, com sucção de $50 \mathrm{kPa}$, utilizada no MIP 46

Tabela 3.5 - Nomenclatura dos corpos de prova não saturados, com sucção de $1000 \mathrm{kPa}$, utilizada no MIP

Tabela 4.1 - Resumo geral dos parâmetros de compressibilidade. 53

Tabela 4.2 - Característica dos corpos de prova do solos saturados. 58

Tabela 4.3 - Característica dos corpos de prova do solos não saturado com sucção de $50 \mathrm{kPa}$.

Tabela 4.4 - Característica dos corpos de prova do solos não saturado com sucção de 1000 $\mathrm{kPa}$.

Tabela 4.5 - Variação do índice de vazios para os solos saturados. 62

Tabela 4.6 - Variação do índice de vazios para os solos não saturados, com sucção de 50 kPa.

Tabela 4.7 - Variação do índice de vazios para os solos não saturados, com sucção de 1000 $\mathrm{kPa}$. 63

Tabela 5.1 - Parâmetros utilizados para ajuste matemático das curvas de retenção do solo._81

Tabela 5.2 - Parâmetros de ajuste completos da densidade dos poros para o solo Natural._ 84

Tabela 5.3 - Parâmetros de ajuste completos da densidade dos poros para o solo Compactado.

Tabela 5.4 - Parâmetros de ajuste completos da densidade dos poros para a Lama. 86

Tabela 5.5 - Parâmetros de ajuste da macro da densidade dos poros do solo Natural. 87

Tabela 5.6 - Parâmetros de ajuste da macro da densidade dos poros do solo Compactado. _ 88

Tabela 5.7 - Parâmetros de ajuste da macro da densidade dos poros do solo Lama. 88

Tabela 5.8 - Valores de índice de vazios microestrutural da curva de extrusão. Ponto de máxima curvatura e ponto final. Para o solo na condição saturada. 90

Tabela 5.9 - Valores de índice de vazios microestrutural da curva de extrusão. Ponto de máxima curvatura e ponto final. Para o solo na condição não saturada, com sucção de $50 \mathrm{kPa}$. 
Tabela 5.10 - Valores de índice de vazios microestrutural da curva de extrusão. Ponto de máxima curvatura e ponto final. Para o solo na condição não saturada, com sucção de 1.000 $\mathrm{kPa}$.

Tabela 5.11 - Coeficiente, de não uniformidade e de curvatura, e inclinação para o solo Natural na condição saturada. 97

Tabela 5.12 - Coeficiente, de não uniformidade e de curvatura, e inclinação para o solo Compactado na condição saturada. 98

Tabela 5.13 - Coeficiente, de não uniformidade e de curvatura, e inclinação para a Lama na condição saturada. 99

Tabela 5.14 - Coeficiente, de não uniformidade e de curvatura, e inclinação para o solo Compactado com sucção de $1.000 \mathrm{kPa}$. 100

Tabela 5.15 - Coeficiente, de não uniformidade e de curvatura, e inclinação para a Lama com sucção de $1.000 \mathrm{kPa}$ 100 


\section{LISTA DE SÍMBOLOS, NOMENCLATURAS E ABREVIAÇÕES}
ABNT
Associação Brasileira de Normas Técnicas
$\mathrm{C}$
Compactada, carregamento de $0 \mathrm{kPa}$, sucção de $0 \mathrm{kPa}$
C-100
Compactada, carregamento de $100 \mathrm{kPa}$, sucção de $0 \mathrm{kPa}$
C-100-1000 Compactada, carregamento de $100 \mathrm{kPa}$, sucção de $1000 \mathrm{kPa}$
C-100-50
Compactada, carregamento de $100 \mathrm{kPa}$ e ciclo de secagem e molhagem com sucção final de $50 \mathrm{kPa}$.
C-200 Compactada, carregamento de $200 \mathrm{kPa}$, sucção de $0 \mathrm{kPa}$
C-200-1000 Compactada, carregamento de $200 \mathrm{kPa}$, sucção de $1000 \mathrm{kPa}$
C-200-50
Compactada, carregamento de $200 \mathrm{kPa}$ e ciclo de secagem e molhagem com
C-400 Compactada, carregamento de $400 \mathrm{kPa}$, sucção de $0 \mathrm{kPa}$
C-400-1000 Compactada, carregamento de 400 kPa, sucção de $1000 \mathrm{kPa}$
C-400-50
Compactada, carregamento de $400 \mathrm{kPa}$ e ciclo de secagem e molhagem com sucção final de $50 \mathrm{kPa}$.
C-50 Compactada, carregamento de $50 \mathrm{kPa}$, sucção de $0 \mathrm{kPa}$
C-50-1000 Compactada, carregamento de $50 \mathrm{kPa}$, sucção de $1000 \mathrm{kPa}$
C-50-50
Compactada, tensão vertical de $50 \mathrm{kPa}$ e ciclo de secagem e molhagem com sucção final de $50 \mathrm{kPa}$.
C-800 Compactada, carregamento de $800 \mathrm{kPa}$, sucção de $0 \mathrm{kPa}$
C-800-1000 Compactada, carregamento de 800 kPa, sucção de $1000 \mathrm{kPa}$
CC Coeficiente de curvatura
$\mathrm{CH} \quad$ Argila inorgânica de alta plasticidade
CL Argila de baixa plasticidade
CNU Coeficiente de não uniformidade
D Diâmetro do poro
e Índice de vazios
$e_{m} \quad$ Índice de vazios dos microporos
$e_{M} \quad$ Índice de vazios dos macroporos
$\mathrm{e}_{\max } \quad$ Índice de vazios máximo
$\mathrm{e}_{\min } \quad$ Índice de vazios mínimo 
$e_{n w} \quad$ Índice de vazios preenchido de mercúrio

ESEM Microscopia eletrônica de varredura ambiental

g Aceleração da gravidade

$\mathrm{G}_{\mathrm{s}} \quad$ Gravidade específica

h Altura da tensão capilar

I Inclinação

MIP Mercury Intrusion Porosimetry ( Porosimetria por Intrusão de Mercúrio)

$\mathrm{N} \quad$ Natural, carregamento de $0 \mathrm{kPa}$, sucção de $0 \mathrm{kPa}$

N-100 Natural, carregamento de $100 \mathrm{kPa}$, sucção de $0 \mathrm{kPa}$

N-200 Natural, carregamento de $200 \mathrm{kPa}$, sucção de $0 \mathrm{kPa}$

N-400 Natural, carregamento de $400 \mathrm{kPa}$, sucção de $0 \mathrm{kPa}$

N-50 Natural, carregamento de $50 \mathrm{kPa}$, sucção de $0 \mathrm{kPa}$

N-800 Natural, carregamento de $800 \mathrm{kPa}$, sucção de $0 \mathrm{kPa}$

NBR Norma Brasileira

$n_{m}$

Parâmetro de ajuste associados com a uniformidade do tamanho dos microporos

Parâmetro de ajuste associados com a uniformidade do tamanho dos

$n_{M}$

P Pressão absoluta aplicada

$p_{o}^{*} \quad$ Tensão de pré-adensamento

PEG Polietileno de glicol

PSD Densidade do tamanho de poros

r Raio do poro

$S \quad$ Sucção

S Lama, carregamento de $0 \mathrm{kPa}$, sucção de $0 \mathrm{kPa}$

S-100 Lama, carregamento de $100 \mathrm{kPa}$, sucção de $0 \mathrm{kPa}$

S-100-1000 Lama, carregamento de $100 \mathrm{kPa}$, sucção de $1000 \mathrm{kPa}$

S-100-50 Lama, carregamento de $100 \mathrm{kPa}$ e ciclo de secagem e molhagem com sucção final de $50 \mathrm{kPa}$

S-200 Lama, carregamento de $200 \mathrm{kPa}$, sucção de $0 \mathrm{kPa}$

S-200-1000 Lama, carregamento de $200 \mathrm{kPa}$, sucção de $1000 \mathrm{kPa}$

S-200-50

Lama, carregamento de $200 \mathrm{kPa}$ e ciclo de secagem e molhagem com sucção final de $50 \mathrm{kPa}$ 
S-400 Lama, carregamento de $400 \mathrm{kPa}$, sucção de $0 \mathrm{kPa}$

S-400-1000 Lama, carregamento de 400 kPa, sucção de 1000 kPa

S-400-50 Lama, carregamento de $400 \mathrm{kPa}$ e ciclo de secagem e molhagem com sucção final de $50 \mathrm{kPa}$

S-50 Lama, carregamento de $50 \mathrm{kPa}$, sucção de $0 \mathrm{kPa}$

S-50-1000 Lama, carregamento de $50 \mathrm{kPa}$, sucção de $1000 \mathrm{kPa}$

Lama, carregamento de $50 \mathrm{kPa}$ e ciclo de secagem e molhagem com sucção final de $50 \mathrm{kPa}$

S-800 Lama, carregamento de $800 \mathrm{kPa}$, sucção de $0 \mathrm{kPa}$

S-800-1000 Lama, carregamento de $800 \mathrm{kPa}$, sucção de $1000 \mathrm{kPa}$

$\mathrm{S}_{\mathrm{e}} \quad$ Saturação efetiva

$\mathrm{S}_{\mathrm{nw}} \quad$ Saturação do solo preenchido por mercúrio

$\mathrm{S}_{\mathrm{r}} \quad$ Saturação

$\mathrm{T}_{\mathrm{S}} \quad$ Tensão superficial do fluido utilizado

$\mathrm{u}_{\mathrm{a}}-\mathrm{u}_{\mathrm{w}} \quad$ sucção

UFG Universidade Federal de Goiás

W umidade do solo

$w_{L} \quad$ Limite de liquidez

$w_{M} \quad$ Umidade retida no macroporo

$w_{m} \quad$ Umidade retida no microporo

$\mathrm{w}_{\text {máx }} \quad$ Umidade de saturação da amostra

$w_{P} \quad$ Limite de Plasticidade

$\mathrm{W}_{\mathrm{r}} \quad$ Umidade de correção devido aos vazios não penetrados pelo mercúrio

$\alpha \quad$ Ângulo de contato da interface fluido-ar para o sólido

$\alpha_{m} \quad$ Parâmetro de ajuste relacionado com tamanho de poro dominante na micro

$\alpha_{M} \quad$ Parâmetro de ajuste relacionado com tamanho de poro dominante na macro

$\beta \quad$ Ângulo de contato

$\gamma \quad$ Tensão interfacial

$\gamma_{\mathrm{hg}} \quad$ Tensão superficial do mercúrio

$\theta_{\mathrm{s}} \quad$ Teor de umidade volumétrico saturada

$\theta_{\mathrm{r}} \quad$ Teor de umidade volumétrico residual

$\kappa \quad$ Índice de de expansão

$\lambda$ Índice de compressibilidade 
$\lambda_{\mathrm{W}}$

$\rho$

$\phi_{\text {hg }}$

$\phi_{\mathrm{w}}$

Tensão superficial da água

Densidade do fluido molhante

Ângulo de contato entre o mercúrio e a amostra

Ângulo de contato entre a água e a amostra 


\section{1 - INTRODUÇÃO}

O comportamento hidromecânico dos solos não saturados tem sido assunto de interesse na Geotecnia. Os desafios acerca do entendimento de solos não saturados são amplificados quando se considera o comportamento de solos tropicais, que possuem características peculiares de estruturação que dificultam o seu entendimento. Este é o caso dos solos do Centro-Oeste Brasileiro.

Considerando o solo um meio poroso multifásico, as variações que ocorrem em qualquer uma das fases afetam diretamente as outras, influenciando o comportamento hidráulico e mecânico do solo. As variações mecânicas influenciam o comportamento hidráulico e as variações hidráulicas podem afetar a resposta mecânica. Ou seja, as deformações no esqueleto sólido causam fluxo de água, e o fluxo de água pode causar deformação no esqueleto sólido.

Os solos não saturados eram analisados separando-se o comportamento mecânico, relacionado à deformabilidade e resistência ao cisalhamento, e o comportamento hidráulico, relacionado ao fluxo e armazenamento, mas surgiu a necessidade de se relacionarem esses dois aspectos para uma melhor compreensão. Com o aparecimento de modernas técnicas de ensaios que caracterizam a microestrutura do solo, os estudos do comportamento hidromecânico de solos não saturados baseados na caracterização microestrutural ganharam espaço, possibilitando o surgimento de modelos constitutivos que relacionam essas dimensões do comportamento do solo.

O comportamento mecânico e hidráulico do solo na condição não saturada pode ser previsto por diversos modelos constitutivos (Alonso et al., 1990; Alonso et al., 1999; Fredlund et al., 1995; Vaunat et al., 2000; Wheeler et al., 2003; Gallipoli et al., 2003; Romero et al., 2011; Sheng, 2011; Vecchia et al., 2012).

O ensaio de Porosimetria por Intrusão de Mercúrio (MIP) tem como finalidade compreender a característica estrutural do solo e verificar as alterações estruturais ocorridas devido a mudanças de índice de vazios e distorções. Estes estudos são cada vez mais utilizados com o objetivo de obter uma melhor compreensão do comportamento macroscópico e as propriedades físicas dos solos.

Os dados obtidos pelo MIP são utilizados em pesquisas para fornecer informação sobre fatores que influenciam a relação propriedade-estrutura (a curva de retenção relacionada com 
a porosimetria) e a mudanças da estrutura (i.e., o efeito da tensão mecânica devido à compressão da amostra).

Existe um número limitado de estudos a respeito da influência da estrutura do solo na condição saturada com relação ao seu comportamento hidromecânico (Delage \& Lefebvre, 1984, Griffiths \& Joshi, 1989), o que torna, portanto, importante o estudo e avaliação dos aspectos de determinação desta.

\section{1 - MOTIVAÇÃO}

A evolução da mecânica dos solos não saturados se deve à necessidade do desenvolvimento de técnicas de controle e medidas de sucção, que permitam a reprodução em laboratório da condição não saturada desses solos, como são encontrados em campo.

Devido à importância da análise da estrutura do solo, para o entendimento da sua influência no comportamento hidromecânico, houve um crescimento nos estudos referentes à estrutura do solo, da avaliação e dos aspectos de determinação dessa estrutura e como ela se relaciona com o comportamento hidráulico e mecânico do solo.

As amostras utilizadas nesta pesquisa foram escolhidas devido à necessidade de compreensão do comportamento do solo tropical sobre diversas estruturas (natural, compactada e lama), por meio dos ensaios de Porosimetria por Intrusão de Mercúrio (MIP), permitindo assim as análises da característica da estrutura desses solos.

Além de dar continuidade ao desenvolvimento da linha de pesquisa em modelos constitutivos realizados pelo Programa de Pós-Graduação de Geotecnia da Universidade de Brasília, esta pesquisa tem intuito de avançar no estudo microestrutural e no processo de modelagem. Dentre os trabalhos que vêm sendo desenvolvidos, há pesquisa de um modelo constitutivo que leva em consideração o arranjo estrutural do solo. Este modelo se baseia na ideia de que a resposta macroscópica do solo é o resultado do que acontece no nível microestrutural e macroestrutural. 


\section{2 - OBJETIVOS}

O principal objetivo desta pesquisa é avaliar como diferenciados tamanhos de poros observados em diferentes estruturas iniciais de amostras (Natural, Compactada e Lama) são afetadas por solicitações externas e como a variação no tamanho destes diferentes poros afeta o comportamento hidromecânico do solo na condição saturada e não saturada.

Como objetivos específicos destacam-se:

- avaliar o comportamento hidráulico, por meio da curva de retenção;

- avaliar o comportamento mecânico, a partir de ensaios oedométrico na condição, saturada e não saturada;

- estudar a evolução da estrutura do solo, sob diferentes cargas hidromecânicas de um solo tropical;

- analisar como a estrutura do solo afeta a compressibilidade e a distribuição do tamanho dos poros;

- modelar os resultados do comportamento hidráulico e estrutural adquiridos;

- realizar uma análise quantitativa da distribuição do tamanho dos poros.

\section{3 - ORGANIZAÇÃO DA TESE}

Esta tese é composta por seis capítulos compostos por introdução e os objetivos, a metodologia utilizada, os resultados e a sua análise e conclusões. O presente capítulo expõe os aspectos gerais da pesquisa descrevendo a importância, a motivação e os principais objetivos desta tese. O Capítulo 2 apresenta uma visão geral sobre os temas abordados nesta tese. Inicialmente são definidos alguns conceitos utilizados nesta tese. Em seguida foi desenvolvida uma revisão a respeito da técnica de Porosimetria por Intrusão de Mercúrio (MIP - Mercury Intrusion Porosimetry), a influência das solicitações hidromecânicas na porosimetria e a relação desta com o comportamento hidráulico e mecânico. No Capítulo 3 é mostrado o solo estudado e são apresentados detalhes sobre os materiais e métodos utilizados nesta pesquisa.

O estudo foi dividido em algumas etapas: ensaios de caracterização física e compactação, preparação das amostras, ensaios mecânicos (adensamento), ensaios hidráulicos (curva de retenção). Após estes ensaios, foram preparados os corpos de prova para a realização de 
ensaios de Porosimetria por Intrusão de Mercúrio, com o intuito de avaliar a estrutura do solo. No Capítulo 4 são apresentados os resultados obtidos dos ensaios laboratoriais realizados a partir das amostras Naturais, Compactadas e Lama do solo do Campo Experimental do Programa de Pós-Graduação em Geotecnia da Universidade de Brasília e a avaliação do comportamento desse solo. Com a intenção de possibilitar uma melhor compreensão do programa experimental, os resultados são divididos em quatro partes: caracterização, curva de retenção, ensaios de compressão oedométrica e caracterização estrutural. O Capítulo 5 apresenta a modelagem e a análise microestrutural realizadas a partir dos resultados obtidos para a curva de retenção e distribuição do tamanho dos poros. O processo de calibração dos parâmetros para os modelos constitutivos requer que os ensaios sejam analisados conjuntamente, de modo a verificar, por exemplo, a influência do comportamento mecânico do solo em questão na sua estrutura. Já o Capítulo 6 apresenta a conclusão da presente tese e as sugestões para trabalhos futuros. 


\section{2 - REVISÃO DE LITERATURA}

Este capítulo apresenta uma visão geral sobre os temas abordados nesta tese. Inicialmente, foram definidos alguns conceitos que foram utilizados nesta tese. Em seguida foi realizada uma revisão a respeito da técnica de Porosimetria por Intrusão de Mercúrio (MIP - Mercury Intrusion Porosimetry), a influência das solicitações hidromecânicas na porosimetria e a relação desta com o comportamento hidráulico e mecânico.

\section{1 - CONCEITOS}

Para melhor entendimento, inicialmente são pontuados alguns conceitos utilizados nesta tese. Por exemplo, o termo poro é utilizado por Lambe \& Whitman (1969) para definir o espaço entre as partículas de solo. O espaço de poros em si é subdividido em interagregado, poros entre multi partículas agregadas ou agregados e intra-agregado, poros entre as partículas (Figura 2.1).

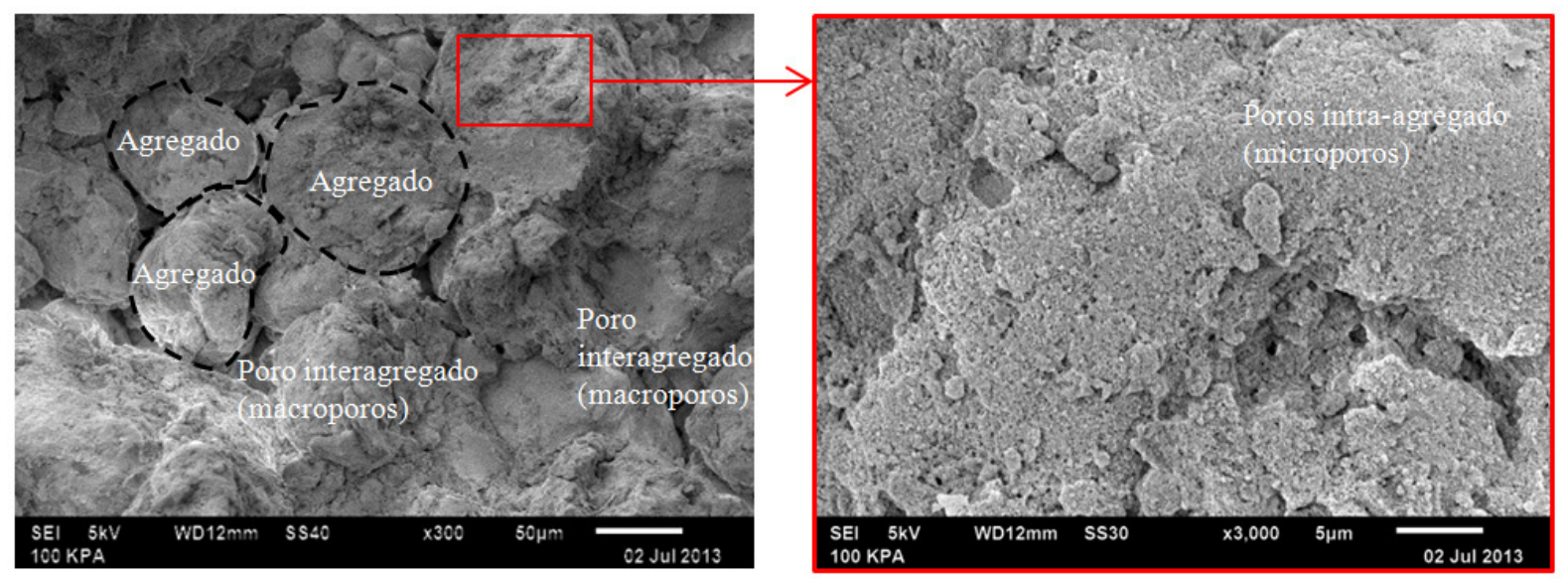

Figura 2.1 - Interagregados (macroporos) e Intra-agregados (microporos)

Esta subdivisão é utilizada por Delage \& Lefebvre (1984). Para estes autores, a parte de microporos são os poros intra-agregados e a de macroporos são os poros interagregados. Segundo Romero (1999), os tamanhos dos grãos são classificados em macroporosidade com tamanhos dos grãos superiores a 1, mesoporidade valores entre 0,1 e $1 \mu \mathrm{m}$, microporosidade entre 20 e $100 \mathrm{~nm}$ e ultra-microporosidade valores menores que $20 \mathrm{~nm}$. O autor também define o microporo como o poro menor que $300 \mathrm{~nm}$ e o macroporo, maior que esse valor, independentemente da condição da amostra (natural, remoldada ou compactada) pra um 
determinado solo. A convenção adotada nesta tese é tal que os poros interagregados são referidos como os macroporos e os poros intra-agregados como microporos.

Outros termos muito utilizados são a Estrutura e a Fábrica do solo. Para tanto é necessário entender a diferença entre estes. De acordo com Lambe \& Whitman (1969) e Mitchell \& Soga (2005), Fábrica refere-se ao arranjo de partículas, grupos de partículas e os espaços dos poros no solo. Enquanto o termo Estrutura é o resultado dos efeitos combinados da fábrica, da composição e das forças interpartículas, do estado de tensões e de outros fatores ambientais. Apesar das diferenças existentes entre a Fabrica e a Estrutura no decorrer da tese será utilizado o termo Estrutura para todos os casos.

As propriedades macroscópicas do solo são função da Estrutura do solo (Mitchell \& Soga, 2005). Por outro lado, solicitações externas podem afetar essa Estrutura. Assim, uma melhor compreensão de como todos esses fatores se relacionam pode proporcionar um melhor entendimento do comportamento do solo.

\section{2 - ANÁLISE MICROESTRUTURAL DO SOLO}

Existem várias técnicas utilizadas para a análise microestrutural do solo, dentre elas, granulometria, curva de retenção, reflectometria (óptica e do domínio do tempo), medições do infravermelho, tomografia, intrusão microestrutural, microscopia eletrônica de varredura ambiental (ESEM) e porosimetria de intrusão de mercúrio (MIP).

Entre as técnicas utilizadas para investigar a microestrutura do solo, o ensaio de Porosimetria por Intrusão de Mercúrio (MIP) é uma das mais utilizadas. De acordo com Zhang et al. (2006), o ensaio de MIP é escolhido devido à sua fácil realização. Porosimetria de intrusão de mercúrio é uma técnica comum para obter uma representação quantitativa da microestrutura de materiais com porosidade interconectada, e a partir desta é possível inferir uma distribuição do tamanho dos poros.

A técnica da porosimetria por intrusão de mercúrio (MIP) foi amplamente utilizada como uma técnica experimental na determinação da distribuição e da estrutura dos solos porosos (Delage \& Lefebvre, 1984; Prapaharan et al., 1985; Griffiths \& Joshi, 1989; Delage et al., 1996; Romero, 1999; Penumadu \& Dean, 2000; Simms \& Yanful, 2001; Buenfil, 2007; Romero \& Simms, 2008; Mascarenha, 2008; Koliji et al., 2010; Sivakumar et al., 2010; Alonso et al., 2011; Alonso et al., 2013). 
Além disso, diversas pesquisas têm sido desenvolvidas para o emprego desta técnica na determinação da curva de retenção (Prapaharan et al., 1985; Kosugi \& Hopmans, 1998; Romero, 1999; Simms \& Yanful, 2002; Romero \& Simms, 2008; Romero et al., 2011) e da condutividade hidráulica do solo ( Juang \& Holtz, 1986; Lapierre et al., 1990; Romero \& Simms, 2008).

Os resultados obtidos a partir desta técnica de análise da microestrutura do solo também permitem uma melhor compreensão do comportamento mecânico, uma vez que permite separar a resposta da micro e da macroestrutura (Alonso et al. 1999; Lloret \& Khalili, 2000).

Segundo Romero \& Simms (2008) uma das limitações do equipamento é o volume de vazios do solo obtido pelo ensaio do MIP, que não coincide com o valor real da amostra. Os autores citam ainda como principais limitações do MIP:

- os poros fechados isolados por sólidos não são medidos, sendo que este tipo de porosidade não é significativo em solos;

- os poros que são acessíveis apenas por meio de poros menores não são detectados até que os últimos poros sejam penetrados, superestimando os valores de poros microestruturais;

- a máxima pressão do aparelho pode não ter capacidade de entrar nos microporos da amostra; e

- o equipamento possui uma pressão prática mínima, que é limitada para detectar o máximo tamanho dos poros.

Apesar destas limitações, vários autores têm utilizado os resultados do MIP para prever as propriedades da curva de retenção do solo (Prapaharan et al. , 1985, Romero, 1999, Aung et al., 2001, Simms \& Yanful, 2002, 2005), bem como as alterações de volume macroscópicas, devido aos efeitos de trajetórias de tensões ( Delage \& Lefebvre, 1984; Griffiths \& Joshi, 1989; Al-Mukhtar et al., 1996; Cui et al., 2002; Simms \& Yanful, 2004; Cuisinier \& Masrouri, 2004; Romero et al., 2005; . Koliji et al., 2006; Hoffmann et al., 2007, Tarantino \& de Col, 2008).

Para a realização do ensaio de Porosimetria por Intrusão de Mercúrio (MIP) recomenda-se que a água seja totalmente extraída da amostra. De acordo com a Simms \& Yanful (2004) os dois métodos para retirar a água do solo as mais comuns são, a secagem em estufa e a 
secagem com congelamento prévio, com ou sem a sublimação. Contudo ainda segundo Simms \& Yanful (2004), a secagem por congelamento com sublimação tem o menor efeito sobre a estrutura do solo, devido ao seu rápido congelamento.

O método da liofilização permite que os vazios dos poros possam ser secos sem o risco da influência das forças de tensão superficiais induzidas pela interface ar-água sendo este considerado o que melhor preserva a estrutura original do solo durante o processo de desidratação em comparação com outros métodos de secagem (Delage \& Lefebvre, 1984; Penumadu \& Dean 2000).

De acordo com Li \& Zhang (2009) as amostras utilizadas no ensaio de porosimetria por intrusão de mercúrio devem ser preparadas pela técnica de secagem por congelamento para desidratar as amostras de solo úmidas. Esta técnica é baseada na suposição de que, durante o congelamento rápido de um solo utilizando nitrogênio líquido, a água não tem tempo suficiente para cristalizar. A transição do estado líquido para um sólido não é acompanhada por uma expansão linear da fase a ser formada e, consequentemente, não provoca deformação significativa da amostra (Penumadu \& Dean, 2000).

Após o congelamento, a amostra é colocada em uma estufa a vácuo (Figura 2.2). Durante o ensaio de MIP, a amostra desidratada é inicialmente cercada com mercúrio em uma pressão específica baixa. Em seguida, a pressão de mercúrio é aumentada passo a passo até atingir a capacidade do sistema. Este volume de mercúrio que entra nos poros é medido para cada incremento de pressão.

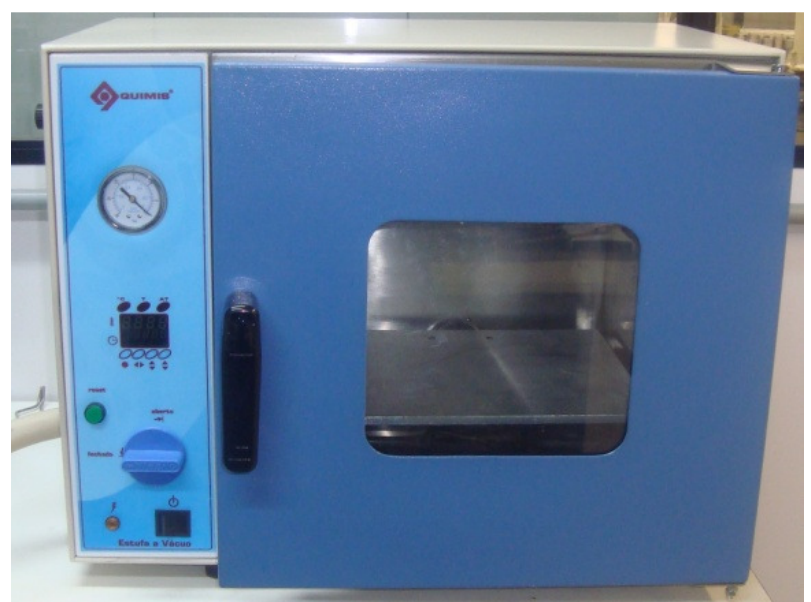

Figura 2.2 - Estufa a vácuo para secar a amostra após o congelamento.

Segundo Vazquez et al. (2010) os ensaios de MIP permitem a medição de cerca de 100 a $0,005 \mu \mathrm{m}$. Esta ampla faixa de valores permite a identificação de diferentes tamanhos de poros do solo ao longo da curva de Distribuição do Tamanho os Poros (PSD). O MIP baseia- 
se no princípio de que um fluido não molhante, como mercúrio, entra num meio poroso quando lhe é aplicada uma pressão suficiente. A cada incremento de pressão aplicada, um diâmetro associado aos poros pode ser estimado. Esta pressão é relacionada com os diâmetros dos poros a partir da equação a seguir:

$\mathrm{D}=-\frac{1}{\mathrm{P}} 4 \gamma_{\mathrm{hg}} \cos \phi_{\mathrm{hg}}$

sendo D o diâmetro do poro; P a pressão absoluta aplicada; $\gamma_{\mathrm{hg}}$ a tensão superficial do mercúrio $\left(\gamma_{\mathrm{hg}}=0,484 \mathrm{~N} / \mathrm{m}\right.$ à $\left.25^{\circ} \mathrm{C}\right)$; e $\phi_{\mathrm{hg}} \mathrm{o}$ ângulo de contato entre o mercúrio e a amostra, sendo este ângulo muito sensível à rugosidade da superfície. Penumadu \& Dean (2000) relataram valores em argilas cauliníticas com ângulos de $158^{\circ}$ a $162^{\circ}$, enquanto Li \& Zhang (2009) adotaram o ângulo de contato como $135^{\circ}$.

A injeção de mercúrio preenche os poros acessíveis e interconectados, enquanto a liberação completa da pressão de intrusão expulsa somente uma parte do mercúrio dos poros (porosidade livre). A diferença entre as curvas de intrusão e extrusão fornece a distribuição de intra-agregados e interagregados do solo. A extrusão de mercúrio fornece as dimensões dos microporos do solo (Delage \& Lefebvre, 1984).

De acordo com Simms \& Yanful (2004), as principais desvantagens, devido a erro da técnica de MIP são os seguintes:

- Os efeitos da preparação da amostra para remover a água;

- O efeito da pressão gerada durante MIP na estrutura do solo;

- A influência da acessibilidade dos poros gerados na PSD.

Romero \& Simms (2008) também relataram que, quando uma amostra de argila é penetrada por mercúrio, o índice de vazios preenchido, estimado sob a máxima pressão aplicada, não coincide com o índice de vazios estimado da amostra por outros meios. As diferenças surgem principalmente devido à não interferência da porosidade com tamanho de poros inferior a 10 nm e à porosidade não detectável para poros maiores que $400 \mu \mathrm{m}$.

Há também uma preocupação com os poros aprisionados, que são acessíveis apenas através de poros menores, que não são detectados até que estes poros de menor diâmetro sejam penetrados. Logo, os autores afirmaram que a PSD não é necessariamente a verdadeira distribuição do tamanho dos poros, devido a vários problemas, incluindo a acessibilidade dos 
poros e tratamento da amostra, no entanto, ela obtém uma caracterização quantitativa útil da microestrutura.

Os dados de intrusão e extrusão do solo são calculados a partir da equação 2.1, considerando o acréscimo e o decréscimo da pressão, respectivamente. As diferenças entre as curvas de intrusão e de extrusão são utilizadas para caracterizar a estrutura dos poros e mostram a relação da porosidade com o diâmetro dos poros.

O gráfico típico do resultado obtido a partir do ensaio do MIP é mostrado na Figura 2.3. Neste gráfico pode-se observar a curva obtida a partir do volume cumulativo de mercúrio introduzido na amostra. A curva de extrusão é obtida quando a pressão é libertada progressivamente e o volume de mercúrio sai da amostra, e este é então registrado. As curvas são diferentes, e alguns autores como Delage \& Lefebvre (1984) e Tarantino \& De Col (2008) sugerem que o volume de mercúrio que permanece na amostra, é aquele que preenche os microporos e que não sai da amostra com a libertação da pressão.

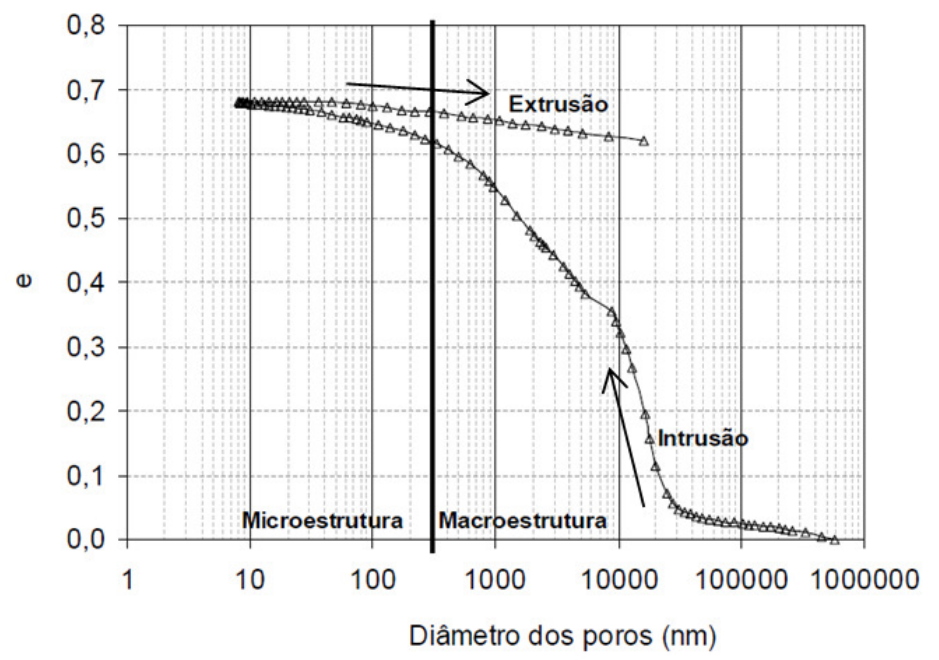

Figura 2.3 - Curvas de extrusão e intrusão da amostra no estado natural (Mascarenha, 2008).

Após a obtenção do ensaio MIP é possível separar os níveis estruturais do solo, em macro e microestrutura, porém até hoje não há um consenso sobre o limite. Uma das questões no desenvolvimento de modelos constitutivos multiescalas é estabelecer um limite entre os níveis micro e macroestruturais. Diferentes critérios para discernir micro e macroporos são publicados na literatura. Alguns autores (Delage \& Lefebvre, 1984; Romero, 1999, Romero et al., 2011; Della Vecchia et al., 2013) sugerem uma análise visual da curva de densidade de tamanho dos poros, fixando desta forma o limite entre os níveis macro e micro de cada solo analisado. 
Barreira (2002) e Penumadu \& Dean (2000) sugeriram em seus estudos que a delimitação dessas regiões ocorre em torno de um diâmetro de $50 \mathrm{~nm}$ e Buenfil (2007) sugere um diâmetro de $150 \mathrm{~nm}$. Segundo Romero (1999), as intrusões volumétricas são classificadas em macroporosidade (tamanho dos poros superiores a $1 \mathrm{~nm}$ ), mesoporidade (entre 0,1 e $1 \mathrm{~nm}$ ), microporosidade (entre 20 e $100 \mathrm{~nm}$ ) e ultra-microporosidade (menores que $20 \mathrm{~nm}$ ).

Para separar os limites da macro e microestrutura Delage \& Lefebvre (1984) usam o limite obtido com ciclo de intrusão/extrusão do MIP, enquanto Romero (1999) usa a curva de retenção com diferentes índices de vazios para estabelecer esse limite. Este último autor observou em seus ensaios que independente do índice de vazios da amostra, a parte microestrutural não sofre modificações, sendo que essa região (ou seja, a que não sofre modificações quando solicitada) define melhor os limites da micro e macroestrutura.

Quando a distribuição do tamanho dos poros é claramente bimodal, o limite entre os níveis micro e macroestruturais é geralmente associado com o vale entre os picos dominantes dos micros e macroporos. Quando a PSD é claramente bimodal a tendência geral é a divisão desta no vale entre os dois picos (Romero et al., 2011; Della Vecchia et al., 2013).

Na Figura 2.3 pode ser visualizada a relação entre os índices de vazios e os diâmetros dos poros da amostra no estado natural, na qual se observa a delimitação entre as regiões de macro e microporosidade, a partir de uma análise visual, correspondente a um diâmetro em torno de $300 \mathrm{~nm}$ para essa amostra. Na curva de extrusão o índice de vazios varia de 0,62 a 0,68, o que representa na microestrutura $8,8 \%$ dos poros do solo. Já a macroestrutura, consequentemente, representa 91,2\% destes poros (Mascarenha, 2008).

A curva PSD, obtida a partir do MIP, é uma análise estrutural que pode ser utilizada para correlacionar as propriedades macroscópicas, tais como, a sua dependência do tipo de compactação (Ahmed et al., 1974), a diferença entre solos compactados em laboratório e campo, para densidade seca e teor de umidade de moldagem (Prapaharan et al., 1991); a permeabilidade saturada (Juang \& Holtz 1986; Lapierre et al., 1990); e mudanças de volume macroscópicas (qualitativas) (Delage \& Lefebvre 1984; Griffiths \& Joshi, 1989).

A PSD é obtida a partir da equação:

$\operatorname{PSD}=\frac{- \text { de }}{\mathrm{d}(\log \mathrm{D})}$

sendo: de o incremento do índice de vazios e d $(\log \mathrm{D})$ o incremento do diâmetro na escala logarítma. 
A relação entre a PSD e o diâmetro dos poros para a amostra no estado natural é apresentada na Figura 2.4, onde se pode observar que a amostra possui dois diâmetros de poros dominantes $(1,2 \mu \mathrm{m}$ e $16 \mu \mathrm{m})$ na região macroestrutural. A PSD obtida a partir do ensaio de MIP é um elemento essencial da estrutura, que está relacionado com algumas características do comportamento do solo, como, as propriedades de condutividade de água, ar e calor, adsorção (fenômeno de capilaridade) e a deformação volumétrica (rearranjo da estrutura) (Romero, 1999).

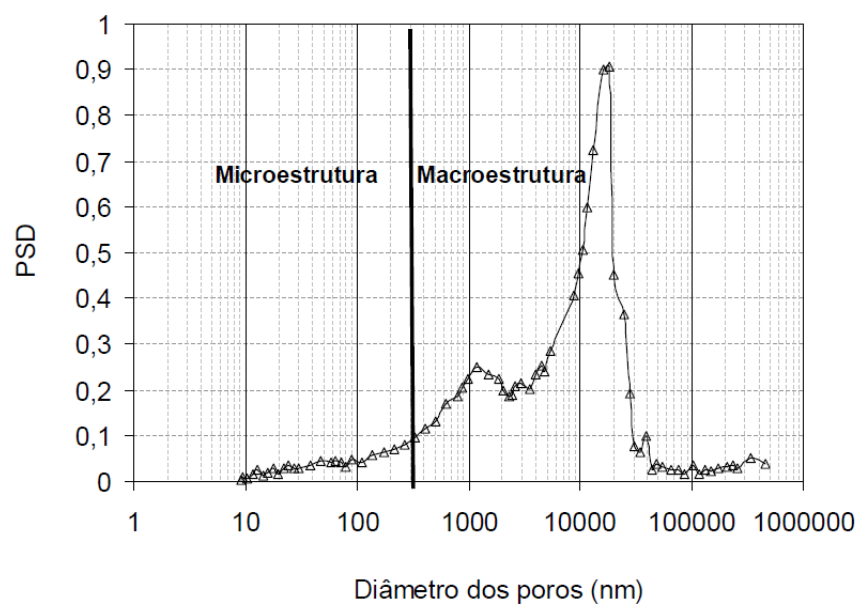

Figura 2.4 - Relação entre o PSD e os diâmetros dos poros da amostra no estado natural (Mascarenha, 2008).

Por outro lado, estudos experimentais microestruturais é uma ferramenta importante para melhorar conhecer o comportamento micro e macroscópicas estão relacionados (Romero, 2013). Vários trabalhos têm seguido esta linha, como Alonso et al., 1999; Loret \& Khalili, 2000; Alonso et al., 2010; Alonso et al., 2013; Della Vecchia et al., 2013; Romero, 2013).

\section{3 - COMPORTAMENTO HIDRÁULICO VERSUS POROSIMETRIA}

A informação da estrutura do solo pode ser obtida por meio da análise da curva de densidade de tamanho dos poros (PSD). De acordo com Romero \& Simms (2008), a PSD foi utilizada em aplicações geotécnicas correlacionadas com as propriedades macroscópicas, tais como permeabilidade e propriedade de retenção do solo, como um elemento essencial da fábrica. Além disso, Vazquez et al. (2010) asseguram que a PSD pode ser vista como uma distribuição estatística singular, portanto, capaz de caracterizar a estrutura de amostra de solo.

Diversos estudos (Delage, 2002; Simms \& Yanful, 2004; Romero \& Simms, 2008; Romero et al., 2011; Vecchia et al., 2012) vêm demonstrando que o comportamento hidromecânico de 
um solo na condição não saturada pode ser previsto a partir da interpretação e análise da curva de retenção, ou seja, a relação entre o teor de umidade e a sucção no solo. Muitas propriedades macroscópicas do solo podem ser explicadas em termos de comportamento microestrutural (tamanho, distribuição e conectividade de poros; tamanho, forma e distribuição das partículas, juntamente com o arranjo e contatos dos grãos), das variáveis de estado volumétrico e gravimétrico (índice de vazio, teor de umidade e grau de saturação), e do histórico de tensões (mecânica e hidráulica), sofridas pelo material (Romero \& Simms, 2008). Analisando curvas características em dois tipos de solos argilosos, Romero (1999) verificou a existência de dois mecanismos de armazenamento de água, um na microestrutura (intraagregados) e outro na macroestrutura (interagregados) do solo. A macroestrutura é dependente dos índices de vazios e consequentemente sensível a ações mecânicas. Essas ações mecânicas produzem mudanças na macroporosidade, afetando os meniscos e a água livre contida nos interagregados, mas sem influenciar a porosidade intra-agregada. Dessa forma, o autor afirma que a microestrutura é uma região do solo pouco afetada por carregamentos.

Romero \& Simms (2008) mostram a importância do tamanho, forma e disposição das agregações de argila, bem como a distribuição e a conectividade de poros, sobre o comportamento do solo, e como tais agregações e poros podem mudar durante os ciclos de umedecimento e secagem dependendo de um número de fatores, incluindo o tipo de mineral de argila e a trajetória de secagem e molhagem. Em geral, o tipo e a quantidade de minerais de argila, bem como a interação com a água dos poros do solo, como têm sido demonstrado, afetam a permeabilidade e a compressibilidade do solo (Marshall, 1958).

No que diz respeito a solos não saturados, os resultados do MIP têm sido utilizados para prever as propriedades da curva de retenção de água (Prapaharan et al. 1985; Romero, 1999; Simms \& Yanful 2002, 2005), bem como as mudanças de volume macroscópicas devido aos efeitos das trajetórias mecânicas e hidráulicas (Simms \& Yanful, 2004).

Romero (1999) resentou uma formulação para obtenção da curva retenção de água no solo, a partir do ensaio de MIP. Para isso é utilizada a seguinte equação:

$\mathrm{D}=-\frac{1}{\mathrm{u}_{\mathrm{a}}-\mathrm{u}_{\mathrm{w}}} 4 \lambda_{\mathrm{w}} \cos \phi_{\mathrm{w}}$

sendo: $\lambda_{\mathrm{w}}$ é a tensão superficial da água. 
A equação 2.3 é derivada da hipótese, descrita por Romero (1999), de que a injeção de mercúrio na amostra tem um ângulo de contato igual à $140^{\circ}\left(\phi_{\mathrm{hg}}\right)$ e que isso é correspondente à saída de água com ângulo de contato igual à $\phi_{\mathrm{w}}=180^{\circ}$.

Substituindo nas equações 2.1 e 2.3 os valores de $\gamma_{\mathrm{hg}}, \phi_{\mathrm{hg}}, \phi_{\mathrm{w}}$ e $\lambda_{\mathrm{w}}$, obtém-se uma relação entre a sucção e a pressão de injeção de mercúrio, conforme a equação a seguir.

$\mathrm{u}_{\mathrm{a}}-\mathrm{u}_{\mathrm{w}}=0,196 \mathrm{P}$

O valor de saturação do solo é fornecido ao se relacionarem os vazios do solo penetrados pelo mercúrio na porosimetria, com os vazios preenchidos por ar em um processo de secagem, conforma a equação:

$\mathrm{S}_{\mathrm{nw}}=\frac{\mathrm{e}_{\mathrm{nw}}}{\mathrm{e}}$

sendo: $\mathrm{e}_{\mathrm{nw}} \mathrm{o}$ valor do índice de vazios penetrado pelo mercúrio e e o índice de vazios da amostra.

Dessa maneira, os valores de saturação e umidade do solo podem ser obtidos pelas equações:

$\mathrm{S}_{\mathrm{r}}=1-\frac{\mathrm{e}_{\mathrm{nw}}}{\mathrm{e}}$

$\mathrm{w}=\mathrm{S}_{\mathrm{r}} \mathrm{w}_{\text {máx }}$

sendo: $\mathrm{w}_{\text {máx }}$ a umidade de saturação da amostra.

Substituindo a equação 2.5 e 2.6 na equação 2.7 , obtém-se a seguinte equação.

$\mathrm{w}=\mathrm{w}_{\text {máx }}\left(1-\mathrm{S}_{\mathrm{nw}}\right)$

Como o mercúrio não penetra em todos os poros do solo, para considerar essa diferença, deve-se corrigir a equação 2.8 conforme a equação a seguir:

$\mathrm{w}=\left(\mathrm{w}_{\text {máx }}-\mathrm{w}_{\mathrm{r}}\right)\left(1-\mathrm{S}_{\mathrm{nw}}\right)+\mathrm{w}_{\mathrm{r}}$

sendo: $\mathrm{w}_{\mathrm{r}}$ a umidade de correção devido aos vazios não penetrados pelo mercúrio.

Igualando a equação 2.9 com a equação 2.7 , tem-se a nova formulação para se determinar o grau de saturação do solo, conforme a equação a seguir. 
$\mathrm{S}_{\mathrm{r}}=\left(1-\mathrm{S}_{\mathrm{nw}}\right)+\left(\frac{\mathrm{w}_{\mathrm{r}}}{\mathrm{w}_{\text {máx }}}\right) \mathrm{S}_{\mathrm{nw}}$

Kosugi \& Hopmans (1998) também propõem equações para determinação de curvas de retenção a partir da distribuição log normal do tamanho dos poros do solo. Esta abordagem foi utilizada como um método eficaz para descrever a variação das propriedades hidráulicas do solo. Brutsaert (1966) define a função de densidade de probabilidade dos raios dos poros (PDF) do solo, p (r) como:

$\mathrm{p}(\mathrm{r})=\mathrm{dS}_{\mathrm{e}} / \mathrm{dr}$

sendo: $\mathrm{S}_{\mathrm{e}}$ a saturação efetiva.

$\mathrm{S}_{\mathrm{e}}=\left(\theta-\theta_{\mathrm{r}}\right) /\left(\theta_{\mathrm{s}}-\theta_{\mathrm{r}}\right)$

sendo: $\theta_{\mathrm{s}}$ e $\theta_{\mathrm{r}}$ o teor de umidade volumétrico saturada e residual, respectivamente.

$\mathrm{Na}$ equação 2.11, $\mathrm{p}(\mathrm{r}) \mathrm{dr}=\mathrm{dS}_{\mathrm{e}}$, representa o volume ocupado com raios variando de $r \rightarrow r+d r$ pelo volume de poro efetivo. O volume efetivo de poro é definido como o produto do volume do solo total e da porosidade efetiva do solo. Integrando-se a equação 2.11 obtémse a função distribuição acumulada dos raios dos poros.

$S_{e}(r)=\int_{0}^{r} p(r) d r$

Portanto, $S_{e}(r)$ representa a saturação efetiva do solo, quando a fração de volume de poros ocupada pelos poros com um raio igual ou menor do que $r$ é preenchido por água. Sendo, $r$ associado com a altura da tensão capilar, $h(\mathrm{~L}),(\mathrm{h}>0$ para o solo não saturado) pela função da tensão capilar:

$\mathrm{h}=2 \gamma \cos \beta / \rho \mathrm{gr}=\mathrm{A} / \mathrm{r} \quad$ ou $\quad \ln \mathrm{h}=\ln \mathrm{A}-\ln \mathrm{r}$

sendo: $\gamma$ a tensão interfacial (ou tensão superficial), $\beta$ o ângulo de contato, $\rho$ a densidade do fluido molhante, e g a aceleração da gravidade. O valor de A para o sistema de solo-água-ar é $0,149 \mathrm{~cm}^{2}$. Conforme Kosugi \& Hopmans (1998) a função $S_{e}(r)$ é transformada em $S_{e}(h)$, que é a curva retenção, com base na correspondência direta de $\mathrm{r}$ e $\mathrm{h}$.

Com o intuito de analisar a obtenção da curva de retenção obtida por meio do MIP, Romero (1999) determinou curvas de retenção de amostras de solo com diferentes densidades a partir de ensaios com o Psicrômetro e a técnica de transferência de vapor. Estas curvas foram 
comparadas às obtidas utilizando os resultados dos ensaios de porosimetria por injeção de mercúrio (Figura 2.5). Analisando a curva obtida por meio do Psicrômetro e da técnica de transferência de vapor e a curva obtida por meio do MIP, observa-se que, embora não possuam os mesmos valores, apresentam uma boa concordância quanto à forma.

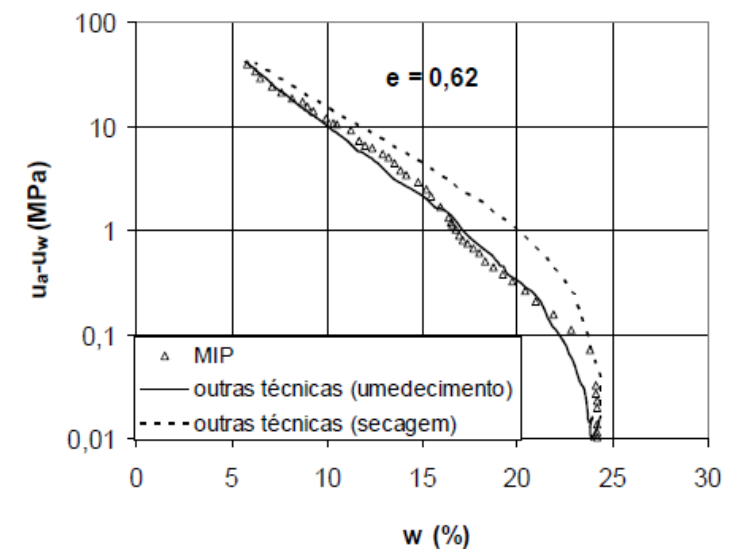

(a)

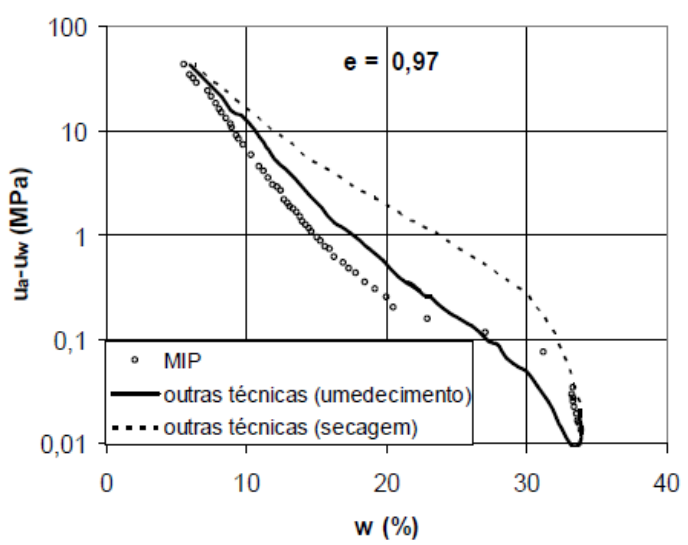

(b)

Figura 2.5 - Curvas de retenção do solo obtidas pelo MIP e outras técnicas:(a) e=0,62; (b) $\mathrm{e}=0,97$ (modificada de Romero, 1999).

Mascarenha (2008) apresenta as curvas de retenção obtidas a partir da equação de Romero (1999) e as obtidas a partir dos resultados do MIP, em trajetórias de secagem e de molhagem. Na Figura 2.6 as curvas de retenção obtidas, em relação à forma, apresentam uma razoável concordância, conforme verificado por Prapaharan et al. (1985), Romero (1999) e Buenfil (2007).

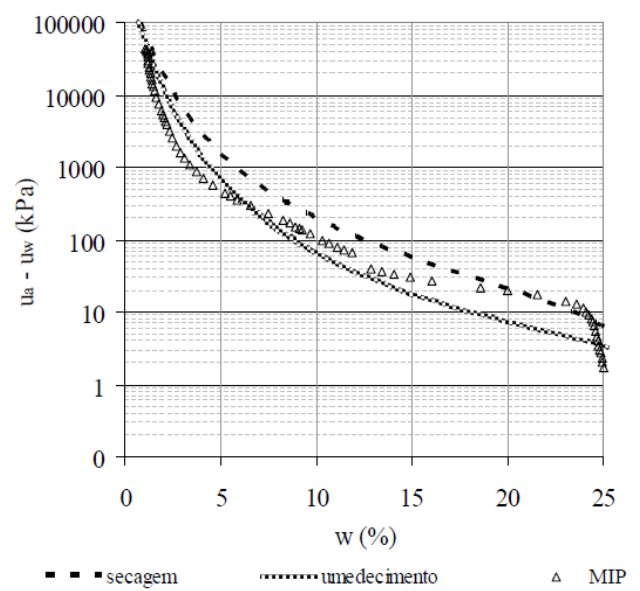

(a)

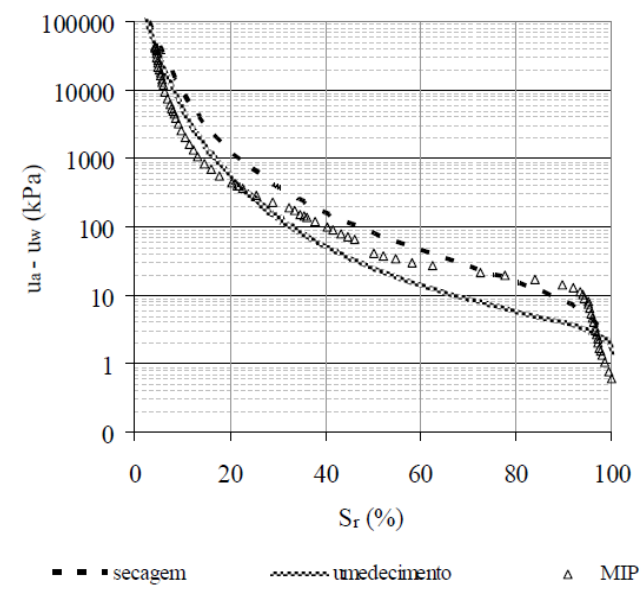

(b)

Figura 2.6 - Curvas de retenção do solo (equação e MIP) (a) em relação à umidade; (b) em relação aos grau de saturação (Mascarenha, 2008).

Partindo do mesmo princípio de obtenção da curva de retenção a partir do MIP, Mascarenha (2008) propõe o caminho inverso, definindo a distribuição do tamanho dos poros do solo por 
meio da curva de retenção, propondo a equação a seguir isolando a pressão de injeção de mercúrio.

$\mathrm{P}=\frac{\mathrm{u}_{\mathrm{a}}-\mathrm{u}_{\mathrm{w}}}{0,196}$

Os valores dos índices de vazios preenchidos por mercúrio $\left(\mathrm{e}_{\mathrm{nw}}\right)$ são obtidos a partir dos valores de saturação da curva de retenção, por meio do rearranjo da Equação 2.9, conforme a equação.

$\mathrm{e}_{\mathrm{nw}}=\mathrm{e}\left(1-\mathrm{S}_{\mathrm{r}}\right)$

Mascarenha (2008) mostra resultados da distribuição do tamanho dos poros obtida utilizando o MIP e a curva de retenção, obtidas por meio de ensaios em trajetórias de molhagem (Figura 2.7a). Além disso, a autora apresenta os resultados da densidade do solo obtidos por meio da curva de retenção, assim como a densidade obtida utilizando o MIP, os resultados são apresentados na Figura 2.7b.

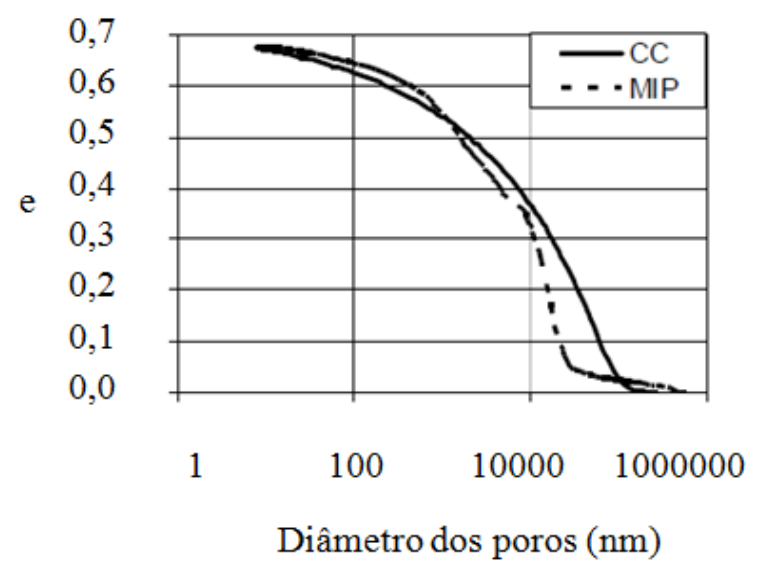

(a)

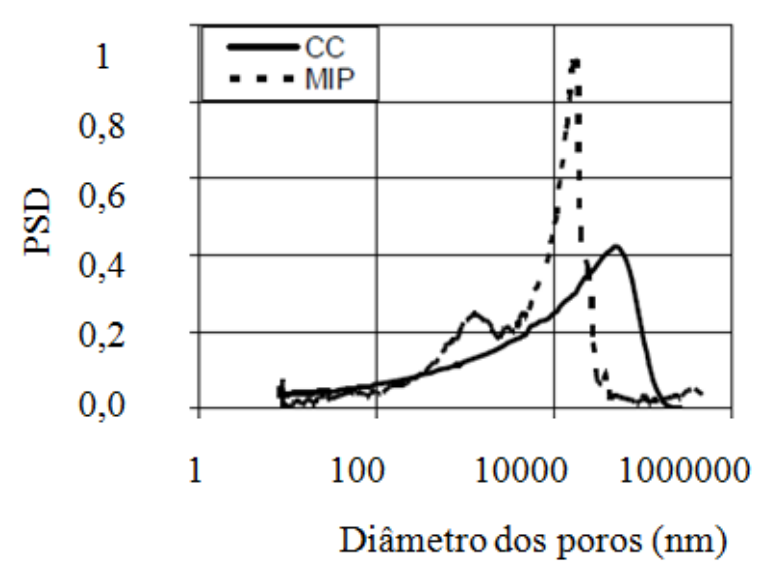

(b)

Figura 2.7 - Resultados obtidos a partir da curva de retenção do solo e resultados obtidos pelo MIP: (a) curva de retenção; (b) distribuição do tamanho dos poros (Mascarenha, 2008).

Mascarenha (2008) também avaliou a representação da relação D x e (Figura 2.7a) obtida pela curva de retenção e observou a semelhança desta à obtida pelo MIP, modificanda apenas para valores de diâmetro de poros maiores que $10 \mu \mathrm{m}$. Além disso, Mascarenha (2008) observou que a relação D x PSD obtida pela curva de retenção (Figura 2.7b) coincide com a obtida por meio do MIP apenas na região microestrutural, sendo que na macroestrutura o comportamento unimodal da amostra é evidenciado e ocorre um deslocamento do valor de pico do diâmetro dos poros. Isso acontece porque, na curva de retenção, o grau de saturação é definido 
considerando o índice de vazios global e não separa os índices de vazios da micro e da macroestrutura do solo.

Baseado no trabalho de Mascarenha (2008), Otálvaro (2013) obteve as curvas de distribuição do tamanho dos poros (PSD) a partir das curvas de injeção de ar (SAIC) para a argila porosa de Brasília (Figura 2.8), e outros dois solos lateríticos, Figura 2.9 (Futai \& Almeida, 2005; Miguel \& Bonder, 2012). De modo geral, a PDS obtida da SAIC assemelha-se às curvas obtidas pelo MIP, porém, dois aspectos não são considerados: o primeiro é a variação do volume, devido ao processo de secagem das amostras para a obtenção da SAIC, além disso, a adsorção da água nas partículas. Otálvaro (2013) então propõem duas correções, sendo uma relacionada à variação de volume dos macroporos e outra, ao diâmetro dos microporos. Os resultados dessas correções podem ser visualizados na Figura 2.10.
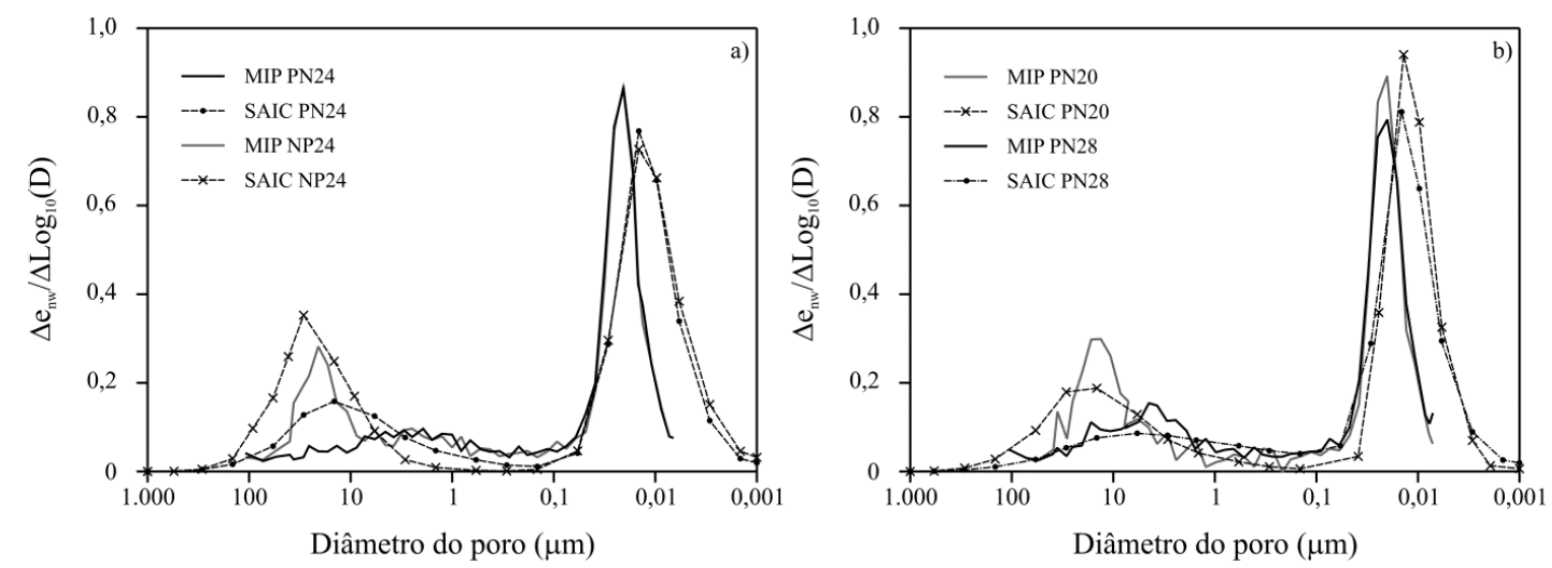

Figura 2.8 - Predição da PSD através da SAIC.
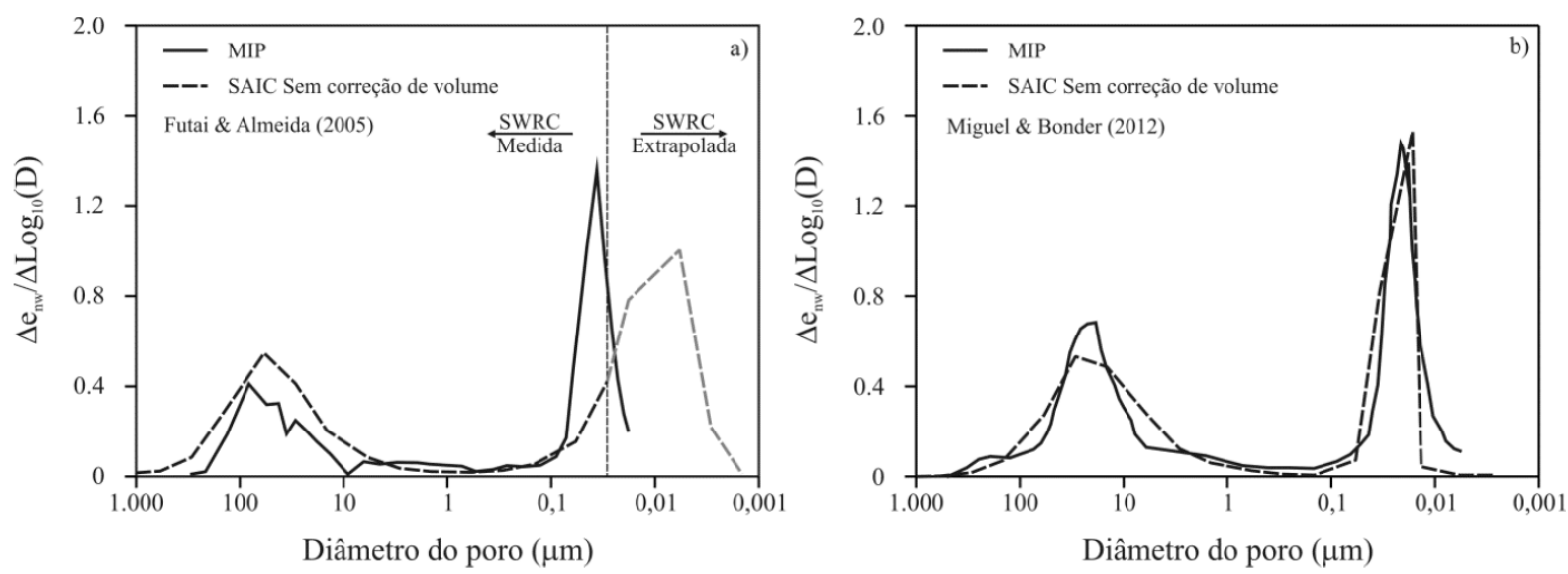

Figura 2.9 - PSD de dois solos tropicais naturais: a) Futai \& Almeida (2005), e b) Miguel \& Bonder (2012). 

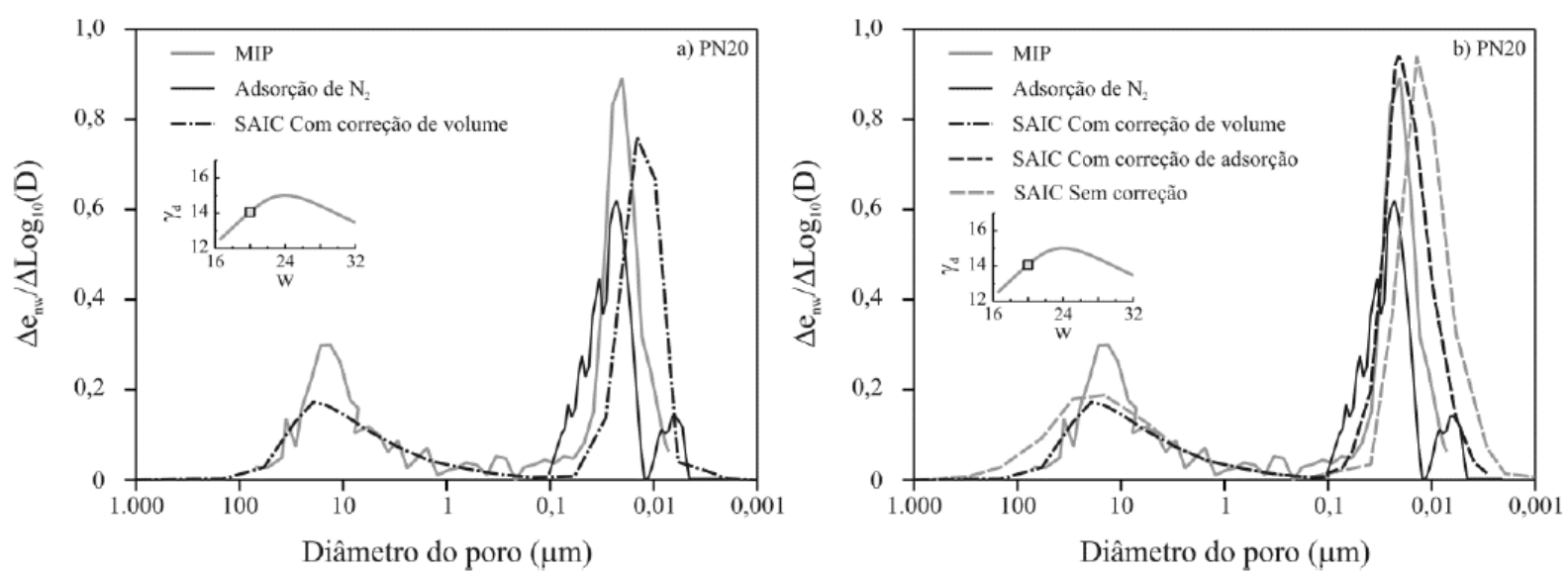

Figura 2.10 - Predição da PSD com a SAIC: a) com correção de volume, e b) com correção de adsorção (Otálvaro, 2014).

\section{4 - COMPORTAMENTO MECÂNICO VERSUS POROSIMETRIA}

A compreensão da mecânica do solo, analisando a parte microscópica, é adequada para solos na condição saturada e não saturada, principalmente em materiais à base de argila, devido à complexidade do comportamento do solo ante a presença de ar e água nos poros.

De modo geral, a distribuição do tamanho de poros em solos não saturados, em muitos casos, é bimodal compreendendo: a microestrutura associada à distribuição de pequenos vazios intra-agregados, ou seja, dentro das agregações de partículas, e uma macroestrutura associado com maiores espaços interagregados, ou seja, vazios entre os agregados (Ahmed et al., 1974; Alonso et al., 1995; Delage et al., 1996).

Diversos autores realizaram estudos que relacionam o comportamento mecânico dos solos com a distribuição de poros (Simms \& Yanful, 2002; Romero et al., 2005; Buenfil, 2007; Hoffmann et al., 2007; Mascarenha, 2008; Sivakumar et al., 2010, e outros). De um modo geral, o foco desses estudos era avaliar os efeitos da aplicação de cargas ou variação da umidade na distribuição dos poros.

Estudos como os de Simms \& Yanful (2002), Romero et al. (2005) e Buenfil (2007) mostram que os resultados da distribuição do tamanho de poros microestrutural com as trajetórias de carregamento, confirmam a definição de microestrutura de Romero \& Vaunat (2000), na qual a microestrutura é a parte do solo não afetada por trajetórias de carregamentos.

Mascarenha (2008) discute os efeitos de carregamentos sobre amostras colapsadas e afirma que até o nível de tensão estudado, apesar de haver mudanças na porosidade, estas decorrem 
da variação dos macroporos, enquanto os microporos permanecem intactos, mesmo nas amostras que sofreram colapso. A relação entre a PSD e o diâmetro dos poros, é ilustrada na Figura 2.11 para amostras no estado natural e colapsadas. Houve poucas alterações na estrutura do solo após o colapso, ocorrendo apenas uma diminuição da densidade dos poros na macroestrutura, com pequena variação do valor dos diâmetros dos poros dominantes. A microestrutura (microporos) do solo se manteve constante nos três casos.

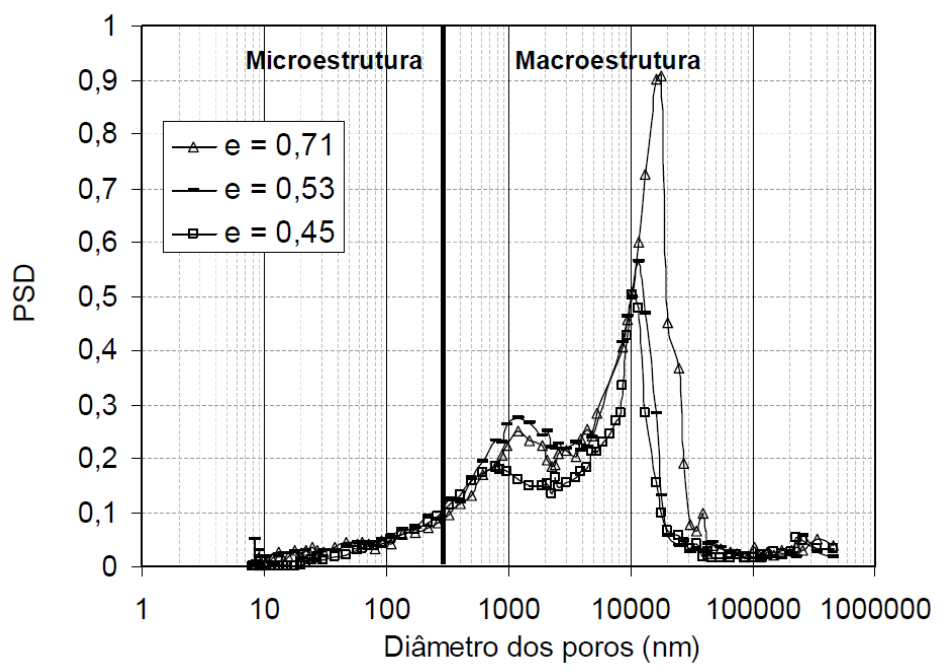

Figura 2.11 - Relação entre a PSD e os diâmetros dos poros das amostras no estado natural e colapsadas (Mascarenha, 2008).

Da mesma forma, Romero (1999) realizou ensaios de MIP para duas amostras de Boom Clay, classificadas como uma argila inorgânica de média a alta plasticidade $(\mathrm{CH})$ e que apresenta valor de peso específico dos sólidos de $27 \mathrm{kN} / \mathrm{m}^{3}$. Estas amostras foram compactadas e apresentam índices de vazios de 0,62 e 0,97. O autor verificou uma diminuição da densidade dos poros do solo (PSD) com a redução dos índices de vazios, conforme Figura 2.12a.

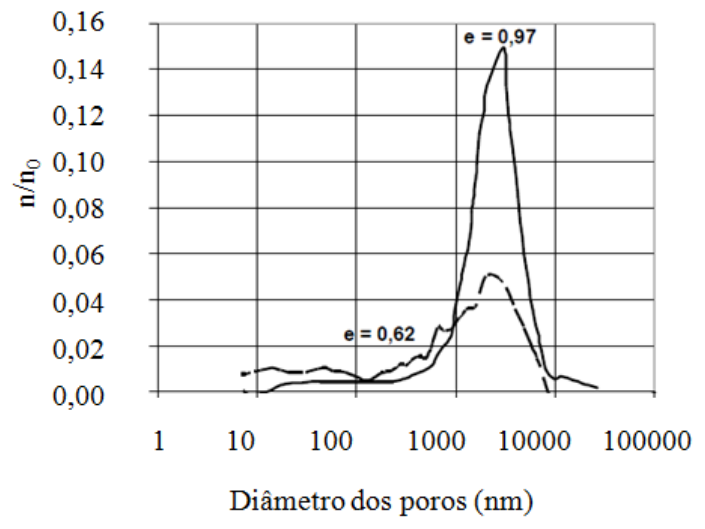

(a)

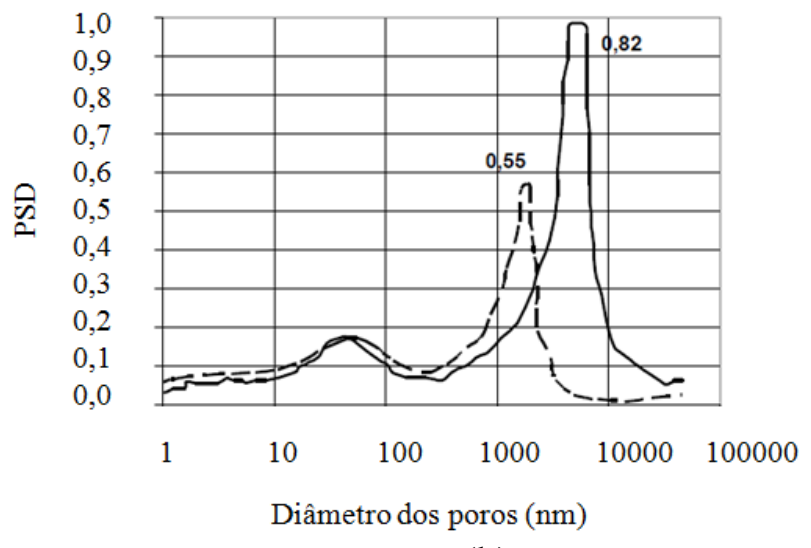

(b)

Figura 2.12 - Distribuição de poros para amostras compactadas a distintas densidades: a) Romero (1999); b) Buenfil (2007). 
Os resultados obtidos por Buenfil (2007) mostrados na Figura 2.12b, seguem a mesma linha de raciocínio. A microestrutura foi mantida em amostras de argila compactadas, com índices de vazios de 0,55 e 0,82, já na macroestrutura ocorreu uma redução do diâmetro do poro dominante de 2000 para $9000 \mathrm{~nm}$. Este solo é classificado como uma argila de baixa plasticidade (CL) e apresenta valor de peso específico dos sólidos de $27,1 \mathrm{kN} / \mathrm{m}^{3}$.

Romero et al. (2005) realizaram ensaios de MIP em amostras de bentonita compactadas, com índices de vazios de 0,64 e 0,93, que apresentam valores de peso específico dos sólidos de 27 $\mathrm{kN} / \mathrm{m}^{3}$. Os autores verificaram uma redução da densidade dos diâmetros dominantes na distribuição do tamanho dos poros da amostra, ao aumentar a energia de compactação. Essas distribuições de poros são apresentadas na Figura 2.13.

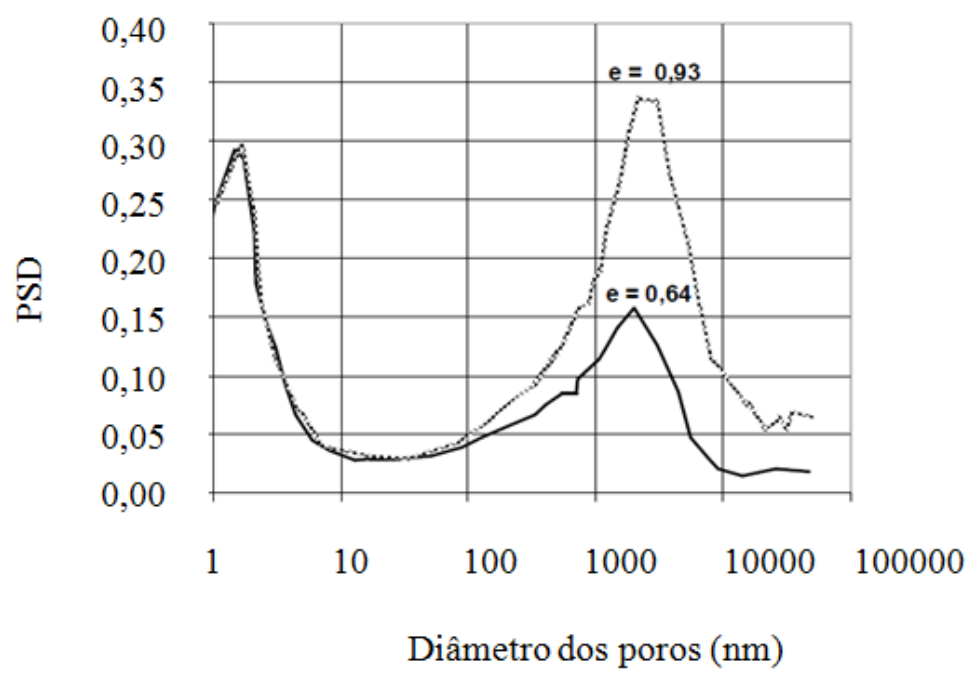

Figura 2.13 -Distribuição do tamanho dos poros para amostras compactadas a distintas densidades (Romero et al., 2005).

Os resultados do MIP para o solo utilizado por Mascarenha (2008), quando comparado aos resultados de solos estudados em outras pesquisas, mostram que o colapso da amostra para essa argila siltosa possui o mesmo efeito que a compactação dos demais solos utilizados por Romero (1999), Buenfil (2007) e Romero et al. (2005).

De acordo com Alonso et al. (1995) e Sivakumar et al. (2006), há três mecanismos envolvidos nas características de mudança de volume de solos não saturados:

- a expansão dos agregados individuais devido à absorção de água;

- o deslizamento do agregado devido ao contato interagregado levando ao colapso por compressão;

- a distorção dos agregados dentro dos poros interagregados. 
A influência de diferentes trajetórias de tensões mecânicas (carregamento), de secagem e molhagem e química (variação da concentração de água nos poros) sobre a PSD de uma bentonita FEBEX compactada, foi analisada por Musso et al. (2003), Romero et al. (2005), Hoffmann et al. (2007) e Lloret \& Villar (2007).

A Figura 2.14 mostra a evolução das funções PSD bimodais na condição oedométrica (uniaxial) de carregamento e teor de umidade constante de 14\%. A região de microporos permanece essencialmente constante, com o aumento da tensão. As alterações no índice de vazios resultam apenas em mudanças na porosidade interagregada (macroporos). Isso também foi observado em solos argilosos compactados, por Delage et al. (1996). É também evidente na Figura 2.14 que o tamanho de poros interagregados diminui ligeiramente com o aumento da energia de compactação.

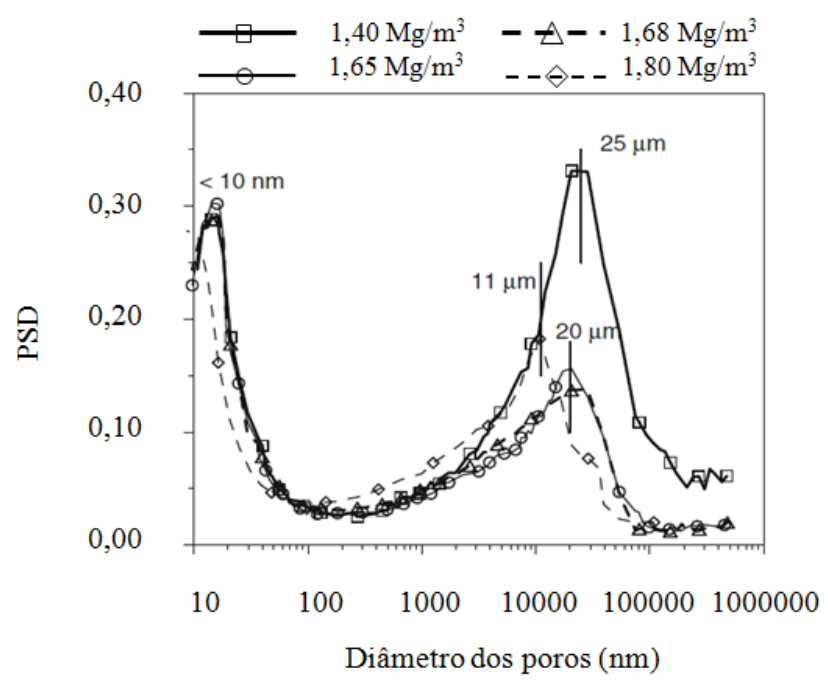

Figura 2.14 - Evolução da função de PSD com o carregamento, em bentonita FEBEX com teor de umidade constante de 14\% (Romero et al., 2005).

A Figura 2.15 mostra a evolução da função PSD ao executar trajetórias de molhagem na mesma bentonita, juntamente com a curva PSD bimodal do solo no estado recompactado a uma densidade seca inicial de $1,40 \mathrm{~g} / \mathrm{cm}^{3}$. Duas séries de trajetórias hidráulicas foram realizadas, uma, a volume constante durante molhagem e a outra, sob uma tensão vertical constante de $2 \mathrm{MPa}$. Observe que na Figura 2.15 aparece um novo modo dominante entre 350 e $1.100 \mathrm{~nm}$. Deste modo, a amostra atinge picos mais elevados à tensão vertical constante, durante a molhagem. No caso da condição de volume constante e as elevadas tensões aplicadas durante molhagem, a porosidade interagregada é reduzida, tendendo à sua oclusão. 


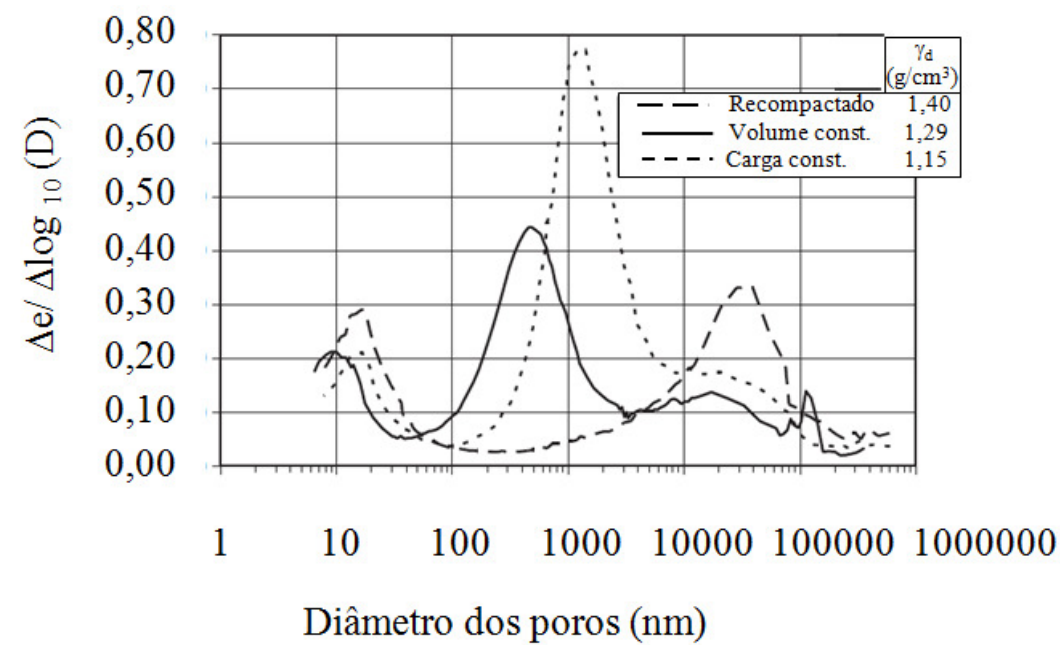

Figura 2.15 - Evolução da função PSD na molhagem a uma tensão vertical constantes e volume constante (Lloret \& Villar, 2007).

A Figura 2.16 apresenta a distribuição do tamanho dos poros em amostras preparadas usando compressão isotrópica, com volume específico inicial médio de 2,19 (levemente comprimida) e 1,99 (fortemente comprimida). Estas amostras são identificadas como IS(A) e IS(B), respectivamente. O tamanho de poro que separa os vazios interagregados e intra-agregados é de cerca de $2 \mu \mathrm{m}$ (Sivakumar et al., 2010).

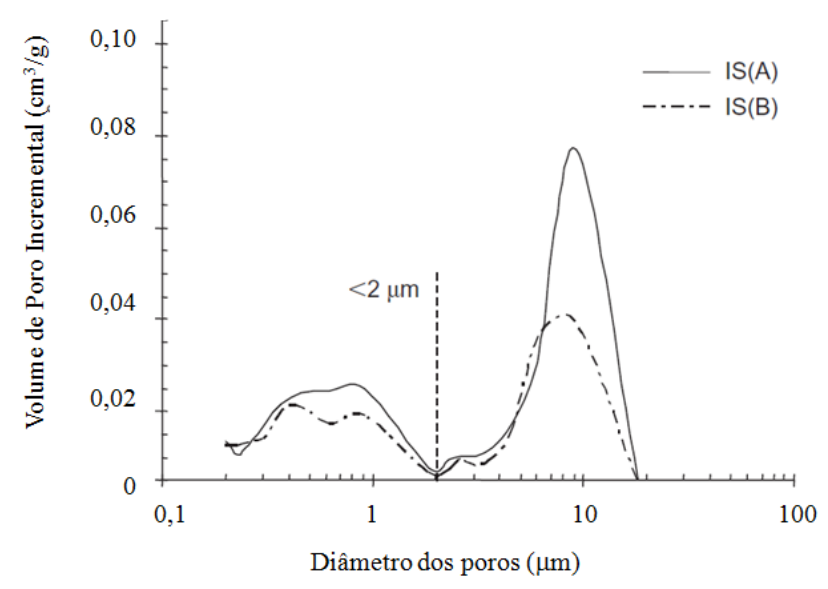

Figura 2.16 -Distribuição do tamanho dos poros de solos não saturados (Sivakumar et al., 2010) .

Para as amostras IS (A) e IS (B) os vazios intra-agregado $(<2 \mu \mathrm{m})$ são aproximadamente similares. No entanto, existe uma diferença entre os macroporos para IS(A) e IS(B). IS(B) foi mais compactado, o que resultou na diminuição dos macroporos interagregados. A sucção nas amostras de IS (A) e IS (B) reduz assim como a água absorvida nas amostras e os processos de equalização progridem. Isto resulta em alterações do volume global do solo.

Sivakumar et al. (2010) demonstram a influencia da saturação das amostras nas distribuições do tamanho dos poros, que são apresentadas na Figura 2.17, nas amostras IS (A) e IS (B), 
obtidas na condição inicial e após a saturação. No caso da amostra levemente comprimida IS (A) (Figura 2.17(a)), na condição inicial, a variação máxima do tamanho do poro foi de aproximadamente $0,075 \mathrm{~cm}^{3} / \mathrm{g}$ em tamanho de poro de $10 \mu \mathrm{m}$, o que representa os poros interagregados, reduzidos para $0,025 \mathrm{~cm}^{3} / \mathrm{g}$, quando a amostra foi saturada.

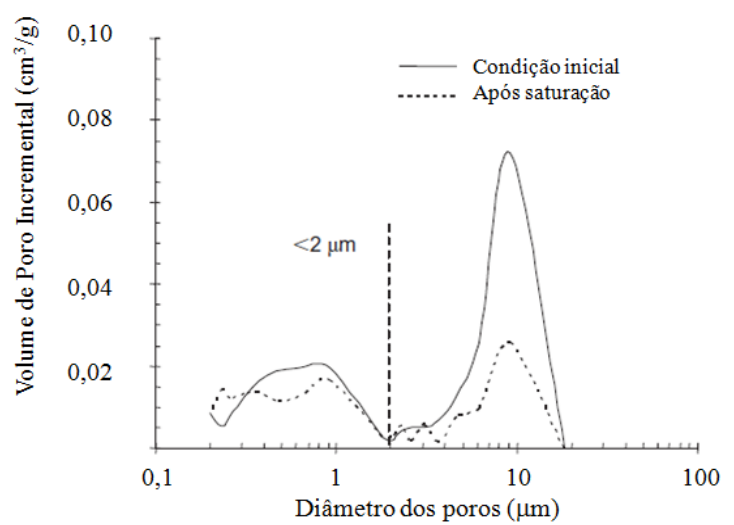

(a)

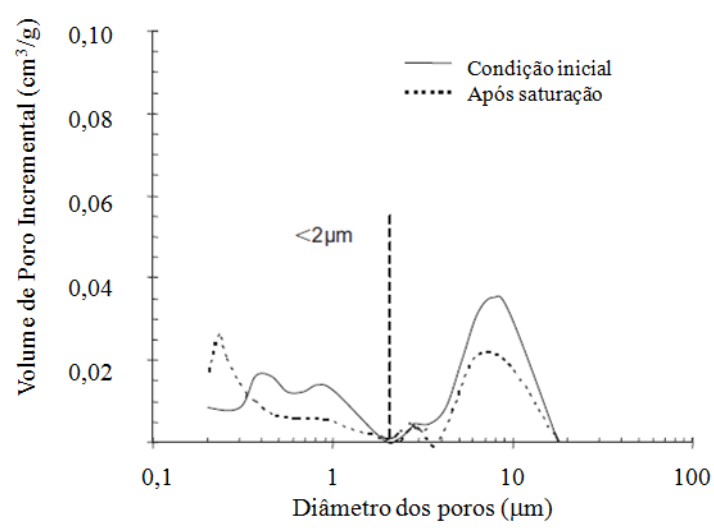

(b)

Figura 2.17 - Distribuição do tamanho dos poros: (a) amostras levemente comprimidas IS(A); (b) amostras fortemente comprimidas IS(B) (Sivakumar et al., 2010).

Já na amostra fortemente comprimida IS (B) (Figura 2.17b), o volume de poro máximo é de $0,035 \mathrm{~cm}^{3} / \mathrm{g}$ para o tamanho de poro de $10 \mu \mathrm{m}$, que reduz para aproximadamente $0,020 \mathrm{~cm}^{3} / \mathrm{g}$, quando a amostra foi saturada. O processo de saturação também resultou num aumento do tamanho dos poros intra-agregado, como pode ser observado no caso do IS (B), mostrado na Figura 2.17b. Entretanto, este aumento não pode ser estabelecido completamente, devido à limitação da pressão aplicada que permite que o mercúrio preencha os menores vazios dos agregados (Sivakumar et al., 2010).

Sivakumar et al. (2010) esperavam que a porosidade interagregada permanecesse inalterada se a expansão dos agregados fosse o único mecanismo para a variação de volume, porém, a Figura 2.17 indica uma redução significativa no volume dos poros interagregados e, consequentemente, na porosidade. Thom et al. (2007) mostram que este fenômeno pode ser explicado pela distorção induzida e expansão dos agregados durante a molhagem, o que acarreta a redução observada no tamanho de poro interagregado.

Wheeler \& Sivakumar (1995) e Sivakumar \& Wheeler (2000) relataram uma série de ensaios de sucção controlada em amostras de solo saturadas, preparadas por compressão estática em um molde de compactação para volumes específicos iniciais de 2,19 e 1,99. Estes resultados obtidos de amostras unidimensionalmente comprimidas são mencionados como ID (A) e ID 
(B), respectivamente, e são comparados com o dados obtidos por Sivakumar et al. (2010) (Figura 2.18).

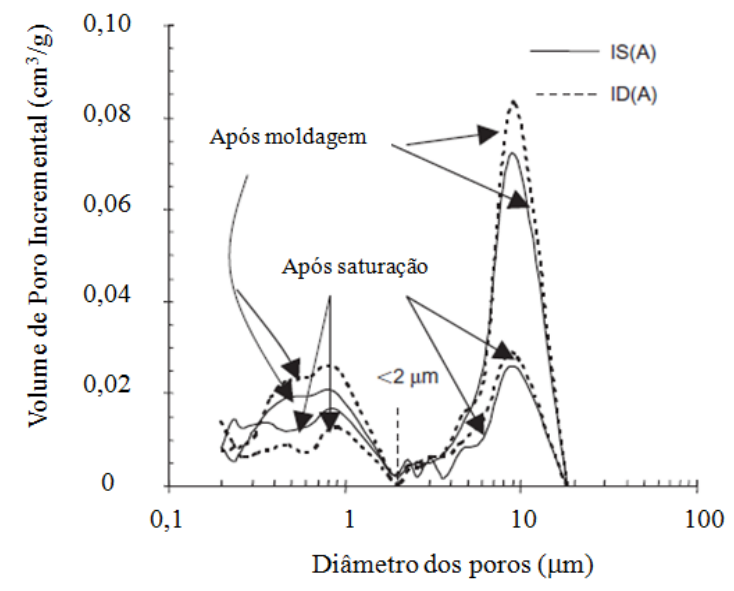

(a)

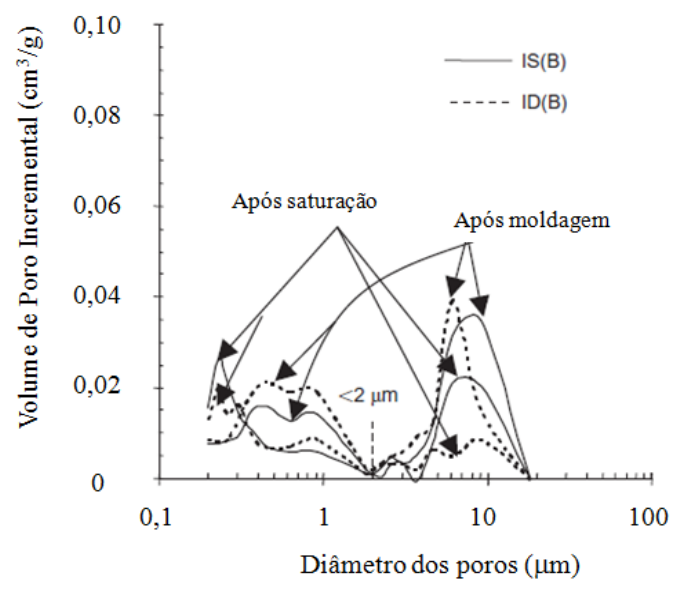

(b)

Figura 2.18 - Efeitos da anisotropia de tensão induzidas na distribuição do tamanho dos poros: (a) levemente comprimida; (b) fortemente comprimida (Sivakumar et al., 2010).

A Figura 2.18 apresenta as distribuições de tamanho de poro das amostras IS (A), ID (A), IS (B) e ID (B), na condição após a compactação e após a saturação. Os resultados indicam uma tendência geral de redução dos poros interagregados e o aumento dos poros intra-agregados após saturação. No entanto, apesar dos volumes específicos iniciais idênticos, as amostras exibiram uma distribuição do tamanho dos poros um pouco diferente, representados nesta figura como "após moldagem".

As amostras preparadas usando compressão unidimensional (ID) possuem uma macroestrutura ligeiramente aberta, para as condições de compressão inicial (ID (A) e ID (B)). A estrutura aberta exibida pela amostra ID (A) pode ter contribuído para instabilidade dos contatos interagregado suscetíveis a colapsarem durante a molhagem.

A amostra IS (A) apresenta uma redução significativa nos poros interagregados em comparação com a amostra mais compacta, IS (B). Para a amostra menos compactada, IS (A), a absorção da água resultou no fechamento dos poros interagregados. Na amostra IS (A) os intra-agregados não sofreram grandes alterações. Para as amostras mais compactas, IS (B), houve também uma redução dos poros interagregados devido à absorção da água. Por outro lado, houve uma diminuição no diâmetro dos poros intra-agregados.

Já nas amostras comprimidas unidimensionalmente (ID (A) e ID (B)), estas observações são diferentes, as reduções nos espaços dos poros interagregados são mais significativas em ambos os casos. Na amostra ID (B), o processo de saturação parece ter quase erradicado a 
presença de uma distribuição bimodal. O comportamento da distribuição do tamanho dos poros é diferente para nas amostras IS (A) e IS (B). Na amostra, mais levemente compactada, ID (A), após saturação, uma distribuição bimodal é ainda evidente (Figura 2.18a).

Koliji et al. (2010) também analisaram a estrutura de um solo agregado sob várias condições de saturação e carregamento, para tentarem entender a resposta macroscópica do solo em relação à sua estrutura. Além disso, os autores compararam a estrutura do solo agregado, que apresentada dupla porosidade, com a do mesmo solo quando reconstituído.

No trabalho de Koliji et al. (2010) foram utilizadas amostras de solo agregado designadas pelo prefixo PS, além de três amostras reconstituídas designadas pelo prefixo PR, e uma amostra de solo agregado seco chamada AGG. Todas estas amostras foram analisadas utilizando o MIP e foram preparadas conforme pode ser visualizado na Figura 2.19, para as amostras PR (reconstituídas) e PS (agregado).

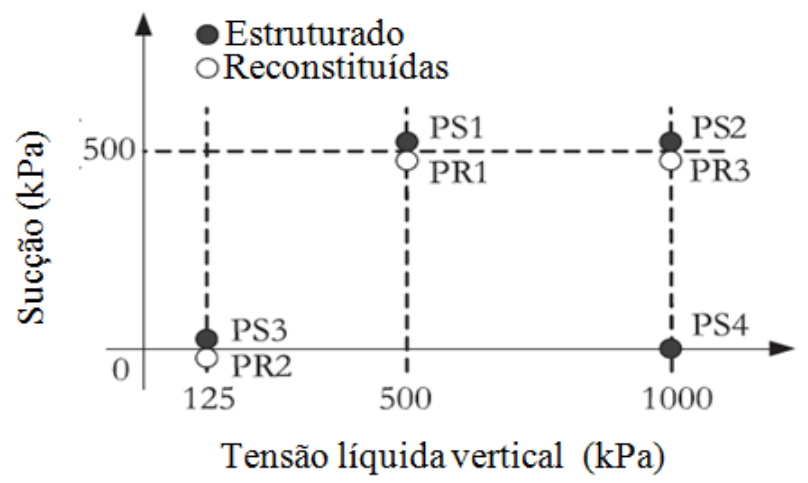

Figura 2.19 - Amostras de Silte Bioley ensaiados para a distribuição do tamanho dos poros (PSD) utilizando a técnica de porosimetria por intrusão de mercúrio (MIP) (Koliji et al., 2010).

As amostras PR e PS foram primeiramente preparadas diretamente na célula oedométrica sem compactação e em seguida levadas para a tensão vertical e de sucção desejada. No caso de amostras saturadas, o solo foi inicialmente seco, com uma tensão determinada e, em seguida, foi umedecido para atingir a saturação. Utilizou-se uma célula oedométrica convencional para as amostras saturadas (PR2, PS3, PS4) e uma célula oedométrica como controle de sucção osmótica para as amostras não saturadas (PSI, PS2. PR1, PR3) (Koliji et al., 2010).

Koliji et al. (2010) apresentam como os efeitos da estrutura, da carga mecânica e da sucção podem afetar a PSD (Figura 2.20). Os efeitos da compactação sobre amostras agregadas não saturadas são avaliados na Figura 2.20 comparando a PSD das amostras agregadas não saturadas com diferentes níveis de tensões verticais e sucção constante. 


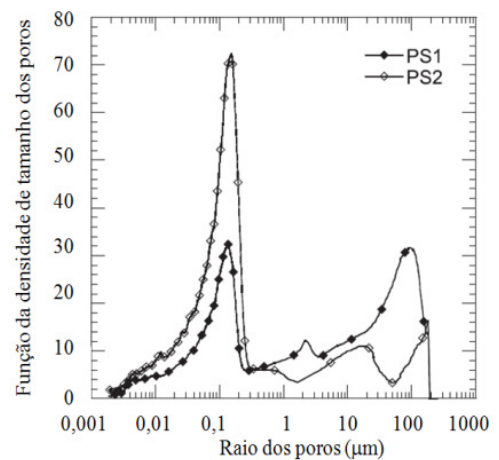

(a)

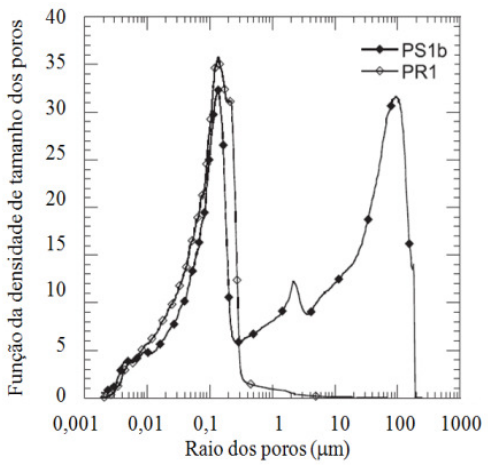

(d)

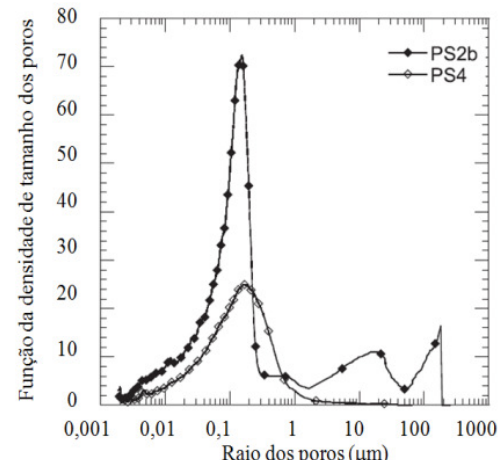

(b)

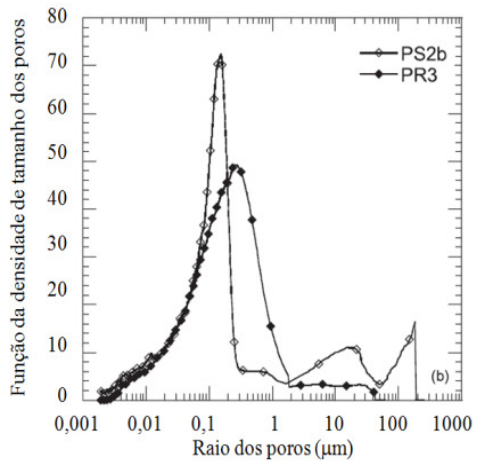

(e)

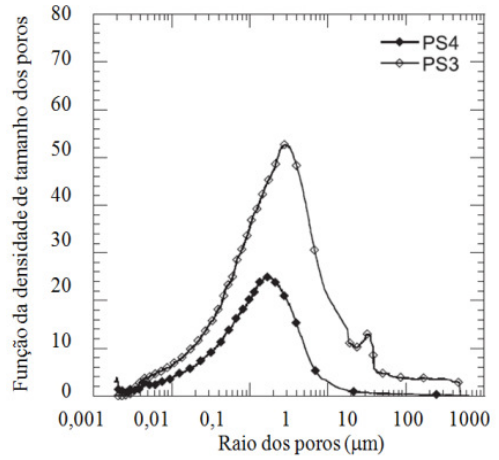

(c)

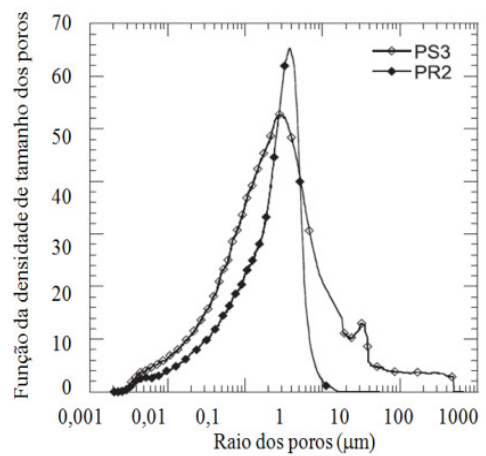

(f)

Figura 2.20 - Comparação de resultados de porosimetria por intrusão de mercúrio: (a) efeito da compactação não saturado; (b) efeito da saturação; (c) efeito da compactação saturada; (df) efeito da estrutura (Koliji et al., 2010).

A Figura 2.20a mostra que a região de macroporos PS1 possui o pico de poros resultante da compactação, já em PS2, este pico desaparece devido ao carregamento. No entanto, os autores relatam que uma conclusão firme sobre a evolução dos macroporos é difícil, devido à limitação do método de MIP para poros maiores. Na região de microporos, embora a diferença no tamanho dos poros dominante não seja significativa, a intensidade de pico aumenta significativamente de 33 em PS1 para 70 em PS2. Isto mostra que o carregamento da amostra aumentou significativamente a porção de microporos, enquanto possivelmente resultou na diminuição do volume de macroporos.

Koliji et al. (2010) avaliaram a influência da saturação da amostra (Figura 2.20b), que se encontram sob tensão vertical de $1.000 \mathrm{kPa}$, porém, PS4 foi saturada. O tamanho do poro dominante permanece quase inalterado, enquanto sua intensidade diminui significativamente. Acredita-se que isto é devido a um colapso da estrutura do agregado e à deformação induzida pelo umedecimento da amostra. A distribuição unimodal da PSD mostra que a saturação da amostra, sob a tensão relativamente alta de $1000 \mathrm{kPa}$ eliminou quase todos seus macroporos. Mascarenha (2008) e Otálvaro (2013) não encontraram resultados semelhantes para os solos 
estudados por estes autores. No caso de Otálvaro (2013), o nível de tensão aplicado era de $2200 \mathrm{kPa}$ e ainda havia a existência de uma estrutura bimodal.

Os efeitos de compactação sobre a estrutura das amostras agregadas após saturação foram avaliados pela comparação dos resultados de amostras de PS3 e PS4, apresentados na Figura 2.20c. Segundo Koliji et al. (2010) nos resultado da saturação, as amostras exibem um ligeiro aumento do tamanho dos poros dominante, a intensidade correspondente diminuiu significativamente da função de densidade do tamanho dos poros de 52 em PS3 e cerca de 24 em PS4. Esta evidência mostra que, no caso de PSD unimodal, a compactação, diminui o volume dos poros dominante enquanto desloca ligeiramente o tamanho dos poros dominante para valores menores.

Por último, os autores comparam as amostras agregadas (PS1, PS2 e PS3) com as amostras reconstituídas correspondente (PR1, PR2 e PR3), nas Figura 2.20d, Figura 2.20e e Figura 2.20f, respectivamente. Cada par de amostras representa o mesmo valor de sucção e tensão vertical. Nas amostras PS1 a PSD é bimodal, e o pico de microporos coincide com a da amostra reconstituída PR1, tanto no raio e como na intensidade.

Já as amostras PS2 e PS3, a PSD é unimodal, a intensidade do pico de solo reconstituído é mais elevada do que a das amostras de agregadas. Os resultados obtidos pelos autores sugerem que a principal diferença entre os solos agregados e reconstituídos está nos seus macroporos, que , quando desaparecem, como no resultado da compactação ou de imersão, as PSDs destes solos apresentam comportamento parecido. 


\section{3 - METODOLOGIA}

O Programa de Pós-Graduação de Geotecnia da Universidade de Brasília vem desenvolvendo a linha de pesquisa em modelos constitutivos. Dentre estes trabalhos, vem sendo elaborado um que leva em consideração os aspectos estruturais do solo, baseado na ideia de que a resposta macroscópica do solo é o resultado do que acontece no nível microestrutural e macroestrutural.

As etapas realizadas para o desenvolvimento da pesquisa, que serão discutidas logo adiante, foram definidas de acordo com o diagrama apresentado pela Figura 3.1.

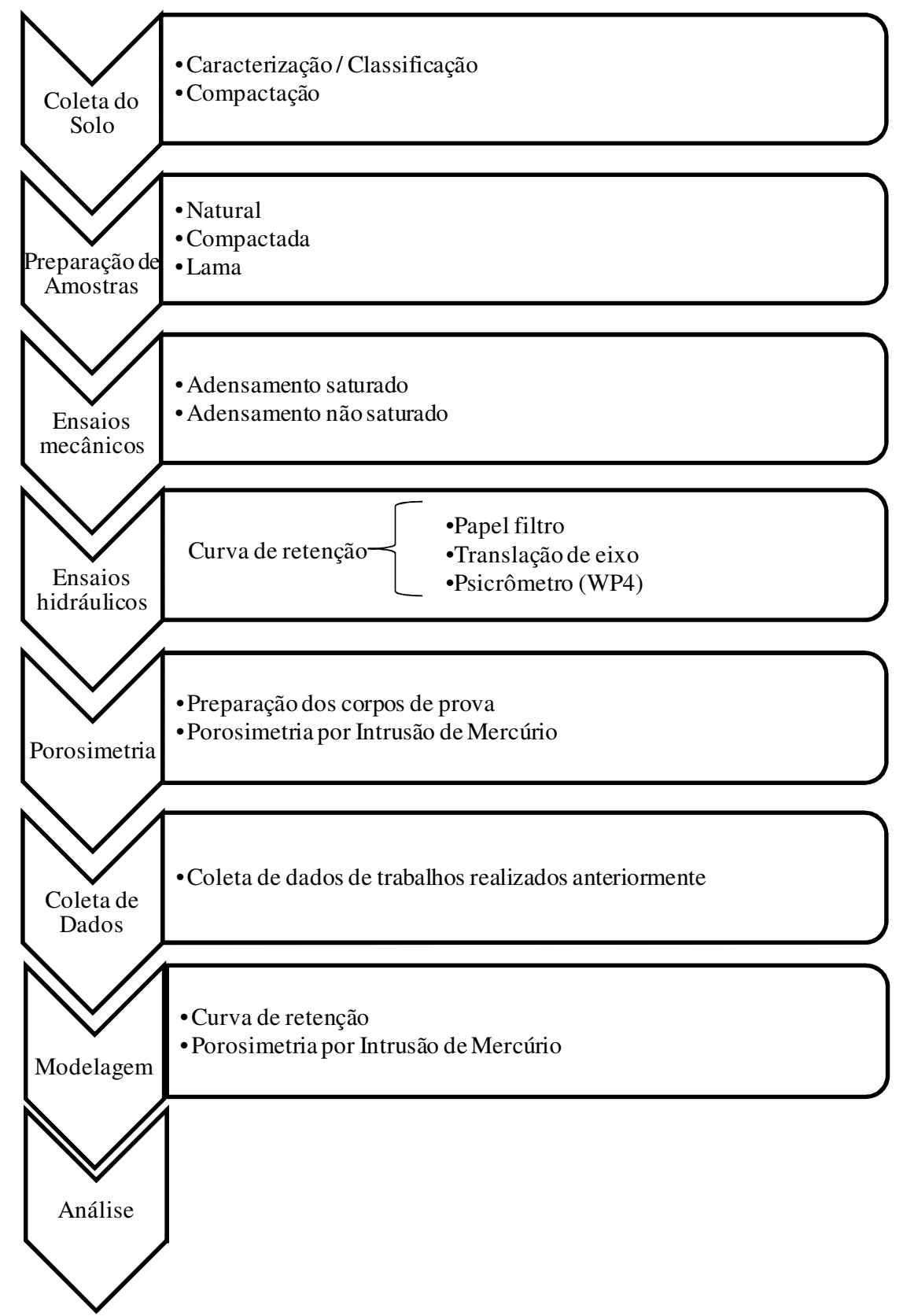

Figura 3.1 - Esquema do desenvolvimento da pesquisa. 
A campanha de ensaios realizados visa compreender o comportamento hidráulico e mecânico do solo e, se possível, relacioná-lo com a resposta microestrutural. O solo estudado é de origem residual intemperizado e foi coletado no Campo Experimental do Programa de PósGraduação em Geotecnia da Universidade de Brasília, localizado em frente ao prédio do SG12. Esta escolha deve-se ao fato de este solo estar sendo estudado há vários anos e, por isso, ter parte de suas características bem conhecidas.

Este estudo foi dividido em algumas etapas: ensaios de caracterização física e compactação, preparação das amostras, ensaios mecânicos (adensamento), ensaios hidráulicos (curva de retenção). Após estes ensaios foram preparados os corpos de prova para a realização de ensaios de porosimetria por intrusão de mercúrio, com o intuito de avaliar a estrutura do solo. Nos próximos itens estão apresentados detalhes sobre os materiais e métodos utilizados nesta pesquisa.

\section{1 - PREPARAÇÃO E CARACTERIZAÇÃO FÍSICA DAS AMOSTRAS}

Os estudos foram realizados em amostras: Natural, Compactada e Lama. A amostra Compactada foi obtida no ramo seco da curva de compactação, utilizando metodologia semelhante à apresentada por Silva (2009). Já a amostra de Lama foi preparada com solo a partir de um estado de lama, de forma semelhante à realizada por Borges (2010). Na área escolhida executou-se a abertura de um poço de amostragem, realizada no mês de agosto de 2010. O poço foi escavado com diâmetro de $1,50 \mathrm{~m}$ e profundidade de $2,5 \mathrm{~m}$. Deu-se prioridade à coleta do material próximo à superfície, na profundidade de 1,70 a 2,30 m.

De acordo com Camapum de Carvalho et al. (1994) essa primeira camada de solo residual laterítico apresenta uma estrutura muito porosa, não saturada e com baixa capacidade de suporte. Essa estrutura promove a formação de agregações, conferindo a estes solos, apesar da matriz argilosa, comportamento hidráulico semelhante ao dos solos granulares finos.

Geralmente, esse material é instável quando submetido a variações no estado de tensão e saturação, apresentando, portanto, um comportamento colapsível. Como na maioria das regiões tropicais, este solo apresenta características peculiares e comportamento geotécnico distinto, consequência dos diversos processos ocorridos desde a sua gênese (Camapum de Carvalho et al., 1994). 
Para a caracterização das amostras foram realizados ensaios de peso específico dos grãos, granulometria por peneiramento e sedimentação, granulometria a laser, limites de liquidez e plasticidade e compactação. A caracterização e as normas são apresentadas na Tabela 3.1.

Tabela 3.1 - Ensaios de caracterização física.

\begin{tabular}{|c|c|c|c|}
\hline Ensaio & Método & Norma & Formas de preparação do solo \\
\hline $\begin{array}{l}\text { Peso específico } \\
\text { real dos grãos }\end{array}$ & $\begin{array}{c}\text { Balão } \\
\text { Volumétrico }\end{array}$ & $\begin{array}{c}\text { NBR 6458 } \\
\text { (ABNT, 1984) }\end{array}$ & $\begin{array}{l}\text { Com secagem prévia ao ar, } \\
\text { amostra passada na \#10 }\end{array}$ \\
\hline $\begin{array}{l}\text { Limite de } \\
\text { liquidez }\end{array}$ & $\begin{array}{l}\text { Aparelho de } \\
\text { Casagrande }\end{array}$ & $\begin{array}{c}\text { NBR } 6459 \\
(\mathrm{ABNT}, 1984)\end{array}$ & Com secagem prévia ao ar \\
\hline $\begin{array}{l}\text { Limite de } \\
\text { plasticidade }\end{array}$ & $\begin{array}{l}\text { Moldagem de } \\
\text { cilindro }\end{array}$ & $\begin{array}{c}\text { NBR 7180 } \\
\text { (ABNT, 1984) }\end{array}$ & Com secagem prévia ao ar \\
\hline Granulometria & $\begin{array}{c}\text { Peneiramento e } \\
\text { Sedimentação }\end{array}$ & $\begin{array}{c}\text { NBR 7181 } \\
(\mathrm{ABNT}, 1984)\end{array}$ & $\begin{array}{l}\text { Com secagem prévia ao ar, com e } \\
\text { sem defloculante. }\end{array}$ \\
\hline Compactação & $\begin{array}{l}\text { Compactação } \\
\text { tipo Proctor }\end{array}$ & $\begin{array}{c}\text { NBR 7182 } \\
(\mathrm{ABNT}, 1986)\end{array}$ & $\begin{array}{c}\text { Sem reuso e com secagem prévia ao } \\
\text { ar }\end{array}$ \\
\hline
\end{tabular}

\section{2 - PREPARAÇÃO DAS AMOSTRAS COMPACTADAS}

O método de preparação das amostras compactadas foi realizado com o objetivo de desenvolver os estudos da pesquisa, com o mínimo possível de variabilidade das propriedades físicas, ou seja, haver uma uniformidade de granulometria e índice de vazios. Para isso, a amostra passou por processo de secagem ao ar, até atingir a umidade higroscópica, e pela peneira \#10 com abertura de 2,0 $\mathrm{mm}$.

Para a moldagem das amostras compactadas utilizadas na realização dos ensaios, foi necessária a obtenção de uma amostra de solo homogênea, controlando a condição de compactação, levando a amostra a uma condição próxima à de campo, no que se refere à umidade. Na preparação destas amostras, a umidade fica próxima ao desejado; já em relação ao índice de vazios, não é possível obter o mesmo valor devido à cimentação existente nas amostras indeformadas (ou naturais).

Para cumprir esta etapa, foi obtida uma curva de compactação Proctor Normal (Figura 3.2), para determinar o ponto de umidade e peso específico seco com que as amostras serão moldadas. O ponto escolhido (Figura 3.2) foi o mesmo já utilizado por Silva (2009), encontrase abaixo das condições ótimas de energia e umidade e está localizado no ramo seco da curva de compactação $\left(w=20 \%\right.$ e $\left.\gamma_{d}=13,5 \mathrm{kN} / \mathrm{m}^{3}\right)$. A escolha do ponto no ramo seco se deve ao fato da obtenção de um solo com estrutura aberta quando compactado em condições inferiores à condição ótima. 


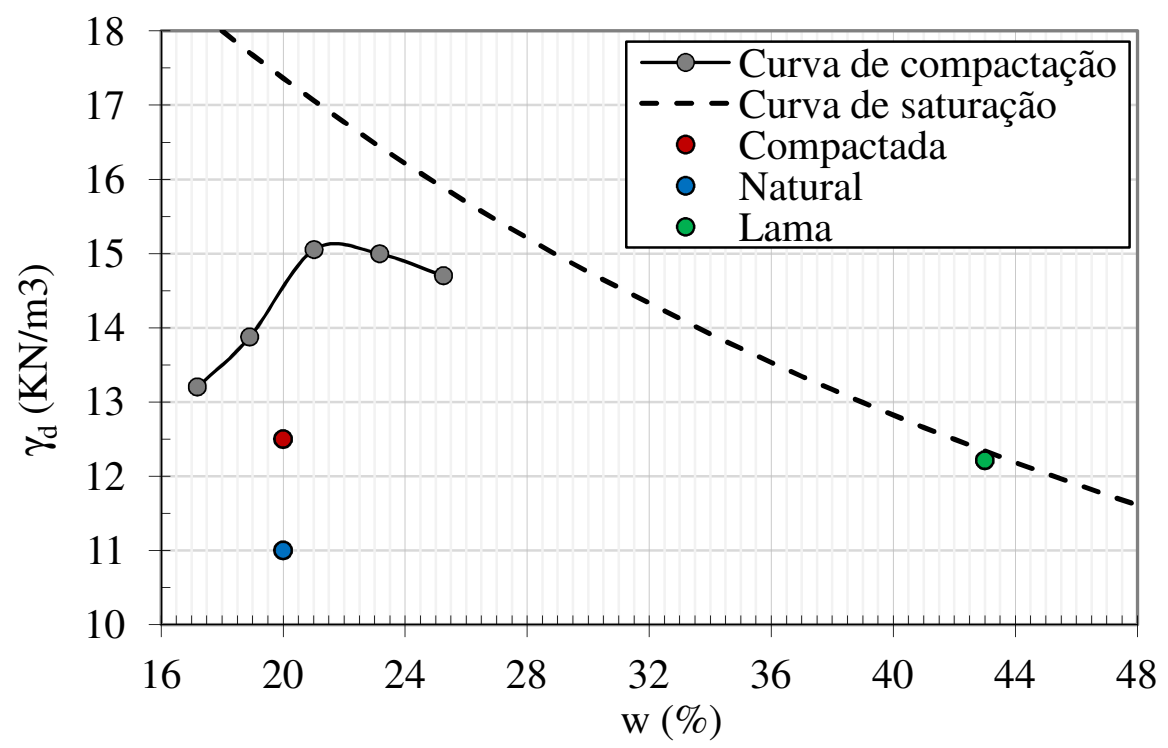

Figura 3.2 - Curva de compactação.

Após a determinação do teor de umidade e do peso específico seco, foram moldadas as amostras pelo processo de compactação semiestática, mantendo-se constantes a densidade, a umidade estabelecida e o índice de vazios calculado $(e=1,20)$. Após a moldagem, foi extraída a amostra do molde e foram elaborados os corpos de prova para os demais ensaios citados posteriormente.

O procedimento de compactação semiestática foi adotado com base no estudo de Camapum de Carvalho et al. (1994), que afirmaram que a utilização da energia de compactação semiestática proporciona uma maior repetição das propriedades dos solos e ainda se ajusta ao comportamento dos solos compactados em campo.

\section{3 - PREPARAÇÃO DAS AMOSTRAS DE LAMA}

O objetivo do processo de preparação das amostras de solo, a partir de um estado de lama, foi fabricar amostras desprovidas da estruturação original do solo indeformado e com valores de índice de vazios elevados. O processo de preparação foi executado com amostras deformadas obtidas na mesma profundidade, ou seja, 1,70 a 2,30 m.

Inicialmente, o solo foi seco ao ar e depois passado na peneira \#10 $(2,0 \mathrm{~mm})$. A partir do valor do limite de liquidez foi adicionada água ao solo até atingir um valor acima do teor de umidade do limite de liquidez $\left(1,5 w_{L}\right)$, obtendo a consistência de lama. Esta amostra foi 
homogeneizada, com o auxílio de um misturador mecânico, por 15 minutos (Figura 3.3a), e deixada em repouso (Figura 3.3b). Após a amostra começar a secar e antes da formação de trincas na superfície do solo, ela foi utilizada para moldagem das novas amostras. O ponto obtido é apresentado na Figura 3.2, juntamente com a curva de compactação e a linha de saturação do solo. É importante ressaltar que durante a secagem deste material não houve formações de trincas.

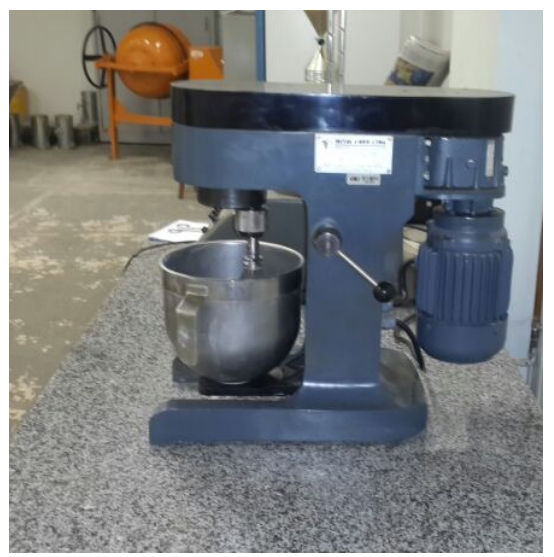

(a)

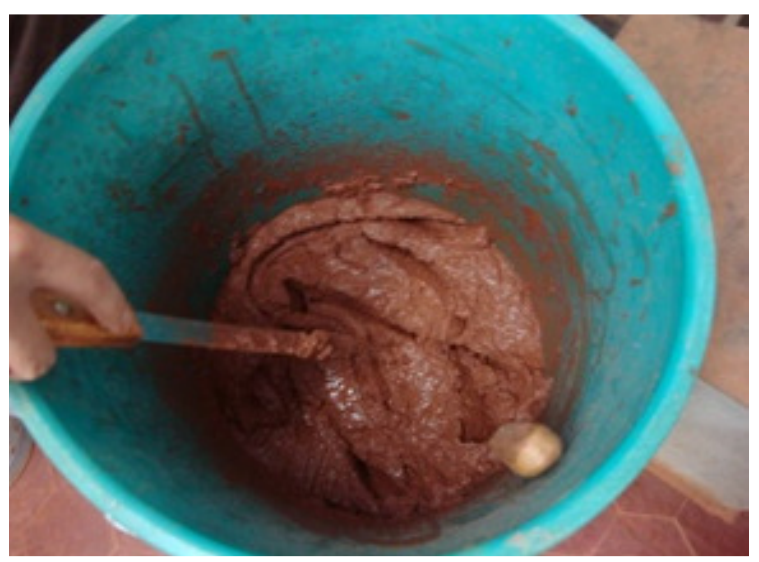

(b)

Figura 3.3 - Processo de fabricação da lama: (a) lama homogeneizada em um misturador mecânico; (b) solo em forma de lama.

O solo de Lama foi utilizado para a realização de ensaios de curva de retenção e de adensamento saturado e com controle de sucção, e para preparação de corpos de prova para a realização do MIP, a partir dos ensaios de adensamento. Para a preparação das amostras de Lama e para a realização dos ensaios citados, após o processo de preparação do material no estado de Lama, este é transferido para os moldes. O solo foi então colocado aos poucos nos moldes, tendo-se o cuidado de, durante este processo, remover eventuais bolhas de ar.

\section{4 - ENSAIOS DE ADENSAMENTO}

Para verificar a influência da estruturação do solo de Brasília foram realizados ensaios de adensamento em amostras Natural, Compactada e Lama, na condição saturada e não saturada. O método de ensaio de adensamento saturado adotado foi baseado na NBR 12007 (ABNT, 1990). Os ensaios de adensamento também foram realizados na condição não saturada, com controle de sucção, usando as técnicas de translação de eixo e osmótica. 


\subsection{1 - CÉLULA DE ADENSAMENTO COM CONTROLE DE SUCÇÃO - TRANSLAÇÃO DE EIXO}

A célula de adensamento com controle de sucção utiliza a técnica de translação de eixo que permite trabalhar com o solo na condição não saturada. Esta técnica permite a determinação e o controle da sucção durante a execução dos ensaios, quando é feita a mudança de referência da pressão atmosférica pela imposição de um aumento de pressão de ar. Este equipamento foi projetado para a realização de ensaios de adensamento para valor de sucção controlado.

O sistema adensamento com controle de sucção - translação de eixo da marca CGTS e modelo SWC-150 (Figura 3.4) - é composto por câmara de pressão, pedras porosas, anel de aço, carneiro pneumático, painel de controle, extensômetro e aquecedor. Existem diferentes tipos de pedra porosa utilizadas neste equipamento (i.e., $1 \mathrm{~B} a \mathrm{r}, 3 \mathrm{~B} a \mathrm{r}, 5 \mathrm{~B} a \mathrm{r}$ e $15 \mathrm{~B} a$ r). Cada pedra porosa possui um valor de entrada de ar (i.e., 1 Bar significa que a pedra porosa possui valor de entrada de ar igual a $100 \mathrm{kPa}$ ). Deve haver especial atenção com a escolha da pedra porosa, já que valores elevados de entrada de ar das pedras porosas permitem a medição de altos valores de sucção do solo, mas diminuem a condutividade hidráulica da pedra porosa (Fredlund \& Rahardjo, 1993).

Neste equipamento, a sucção matricial do solo $\left(u_{a}-u_{w}\right)$ é obtida pela diferença entre a pressão de ar e a pressão de água após o equilíbrio; esta diferença é a sucção do solo. Quando a pressão de ar é igual à pressão atmosférica (i.e. $u_{a}=0$ ), a sucção matricial é igual à poropressão de água negativa. Medições de poropressão negativas podem ser executadas utilizando a técnica de translação de eixo, que transfere a origem de referência de poropressão negativa para uma pressão de ar maior que a atmosférica. Como resultado, a pressão de água no sistema de medição não precisa se tornar negativa, evitando problemas relacionados à cavitação. (Fredlund \& Rahardjo, 1993).

A célula de adensamento com controle de sucção-translação de eixo foi utilizada para obter as curvas de adensamento com controle de sucção nas amostras Compactadas. Para a realização desta curva, a amostra de solo foi moldada em um anel de aço e colocada em cima de uma pedra porosa, para a sua saturação. Após a saturação, a amostra foi instalada na câmara em cima da pedra porosa com alto valor de entrada de ar. Durante o ensaio, a amostra foi submetida a uma sucção de $1000 \mathrm{kPa}$ e, após a estabilização, foram realizados incrementos de carga vertical pelo sistema hidráulico de aplicação de carregamento vertical. Para a realização 
da curva de adensamento foram aplicados valores de tensão de 50, 100, 200, 400 e $800 \mathrm{kPa}$, mantendo a sucção constante.

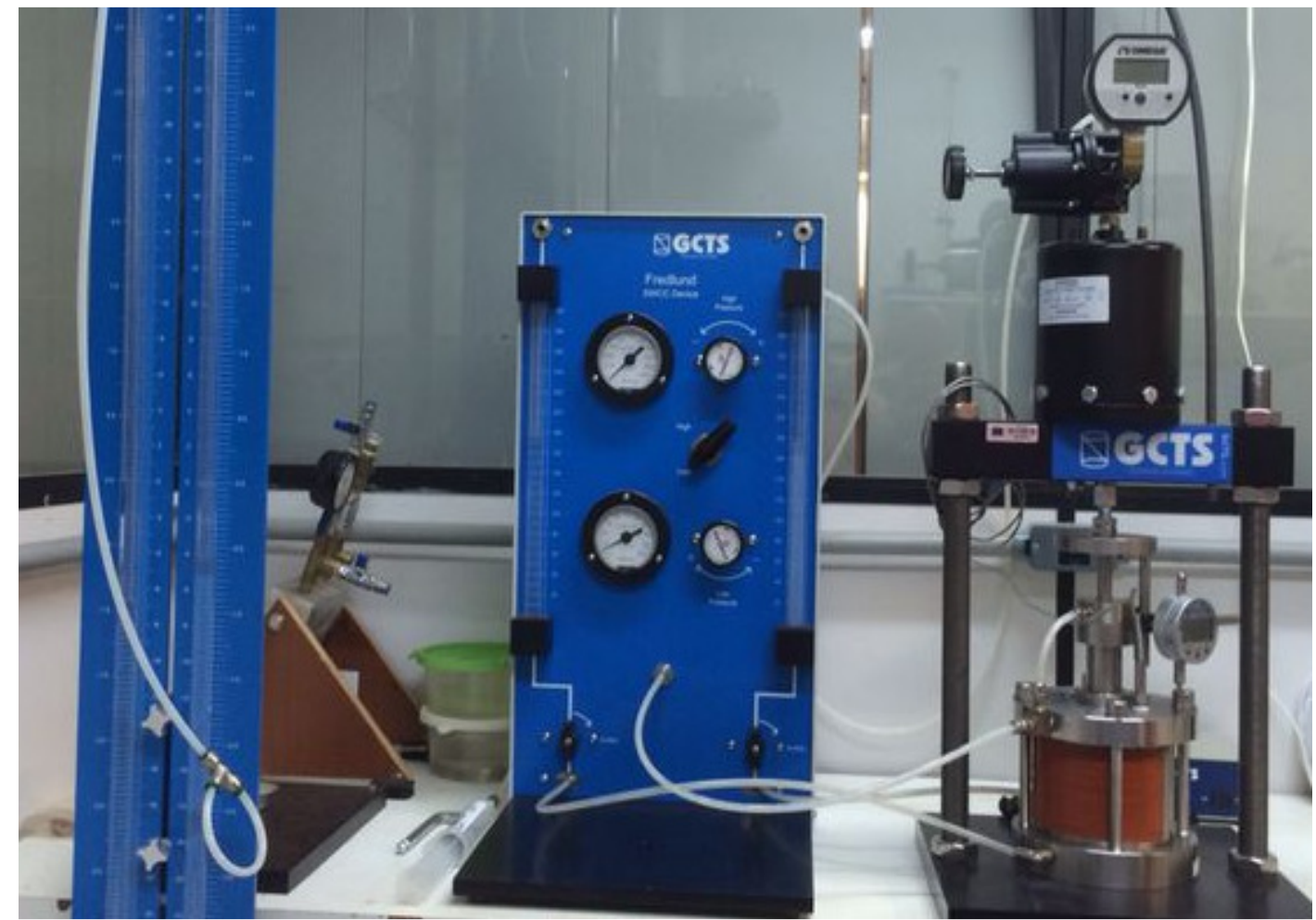

Figura 3.4 - Equipamento de adensamento com controle de sucção/pressão.

\subsection{2 - CÉLULA DE ADENSAMENTO COM CONTROLE DE SUCÇÃO OSMÓTICA}

A célula de adensamento com controle de sucção osmótica utiliza o princípio de osmose. Este sistema consiste em colocar o solo em contato, por meio de uma membrana semipermeável, com uma solução normalmente composta de polietileno de glicol (PEG). O solvente passa de forma espontânea de uma solução de baixa concentração para uma de alta concentração, através da membrana semipermeável. A diferença de potencial tende a movimentar a água através da membrana, até que o equilíbrio seja estabelecido.

O sistema aplica somente sucção matricial, pois a membrana é permeável aos íons do soluto da água do solo. O valor da sucção imposta depende da concentração da solução, sendo que quanto maior a concentração, maior a sucção. Vale ressaltar que a pressão osmótica é gerada devido à impossibilidade de as moléculas de PEG atravessarem a membrana, permitindo somente o fluxo de água.

As membranas utilizadas no método osmótico são compostas, geralmente, de celulose regenerada, acetato celulose, policarbonato, polietileno, polipropileno, dentre outros. Essas 
membranas são projetadas para oferecer resistência química a determinados produtos (hidrocarbono, alguns ácidos, álcool e outros), resistência mecânica e resistência à temperatura (Soto, 2004). Segundo Delage \& Cui (2008), o maior problema dessa técnica é a suscetibilidade dessas membranas a ataques de bactérias. Para evitar estas contaminações, a montagem do ensaio foi realizada com cuidado, evitando ao máximo o contato do material com o ambiente.

A Figura 3.5 mostra o equipamento utilizado para medir a sucção, com a técnica osmótica e o detalhamento dos seus itens. Este equipamento foi utilizado para obter as curvas de adensamento com controle de sucção nas amostras de Lama.

Para a realização destas curvas, a amostra de solo foi moldada em um anel de aço e instalada na célula em cima de uma membrana semipermeável. Foi utilizada uma solução preparada de PEG para atingir um valor de $1000 \mathrm{kPa}$. A bomba peristáltica foi ligada e a solução foi levada pelos tubos de silicone, fazendo com que a solução flua e entre em contato, através da membrana, com o solo. Após a estabilização foram realizados incrementos de carregamento vertical pelo sistema hidráulico de aplicação de carga vertical. Para a realização da curva de adensamento foram aplicados valores de tensão de 50, 100, 200, 400 e $800 \mathrm{kPa}$, mantendo a sucção constante.

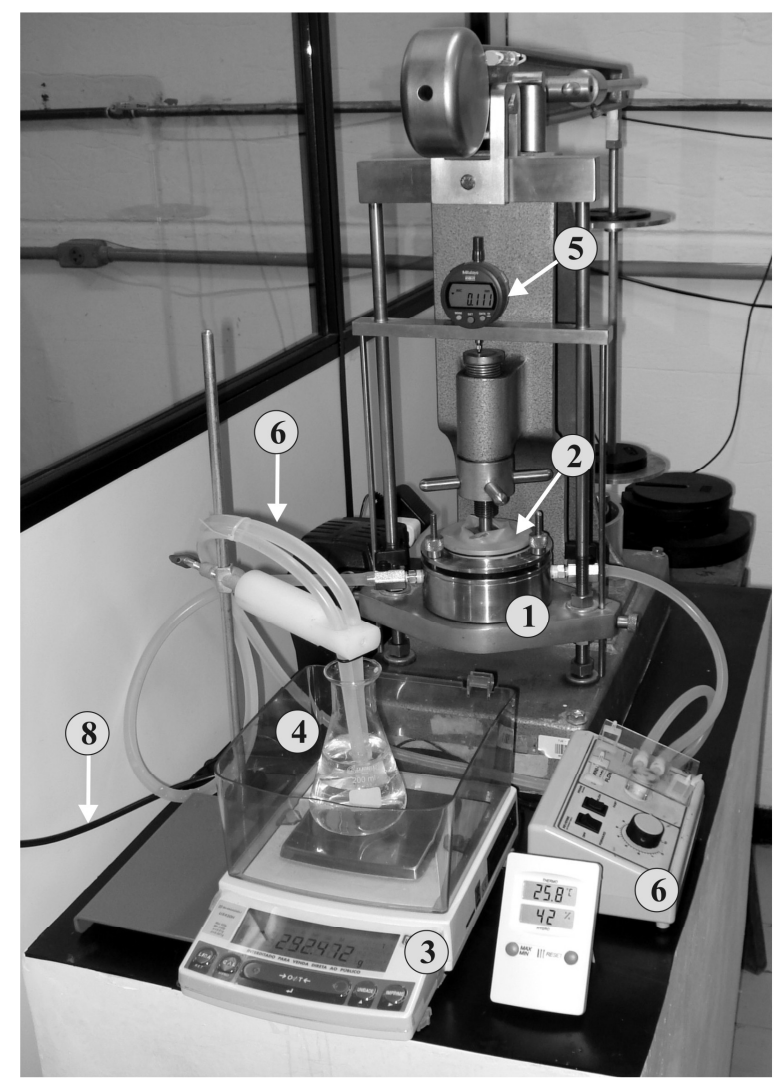

(1) Oedometro

(2) Membrana de latex

(3) Balança analítica $(0.001 \mathrm{~g})$

(4) Reservatório com solução de PEG

(5) Relógio comparador $(0.001 \mathrm{~mm})$

6) Tubo de silicone para fluxo da solução

(7) Bomba peristaltica

(8) Conexão RS232

Detalhe célula
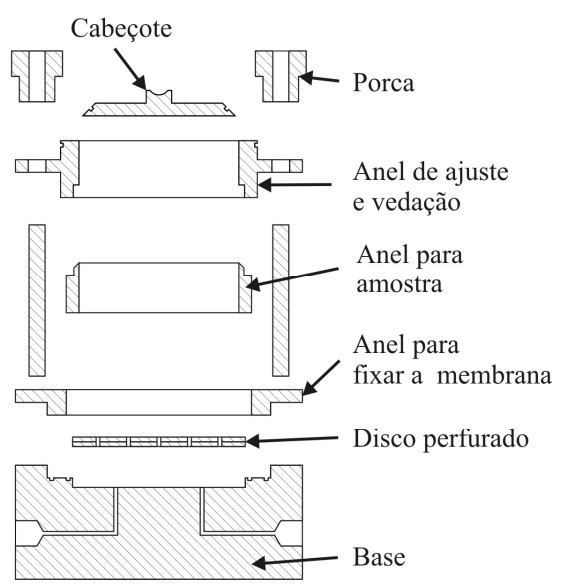

Figura 3.5 - Equipamento de medida de sucção pela técnica osmótica (Otálvaro, 2013) 


\section{5 - DETERMINAÇÃO DA CURVA DE RETENÇÃO}

Atualmente, os equipamentos desenvolvidos para estudo do comportamento hidromecânico de solos não saturados utilizam basicamente três técnicas de imposição de sucção: translação de eixo, osmótica e equilíbrio de vapor. Estas técnicas também podem ser utilizadas para determinação da curva de retenção. A técnica de translação de eixo está relacionada à medida de sucção matricial, por meio de transferência e equilíbrio de fluxos de água líquida.

Além destes equipamentos, para valores elevados de sucção, foi utilizada a técnica de papel filtro. O método do papel filtro permite determinar uma grande faixa de sucções, podendo atingir valores muito altos. Para valores de sucção superiores a $1000 \mathrm{kPa}$, a movimentação da água pode ocorrer por transferência de vapor, pois a partir desse valor o papel filtro não está em contato íntimo com água do solo (Marinho \& Oliveira, 2006). Marinho (1994) mostra a influência da distância entre o papel filtro e a fonte de vapor (solo), além da preocupação quanto à perda de umidade para o ambiente durante a pesagem dos papéis.

Um dos aspectos mais importantes para obtenção adequada de sucção é a garantia de que o papel filtro, após o equilíbrio, seja removido do ambiente de equilíbrio sem perda significativa de umidade. Segundo Marinho (1994), a taxa de variação de umidade pode chegar à ordem de 1,5\% por minuto, para uma umidade de aproximadamente 35\%. Esta perda depende da umidade do papel filtro e da umidade relativa do ar do ambiente do laboratório. Para valores de baixas umidades (altas sucções), a evaporação é menor. Quando é retirado da estufa, o papel filtro absorve água do ar e, portanto, deve ser rapidamente colocado em recipiente e selado (Marinho, 1994).

Outro equipamento também utilizado na pesquisa foi o WP4 (Dewpoint Potencia Meter), que realiza medidas de sucção total. Neste caso, foi considerado que, para o solo estudado, a diferença entre a sucção total e matricial é pequena.

Após a obtenção destes resultados, foi realizado o ajuste da curva de retenção utilizando as equações propostas por Otálvaro \& Cordão Neto (2011), de forma que possibilite o melhor entendimento do comportamento das curvas de retenção.

Nos próximos itens é apresentado um breve resumo sobre as técnicas do papel filtro, translação de eixo e psicrômetro (WP4), utilizadas nesta pesquisa. 


\subsection{1 - PAPEL FILTRO}

O método do papel filtro é baseado na colocação do solo, com determinado teor de umidade, em contato com um material poroso ou próximo deste (i.e. papel filtro), com uma umidade menor, que possua a capacidade de absorver água. $\mathrm{O}$ contato ou a proximidade faz com o papel filtro absorva uma quantidade de água do solo até que o equilíbrio de energia livre da água seja alcançado. A sucção do solo é obtida a partir da umidade do papel filtro e da sua curva de calibração. Quando o equilíbrio é alcançado, os materiais atingem um valor de sucção igual, porém com umidades diferentes (Marinho, 1994).

O ensaio de papel filtro foi realizado nas amostras Naturais e Compactadas. Para a realização do ensaio na amostra Natural, foram moldados 10 corpos de prova e, a partir da umidade obtida na moldagem (umidade de campo), parte dos corpos de prova passou por trajetória de secagem e outra parte por trajetória de molhagem, obtendo-se assim uma curva mista. $\mathrm{O}$ mesmo procedimento foi utilizado para as amostras Compactadas, sendo a umidade inicial de 20\%. O procedimento utilizado foi o mesmo proposto por Fredlund \& Rahardjo (1993) para medidas de sucção matricial.

Foi utilizado um conta-gotas, para efetuar a molhagem dos corpos de prova, até atingirem o teor de umidade desejado. Já no processo de secagem, os corpos de prova foram deixados ao ar para secarem e seu controle foi feito por medidas de peso sucessivas.

Após os corpos de prova atingir a umidade desejada, iniciou-se o processo de montagem do sistema. O sistema foi constituído de um corpo de prova, papel filtro comum de proteção, papel filtro para medida de sucção matricial, outro papel filtro comum para proteção. Embalou-se todo o sistema em papel filme e, em seguida, em papel alumínio. Reservou-se o conjunto em um recipiente com tampa e em uma caixa de isopor, para que não houvesse variação da temperatura. Os corpos de prova permaneceram armazenados por 14 dias. Após este período, os papéis foram retirados e pesados em balança de precisão $(0,0001 \mathrm{~g})$. Em seguida eles foram levados à estufa por 24 horas e pesados novamente, para a determinação do teor de umidade.

A partir da umidade de cada papel filtro foi possível obter os valores de sucção correspondentes, a partir da curva de calibração do papel. A curva de calibração depende do tipo de papel utilizado. 
Na Tabela 3.2 são mostradas algumas das curvas de calibração previamente publicadas para o papel filtro Whatman $n^{0} 42$, que foi o utilizado nesta pesquisa. A equação de calibração utilizada nesta pesquisa, para a determinação dos valores de sucção, foi a do Chandler e Gutierrez (1986) e Chandler et al. (1992).

Tabela 3.2 - Curvas de calibração do papel filtro Whatman $n^{\circ} 42$

\begin{tabular}{|c|c|c|c|}
\hline Referência & Medida & Curva de calibração & \\
\hline Hambling (1981) & Sucção matricial & $\begin{aligned} \log \psi^{(1)}= & 8,022 \\
& -3,683 \log w_{f}(2)\end{aligned}$ & \\
\hline \multirow{2}{*}{ van Genuchten (1980) } & Sucção matricial & $\psi=0,051\left[\left(\frac{248}{w_{f}}\right)^{9,615}-1\right]^{0,473}$ & \\
\hline & Sucção total & $\psi=56180\left[\left(\frac{37}{w_{f}}\right)^{0,44}-1\right]^{2}$ & \\
\hline \multirow{2}{*}{$\begin{array}{l}\text { Chandler e Gutierrez } \\
\text { (1986) } \\
\text { Chandler et al. (1992) }\end{array}$} & \multirow{2}{*}{$\begin{array}{c}\text { Sucção matricial } \\
\text { e total }\end{array}$} & $\log \psi=4,84-0,0622 w_{f}$ & $w_{f} \leq 47$ \\
\hline & & $\log \psi=6,05-2,48 \log w_{f}$ & $w_{f}>47$ \\
\hline \multirow{4}{*}{ Leong et al. (2002) } & \multirow{2}{*}{ Sucção matricial } & $\log \psi=2,909-0,0229 w_{f}$ & $w_{f} \geq 47$ \\
\hline & & $\log \psi=4,945-0,0673 w_{f}$ & $w_{f}<47$ \\
\hline & \multirow{2}{*}{ Sucção total } & $\log \psi=8,778-0,222 w_{f}$ & $w_{f} \geq 26$ \\
\hline & & $\log \psi=5,31-0,0879 w_{f}$ & $w_{\mathrm{f}}<26$ \\
\hline
\end{tabular}

(1) Sucção $(k P a)$; (2) Teor de umidade do papel filtro.

\subsection{2 - TRANSLAÇÃO DE EIXO}

Como já explicado anteriormente, a célula de adensamento com controle de sucção (Figura 3.4) é um sistema de translação de eixo. Com este equipamento é possível traçar curvas de retenção, com medições de $1 \mathrm{kPa}$ até $2000 \mathrm{kPa}$. Para valores de sucções baixas (até $10 \mathrm{kPa}$ ), utiliza-se a coluna d'água. Para valores até $200 \mathrm{kPa}$, existe um regulador de pressões baixas e, para valores de sucções altas, existe outro regulador de pressões altas.

Para complementar a curva de retenção realizada pela técnica do papel filtro, foi utilizada esta técnica de translação de eixo com pressões baixas, obtendo uma melhor definição da curva de retenção, próxima ao valor de entrada de ar. Além disso, o equipamento permite medir, de forma muito cuidadosa, a variação de volume total e o estabelecimento preciso das sucções de interesse. 


\subsection{3 - PSICRÔMETRO - WP4}

Devido à dificuldade em moldar as amostras de Lama, foram utilizados os Psicrômetros (WP4), da Universidade Federal de Goiás (UFG), para obtenção da curva de retenção deste material. Os psicrômetros são dispositivos de medição de sucção baseados no princípio da umidade relativa. O psicrômetro apresentado na Figura 3.6, que foi utilizado nesta pesquisa, é o WP4C (Dewpoint Potential Meter).

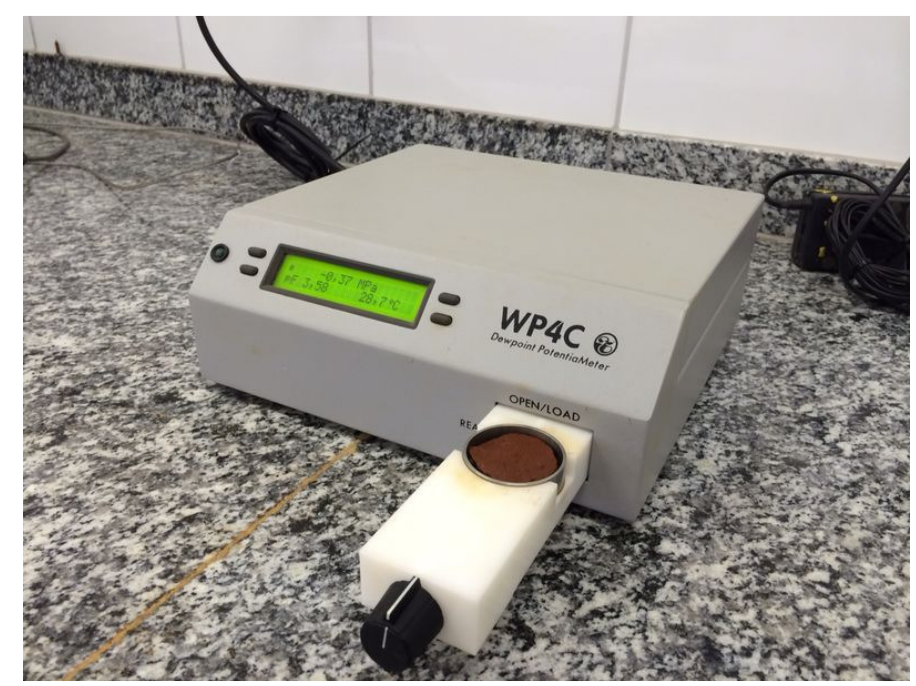

Figura 3.6 - Equipamento WP4C (Dewpoint PotenciaMeter)

Este dispositivo consiste em uma câmara selada constituída de um espelho, um sensor fotoelétrico, um par termoelétrico, um termômetro infravermelho e um ventilador. Uma amostra de solo em equilíbrio com o ar e colocada dentro da câmara. A presença de água condensada no espelho é detectada pelo sensor fotoelétrico, devido à redução de reflexo do espelho.

Um par termoelétrico determina a temperatura em que ocorreu a condensação, enquanto um termômetro infravermelho determina a temperatura da amostra. A diferença entre essas duas temperaturas fornece a umidade relativa do solo e, consequentemente, o valor da sucção. A função do ventilador é a de simplesmente circular o ar dentro da câmara para reduzir o tempo de equilíbrio (Decagon Devices, 2014).

O WP4 deve estar localizado em um ambiente com temperatura controlada, devido à sua grande sensibilidade a variações de temperatura. Esse equipamento fornece valores de sucção de forma rápida, normalmente em um tempo inferior a 10 minutos. 


\section{6 - ENSAIO DE POROSIMETRIA POR INTRUSÃO DE MERCÚRIO}

Estudos microestruturais são úteis no entendimento do comportamento hidromecânico dos solos. Estes estudos são especialmente importantes para solos tropicais que sofreram fortes processo de intemperismos, tais como a argila porosa de Brasília (Camapum de Carvalho et al., 1994), que tem uma estrutura muito complexa.

Delage et al. (1996) fez observações e medições importantes em nível microestrutural, sabendo que elas possibilitam um melhor entendimento da influência da microestrutura nas propriedades e no comportamento dos materiais em diversas condições de estado de tensão hidromecânico.

$\mathrm{Na}$ caracterização microestrutural do solo, existem diversas técnicas de ensaios de laboratório capazes de caracterizar a microestrutura do solo, como por exemplo, a microscopia eletrônica de varredura (SEM), a microscopia eletrônica de varredura ambiental (ESEM), o microscópio de varredura a laser e a porosimetria por injeção de mercúrio (MIP). Utilizou-se nesta pesquisa apenas o MIP.

A técnica de intrusão de mercúrio (MIP) foi realizada com o equipamento de intrusão de mercúrio, AutoPore IV 9500 Micromeritics Instrument Corporation, disponível no Departamento de Engenharia Civil e Ambiental da Universidade dos Andes,BogotáColombia, mostrado na Figura 3.7.

Este equipamento é capaz de aplicar uma pressão de mercúrio máxima de 33.000 Psi (227 $\mathrm{MPa}$ ). Para realizar os ensaios, uma amostra do solo seca foi colocada no penetrômetro do MIP, que foi fechado e inserido na porta de baixa pressão do equipamento. Na primeira fase, o ar foi retirado da amostra e, em seguida, substituído por mercúrio em incrementos até que o penetrômetro ficou cheio. Em seguida, o penetrômetro, agora cheio de mercúrio, foi removido da porta amostra de pressões baixas, pesado e colocado na porta de alta pressão, onde foi pressurizado incrementalmente até a pressão máxima. A massa das amostras secas utilizadas na análise do MIP variou entre 1,0 e 3,0 g.

A técnica da porosimetria por injeção de mercúrio se baseia no fato de que o mercúrio não penetra espontaneamente nos poros, a menos que se aplique uma pressão sobre ele. $\mathrm{O}$ procedimento de ensaio consiste em colocar a amostra num recipiente que é preenchido com mercúrio. Com os valores do volume de poros do solo penetrado pelo mercúrio e com as respectivas pressões aplicadas, uma curva de distribuição do tamanho dos poros é obtida. 


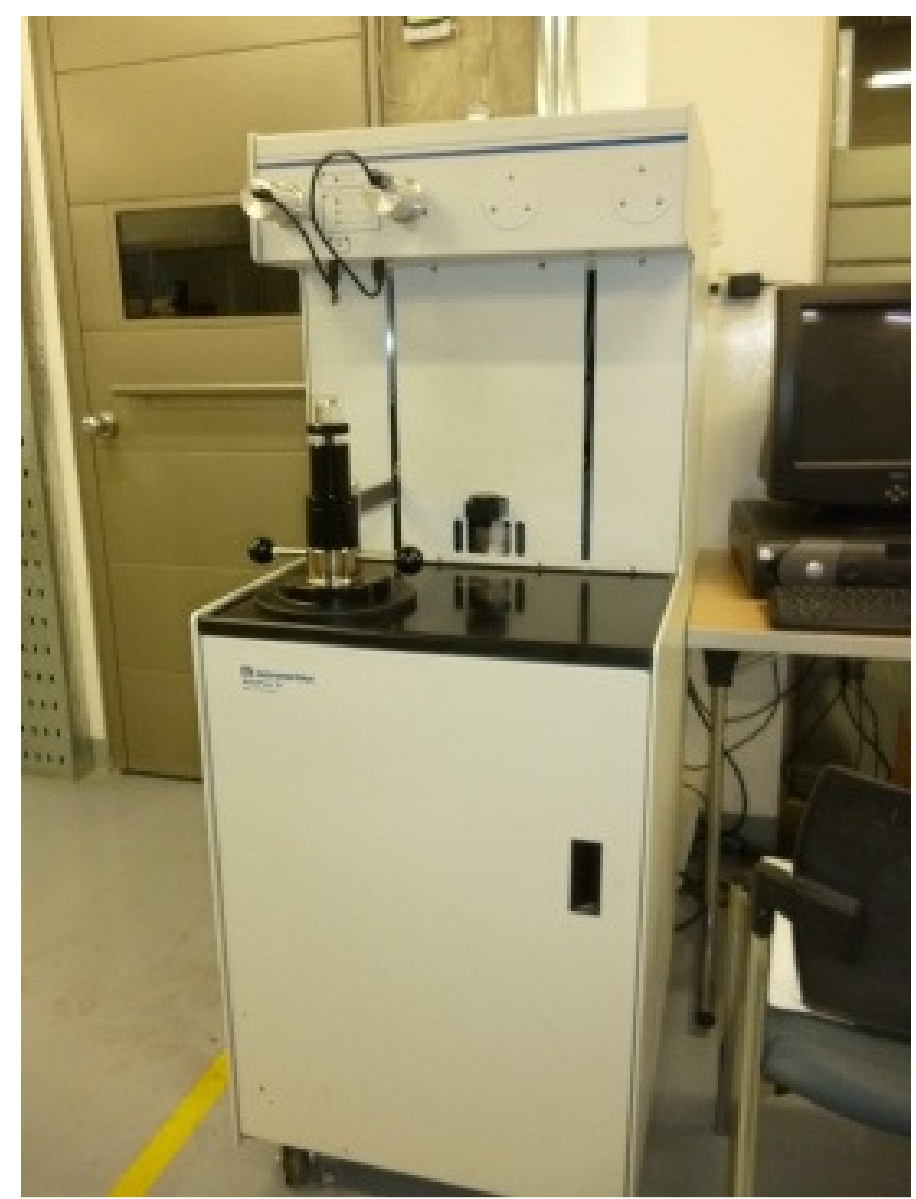

Figura 3.7 - Equipamento AutoPore IV 9500 Micromeritics Instrument Corporation da Universidade dos Andes.

\section{7 - PREPARAÇÃO DE CORPOS DE PROVA PARA ANÁLISE ESTRUTURAL}

Ensaios de porosimetria por intrusão de mercúrio (MIP) foram realizados em corpos de prova em diferentes condições, a fim de se observarem as características microestruturais existentes. Os corpos de prova do MIP foram obtidos com diferentes estados, ou seja, condição Natural, Compactada e Lama, e com diferentes índices de vazio, seguindo a curva de compressão oedométrica nas condições saturadas e não saturadas. Em seguida, amostras de $1 \mathrm{~cm}^{3}$ e de forma cilíndrica foram moldadas.

Antes de se levarem as amostras para o equipamento, os corpos de provas passaram ainda por um processo de retirada de água armazenada, sendo que o processo de liofilização foi utilizado de modo a não produzir alterações na estrutura do solo. Uma breve descrição do processo de liofilização é apresentada a seguir. 
Os corpos de prova preparados por liofilização foram colocados em porta amostra e imersos por 1 minuto em um recipiente com nitrogênio líquido. Após o congelamento, a água dos poros foi removida por sublimação numa estufa a vácuo, passando pela trajetória mostrada na Figura 3.8. Cabe destacar que a bomba de vácuo fornece uma pressão absoluta de $4 \mathrm{~Pa}$.

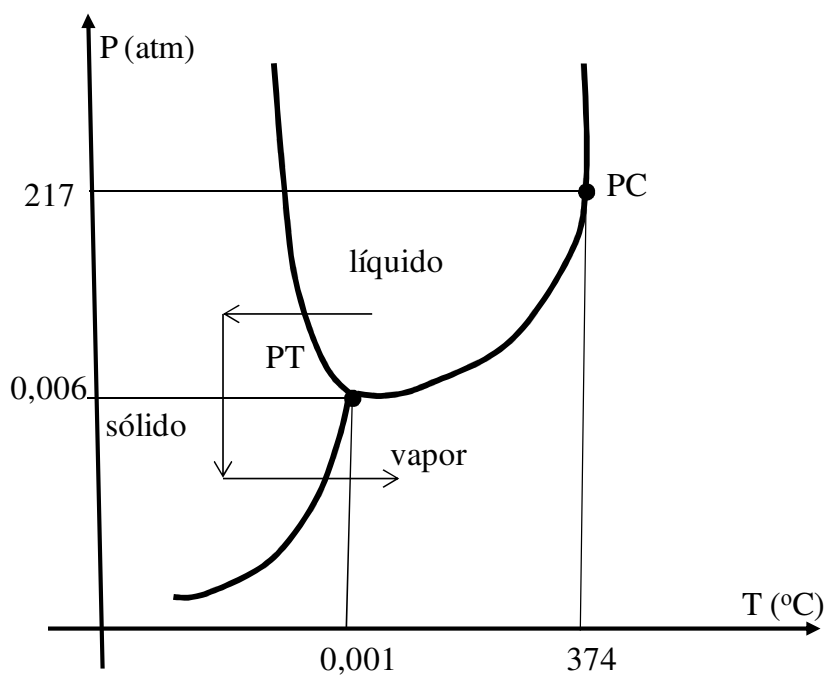

Figura 3.8 - Trajetória mostrada no diagrama de fases da água.

Os ensaios de porosimetria por injeção de mercúrio foram realizados em corpos de prova com diferentes índices de vazios seguindo trajetórias de carregamentos saturadas e não saturadas. Estes procedimentos têm o intuito de obterem informações que ajudem a entender como as solicitações afetam a distribuição do tamanho dos poros. Os pontos escolhidos para a realização do ensaio de MIP são apresentados na Figura 3.9, Figura 3.11 e Figura 3.12, e descritos nos próximos itens.

\subsection{1 - CORPOS DE PROVA SATURADOS}

Conforme dito anteriormente, os corpos de provas utilizados para realização do MIP apresentam diferentes índices de vazios. Para cada índice de vazio desejado, uma amostra de solo foi colocada na célula oedométrica e carregada com a tensão objetivo (tensão associada a este índice de vazio).

Na Figura 3.9 são apresentados os pontos obtidos a partir do ensaio do MIP em comparação com a curva de adensamento do solo na condição natural saturado. Observe que os resultados de obtenção das amostras são satisfatórios e serão discutidos posteriormente no Capítulo 4. 


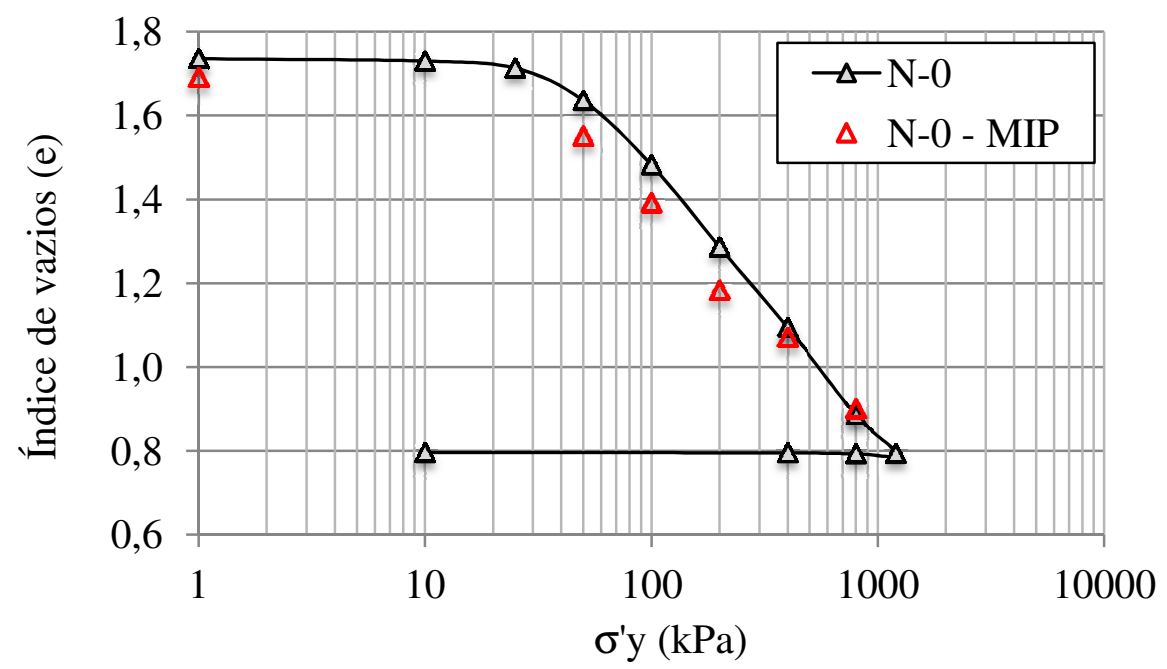

Figura 3.9 - Exemplo do processo de amostragem dos corpos de prova para realização do MIP e curva de adensamento $(0,50,100,200,400$ e $800 \mathrm{kPa})$

Após o período de estabilização, para cada tensão objetivo, a amostra saturada foi removida da célula de adensamento e o corpo de prova com as dimensões requeridas para o ensaio MIP foi moldado. O processo foi repetido para todos os carregamentos. Os pontos para realização do ensaio de porosimetria são 0 (sem nenhum carregamento), 50, 100, 200, 400 e 800 kPa, conforme apresentado na Tabela 3.3.

Tabela 3.3 - Nomenclatura dos corpos de prova saturados utilizada no MIP

\begin{tabular}{ll}
\hline \multicolumn{1}{c}{ Simbologia } & \multicolumn{1}{c}{ Descrição } \\
\hline $\mathrm{N}$ & Natural, carregamento de $0 \mathrm{kPa}$, sucção de $0 \mathrm{kPa}$ \\
$\mathrm{N}-50$ & Natural, carregamento de $50 \mathrm{kPa}$, sucção de $0 \mathrm{kPa}$ \\
$\mathrm{N}-100$ & Natural, carregamento de $100 \mathrm{kPa}$, sucção de $0 \mathrm{kPa}$ \\
$\mathrm{N}-200$ & Natural, carregamento de $200 \mathrm{kPa}$, sucção de $0 \mathrm{kPa}$ \\
$\mathrm{N}-400$ & Natural, carregamento de $400 \mathrm{kPa}$, sucção de $0 \mathrm{kPa}$ \\
$\mathrm{N}-800$ & Natural, carregamento de $800 \mathrm{kPa}$, sucção de $0 \mathrm{kPa}$ \\
\hline $\mathrm{C}$ & Compactada, carregamento de $0 \mathrm{kPa}$, sucção de $0 \mathrm{kPa}$ \\
$\mathrm{C}-50$ & Compactada, carregamento de $50 \mathrm{kPa}$, sucção de $0 \mathrm{kPa}$ \\
$\mathrm{C}-100$ & Compactada, carregamento de $100 \mathrm{kPa}$, sucção de $0 \mathrm{kPa}$ \\
$\mathrm{C}-200$ & Compactada, carregamento de $200 \mathrm{kPa}$, sucção de $0 \mathrm{kPa}$ \\
$\mathrm{C}-400$ & Compactada, carregamento de $400 \mathrm{kPa}$, sucção de $0 \mathrm{kPa}$ \\
$\mathrm{C}-800$ & Compactada, carregamento de $800 \mathrm{kPa}$, sucção de $0 \mathrm{kPa}$ \\
\hline $\mathrm{S}$ & Lama, carregamento de $0 \mathrm{kPa}$, sucção de $0 \mathrm{kPa}$ \\
$\mathrm{S}-50$ & Lama, carregamento de $50 \mathrm{kPa}$, sucção de $0 \mathrm{kPa}$ \\
$\mathrm{S}-100$ & Lama, carregamento de $100 \mathrm{kPa}$, sucção de $0 \mathrm{kPa}$ \\
$\mathrm{S}-200$ & Lama, carregamento de $200 \mathrm{kPa}$, sucção de $0 \mathrm{kPa}$ \\
$\mathrm{S}-400$ & Lama, carregamento de $400 \mathrm{kPa}$, sucção de $0 \mathrm{kPa}$ \\
$\mathrm{S}-800$ & Lama, carregamento de $800 \mathrm{kPa}$, sucção de $0 \mathrm{kPa}$ \\
\hline
\end{tabular}




\subsection{2 - CORPOS DE PROVA NÃO SATURADOS ( $=50 \mathrm{kPa})$}

Além de ensaios de adensamento saturados foram realizados ensaios não saturados, permitindo assim a obtenção dos corpos de prova com a tensão constante, variando a sucção. Para isso, foram realizados ensaios de adensamento não saturados com controle de sucção pela técnica de translação de eixo (Figura 3.10). O procedimento realizado é semelhante ao descrito anteriormente, sendo que neste caso é necessário controlar tensão e sucção.

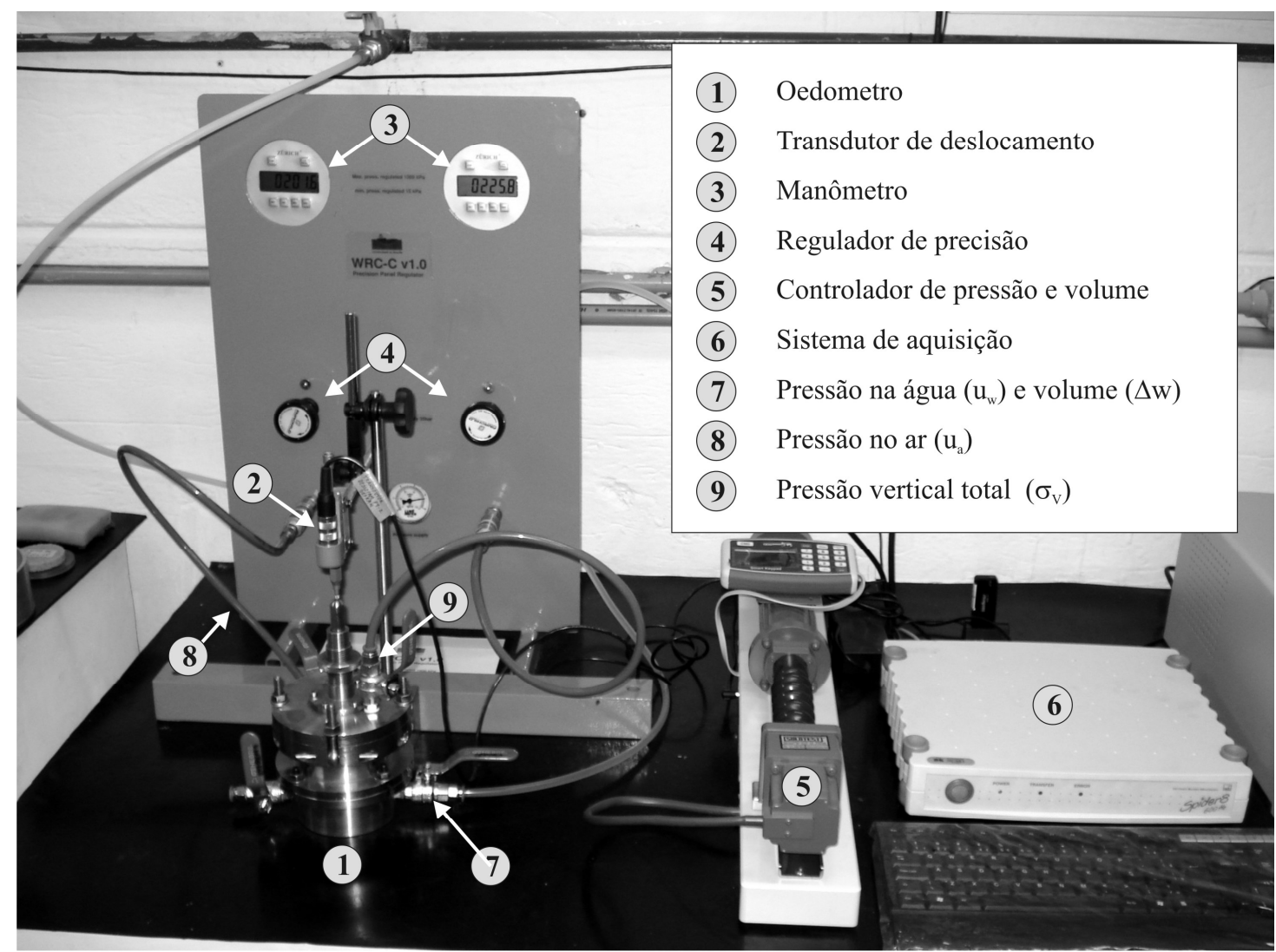

Figura 3.10 - Equipamento de adensamento com controle de sucção (Otálvaro, 2013)

Na Figura 3.11 é apresentada a trajetória utilizada para obtenções dos corpos de prova não saturados com sucção de $50 \mathrm{kPa}$. As tensões verticais utilizadas foram: 50, 100, 200 e 400 $\mathrm{kPa}$. Inicialmente foi aplicada a tensão vertical desejada juntamente com a sucção de $50 \mathrm{kPa}$, que foi mantida constante até a estabilização dos deslocamentos. Em seguida, uma trajetória de secagem foi realizada por meio da aplicação de uma sucção de $350 \mathrm{kPa}$. Após a estabilização da quantidade de água armazenada, a sucção foi reduzida novamente para o valor de $50 \mathrm{kPa}$ e, após a estabilização do volume de água, o equipamento foi desmontado e o corpo de prova para realização do MIP foi obtido.

A Tabela 3.4 apresenta a simbologia utilizada para os diferentes corpos de prova. 


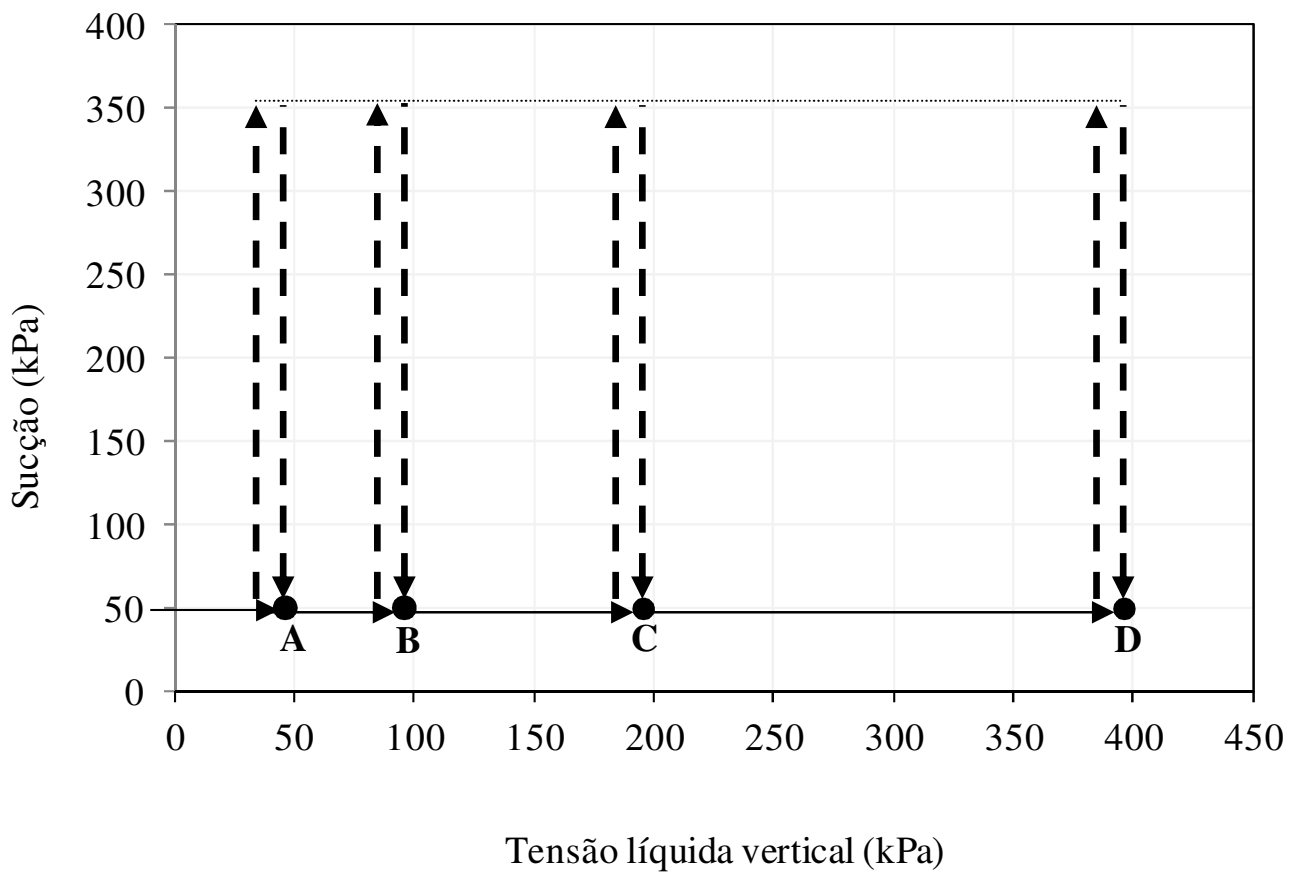

Figura 3.11 - Preparação de corpos de prova por adensamento com variação de sucção para realização do MIP

Tabela 3.4 - Nomenclatura dos corpos de prova não saturados, com sucção de $50 \mathrm{kPa}$, utilizada no MIP

\begin{tabular}{ll}
\hline Simbologia & Descrição \\
\hline C-50-50 & $\begin{array}{l}\text { Compactada, tensão vertical de } 50 \mathrm{kPa} \text { e ciclo de secagem e molhagem com sucção } \\
\text { final de 50kPa. } \\
\text { Compactada, carregamento de } 100 \mathrm{kPa} \text { e ciclo de secagem e molhagem com sucção } \\
\text { final de 50kPa. }\end{array}$ \\
C-100-50 & $\begin{array}{l}\text { Compactada, carregamento de } 200 \mathrm{kPa} \text { e ciclo de secagem e molhagem com sucção } \\
\text { final de 50kPa. }\end{array}$ \\
C-200-50 & $\begin{array}{l}\text { Compactada, carregamento de } 400 \mathrm{kPa} \text { e ciclo de secagem e molhagem com sucção } \\
\text { final de 50kPa. }\end{array}$ \\
C-400-50 & $\begin{array}{l}\text { Lama, carregamento de } 50 \mathrm{kPa} \text { e ciclo de secagem e molhagem com sucção final de } \\
50 \mathrm{kPa} .\end{array}$ \\
S-50-50 & $\begin{array}{l}\text { Lama, carregamento de } 100 \mathrm{kPa} \text { e ciclo de secagem e molhagem com sucção final de } \\
50 \mathrm{kPa} .\end{array}$ \\
S-100-50 & $\begin{array}{l}\text { Lama, carregamento de } 200 \mathrm{kPa} \text { e ciclo de secagem e molhagem com sucção final de } \\
50 \mathrm{kPa} .\end{array}$ \\
S-200-50, carregamento de $400 \mathrm{kPa}$ e ciclo de secagem e molhagem com sucção final de \\
S-400-50
\end{tabular}

\subsection{3 - CORPOS DE PROVA NÃO SATURADOS $(\mathrm{s}=1.000 \mathrm{kPa})$}

Para a preparação de corpos de prova para a realização do MIP, com sucção de $1.000 \mathrm{kPa}$, foram realizados ensaios de adensamento não saturados com controle de sucção pela técnica de translação de eixo e osmótica, para as amostras Compactada e Lama, respectivamente. 
O procedimento realizado foi semelhante aos anteriores, sendo que neste caso foi necessário aplicar a sucção desejada (1000 kPa) e, após a estabilização, aplicar a tensão objetivo. Na Figura 3.12 é apresentada a trajetória utilizada no processo de obtenções de corpos de prova não saturados com sucção de $1000 \mathrm{kPa}$.

As tensões verticais utilizadas na obtenção dos pontos para realização do ensaio de porosimetria são 50, 100, 200 e 400 e $800 \mathrm{kPa}$, sendo que na Tabela 3.5 são apresentadas as simbologias.

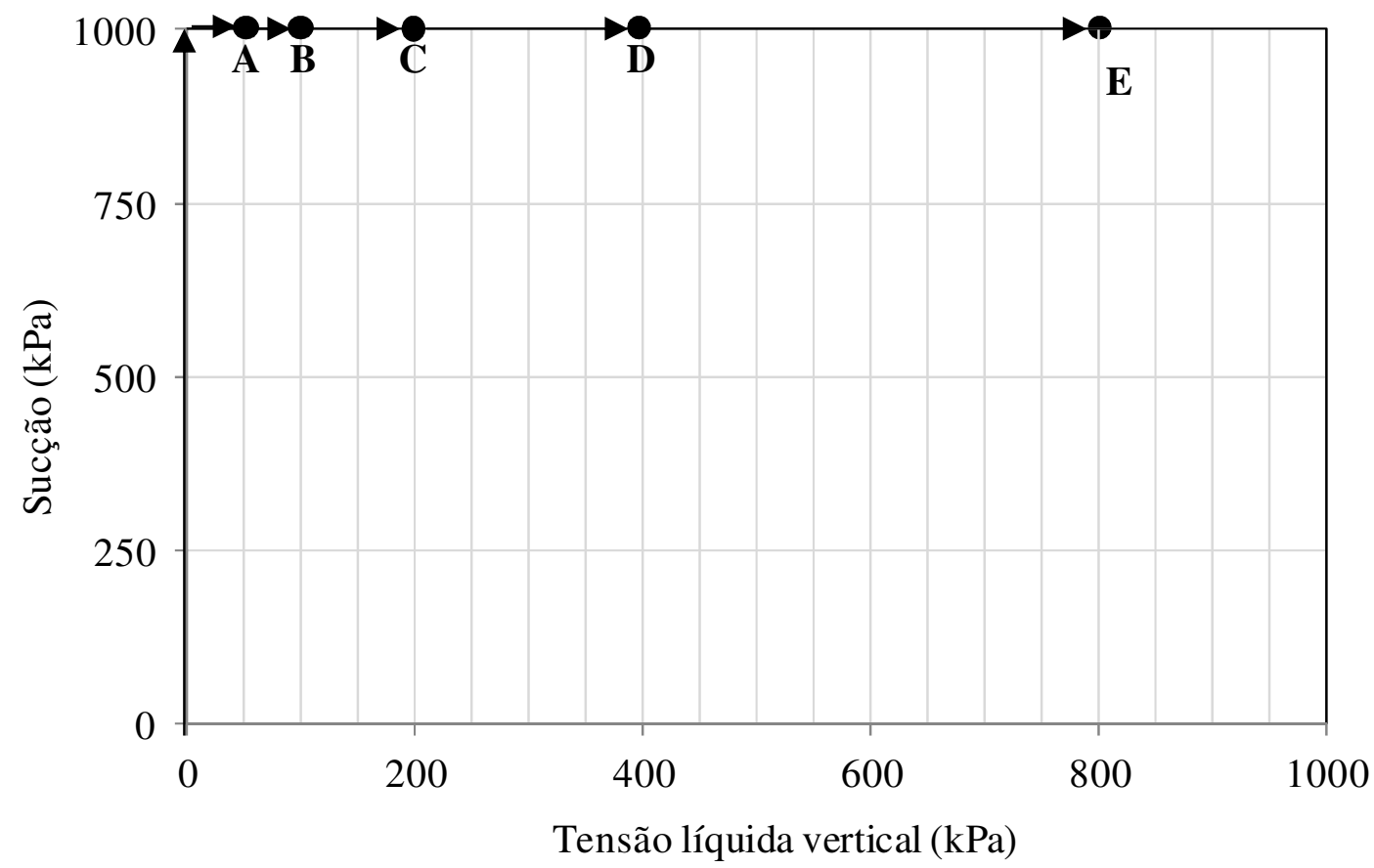

Figura 3.12 - Preparação de corpos de prova por adensamento com sucção de 1000 kPa realização do MIP

Tabela 3.5 - Nomenclatura dos corpos de prova não saturados, com sucção de $1000 \mathrm{kPa}$, utilizada no MIP

\begin{tabular}{ll}
\hline Simbologia & Descrição \\
\hline C-50-1000 & Compactada, carregamento de $50 \mathrm{kPa}$, sucção de $1000 \mathrm{kPa}$ \\
C-100-1000 & Compactada, carregamento de $100 \mathrm{kPa}$, sucção de $1000 \mathrm{kPa}$ \\
C-200-1000 & Compactada, carregamento de $200 \mathrm{kPa}$, sucção de $1000 \mathrm{kPa}$ \\
C-400-1000 & Compactada, carregamento de $400 \mathrm{kPa}$, sucção de $1000 \mathrm{kPa}$ \\
C-800-1000 & Compactada, carregamento de $800 \mathrm{kPa}$, sucção de $1000 \mathrm{kPa}$ \\
\hline S-50-1000 & Lama, carregamento de $50 \mathrm{kPa}$, sucção de $1000 \mathrm{kPa}$ \\
S-100-1000 & Lama, carregamento de $100 \mathrm{kPa}$, sucção de $1000 \mathrm{kPa}$ \\
S-200-1000 & Lama, carregamento de $200 \mathrm{kPa}$, sucção de $1000 \mathrm{kPa}$ \\
S-400-1000 & Lama, carregamento de $400 \mathrm{kPa}$, sucção de $1000 \mathrm{kPa}$ \\
S-800-1000 & Lama, carregamento de $800 \mathrm{kPa}$, sucção de $1000 \mathrm{kPa}$ \\
\hline
\end{tabular}




\section{4 - RESULTADOS}

Este capítulo apresenta os resultados obtidos dos ensaios laboratoriais realizados a partir das amostras Naturais, Compactadas e Lama do solo do Campo Experimental do Programa de Pós-Graduação em Geotecnia da Universidade de Brasília e a avaliação do comportamento destas.

Com a intenção de possibilitar uma melhor compreensão do programa experimental, os resultados são divididos em quatro partes: caracterização, curva de retenção, ensaios de compressão oedométrica e caracterização estrutural.

Desta forma, neste capítulo são apresentados os resultados de todos os ensaios realizados durante esta pesquisa, conforme descrito no Capítulo três, bem como comentários de como as condições em que estes foram realizados influenciaram nos resultados.

\section{1 - CARACTERIZAÇÃO}

O solo estudado foi coletado no Campo Experimental do Programa de Pós-Graduação em Geotecnia da Universidade de Brasília, que já vem sendo estudado há vários anos, tendo, portanto, grande parte de suas características já conhecidas.

Nos solos de clima tropical as partículas de solo geralmente encontram-se agregadas. No caso específico da argila porosa de Brasília, esta possui características marcantes, como, por exemplo, a presença de óxido de alumínio e de ferro, que estão presentes neste solo e, devido a isso, ocorrem ligações das partículas que formam as agregações, isto é, agregados de solo. Estas agregações dão ao solo uma estrutura bimodal, que pode ser visualizada na curva de retenção e na curva de distribuição do tamanho dos poros.

O solo em estudo apresenta valores de limite de liquidez $\left(w_{L}\right)$ de $42 \%$, limite de plasticidade $\left(w_{P}\right)$ de $24 \%$, sendo estes valores obtidos com a secagem prévia do material. O peso específico real dos grãos deste material é de $26,87 \mathrm{kN} / \mathrm{m}^{3}$. Este valor é comumente encontrado na região.

A Figura 4.1 apresenta os resultados das análises granulométricas convencionais, por peneiramento e sedimentação, em amostra Natural com secagem prévia ao ar, na profundidade de 1,70 a 2,30 metros. 


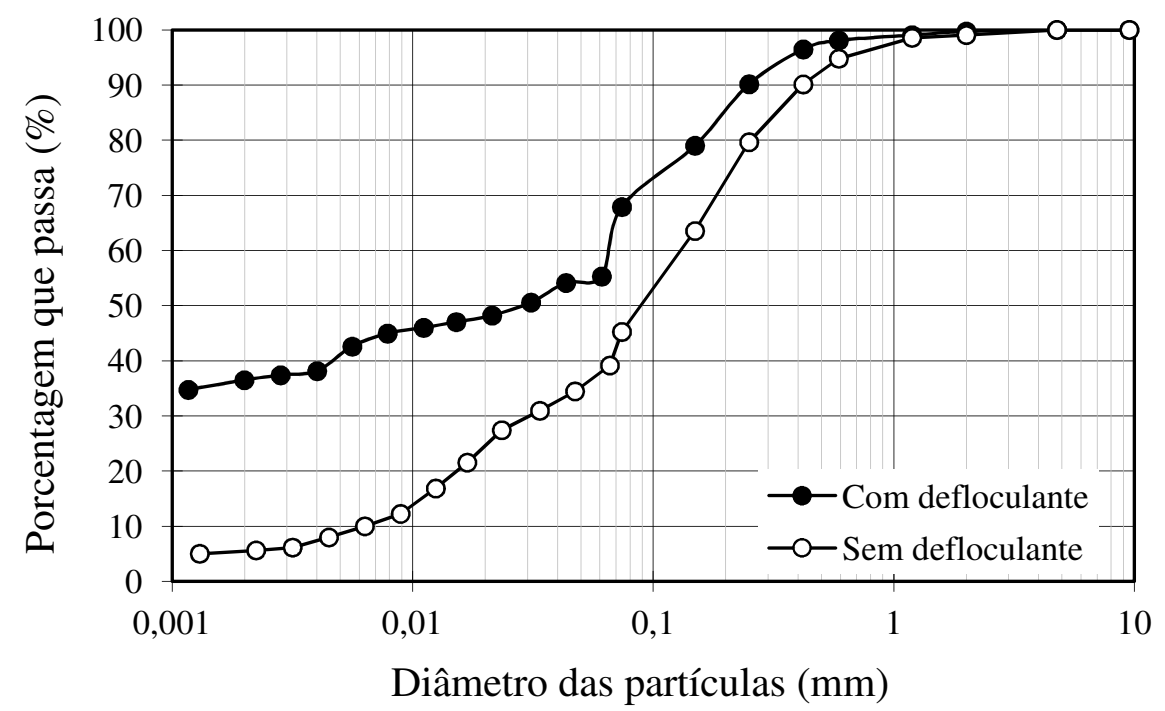

Figura 4.1 - Curva granulométrica do solo de Brasília-DF (1,7 a 2,30 m): ensaio convencional com o uso de defloculante e sem defloculante.

O uso de defloculante (desagregador químico) resultou em curvas distintas (Figura 4.1). As agregações sofrem influência, assim, fica constatada a capacidade do defloculante de desagregar as partículas destes solos. A utilização do desagregador químico tem como principal objetivo obter a textura real das partículas de solo individualizadas.

Há diferenças no tipo de comportamento observado com relação ao uso de um desagregador químico, indicativo de solos com concreções formadas pela cimentação de partículas menores, que são estáveis em presença de água e são desfeitas pelo defloculante. Nos solos tropicais é observado com frequência este tipo de comportamento (Lima et al., 2002; Roseno \& Camapum de Carvalho, 2007).

Nos resultados apresentados na Figura 4.1, os valores encontrados na curva granulométrica mostram que o solo, quando analisado sem o uso de defloculante, é tipicamente uma areia siltosa, porém, quando o defloculante é usado no ensaio, sua granulometria é de argila arenosa.

\section{2 - COMPORTAMENTO HIDRÁULICO}

Para avaliar o comportamento hidráulico do solo serão apresentados resultados de ensaios de curvas de retenção com três estruturas distintas: Natural, Compactado e Lama. Os resultados da curva de retenção do solo foram obtidos por meio da técnica do papel filtro, translação de eixo, placa de pressão e psicrômetro, tanto por trajetórias de secagem como de molhagem. 
Inicialmente serão apresentados os resultados de curvas de retenção provenientes de trabalhos anteriores, conforme mostrado no trabalho de Mascarenha et al. (2014) e de amostra Natural por Grau (2014). A seguir serão apresentados os resultados desta pesquisa para as amostras denominadas de Compactada e Lama.

Na Figura 4.2 estão apresentados os resultados de curvas de retenção provenientes de trabalhos anteriores. Os resultados de Guimarães (2002) e Silva (2007) são associados ao solo no seu estado natural, enquanto os resultados de Silva (2009), com diferentes índices de vazios, são provenientes de amostras compactadas e posteriormente carregadas em diferentes condições. As agregações presentes nestes solos lhes dão uma estrutura bimodal, que pode ser visualizada na curva de retenção por meio da existência de dois valores de entrada de ar, um para os microporos e outro para os macroporos. É possível ainda observar a proximidade das curvas para valores de sucção maiores que $2.000 \mathrm{kPa}$, sendo essa região associada à água armazenada nos microporos.

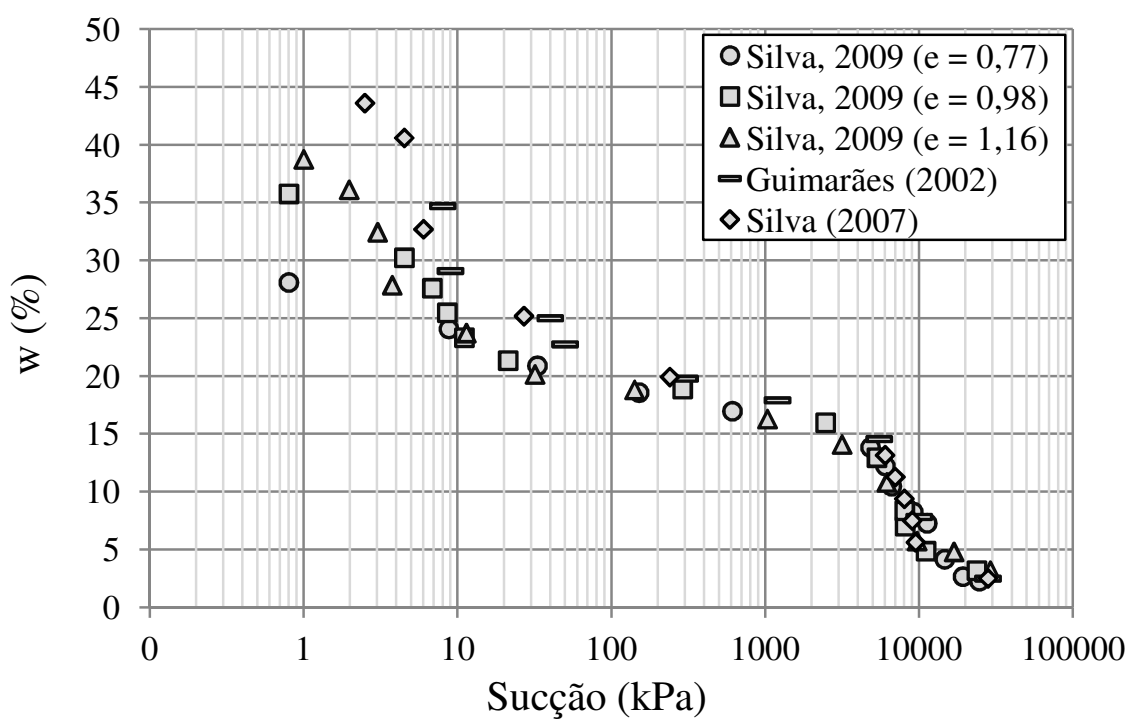

Figura 4.2 - Curva de retenção do solo (modificado - Mascarenha et al., 2014).

O processo de compactação e posterior aplicação de um carregamento e a decorrente alteração dos valores de índice de vazios $(e=1,16$; $e=0,98$; e $e=0,77)$ não afetam o trecho associado aos microporos. Isso corrobora com o conceito apresentado por Romero (1999) e Mascarenha (2008) de que este tamanho de poros (microporos) não é afetado por carregamentos.

É possível observar que a variação do índice de vazios, produz um aumento do valor de entrada de ar dos macroporos, que, como já havia sido comentada anteriormente, não afeta o valor de entrada de ar dos microporos. 
Na Figura 4.3 são apresentados os resultados da curva de retenção do solo Natural obtidos por Grau (2014). Alguns pontos foram adicionados à curva original. Ao contrário dos resultados apresentados na Figura 4.3, em que somente a técnica de papel filtro foi utilizada, nos resultados da Figura 4.4 foram utilizadas as técnicas de papel filtro e placa de sucção. As técnicas utilizadas se complementam, tendo pontos em comum para mesma sucção. Cabe destacar que na placa de sucção foi utilizada uma trajetória de secagem e que, no papel filtro, foi utilizada uma trajetória de molhagem.

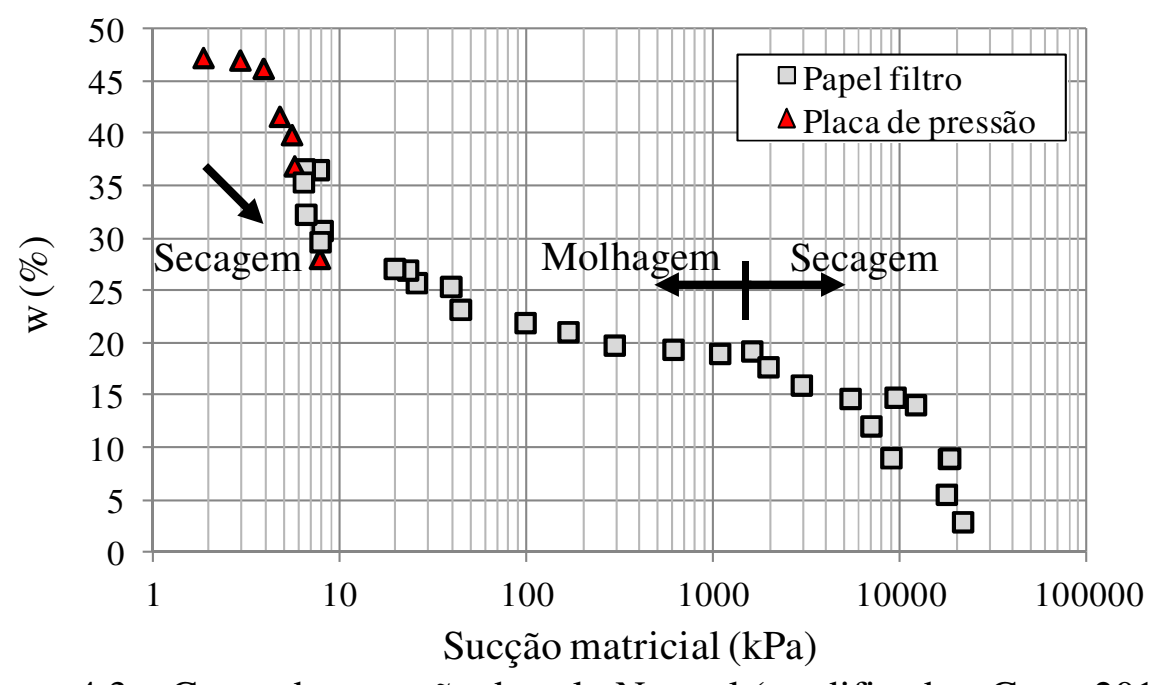

Figura 4.3 - Curva de retenção do solo Natural (modificado - Grau, 2014).

Como observados no solo natural, na Figura 4.3, os resultados da Figura 4.4 apresentam uma curva bimodal. $\mathrm{O}$ valor de entrada de ar nos macroporos para este solo é de $4 \mathrm{kPa}$, e o valor de entrada de ar nos microporos é de $4.000 \mathrm{kPa}$. O valor de entrada de ar nos macroporos é semelhante ao de areias, enquanto o dos microporos seria semelhante ao de argilas préconsolidadas.

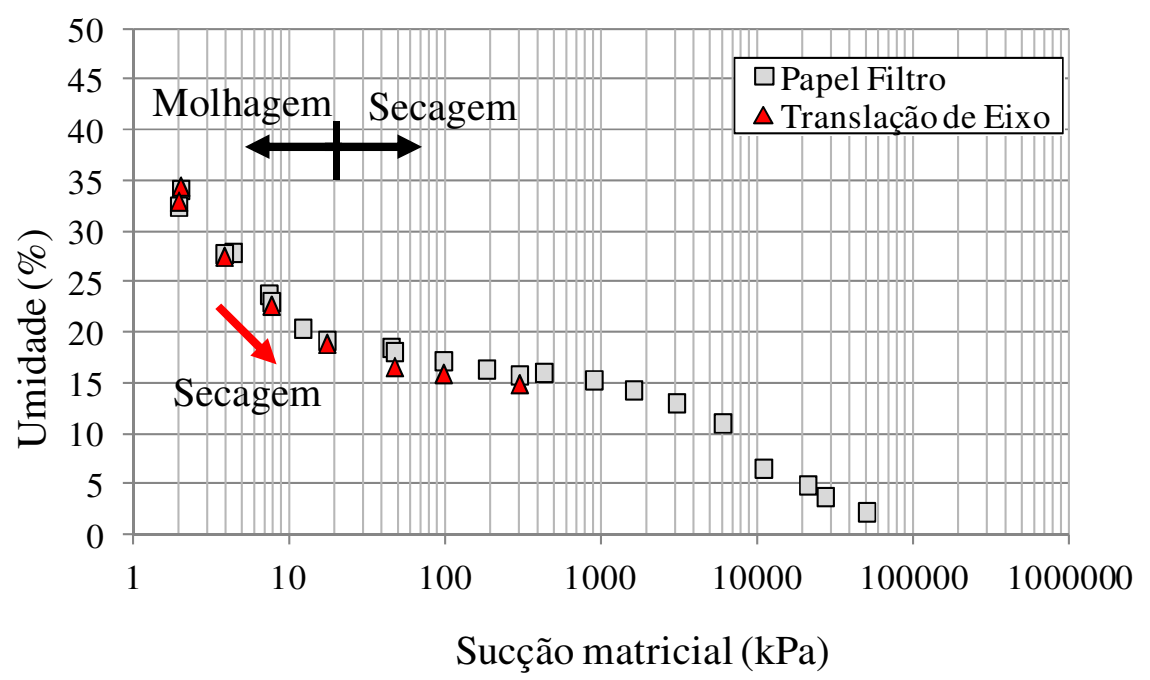

Figura 4.4 - Curva de retenção do solo para amostra Compactada $(e=1,20)$. 
Na Figura 4.5 é apresentada a curva de retenção da amostra Compactada. Comparando com os resultados obtidos por Silva (2009), a curva também apresenta um aspecto bimodal. Há uma coincidência entre os valores obtidos pela técnica de papel filtro e translação de eixo. $\mathrm{O}$ valor de entrada ar nos macroporos para esta amostra é menor que $3 \mathrm{kPa}$, e o valor de entrada de ar dos microporos é de $4.000 \mathrm{kPa}$.

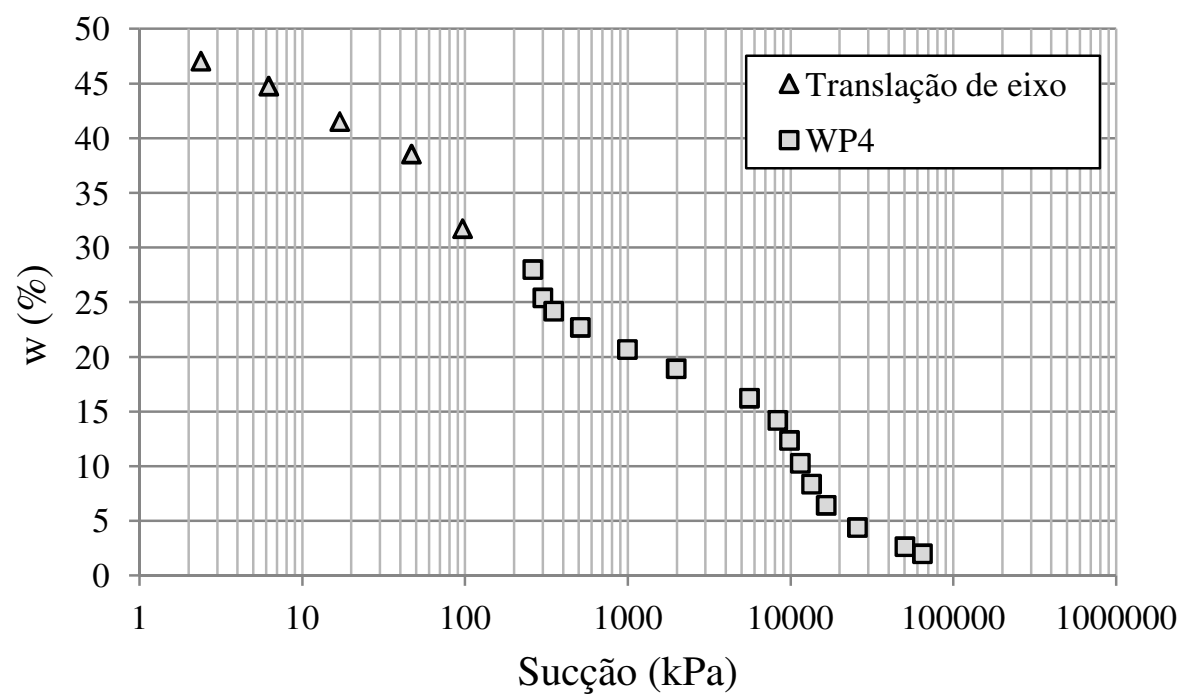

Figura 4.5 - Curva de retenção do solo para amostra de Lama.

A curva de retenção traçada para Lama, estudada nesta pesquisa, foi obtida somente por trajetória de secagem, devido à dificuldade de moldagem e controle do seu volume, utilizando a translação de eixo e o psicrômetro (WP4). O resultado é apresentado na Figura 4.5. Observe que mesmo esta amostra apresenta uma curva bimodal, sendo o valor de entrada de ar do macroporos entre 20 e $50 \mathrm{kPa}$, enquanto o valor de entrada de ar dos microporos é de 9.000 $\mathrm{kPa}$. Esta diferença pode ocorrer devido ao fato de o WP4 medir sucções totais.

A Figura 4.6 apresenta os dados das amostras Compactada, da Lama e Natural. É possível observar a influência da estrutura do solo na curva de retenção. Dois efeitos são observados: a translação das curvas e uma mudança no formato e na inclinação, decorrente das diferentes estruturas utilizadas. Esta diferença é mais evidente na amostra de Lama.

A inclinação da curva de retenção indica a distribuição do tamanho de poros. Curvas mais inclinadas indicam distribuições de poros relativamente uniformes. Neste caso, as amostras compactadas e naturais teriam uma distribuição mais uniforme que a de lama.

Comparado o valor de entrada de ar dos macroporos obtidos pelas diferentes amostras (Figura 4.6), observa-se que a amostra compactada tem o menor valor, seguido da amostra natural e da lama. O fato de a amostra natural ficar numa posição intermediária entre a lama e o solo 
compactado pode ser explicado pela existência de agregações que permitem ao solo ter uma estrutura mais aberta do que a do solo compactado.

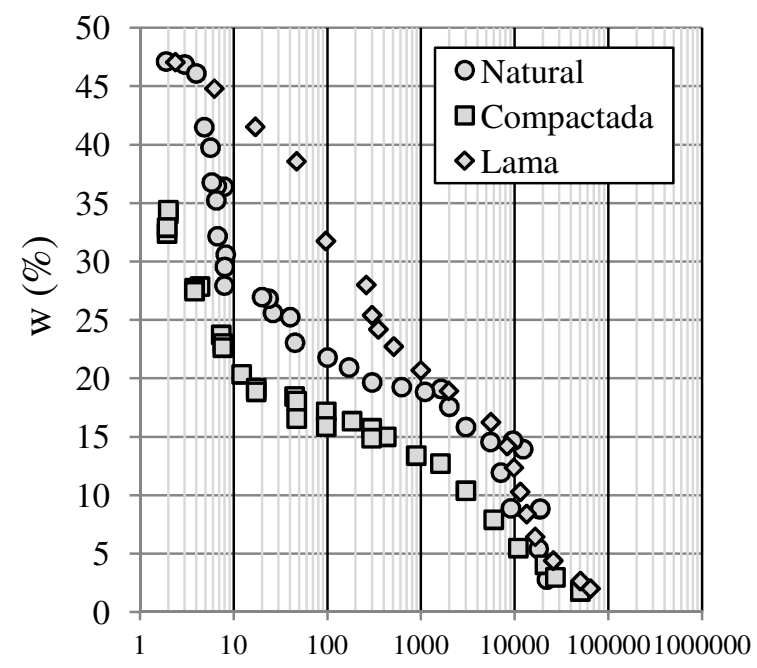

Sucção matricial $(\mathrm{kPa})$

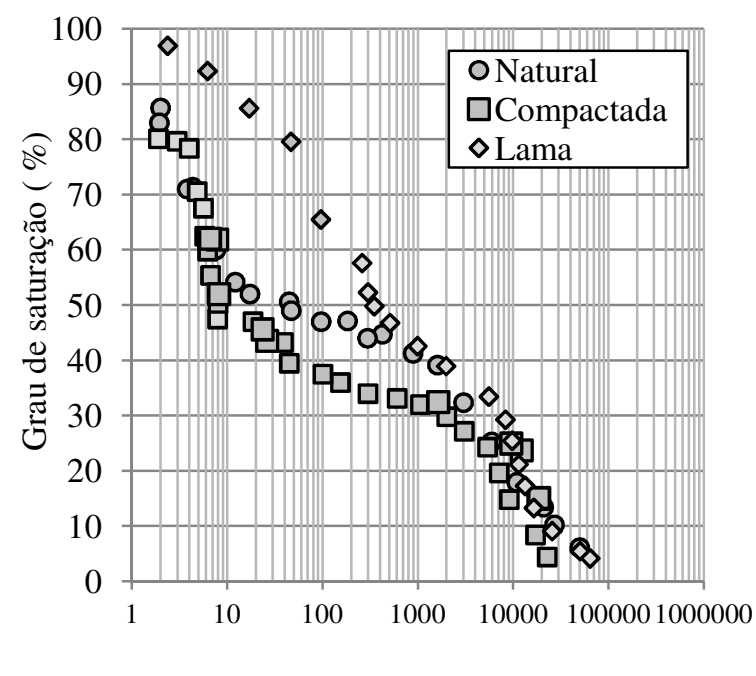

Sucção matricial $(\mathrm{kPa})$

Figura 4.6 - Resultados da curva de retenção do solo para amostra Natural, Compactada e Lama.

\section{3 - COMPORTAMENTO MECÂNICO}

Para avaliar o comportamento mecânico do solo foram realizados ensaios de adensamento com três estruturas distintas: Natural, Compactada e Lama. Esses ensaios foram realizados nas condições saturadas e não saturadas.

A partir do ensaio de adensamento destas amostras foram obtidos parâmetros de compressibilidade: índice de compressibilidade do trecho virgem $(\lambda)$ e de expansão ou de recompressão $(\kappa)$, e tensão de pré-adensamento $\left(p_{o}^{*}\right)$. Os valores são mostrados na Tabela 4.1 e servem apenas com indicativo de como o comportamento do solo é influenciado pela estrutura, não sendo utilizados para outras finalidades.

Tabela 4.1 - Resumo geral dos parâmetros de compressibilidade.

\begin{tabular}{lccc}
\hline Amostras & $\lambda$ & $\kappa$ & $p_{o}^{*}(k P a)$ \\
\hline Compactada (C) & 0,174 & 0,003 & 90 \\
Compactada com sucção controlada (C- 1000) & 0,270 & 0,003 & 180 \\
Lama (S) & 0,106 & - & - \\
Lama com sucção controlada (S - 1000) & 0,177 & - & - \\
Natural (N) & 0,200 & 0,004 & 40 \\
SILVA (2009) - Umidade de compactação & 0,213 & 0,005 & 400 \\
SILVA (2009) - Saturado & 0,222 & 0,005 & 80 \\
\hline
\end{tabular}


Os ensaios de adensamento realizados por Silva (2009) para as amostras compactadas, saturadas e na umidade de compactação, são apresentados na Figura 4.7. As curvas mostram um potencial de colapso como consequência da estrutura metaestável. Essa estrutura é consequência do processo de compactação que foi realizado no ramo seco e com uma energia inferior a Proctor Normal, como descrito na metodologia (Figura 3.2). A diferença de índice de vazios apresentada para os primeiros carregamentos está associada à variabilidade natural do processo de preparação da amostra, não devendo ser confundida com um possível comportamento expansivo da amostra. Além disso, dois aspectos devem ser destacados: o primeiro é a diferença no valor da tensão de pré-adensamento, menor para a amostra saturada, e o segundo é que os trechos de compressão virgens possuem inclinações muito semelhantes. Cabe destacar que o ensaio não saturado (sucção inicial correspondente à umidade de compactação) foi realizado sem controle de sucção e, durante o ensaio, é provável que essa sucção tenha variado. De fato, Silva (2009) apresenta resultados em que é possível visualizar a variação da sucção durante o ensaio.

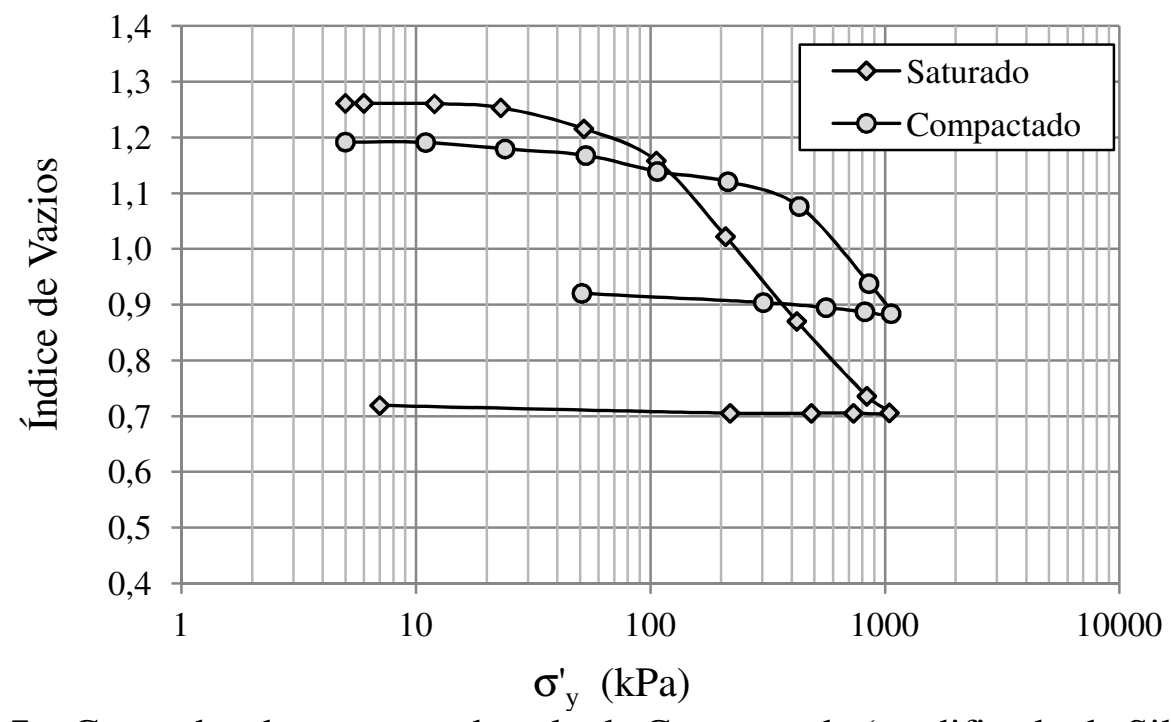

Figura 4.7 - Curva de adensamento do solo de Compactada (modificado de Silva, 2009).

Na Figura 4.8 e na Figura 4.9 são apresentados os resultados dos ensaios para as amostras Compactadas e para a Lama, na condição saturada e não saturada, com sucção de 1.000 kPa. Comparando a Figura 4.8, resultados realizados nesta pesquisa, com a Figura 4.7, pesquisa realizada por Silva (2009), novamente a variação do índice de vazios inicial não está associada nem à expansão nem à contração, mas sim à variabilidade do processo de amostragem. Além disso, novamente há um aumento do valor da tensão de pré-adensamento (Tabela 4.1), porém, os valores de carga atingidos não foram suficientes para definir de forma 
conclusiva a inclinação dos trechos virgens, principalmente da trajetória não saturada. Nos resultados apresentados na Figura 4.8, é possível observar que há uma tendência de convergência entre as curvas, caso estas fossem levadas a cargas maiores. Resultados semelhantes foram encontrados em outros trabalhos com o mesmo solo, como por exemplo, o de Otálvaro (2013).

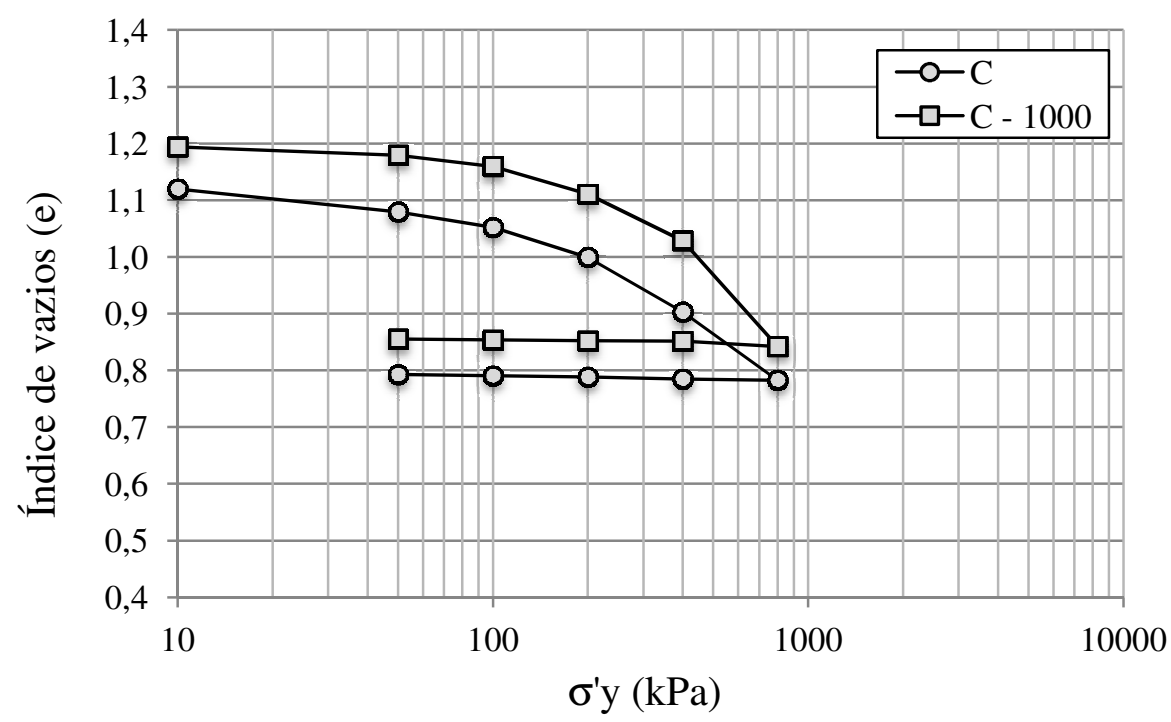

Figura 4.8 - Curva de adensamento do solo Compactado.

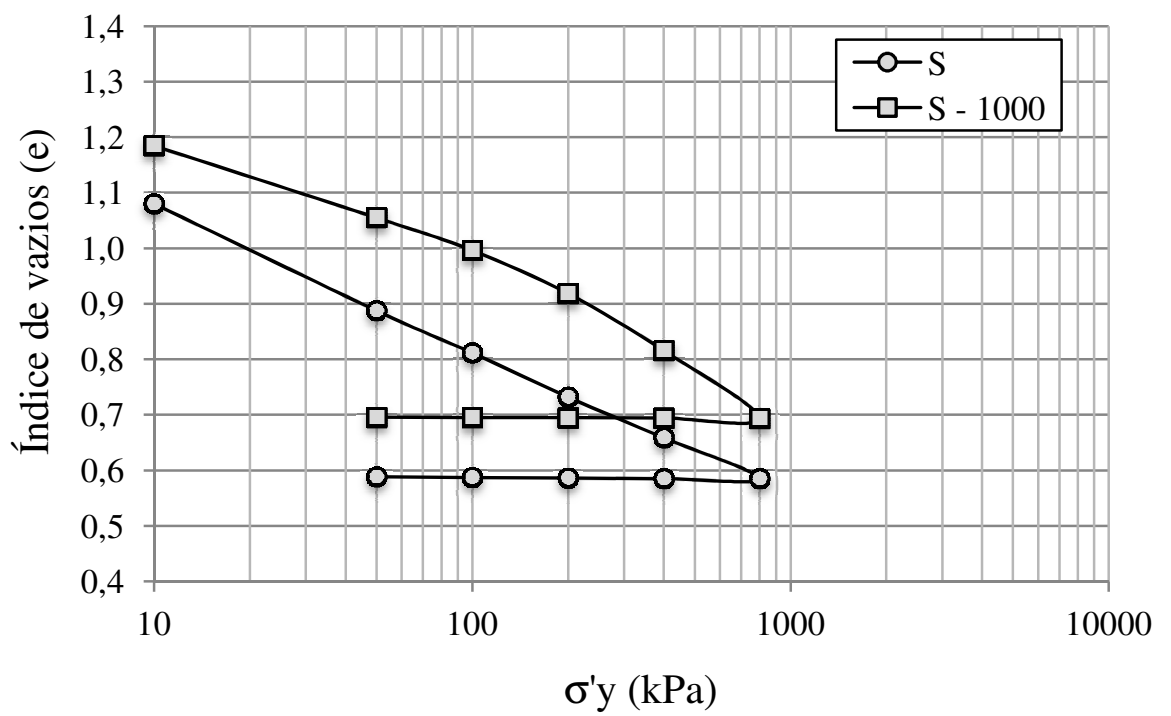

Figura 4.9 - Curva de adensamento do solo de Lama.

Na Figura 4.9 são apresentados os resultados para a amostra de Lama saturada e com sucção de $1.000 \mathrm{kPa}$. As curvas com diferentes sucções são muito semelhantes em sua forma e se apresentam transladadas. Além disso, não é possível identificar a tensão de pré-adensamento das amostras, e a variação dos índices de vazios iniciais deve-se à variabilidade da 
preparação, que neste caso é ainda maior que nas outras amostras. De modo geral, não há diferenças significativas associadas à sucção.

A Figura 4.10 compara as curvas de compressibilidade das amostras com diferentes estruturas, Natural, Compactada e Lama, para a condição saturada. Da Figura 4.10, é possível constatar que a amostra Natural é mais compressível e a lama não apresenta um trecho préadensado. É possível imaginar que, para carregamentos mais elevados, haveria uma tendência de convergências das curvas. Resultados semelhantes foram encontrados por outros autores, como, por exemplo, Leroueil \& Vaughan (1990), e podem ser explicados pelo fato de que, para carregamentos muito elevados, a resposta mecânica do solo não seria mais controlada pela estrutura inicial, que já teria sido completamente destruída pelo carregamento.

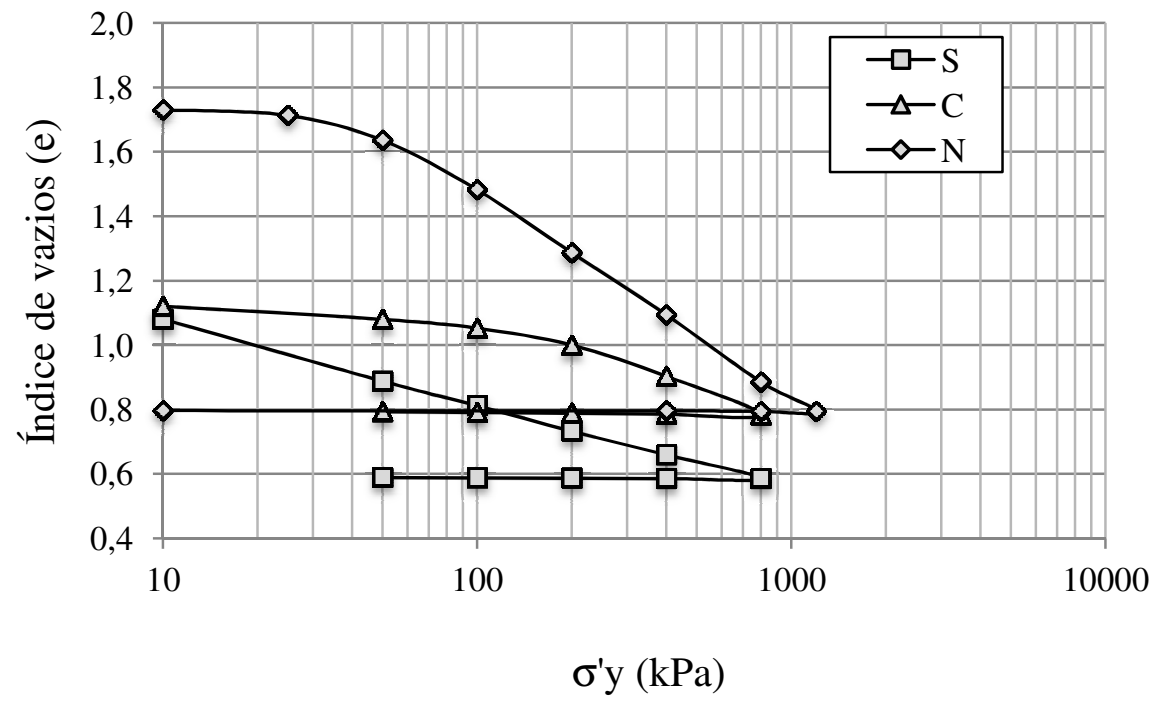

Figura 4.10 - Curva de adensamento do solo saturado, Natural, Compactado e Lama.

Devido à inexistência de trajetórias de carregamentos com sucção controlada (s=1.000 kPa) para amostra Natural, a Figura 4.11 apresenta somente os resultados da amostra Compactada e da Lama. Os valores do índice de vazios inicial das amostras são muito próximos, porém, a amostra Compactada é menos compressível do que a Lama, no inicio do carregamento. Ao alcançar o trecho de compressão virgem, porém, a amostra Compactada passa a ter inclinação superior à Lama. Novamente, fica difícil definir um valor para a tensão de pré-adensamento para a Lama. 


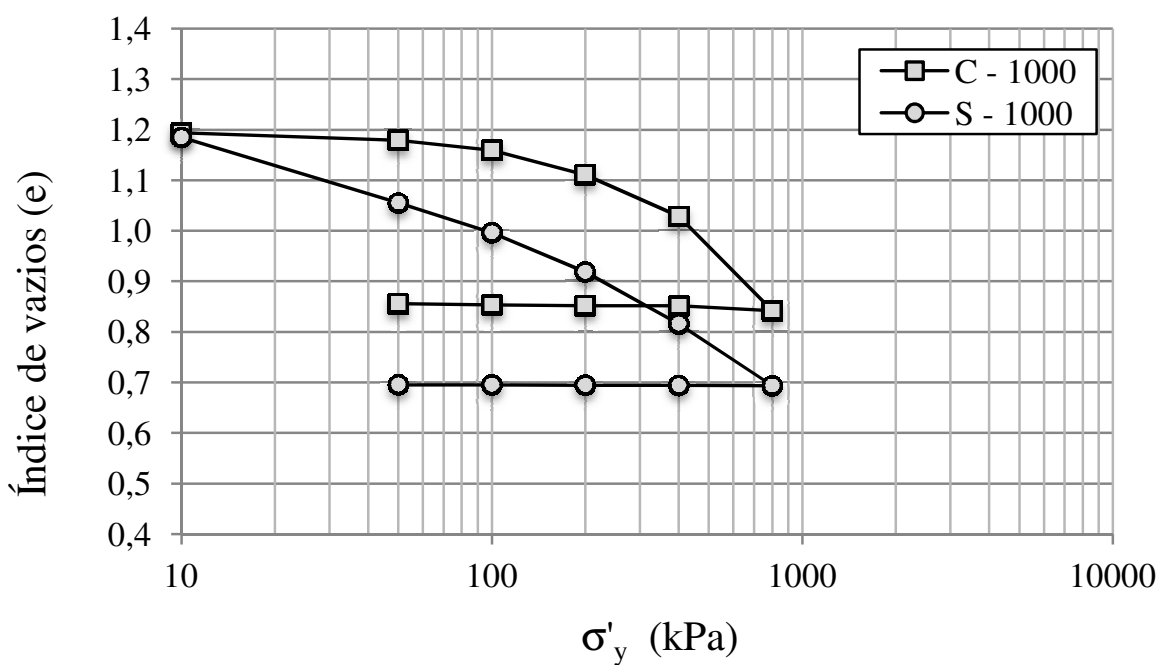

Figura 4.11 - Curva de adensamento do solo não saturado (s=1000 kPa), Compactado e Lama.

Todos os resultados até aqui apresentados demonstram que a estrutura tem um efeito maior sobre o comportamento do solo para os carregamentos iniciais e que, após atingido um certo nível de carregamento, se este foi suficiente para apagar a estrutura inicial existente no solo, as diferentes amostras tendem a ter comportamento mecânico semelhantes.

A Figura 4.12 mostra resultados de Leroueil \& Vaughan (1990) que são semelhantes aos apresentados nesta pesquisa, ou seja, o mesmo solo em três estados diferentes: Indeformado, Lama e Remoldado.

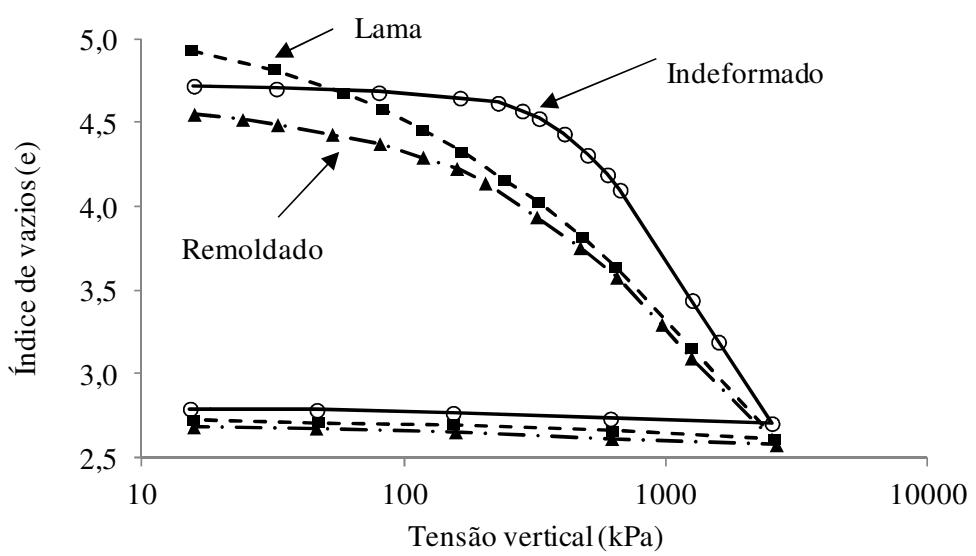

Figura 4.12 - Estado da estrutura (modificado - Leroueil \& Vaughan, 1990).

\section{4 - COMPORTAMENTO ESTRUTURAL}

Da mesma forma, os próximos subitens apresentam a preparação dos corpos de prova para realização do MIP, um estudo sobre as variações que ocorrem durante o processo de amostragem e uma comparação das amostras com seus respectivos pontos nas curvas da curva 
de compressão oedométrica. Foi analisada a relação do índice de vazios da amostra obtido com o índice de vazios medido pelo porosímetro de mercúrio. Além disso, foram realizadas análises da distribuição do tamanho dos poros nos três estados de amostras, em várias condições impostas.

\subsection{1 - PREPARAÇÃO DOS CORPOS DE PROVA}

Nesta seção são apresentadas, inicialmente, algumas características dos corpos de prova, como os valores do índice de vazios, peso específico seco e umidade final dos corpos de prova do solo Natural, Compactado e Lama, nas condições em que estes foram preparados. Estes corpos de prova foram moldados para os ensaios de Porosimetria por Intrusão de Mercúrio, para a realização da análise estrutural. A seguir, são apresentados os pontos dos corpos de prova obtidos para a realização do MIP, juntamente com a curva de adensamento.

Na Tabela 4.2 são apresentadas algumas características dos corpos de prova, como os valores do índice de vazios, peso específico seco e umidade final do solo na condição saturada. As amostras Naturais utilizadas, mesmo que com carregamentos maiores, por exemplo, de 800 $\mathrm{kPa}$, possuem índice de vazios maior que o das amostras Compactada e Lama.

Tabela 4.2 - Característica dos corpos de prova do solos saturados.

\begin{tabular}{ccccc}
\hline Solo & Amostras & $e$ & $\boldsymbol{\gamma}_{\boldsymbol{d}}\left(\mathrm{kN} / \mathrm{m}^{3}\right)$ & $\begin{array}{c}\text { Umidade final } \\
(\%)\end{array}$ \\
\hline \multirow{5}{*}{ Natural } & $\mathrm{N}$ & 1,69 & 9,91 & 13,02 \\
& $\mathrm{~N}-50$ & 1,55 & 10,50 & 45,42 \\
& $\mathrm{~N}-100$ & 1,39 & 11,28 & 42,84 \\
& $\mathrm{~N}-200$ & 1,18 & 12,36 & 36,90 \\
& $\mathrm{~N}-400$ & 1,07 & 12,95 & 32,69 \\
Compactado & $\mathrm{N}-800$ & 0,90 & 14,13 & 27,64 \\
Saturado & $\mathrm{C}$ & 1,22 & 12,21 & 20,00 \\
& $\mathrm{C}-50$ & 1,06 & 13,01 & 40,15 \\
& $\mathrm{C}-100$ & 1,02 & 13,31 & 38,16 \\
& $\mathrm{C}-200$ & 0,99 & 13,44 & 36,31 \\
& $\mathrm{C}-400$ & 0,91 & 14,03 & 33,20 \\
& $\mathrm{C}-800$ & 0,77 & 15,21 & 28,19 \\
\hline Lama & $\mathrm{S}$ & 1,14 & 12,66 & 44,58 \\
& $\mathrm{~S}-50$ & 0,95 & 13,24 & 36,37 \\
& $\mathrm{~S}-100$ & 0,90 & 13,73 & 34,61 \\
& $\mathrm{~S}-200$ & 0,82 & 14,42 & 31,33 \\
& $\mathrm{~S}-400$ & 0,73 & 15,21 & 28,11 \\
& $\mathrm{~S}-800$ & 0,68 & 15,60 & 26,24 \\
\hline
\end{tabular}


Na Tabela 4.3 são apresentadas algumas características dos corpos de prova, como os valores do índice de vazios, peso específico seco e umidade final do solo na condição não saturada, com sucção de $50 \mathrm{kPa}$.

Tabela 4.3 - Característica dos corpos de prova do solos não saturado com sucção de $50 \mathrm{kPa}$.

\begin{tabular}{ccccc}
\hline Solo & Amostras & $e$ & $\boldsymbol{\gamma}_{\boldsymbol{d}}\left(\mathrm{kN} / \mathrm{m}^{3}\right)$ & $\begin{array}{c}\text { Umidade final } \\
(\%)\end{array}$ \\
\hline \multirow{3}{*}{$\begin{array}{c}\text { Compactado Não } \\
\text { Saturado }\end{array}$} & C-50-50 & 1,05 & 12,45 & 18,64 \\
& C-100-50 & 0,92 & 12,99 & 20,21 \\
& C-200-50 & 0,82 & 13,38 & 19,23 \\
C-400-50 & 0,74 & 13,93 & 15,56 \\
\hline Sama Não & S-50-50 & 1,16 & 13,11 & 34,35 \\
Saturada & S-100-50 & 1,07 & 14,01 & 30,66 \\
& S-200-50 & 1,01 & 14,32 & 29,16 \\
\hline
\end{tabular}

Já a Tabela 4.4 apresenta algumas características dos corpos de prova, como os valores do índice de vazios, peso específico seco e umidade final do solo na condição não saturada, com sucção de $1.000 \mathrm{kPa}$.

Tabela 4.4 - Característica dos corpos de prova do solos não saturado com sucção de $1000 \mathrm{kPa}$.

\begin{tabular}{ccccc}
\hline Solo & Amostras & $e$ & $\boldsymbol{\gamma}_{\boldsymbol{d}}\left(\mathrm{kN} / \mathrm{m}^{3}\right)$ & $\begin{array}{c}\text { Umidade final } \\
(\%)\end{array}$ \\
\hline \multirow{3}{*}{ Solo } & C-50-1000 & 1,26 & 11,87 & 16,45 \\
Compactado & C-100-1000 & 1,12 & 12,67 & 17,58 \\
Não Saturado & C-200-1000 & 1,06 & 13,07 & 15,86 \\
& C-400-1000 & 0,93 & 13,92 & 16,45 \\
& C-800-1000 & 0,84 & 14,62 & 13,19 \\
\hline Lama Não & S-50-1000 & 1,02 & 13,29 & 21,56 \\
Saturado & S-100-1000 & 0,96 & 13,71 & 21,38 \\
& S-200-1000 & 0,89 & 14,25 & 23,58 \\
& S-400-1000 & 0,78 & 15,10 & 18,92 \\
& S-800-1000 & 0,66 & 16,18 & 21,54 \\
\hline
\end{tabular}

A Figura 4.13 apresenta a comparação entre as amostras do MIP e os pontos da curva de compressão oedométrica do solo Natural. Em geral, é possível concluir que a obtenção da amostra, a partir deste processo, pode ser considerada como representativa desta curva. Vale a pena lembrar que a amostra Natural é muito heterogênea, porém não há muita diferença entre as amostras do MIP e a curva de consolidação. 


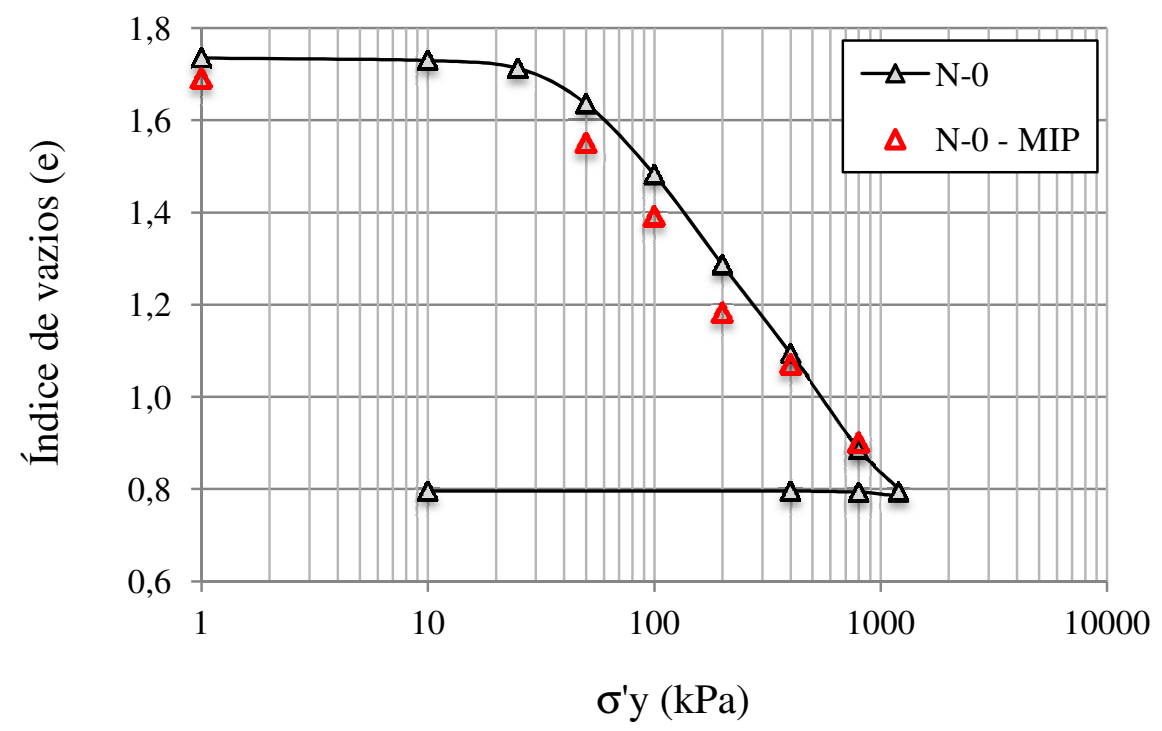

Figura 4.13 - Curvas de adensamento do solo Natural e os pontos de ensaio do MIP.

A Figura 4.14 e a Figura 4.15 apresentam uma comparação entre as amostras do MIP e o pontos da curva de compressão oedométrica do solo Compactado e da Lama, saturados e com sucção de $1.000 \mathrm{kPa}$. Observando as curvas, juntamente com os pontos em que foram moldados os corpos de prova do MIP, para os primeiros carregamentos, há diferença no índice de vazios. Esta variação pode ser devido a problemas na compactação e/ou na preparação das amostras.

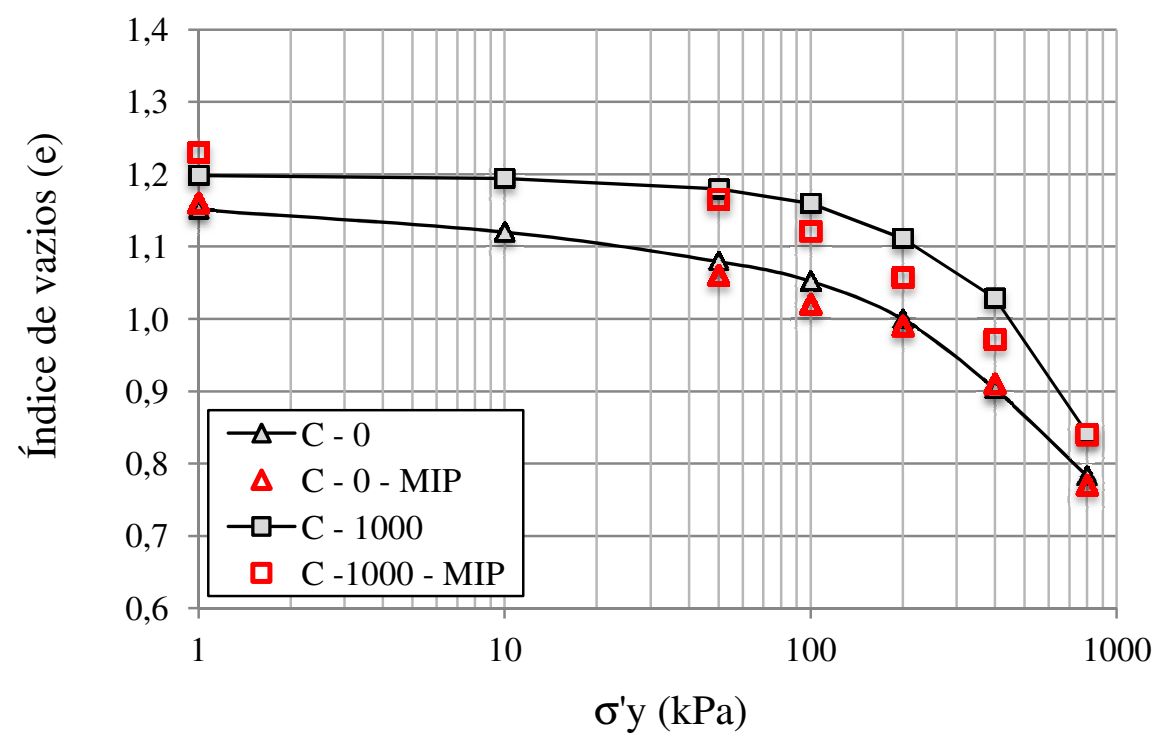

Figura 4.14 - Curvas de adensamento do solo Compactado saturados e com sucção de 1000 $\mathrm{kPa}$ e os pontos de ensaio do MIP. 


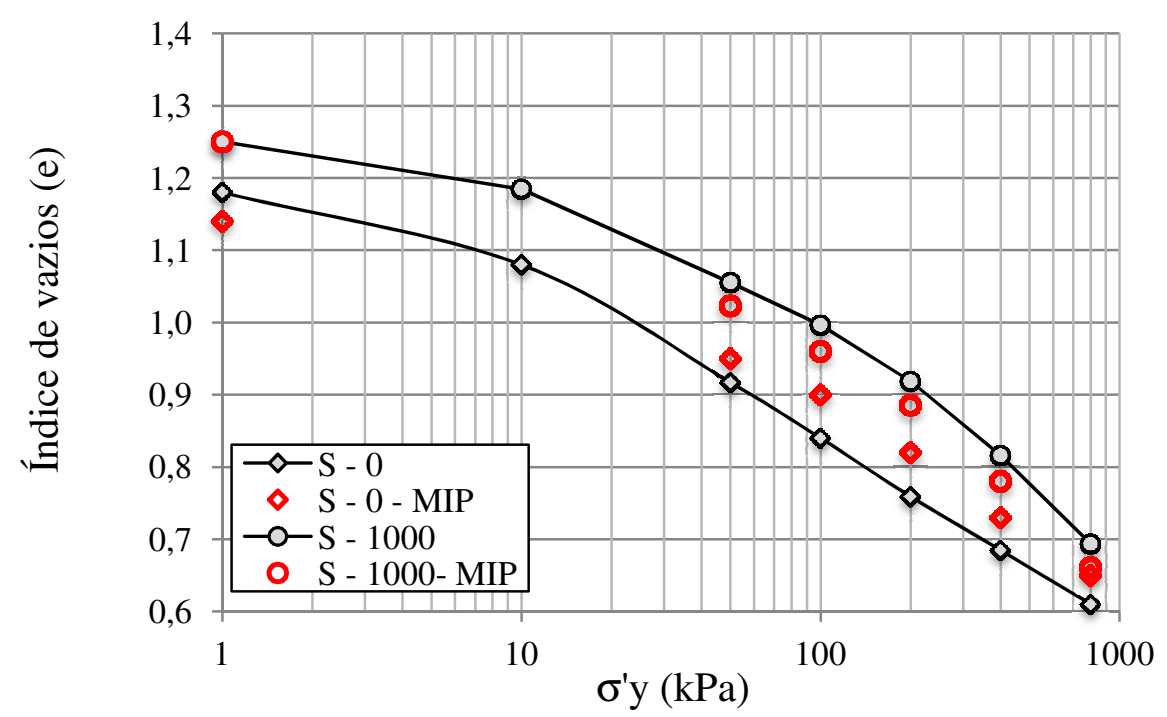

Figura 4.15 - Curvas de adensamento da Lama, saturados e com sucção de $1.000 \mathrm{kPa}$ e os pontos de ensaio do MIP.

Nos ensaios de adensamento não saturados com sucção de $50 \mathrm{kPa}$, as curvas de consolidação não foram traçadas, tendo somente os resultados dos pontos dos corpos de prova para a realização do MIP. Estes pontos são mostrados na Figura 4.16.

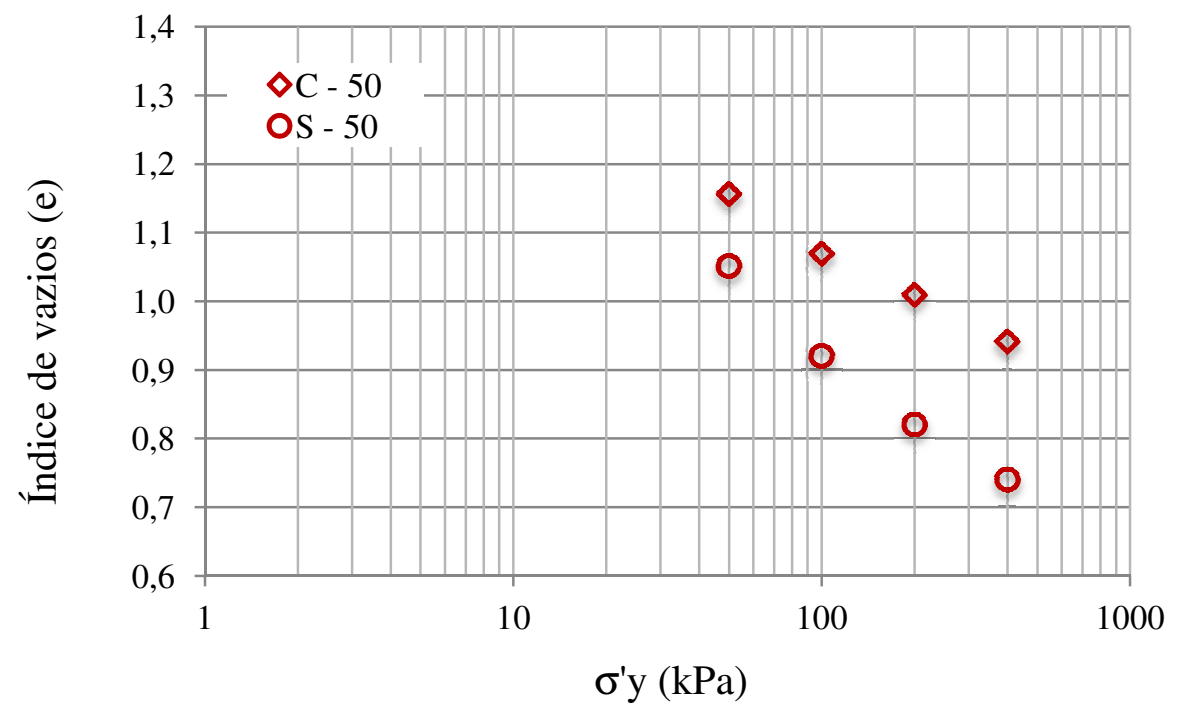

Figura 4.16 - Pontos do ensaio do MIP do solo Compactado e da Lama, não saturados com sucção de $50 \mathrm{kPa}$.

O ensaio MIP funciona empurrando o mercúrio para preencher os vazios dos poros, que começa a ter dificuldade para entrar nos poros, com isso, aumenta-se a pressão para forçar a sua entrada. Em determinado momento, não se consegue mais preencher os vazios. Para que seja possível analisar a relação do índice de vazios inicial com o índice de vazios que o mercúrio preencheu nos corpos de prova, foi calculado o erro desses índices de vazios. Além 
dos efeitos da variabilidade na confecção dos corpos de prova, esta diferença está associada a dois outros efeitos. O primeiro, associado a poros existentes dentro das agregações de argila que não estavam ligados a poros maiores e que assim ficaram isolados dentro da amostra. $\mathrm{O}$ outro efeito é a existência de poros menores que ultrapassam a capacidade do equipamento. Diversos autores, dentre eles Romero \& Simms (2008), discutem e relatam que o volume de vazios de um solo obtido pelo MIP não coincide com o valor real da amostra e que essa seria uma das limitações da técnica.

Na Tabela 4.5 são apresentadas as variações do índice de vazios que ocorreram nos corpos de prova, tanto no estado Natural, como Compactado e de Lama. Nos corpos de prova, Compactado e Lama, nota-se que há uma menor variação, porém existem valores entre 10 e $14 \%$. Nos corpos de prova Naturais há uma maior diferença para valores de carregamento baixo (50 e $100 \mathrm{kPa}$ ), sendo esta diferença superiores a 20\%. Cabe destacar que isso não significa que, por exemplo, $20 \%$ do percentual do volume de poros não foram preenchidos, uma vez que a própria medida do índice de vazio possui um erro inerente ao ensaio.

Tabela 4.5 - Variação do índice de vazios para os solos saturados.

\begin{tabular}{cccc}
\hline Corpos de Prova & $\mathrm{e}_{\mathrm{i}}$ & $\mathrm{e}_{\mathrm{nw}}$ & $\Delta e=\left(e_{i}-e_{n w}\right) / e_{i}$ \\
\hline $\mathrm{N}$ & 1,690 & 1,502 & $+11 \%$ \\
$\mathrm{~N}-50$ & 1,550 & 1,243 & $+20 \%$ \\
$\mathrm{~N}-100$ & 1,391 & 1,049 & $+25 \%$ \\
$\mathrm{~N}-200$ & 1,182 & 1,058 & $+10 \%$ \\
$\mathrm{~N}-400$ & 1,070 & 0,937 & $+12 \%$ \\
$\mathrm{~N}-800$ & 0,900 & 0,818 & $+9 \%$ \\
\hline $\mathrm{C}$ & 1,227 & 1,052 & $+14 \%$ \\
$\mathrm{C}-50$ & 1,062 & 0,989 & $+7 \%$ \\
$\mathrm{C}-100$ & 1,015 & 1,011 & $+0 \%$ \\
$\mathrm{C}-200$ & 0,957 & 1,055 & $-10 \%$ \\
$\mathrm{C}-400$ & 0,874 & 0,941 & $-8 \%$ \\
$\mathrm{C}-800$ & 0,738 & 0,812 & $+10 \%$ \\
$\mathrm{~S}$ & 1,119 & 0,967 & $+9 \%$ \\
$\mathrm{~S}-50$ & 0,958 & 0,869 & $+10 \%$ \\
$\mathrm{~S}-100$ & 0,911 & 0,816 & $+10 \%$ \\
$\mathrm{~S}-200$ & 0,823 & 0,744 & $+8 \%$ \\
$\mathrm{~S}-400$ & 0,736 & 0,677 & $+4 \%$ \\
$\mathrm{~S}-800$ & 0,686 & 0,661 & \\
\hline
\end{tabular}

Na Tabela 4.6 são apresentadas as variações do índice de vazios que ocorreram nos corpos de prova não saturados, com sucção de $50 \mathrm{kPa}$, tanto no estado Compactado, como na Lama. Nos corpos de prova da amostra Compactada há uma variação muito pequena. Somente para o carregamento de $50 \mathrm{kPa}$ essa variação é em torno de $10 \%$. Já nos corpos de prova da Lama há 
uma variação maior entre 15 e $27 \%$. As amostras de Lama são as que sofrem maiores variações.

Tabela 4.6 - Variação do índice de vazios para os solos não saturados, com sucção de $50 \mathrm{kPa}$.

\begin{tabular}{cccc}
\hline Corpos de prova & $\mathrm{e}_{\mathrm{i}}$ & $\mathrm{e}_{\mathrm{nw}}$ & $\Delta e=\left(e_{i}-e_{n w}\right) / e_{i}$ \\
\hline $\mathrm{C}-50-50$ & 1,118 & 1,005 & $+10 \%$ \\
$\mathrm{C}-100-50$ & 1,030 & 0,976 & $+5 \%$ \\
$\mathrm{C}-200-50$ & 0,971 & 1,010 & $-4 \%$ \\
$\mathrm{C}-400-50$ & 0,893 & 0,925 & $-4 \%$ \\
\hline $\mathrm{S}-50-50$ & 1,012 & 0,741 & $+27 \%$ \\
$\mathrm{~S}-100-50$ & 0,882 & 0,718 & $+19 \%$ \\
$\mathrm{~S}-200-50$ & 0,841 & 0,713 & $+15 \%$ \\
$\mathrm{~S}-400-50$ & 0,704 & 0,689 & $+2 \%$ \\
\hline
\end{tabular}

Já na Tabela 4.7 são apresentadas as variações do índice de vazios que ocorreram nos corpos de prova não saturadas, com sucção de $1.000 \mathrm{kPa}$, tanto no estado Compactado, como na Lama. Observe que para esse valor de sucção os corpos de prova apontam uma variação muito pequena, porém nos corpos de prova da Lama ainda há uma variação entre 11 e $18 \%$, presente nos carregamentos menores. Já os corpos de prova das amostras Compactadas são os que sofreram menores variações, para todos os carregamentos, em torno de $3 \%$.

Tabela 4.7 - Variação do índice de vazios para os solos não saturados, com sucção de $1000 \mathrm{kPa}$.

\begin{tabular}{cccc}
\hline Corpos de prova & $\mathrm{e}_{\mathrm{i}}$ & $\mathrm{e}_{\mathrm{nw}}$ & $\Delta e=\left(e_{i}-e_{n w}\right) / e_{i}$ \\
\hline $\mathrm{C}-50-1000$ & 1,124 & 1,104 & $+2 \%$ \\
$\mathrm{C}-100-1000$ & 1,081 & 1,049 & $+3 \%$ \\
$\mathrm{C}-200-1000$ & 1,018 & 1,010 & $+1 \%$ \\
$\mathrm{C}-400-1000$ & 0,934 & 0,959 & $-3 \%$ \\
$\mathrm{C}-800-1000$ & 0,804 & 0,822 & $+18 \%$ \\
\hline $\mathrm{S}-50-1000$ & 0,985 & 0,812 & $+15 \%$ \\
$\mathrm{~S}-100-1000$ & 0,923 & 0,789 & $+11 \%$ \\
$\mathrm{~S}-200-1000$ & 0,850 & 0,753 & $+6 \%$ \\
$\mathrm{~S}-400-1000$ & 0,746 & 0,700 & $-1 \%$ \\
$\mathrm{~S}-800-1000$ & 0,630 & 0,633 & \\
\hline
\end{tabular}

É possível observar que em todos os resultados apresentados na Tabela 4.5, na Tabela 4.6 e na Tabela 4.7, os corpos de prova da amostra de Lama foram os que sofreram maiores variações. A primeira suspeita para esta ocorrência é a presença de água no corpo de prova, que pode não ter secado totalmente, ou a própria estrutura deste material pode dificultar essa secagem, além disso, pode ter ocorrido erro na medida do índice de vazio.

Há certos aspectos associados com o procedimento de ensaio do MIP que podem afetar os resultados. Em particular, para a análise de MIP de argilas moles, danos estruturais podem ocorrer dentro da amostra, enquanto a água está saindo do poro, durante a secagem, que 
podem ser significativos. Alguns pesquisadores relataram que o índice de vazios de suas amostras tem sido subestimado pela análise do MIP (Simms \& Yanful, 2004; Romero \& Simms, 2008; Koliji et al., 2010).

Sasanian \& Newson (2013) avaliaram os efeitos das variações do teor de umidade sobre a distribuição do tamanho dos poros de duas argilas. Segundo os autores, as duas argilas possuem resultados semelhantes, sugerindo que o erro pode ser inerente ao ensaio e independente do tipo de argila.

\subsection{2 - ANÁLISE ESTRUTURAL}

Para análise estrutural do solo foram realizados ensaios de MIP nas amostras, Compactada, Natural e Lama. No eixo vertical são plotados os valores de $e_{n w}$, que é a relação entre o volume de vazio preenchido por mercúrio e volume de sólido, e a densidade do tamanho dos poros (PSD), definida pela equação (2.2). No eixo horizontal é plotado o diâmetro equivalente dos poros do solo. A delimitação utilizada para separar a micro e macroestrutura deste solo é o valor de $0,3(\mu \mathrm{m})$.

A Figura 4.17 mostra a distribuição do tamanho dos poros nos três estados de amostras de argila porosa de Brasília. O segmento da curva associado com os microporos, nos três estados do solo, é o mesmo. Isto significa que a diferença da estrutura do solo não afeta o nível de microporos. As curvas exibem mudanças apenas no trecho associado aos macroporos.

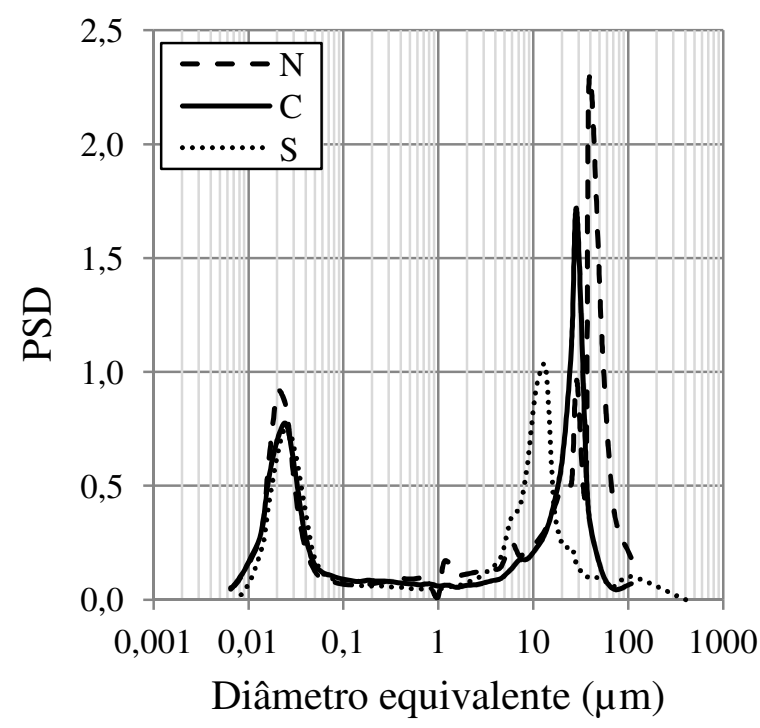

(a)

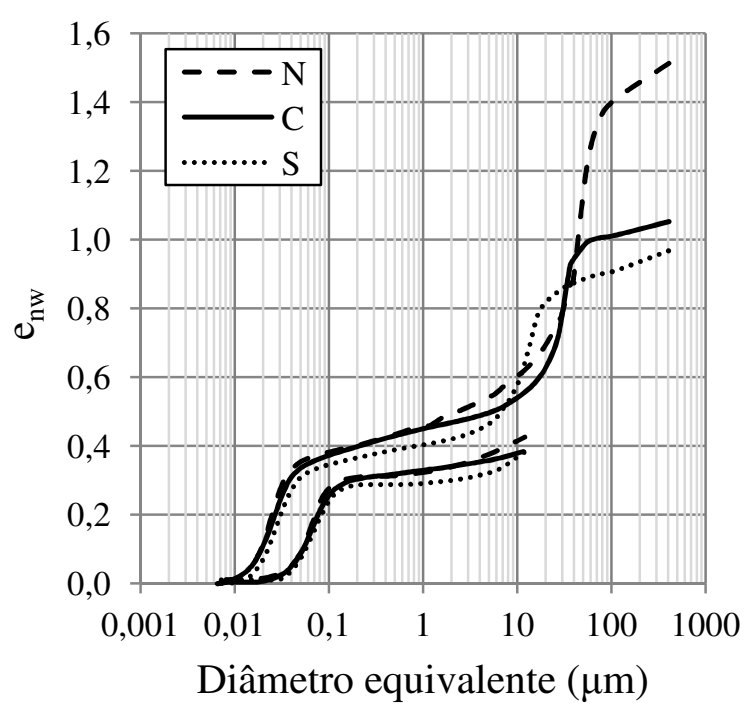

(b)

Figura 4.17 - Argila porosa de Brasília em diferentes estados: (a) Distribuição do tamanho dos poros; (b) Densidade do tamanho dos poros. 
A variação de diâmetro equivalente mostrado na distribuição é de cerca de $0,01 \mu \mathrm{m}$ até 200 $\mu \mathrm{m}$. Nesta faixa, existe um comportamento bimodal (Figura 4.17). Este tipo de comportamento foi observado em outros trabalhos para solos tropicais, como os de Futai \& Almeida (2005) e Miguel \& Bonder (2012), que mostram curva de distribuição do tamanho dos poros para solos tropicais similares.

Para poros menores que $0,1 \mu \mathrm{m}$, Otálvaro (2013) realizou ensaios de adsorção de Nitrogênio $\left(\mathrm{N}_{2}\right)$ no mesmo solo e concluiu que a diferença entre os microporos, determinada pelo MIP e pelo $\mathrm{N}_{2}$, não é relevante neste solo. Os microporos são provavelmente associados com as agregações. Vale ressaltar que as amostras com diferentes estruturas iniciais (Natural, Compactada e Lama) apresentam distribuição do tamanho dos poros coincidentes para o diâmetro menor que $1 \mu \mathrm{m}$. É possível concluir que a compactação e o processo utilizado para obter Lama não foram capazes de afetar os microporos dentro das agregações (Figura 4.17), ou ainda, não são capazes de afetar as agregações.

As amostras, Natural e Compactada, têm um comportamento muito semelhante, e o principal ponto que as diferencia é o índice de vazios total. Comparando as curvas, é possível observar que estas são iguais para diâmetros de poros menores que $1 \mu \mathrm{m}$ e os poros dominantes da micro são semelhantes. Na parte da macroestrutura, para diâmetros de poros maiores do que 1 $\mu \mathrm{m}$, há alguma diferença, mas a diferença principal é o ponto onde as curvas começam a ser horizontais. Quando essas últimas duas curvas são comparadas com a amostra de Lama, é fácil identificar que o diâmetro dominante dos macroporos da Lama $(\mathrm{D} \approx 10 \mu \mathrm{m})$ é menor que dos outros dois solos (Compactada - $\mathrm{D} \approx 40 \mu \mathrm{m}$, Natural - $\mathrm{D} \approx 30 \mu \mathrm{m}$ ).

A Figura 4.18 apresenta a densidade do tamanho dos poros nos três estados de amostras de argila porosa de Brasília, para carregamento de $50 \mathrm{kPa}$, na condição saturada. Estas curvas exibem apenas as mudanças no trecho representando os macroporos, evidenciando o efeito da estrutura na densidade destes poros, mesmo com o carregamento de $50 \mathrm{kPa}$. Comparando a Figura 4.17 e a Figura 4.18, há uma pequena variação no diâmetro de poro dominante da amostra Compactada $(\mathrm{D} \approx 25 \mu \mathrm{m})$ da Lama $(\mathrm{D} \approx 7 \mu \mathrm{m})$, não havendo alteração na amostra Natural ( $\mathrm{D} \approx 30 \mu \mathrm{m}$ ), porém é possível observar uma diminuição na densidade do tamanho dos poros. Além disso, o carregamento não afetou os poros dominantes da microestrutura. Cabe destacar que a amostra natural possui a estrutura mais aberta. 


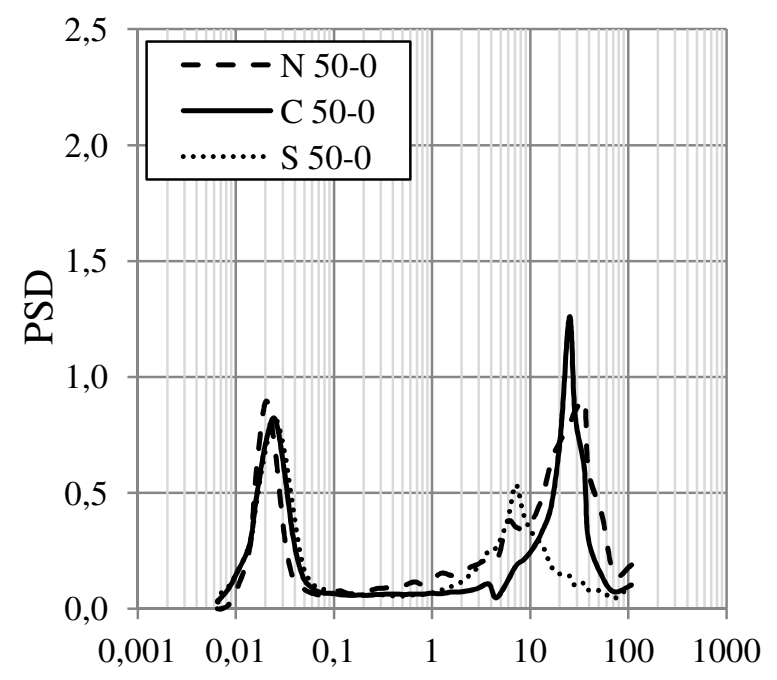

Diâmetro equivalente $(\mu \mathrm{m})$

(a)

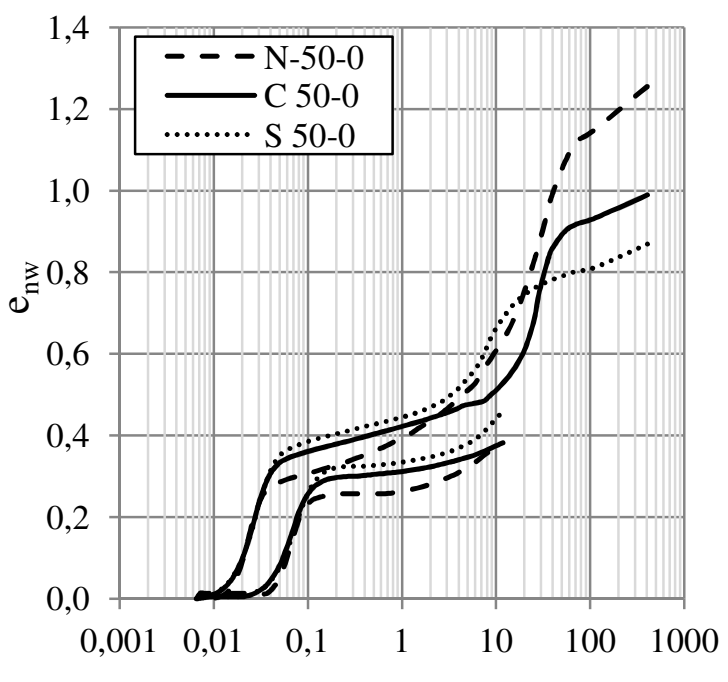

Diâmetro equivalente $(\mu \mathrm{m})$

(b)

Figura 4.18 - Argila porosa de Brasília em diferentes estados com carregamento de $50 \mathrm{kPa}$ :

(a) Distribuição do tamanho dos poros; (b) Densidade do tamanho dos poros.

Na sequência da Figura 4.18 até a Figura 4.22 é possível observar a evolução das PSD das amostras com diferentes estruturas. A Figura 4.22 apresenta PSD para o carregamento de 800 $\mathrm{kPa}$. Mesmo para este carregamento, as curvas também exibem apenas mudanças nos macroporos. A partir da sequência de figuras é possível imaginar que carregamentos ainda maiores tenderiam a destruir os poros maiores que $10 \mu \mathrm{m}$.

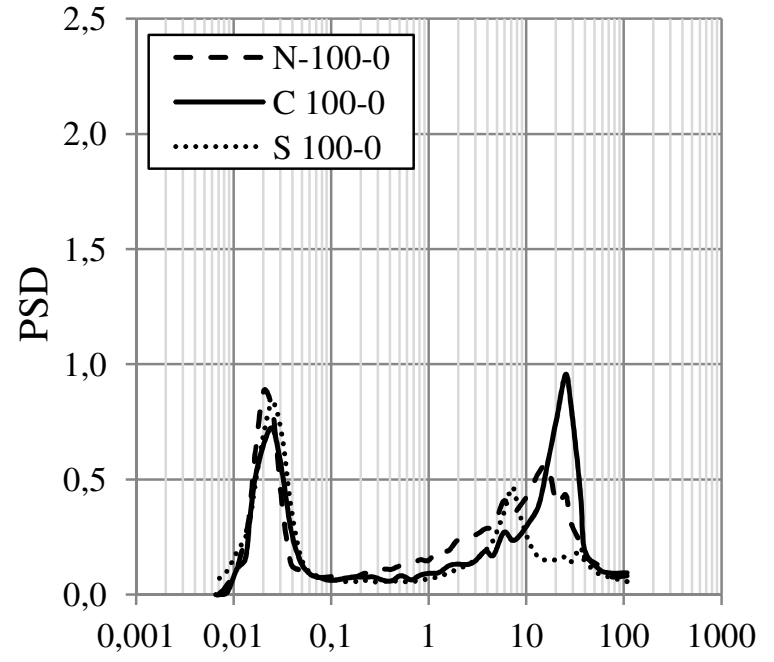

Diâmetro equivalente $(\mu \mathrm{m})$

(a)

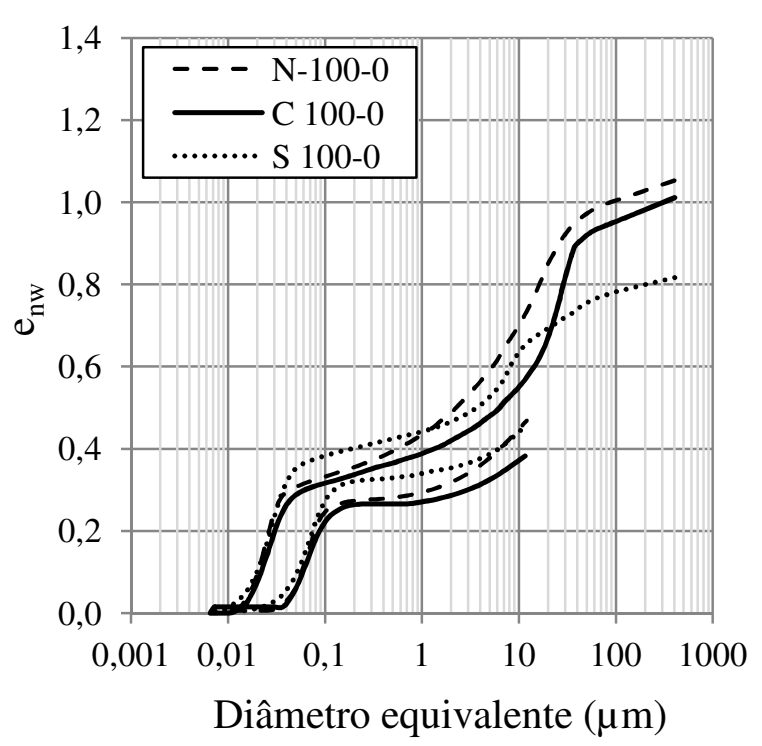

(b)

Figura 4.19 - Argila porosa de Brasília em diferentes estados com carregamento de $100 \mathrm{kPa}$ :

(a) Distribuição do tamanho dos poros; (b) Densidade do tamanho dos poros. 
Ainda nesta sequência da Figura 4.18 até a Figura 4.22 é importante notar que, do ponto de vista de distribuição do tamanho dos poros, as três amostras que possuem diferentes estruturas concentram essas diferenças exatamente na distribuição dos macroporos. Caso esses macroporos sejam destruídos e não haja mudanças significativas nos microporos, é possível que estas três amostras passem a ter comportamentos semelhantes. Isso pode explicar a tendência de convergência existente entre as curvas de compressão oedométrica apresentadas neste trabalho (Figura 4.10) e por Leroueil \& Vaughan (1990) (Figura 4.12).

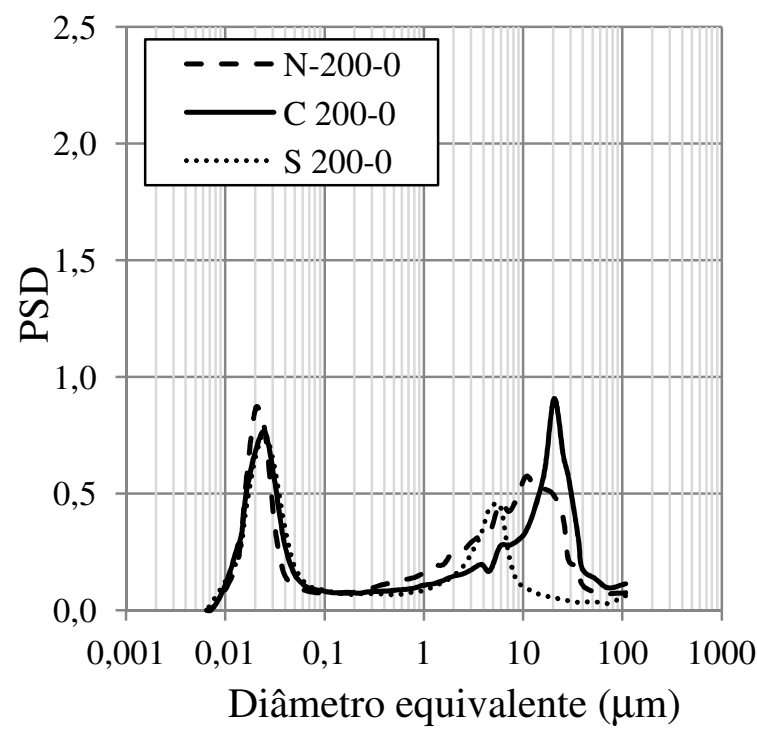

(a)

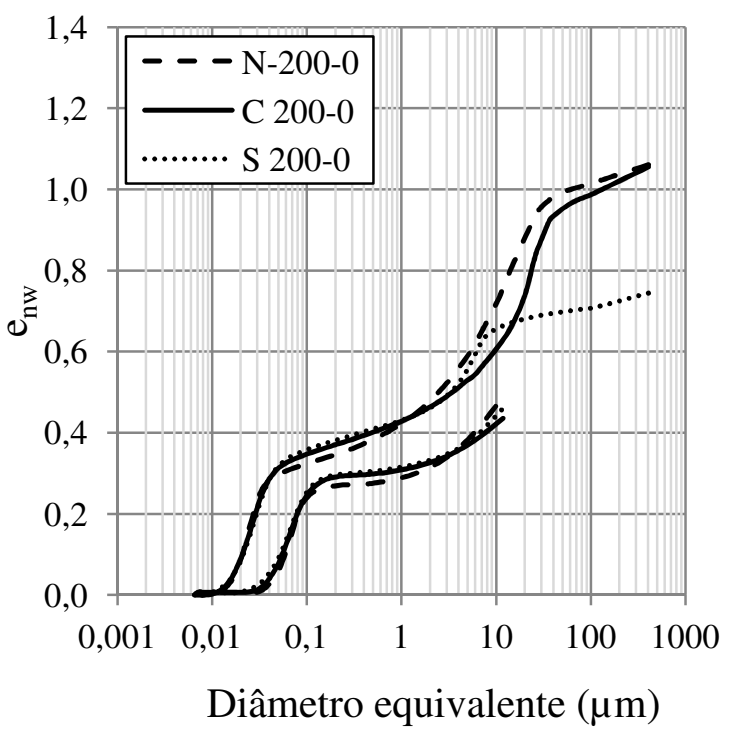

(b)

Figura 4.20 - Argila porosa de Brasília em diferentes estados com carregamento de $200 \mathrm{kPa}$ :

(a) Distribuição do tamanho dos poros; (b) Densidade do tamanho dos poros.

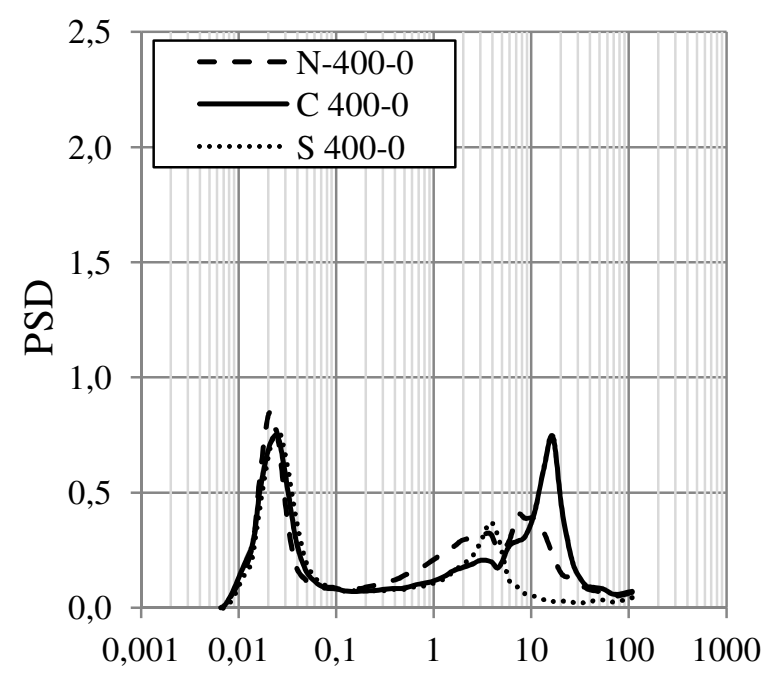

Diâmetro equivalente $(\mu \mathrm{m})$

(a)

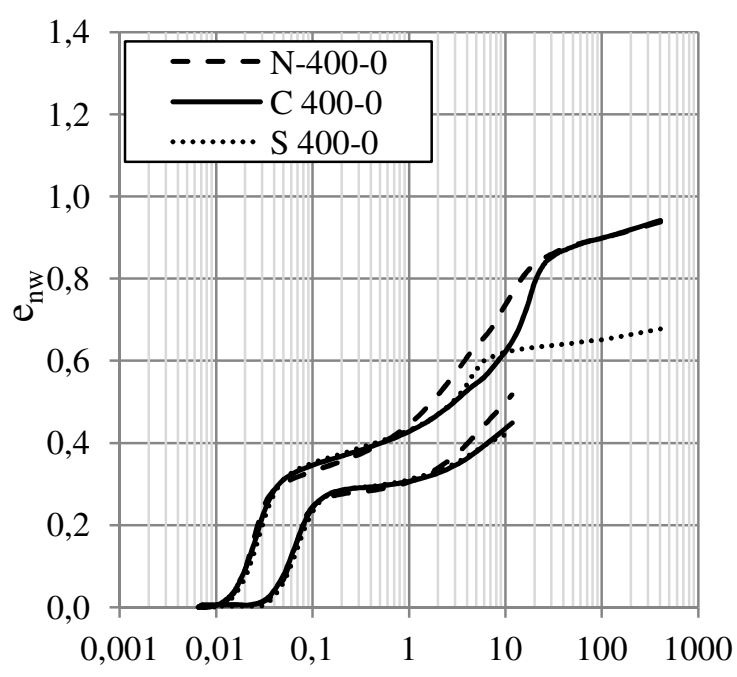

Diâmetro equivalente $(\mu \mathrm{m})$

(b)

Figura 4.21 - Argila porosa de Brasília em diferentes estados com carregamento de $400 \mathrm{kPa}$ :

(a) Distribuição do tamanho dos poros; (b) Densidade do tamanho dos poros. 


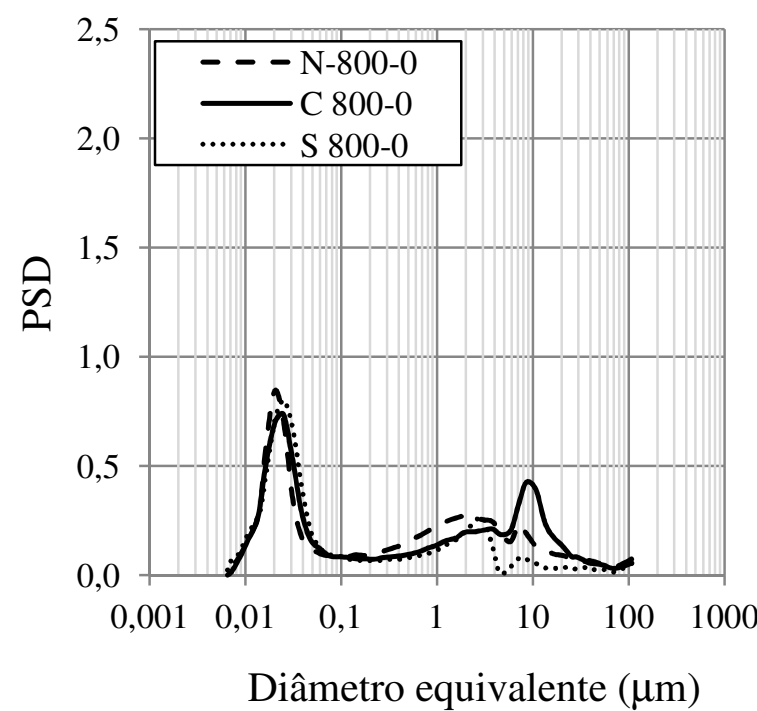

(a)

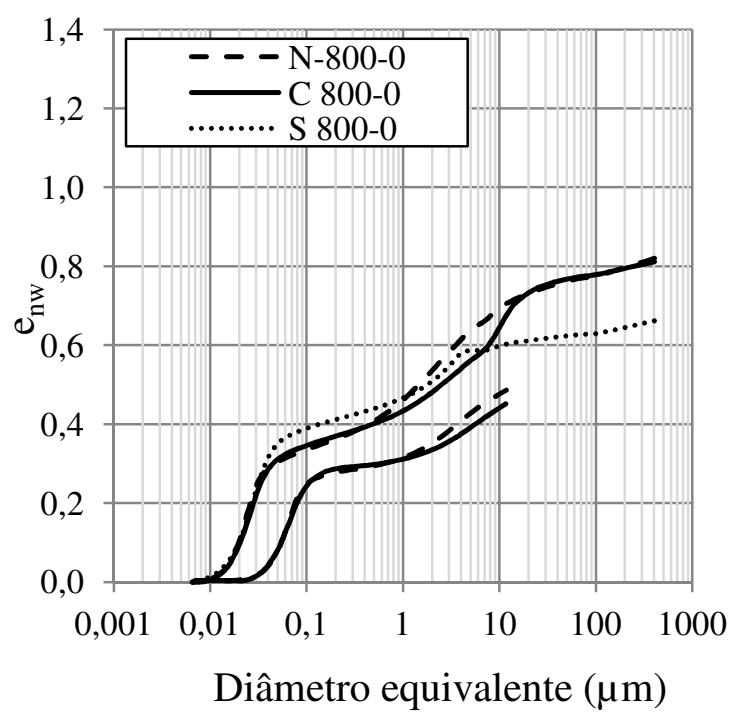

(b)

Figura 4.22 - Argila porosa de Brasília em diferentes estados com carregamento de $800 \mathrm{kPa}$ :

(a) Distribuição do tamanho dos poros; (b) Densidade do tamanho dos poros.

A Figura 4.23 ilustra as PSDs da argila porosa de Brasília no estado Natural, na condição saturada, e as mudanças que ocorrem com a aplicação de carregamento. Não há mudança na microestrutura, apenas na macroestrutura (Figura 4.23a). Além da redução do índice de vazios com o carregamento (Figura 4.23b), há uma tendência a diminuir o tamanho de poros dominantes.

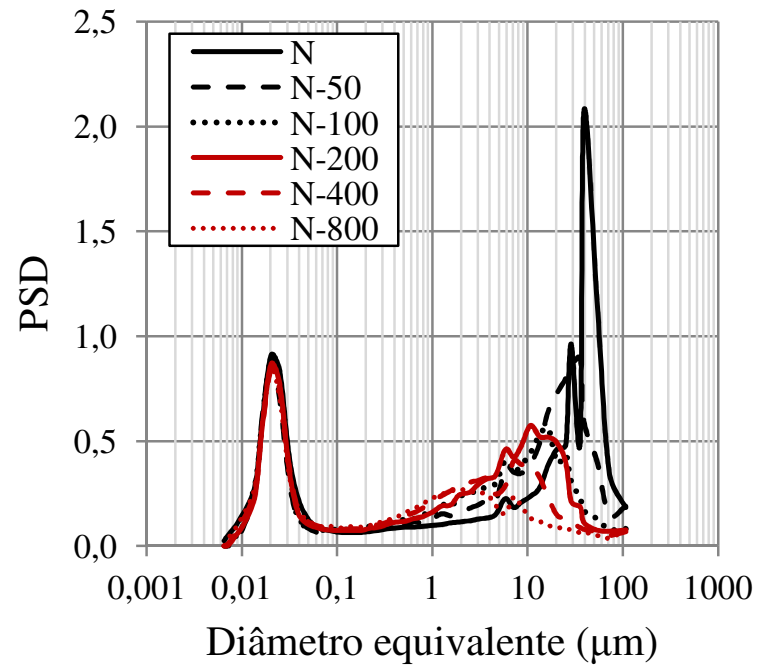

(a)

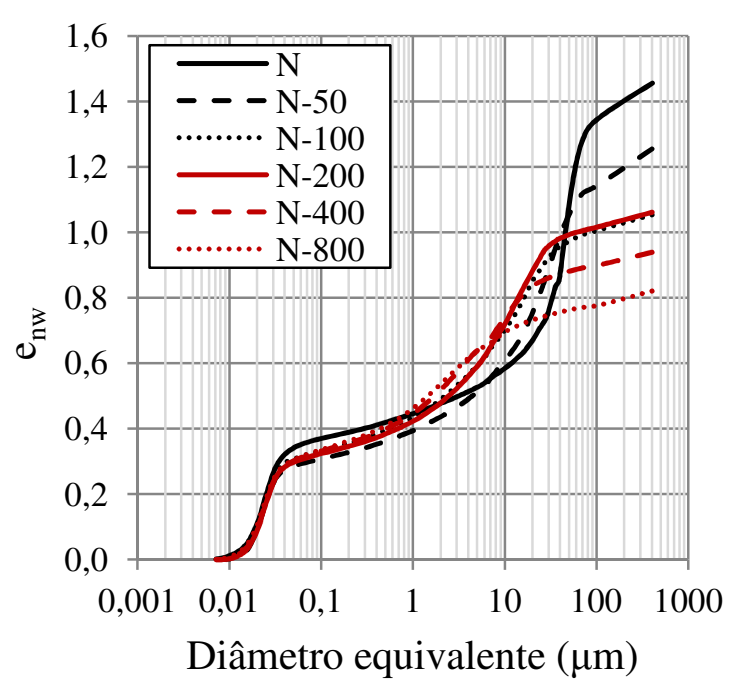

(b)

Figura 4.23 - Argila porosa de Brasília, solo em estado Natural, na condição saturada, para diferentes carregamentos: (a) Distribuição do tamanho dos poros; (b) Densidade do tamanho dos poros.

A Figura 4.24 ilustra as PSDs das amostras Compactadas na condição saturada e como estas são afetadas pelo carregamento. Assim como o solo natural, este solo apresenta uma 
distribuição bimodal da curva da PSD, o que também é observado nas curvas de retenção do solo, apresentadas na Figura 4.5. Apesar dos diferentes estados e índice de vazios, não há nenhuma mudança nos microporos.

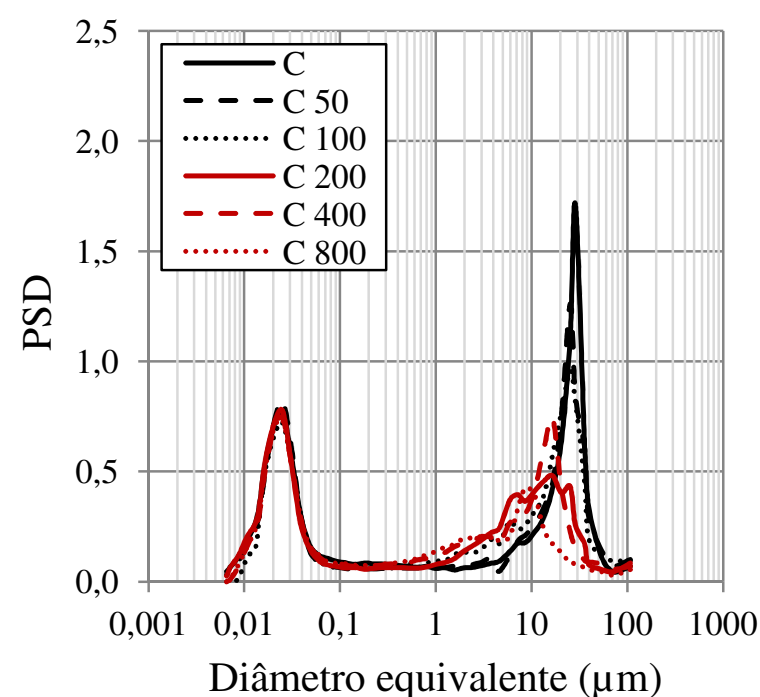

(a)

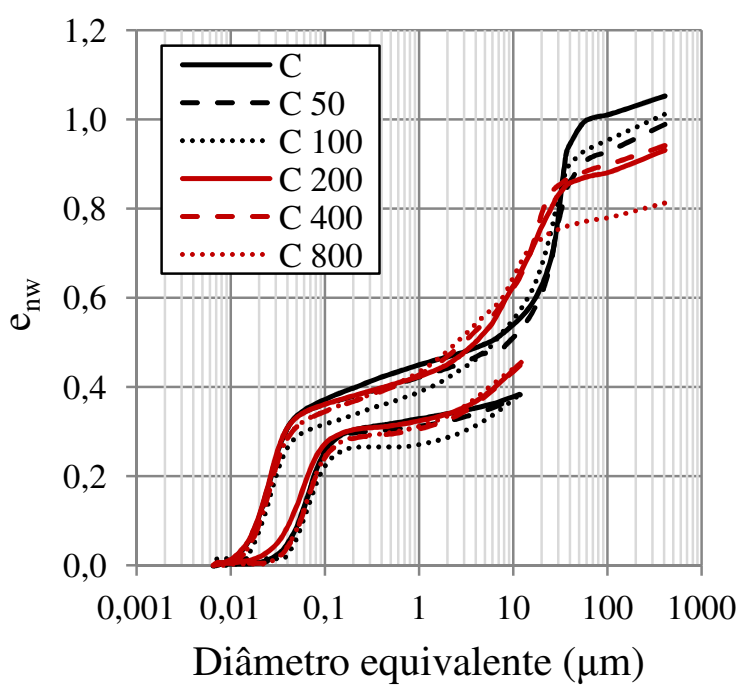

(b)

Figura 4.24 - Argila porosa de Brasília, solo Compactado, na condição saturada para diferentes carregamentos: (a) Distribuição do tamanho dos poros; (b) Densidade do tamanho dos poros.

A Figura 4.25 ilustra as PSDs das amostras no estado de Lama, na condição saturada, e as mudanças devido a carregamentos. Mesmo no estado de Lama, o solo tem uma distribuição bimodal da curva da PSD. Também é possível observar as mesmas características na curva de retenção da amostra com estrutura semelhante apresentada na Figura 4.6. Mesmo em estado de Lama, não há nenhuma mudança nos microporos nas curvas.

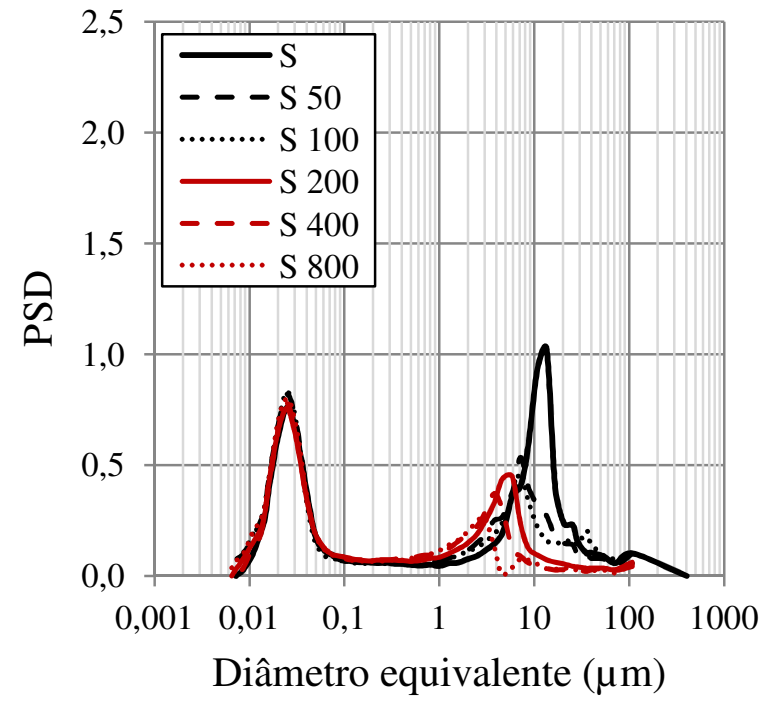

(a)

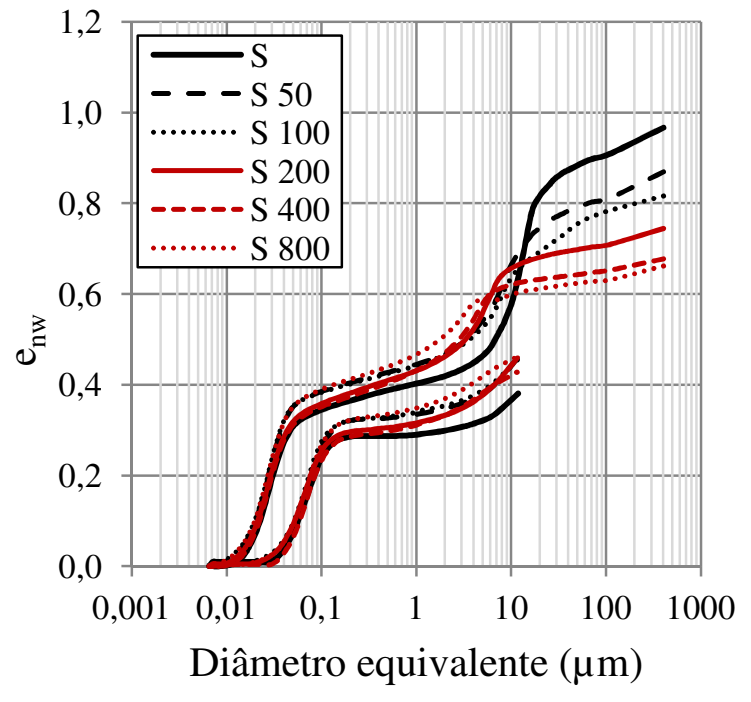

(b)

Figura 4.25 - Argila porosa de Brasília, solo em estado de Lama em diferentes carregamentos para o solo saturado: (a) Distribuição do tamanho dos poros; (b) Densidade do tamanho dos poros. 
Os resultados dos ensaios apresentados na Figura 4.26 são da amostra Compactada com diferentes carregamentos e sucção igual a $50 \mathrm{kPa}$. Não há mudança na microestrutura, apenas na macroestrutura. Do mesmo modo que nas amostras saturadas, há uma redução do índice de vazios com o carregamento e uma leve tendência a diminuir o tamanho de poros dominantes da macroestrutura, porém essa redução é pequena (menor que uma ordem de grandeza). Por outro lado, há uma pequena redução na densidade dos poros. Aparentemente, a sucção ajudou a manter a macroestrutura menos deformável do que o observado na condição saturada.

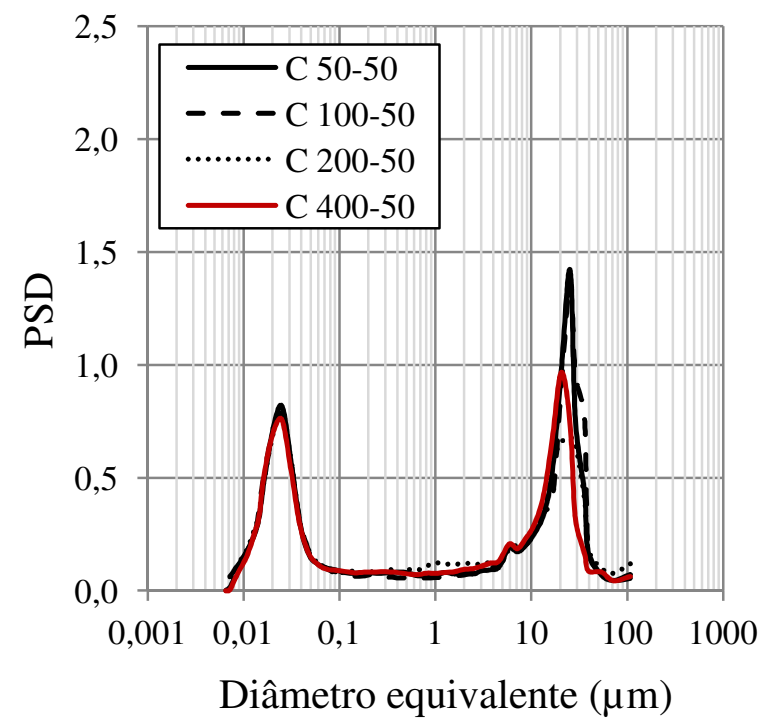

(a)

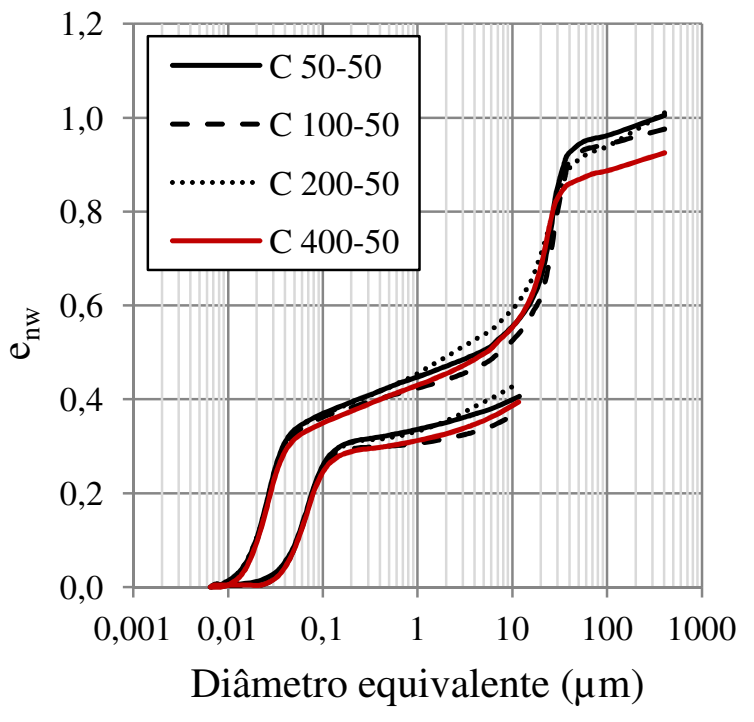

(b)

Figura 4.26 - Argila porosa de Brasília, solo Compactado, na condição não saturada, com sucção de $50 \mathrm{kPa}$, para diferentes carregamentos: (a) Distribuição do tamanho dos poros; (b) Densidade do tamanho dos poros.

Na Figura 4.27 são apresentados os resultados do solo em estado de Lama, para diferentes carregamentos e sucção igual a $50 \mathrm{kPa}$. Para estes resultados houve uma grande diferença entre os resultados dos índices de vazios das amostras e o obtido a partir do ensaio de porosimetria apresentado na Tabela 4.6. Este fato dificultou a análise destes resultados, mas vale ressaltar que mesmo com esses problemas, foi possível observar que não há mudança na microestrutura e que somente os macroporos são afetados. Além da redução do índice de vazios com o carregamento (Figura 4.27b), há uma tendência a diminuir o tamanho de macroporos dominante (Figura 4.27a). 


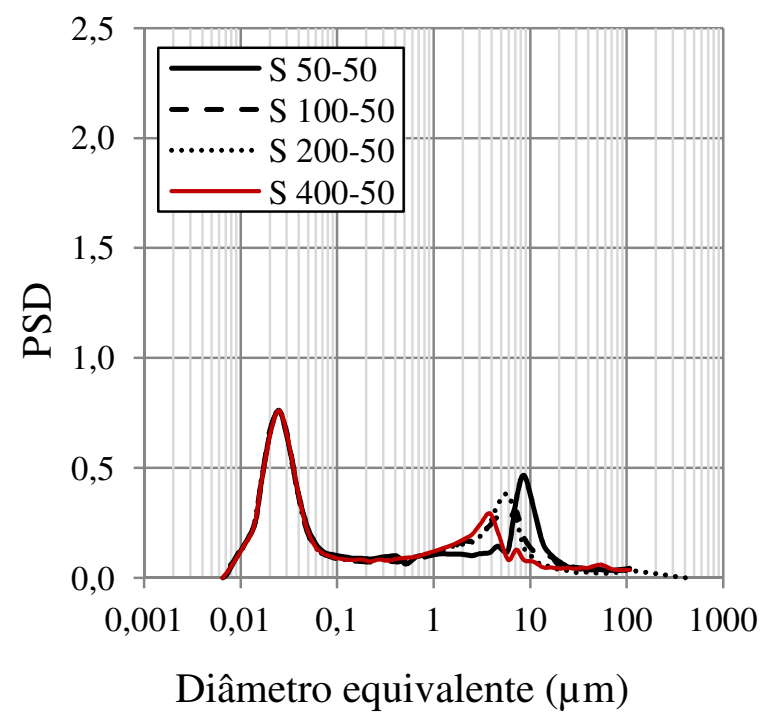

(a)

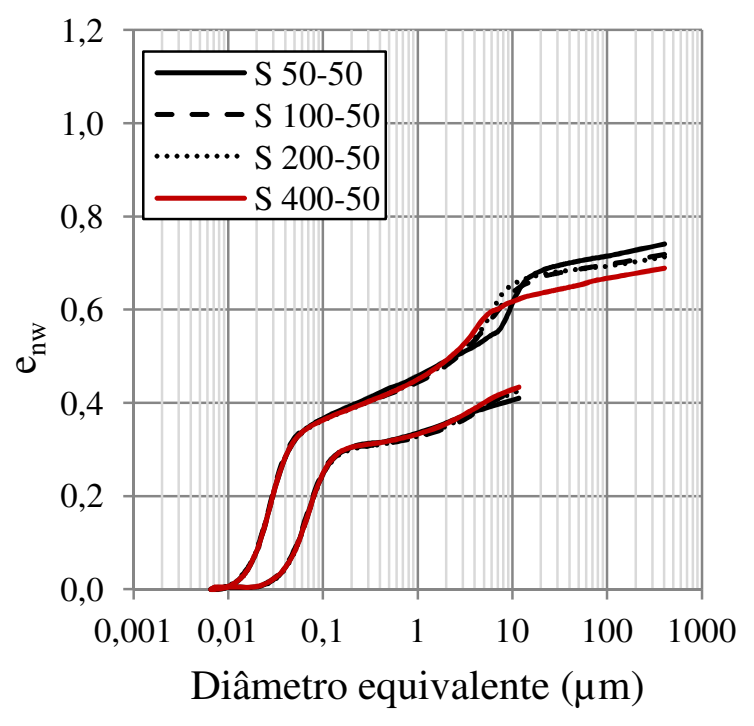

(b)

Figura 4.27 - Argila porosa de Brasília, solo em estado de Lama, na condição não saturada, sucção de $50 \mathrm{kPa}$ em diferentes carregamentos: (a) Distribuição do tamanho dos poros; (b) Densidade do tamanho dos poros.

Conforme descrito na metodologia, as amostras cujos resultados são apresentados na Figura 4.26 e na Figura 4.27 sofreram um processo de ciclagem (trajetória de molhagem-secagemmolhagem). Observe que este ciclo não foi capaz de alterar a estrutura dos microporos. Isso se deve ao fato de o ciclo não ter atingido sucções suficientes elevadas $(>5.000 \mathrm{kPa})$ para retirar água dos microporos, o que poderia levar a mudanças nos microporos. Ao contrário, todo o ciclo atingiu somente a água dos macroporos (Figura 4.26).

Nas amostras Compactadas com diferentes carregamentos e sucção igual a 1.000 kPa (Figura 4.28), observe que o ponto de maior curvatura (Figura 4.28b) praticamente não sofre alteração com os carregamentos, sendo que há uma redução do índice de vazio sem que haja mudanças na forma da curva de distribuição do tamanho dos poros. Isso significa que não há mudança significativa no tamanho dos macroporos dominantes, havendo apenas uma pequena redução na sua densidade. Esta mudança de comportamento esta associada à sucção aplicada (1.000 $\mathrm{kPa}$ ), que dificulta o fechamento dos macroporos.

Da Tabela 4.1 tem-se que a tensão de pré-adensamento dessa amostra (Compactada com sucção $1.000 \mathrm{kPa}$ ) é igual a $180 \mathrm{kPa}$. Na Figura 4.28, as amostras associadas às cargas verticais de 50 e $100 \mathrm{kPa}$ praticamente não tiveram mudanças, enquanto as amostras com cargas mais elevadas (400 e $800 \mathrm{kPa}$ ) foram afetadas de forma mais evidente. 


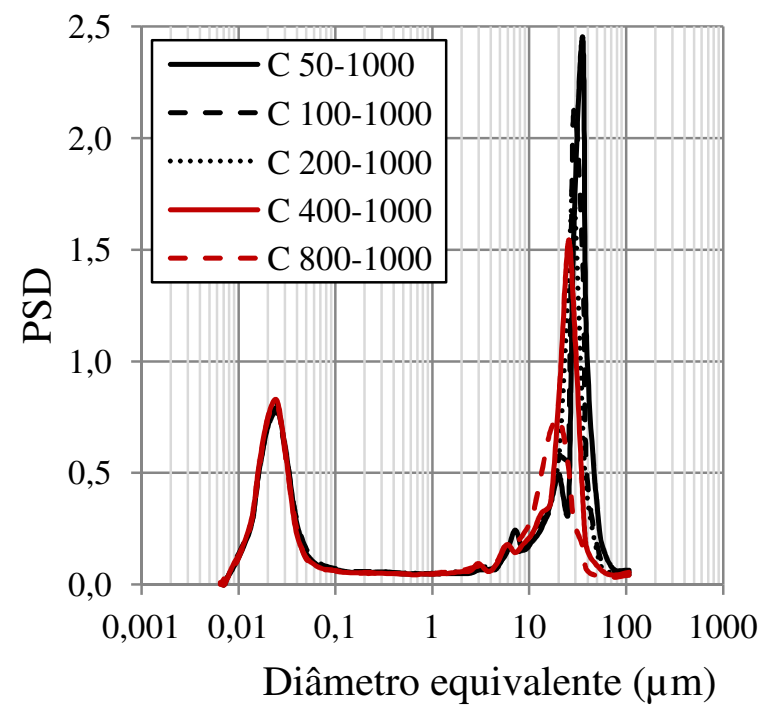

(a)

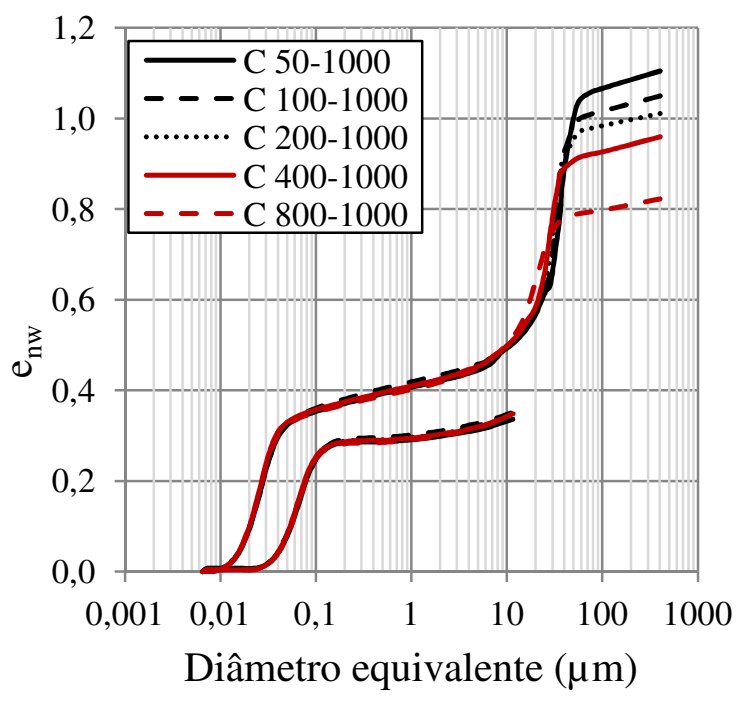

(b)

Figura 4.28 - Argila porosa de Brasília, solo Compactado para diferentes carregamentos para o solo com sucção de 1.000 kPa: (a) Distribuição do tamanho dos poros; (b) Densidade do tamanho dos poros.

Vale ressaltar que analisando a curva de retenção do solo Compactado, Figura 4.5, para valores de sucção entre $50 \mathrm{kPa}$ e $1.000 \mathrm{kPa}$, não há grande variação da umidade. Estes valores de sucção encontram-se na zona transição entre a água armazenada nos micro e macroporos da curva de retenção. Isso pode explicar por que os resultados da Figura 4.26 e da Figura 4.28 são semelhantes, uma vez que não há grandes variações na quantidade de água armazenada.

$\mathrm{Na}$ análise das amostras de Lama, com sucção de 1.000 kPa (Figura 4.29), o resultado obtido para o carregamento de $400 \mathrm{kPa}$ está com o comportamento anômalo, uma vez que possui o diâmetro do poro dominante da macroestrutura maior que da amostra com carregamento de 50 $\mathrm{kPa}$. Além disso, a amostra correspondente a $800 \mathrm{kPa}$ possui uma estrutura com um dos poros dominantes elevado. Esse tipo de comportamento pode estar associado ao aparecimento de trincas nas amostras.

Descartando este carregamento, é possível observar que inclinação da curva correspondente ao trecho dos macroporos muda com o carregamento (Figura 4.29b). Isso significa que há uma mudança na distribuição do tamanho dos poros, que será discutida no próximo capítulo. Ao contrario das amostras compactadas, a sucção não teve o efeito de preservar a macroestrutura, sendo que neste caso o aumento das cargas verticais levou a uma destruição dos macroporos. 


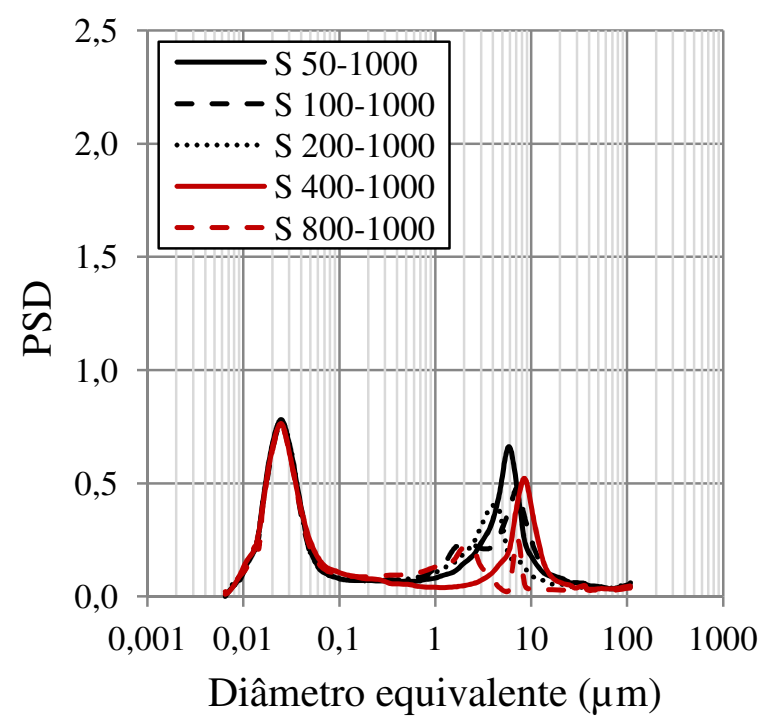

(a)

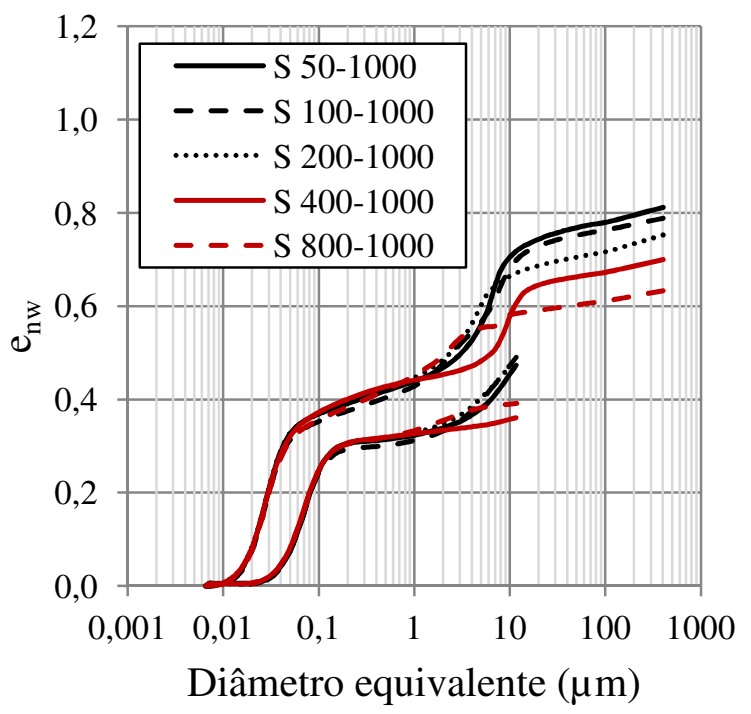

(b)

Figura 4.29 - Argila porosa de Brasília, solo em estado de Lama em diferentes carregamentos para o solo com sucção de $1.000 \mathrm{kPa}$ : (a) Distribuição do tamanho dos poros; (b) Densidade do tamanho dos poros.

Além do efeito do carregamento nas amostras de solo saturado ou não, os dados disponíveis neste trabalho permitem avaliar o efeito da sucção sobre a distribuição do tamanho dos poros. Para isso, os resultados de cada carregamento vertical, com diferentes sucções, serão comparados.

$\mathrm{Na}$ Figura 4.5 foram apresentadas as curvas de retenção do solo, e observa-se que a quantidade de água retirada do solo, quando a sucção é elevada de 50 para $1000 \mathrm{kPa}$, é pequena, se comparada à quantidade que sai quando o solo sai da sucção de 0 para $50 \mathrm{kPa}$. Apesar disso, observa-se que, Figura 4.30 e Figura 4.31, a sucção ajuda a manter os macroporos menos deformáveis nas amostras Compactadas, porém, isso não foi observado com a mesma intensidade nas amostras de Lama (Figura 4.32 e Figura 4.33). 


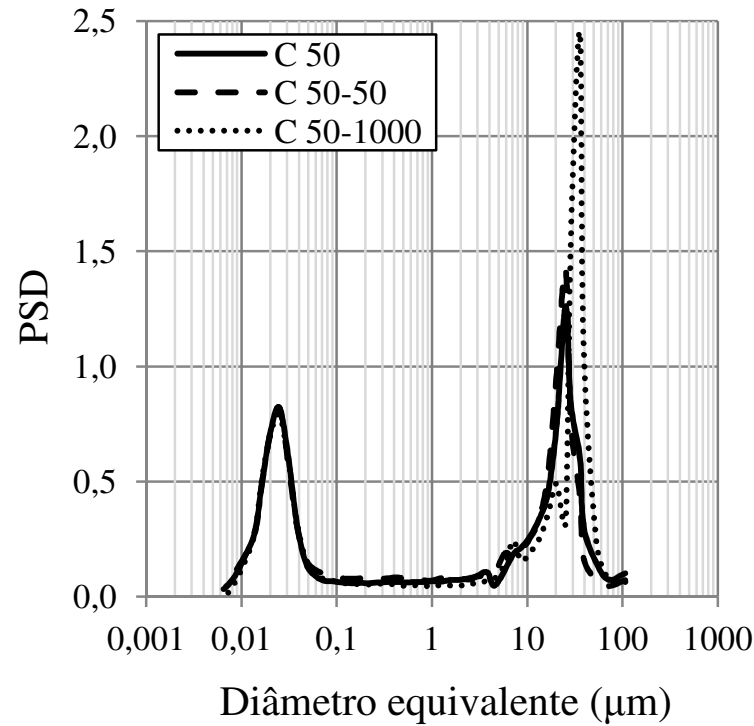

(a)

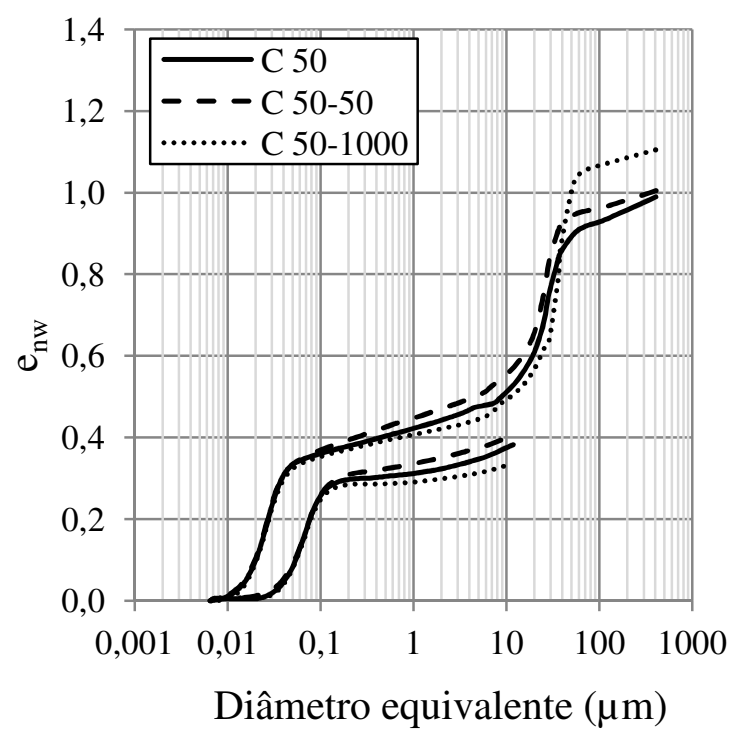

(b)

Figura 4.30 - Argila porosa de Brasília, solo Compactado com tensão vertical de $50 \mathrm{kPa}$ em diferentes estados para diferentes sucções: (a) Distribuição do tamanho dos poros; (b) Densidade do tamanho dos poros.

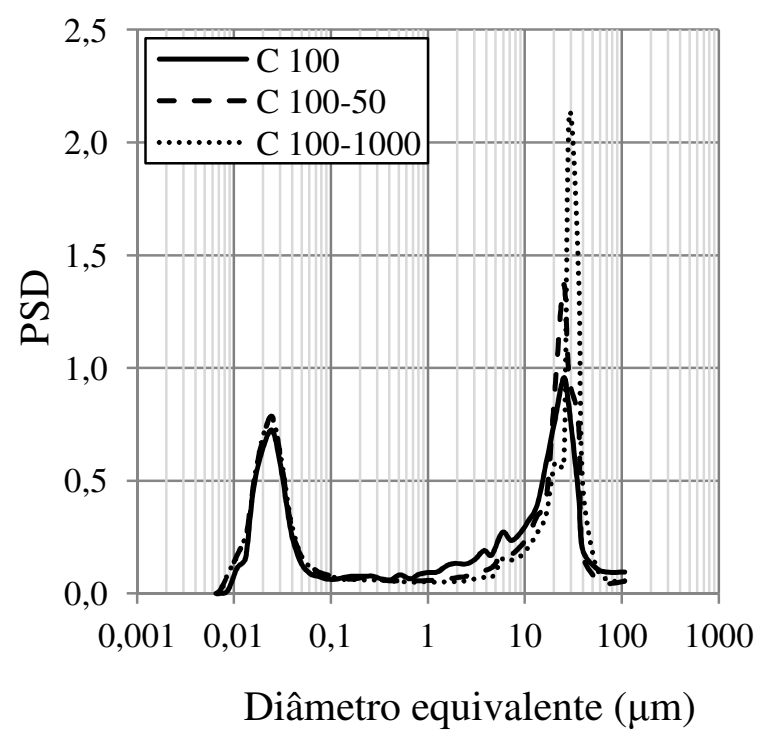

(a)

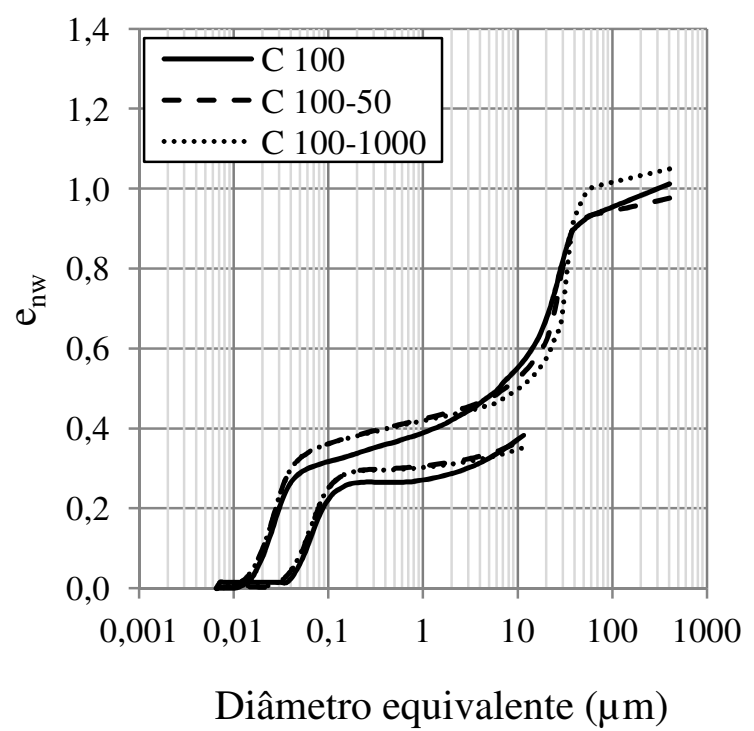

(b)

Figura 4.31 - Argila porosa de Brasília, solo Compactado com tensão vertical de $100 \mathrm{kPa}$ de tensão vertical em diferentes estados para diferentes sucções: (a) Distribuição do tamanho dos poros; (b) Densidade do tamanho dos poros. 


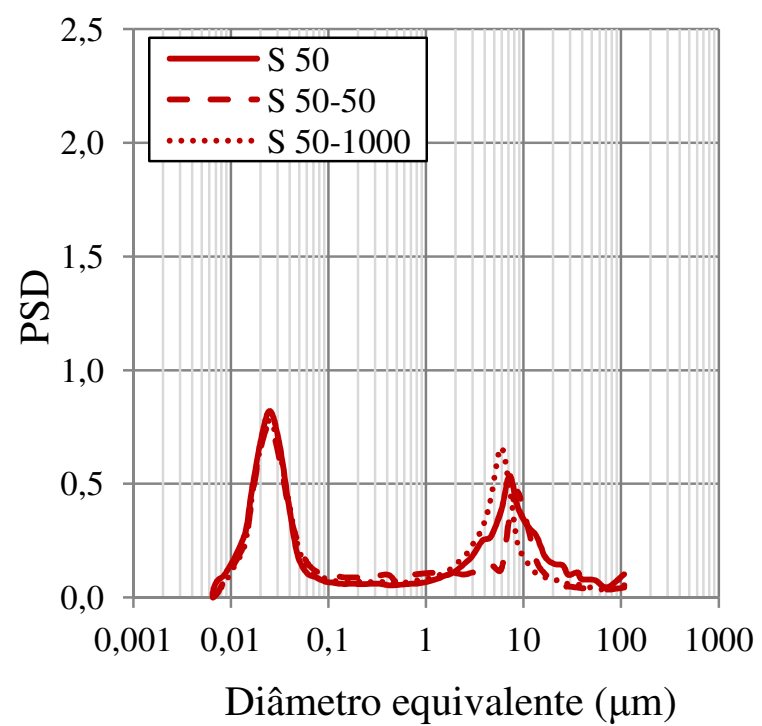

(a)

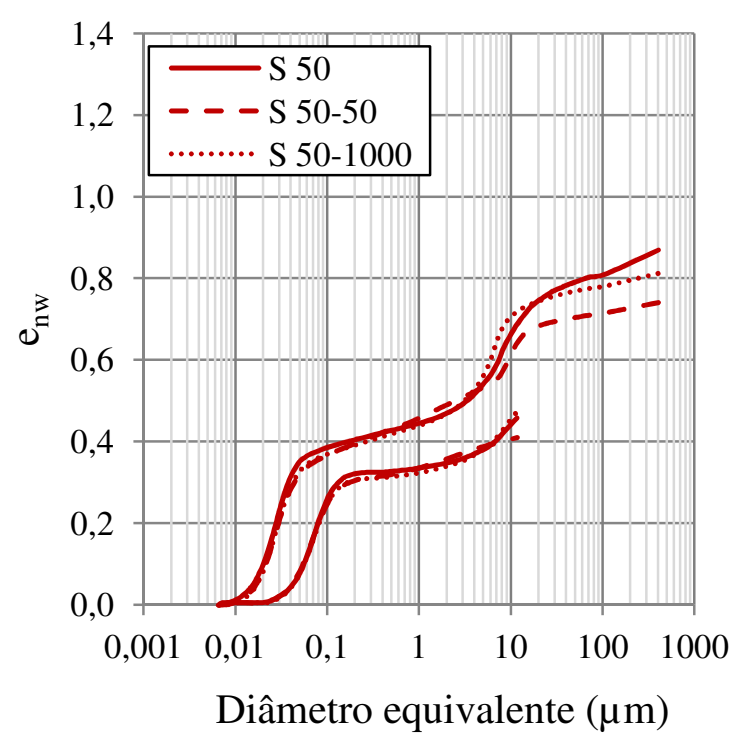

(b)

Figura 4.32 - Argila porosa de Brasília, solo em estado de Lama com tensão vertical de 50 kPa em diferentes estados para diferentes sucções: (a) Distribuição do tamanho dos poros; (b) Densidade do tamanho dos poros.

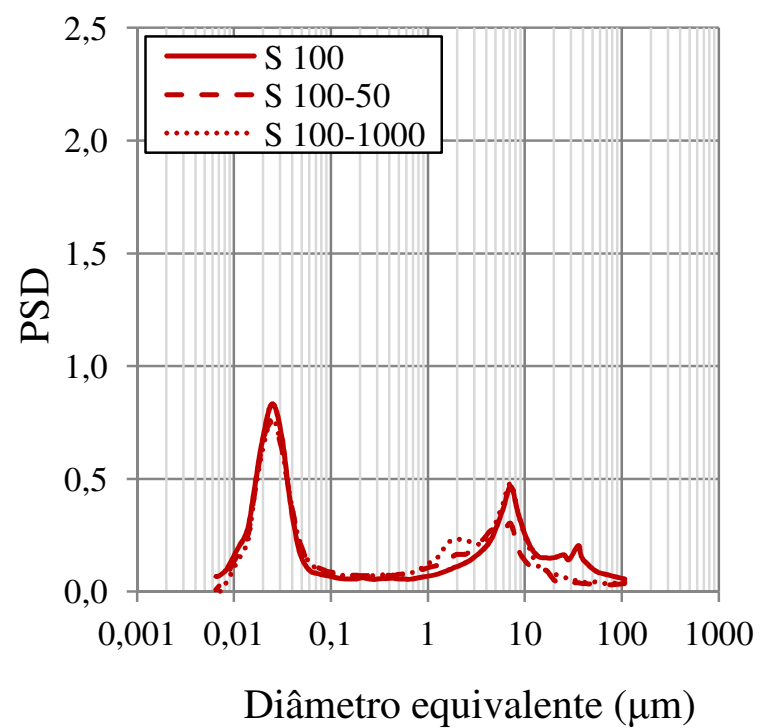

(a)

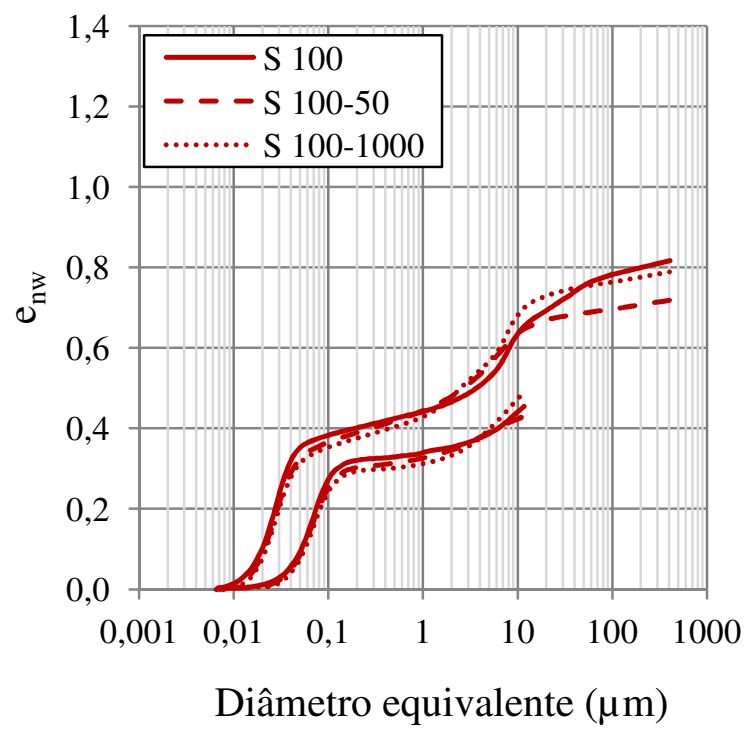

(b)

Figura 4.33 - Argila porosa de Brasília, solo em estado de Lama com tensão vertical de 100 kPa de tensão vertical em diferentes estados, para diferentes sucções: (a) Distribuição do tamanho dos poros; (b) Densidade do tamanho dos poros.

$\mathrm{O}$ efeito de sucções mais elevadas fica mais evidente para carregamentos mais altos (Figura 4.34 a Figura 4.39). É nítido que as amostras associadas à sucção mais elevada tendem ter menores efeitos do carregamento na macroestrutura. Isso é mais evidente nas amostras compactadas, porém esse efeito também é visto nas amostras de Lama. 
Tanto essa observação de que a sucção ajuda a manter os macroporos menos deformáveis, quanto o fato de que os microporos praticamente não são afetados pelo processo de carregamento, estão de acordo com trabalhos anteriores (Romero, 1999; Simms \& Yanful, 2002; Romero et al., 2005 e Buenfil, 2007), como também explicam por que novos modelos constitutivos isolam o efeito das variáveis de estado a somente a macroestrutura do solo, como por exemplo, a proposta de Alonso et al. (2013).

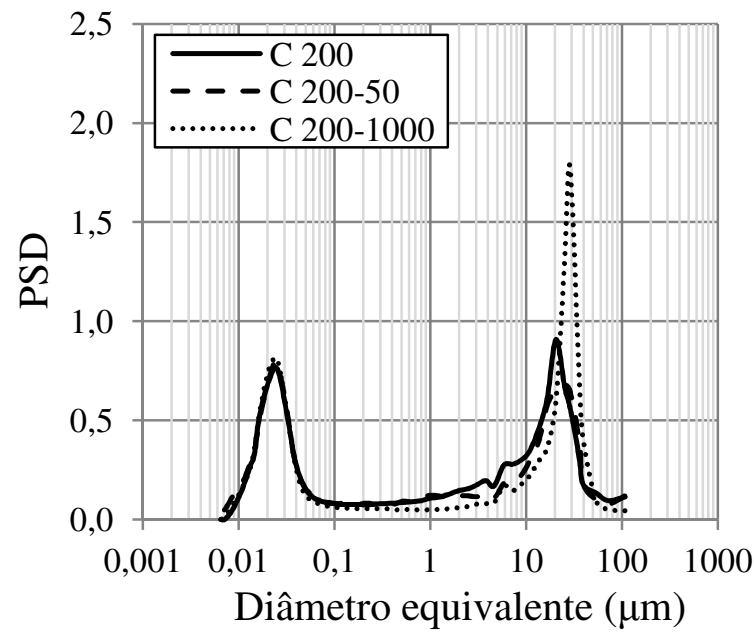

(a)

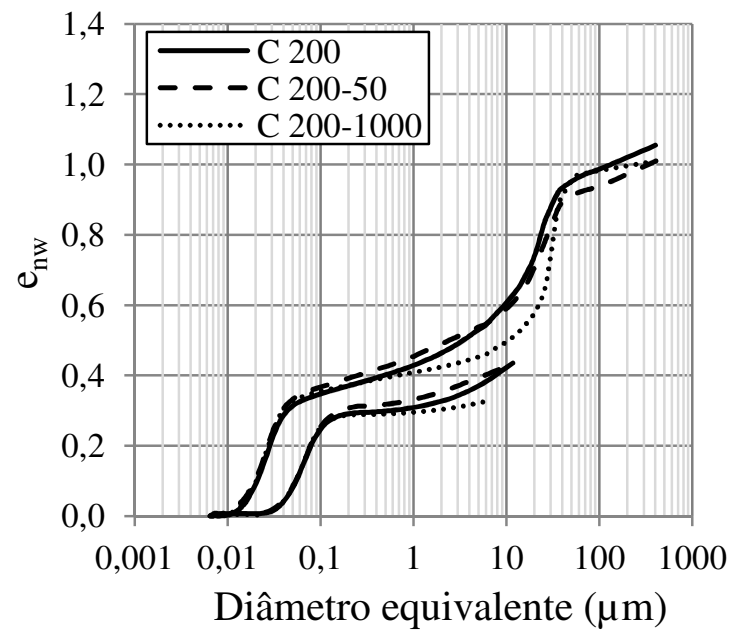

(b)

Figura 4.34 - Argila porosa de Brasília, solo Compactado com tensão vertical de $200 \mathrm{kPa}$ de tensão vertical em diferentes estados, para diferentes sucções: (a) Distribuição do tamanho dos poros; (b) Densidade do tamanho dos poros.

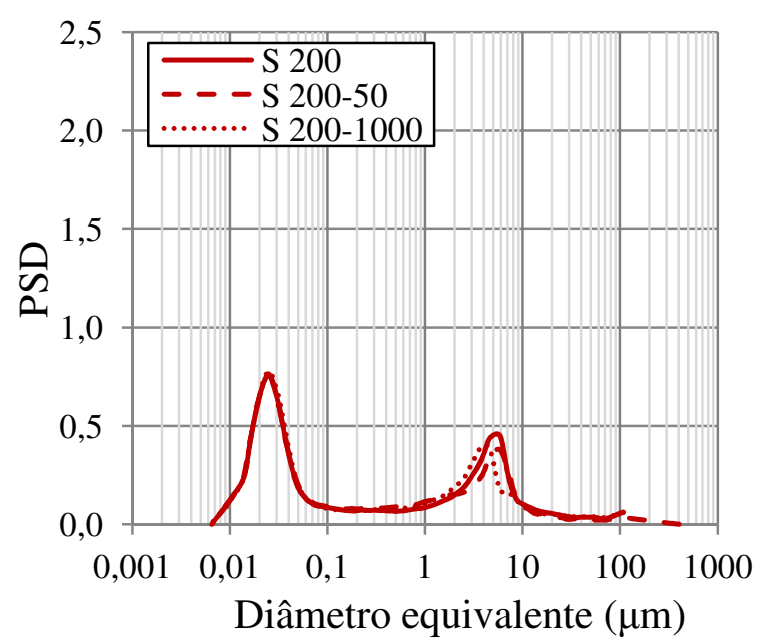

(a)

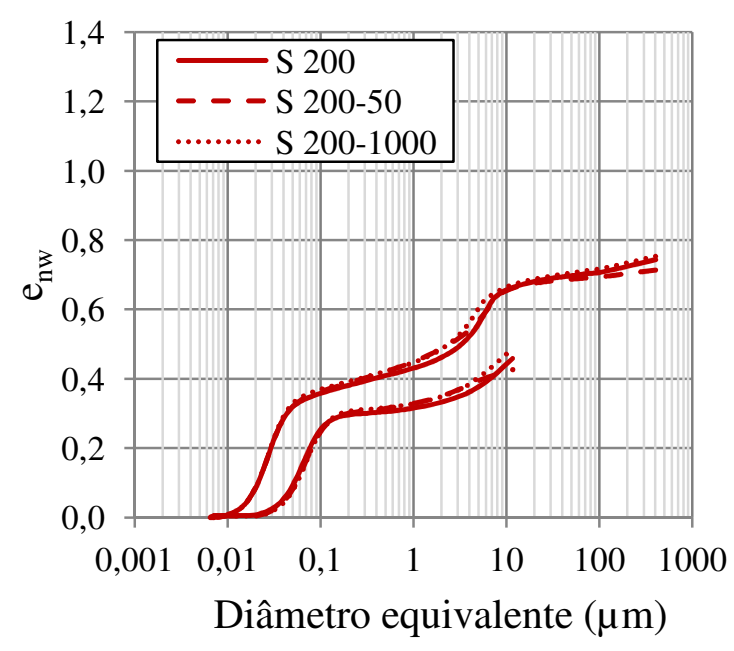

(b)

Figura 4.35 - Argila porosa de Brasília, solo em estado de Lama com tensão vertical de 200 kPa de tensão vertical em diferentes estados, para diferentes sucções: (a) Distribuição do tamanho dos poros; (b) Densidade do tamanho dos poros. 


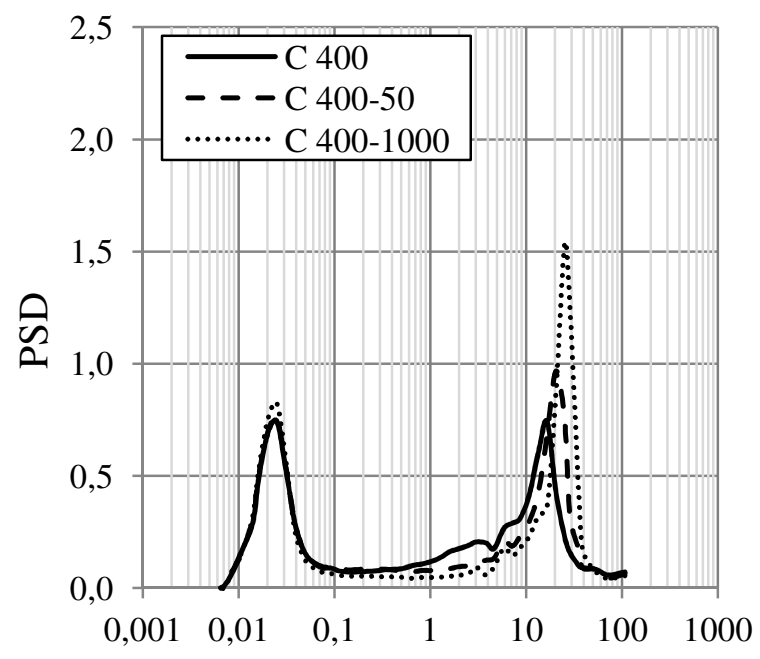

Diâmetro equivalente $(\mu \mathrm{m})$

(a)

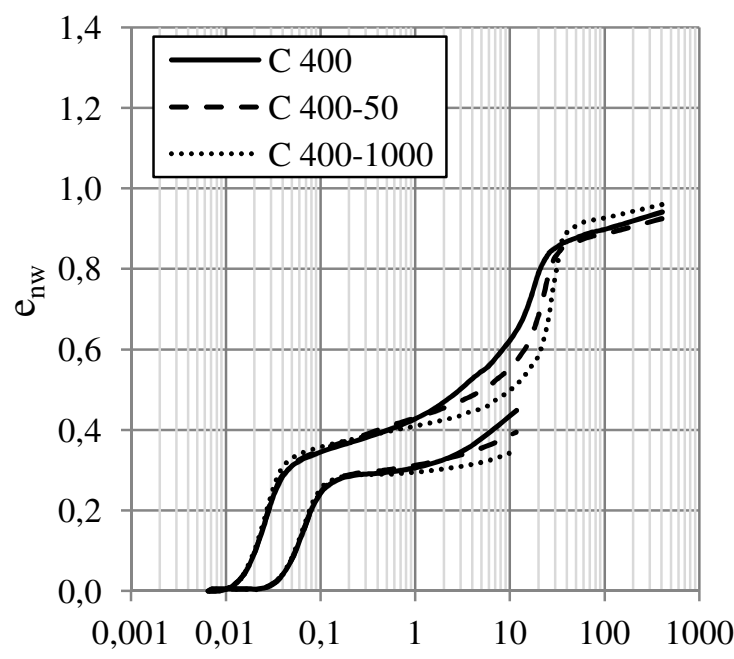

Diâmetro equivalente $(\mu \mathrm{m})$

(b)

Figura 4.36 - Argila porosa de Brasília, solo Compactado com tensão vertical de $400 \mathrm{kPa}$ de tensão vertical em diferentes estados, para diferentes sucções: (a) Distribuição do tamanho dos poros; (b) Densidade do tamanho dos poros.

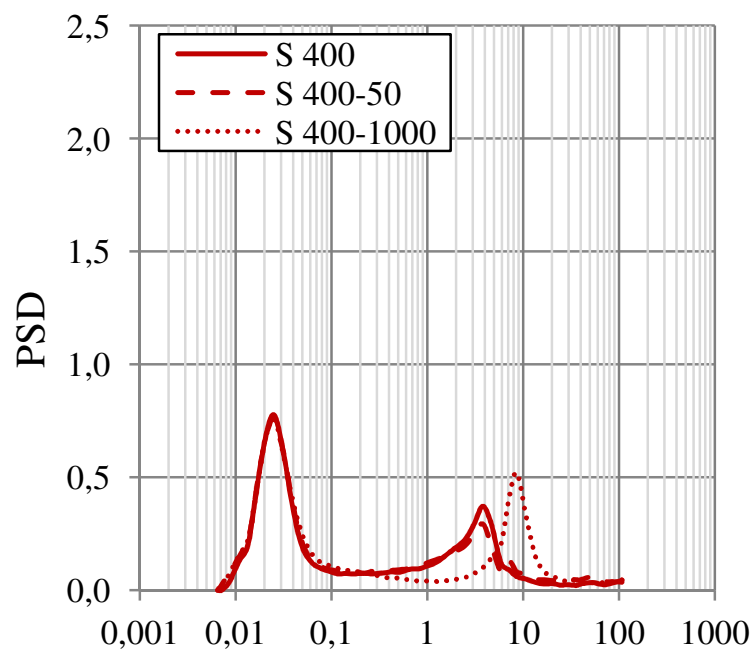

Diâmetro equivalente $(\mu \mathrm{m})$

(a)

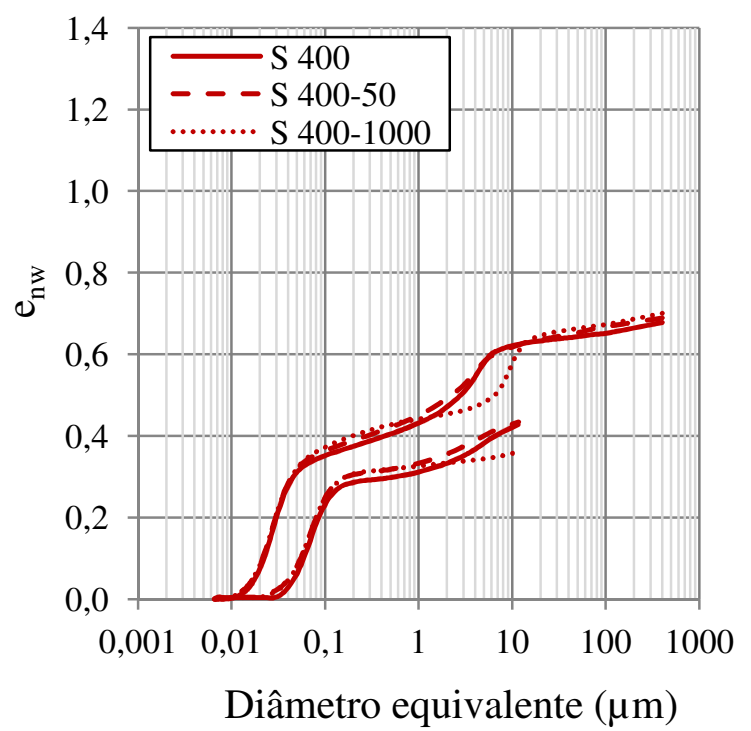

(b)

Figura 4.37 - Argila porosa de Brasília, solo em estado de Lama com tensão vertical de 400 kPa de tensão vertical em diferentes estados, para diferentes sucções: (a) Distribuição do tamanho dos poros; (b) Densidade do tamanho dos poros. 


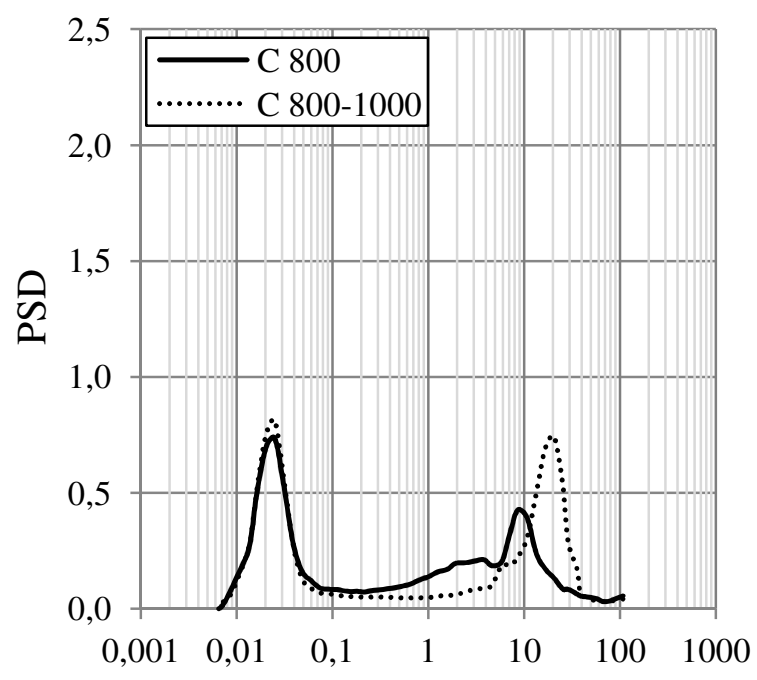

Diâmetro equivalente $(\mu \mathrm{m})$

(a)

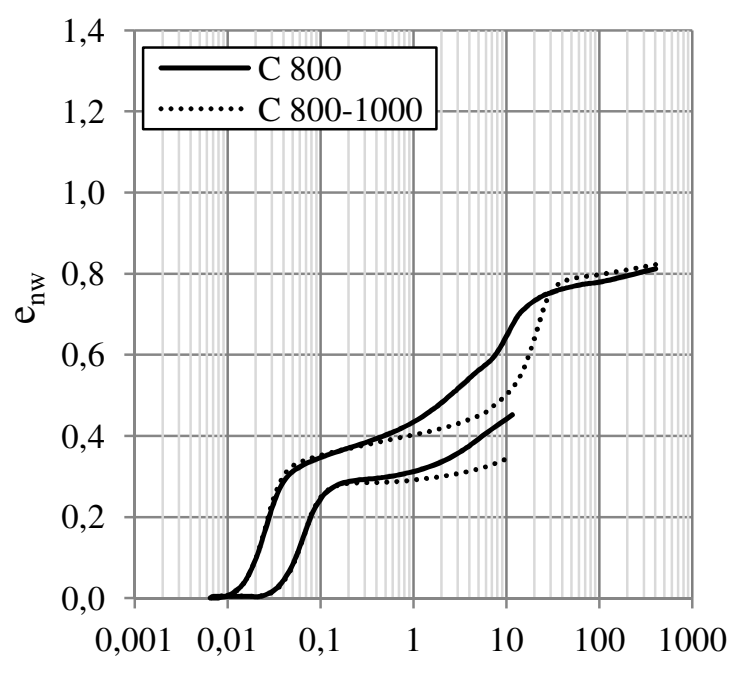

Diâmetro equivalente $(\mu \mathrm{m})$

(b)

Figura 4.38 - Argila porosa de Brasília, solo Compactado com tensão vertical de $800 \mathrm{kPa}$ de tensão vertical em diferentes estados, para diferentes sucções: (a) Distribuição do tamanho dos poros; (b) Densidade do tamanho dos poros.

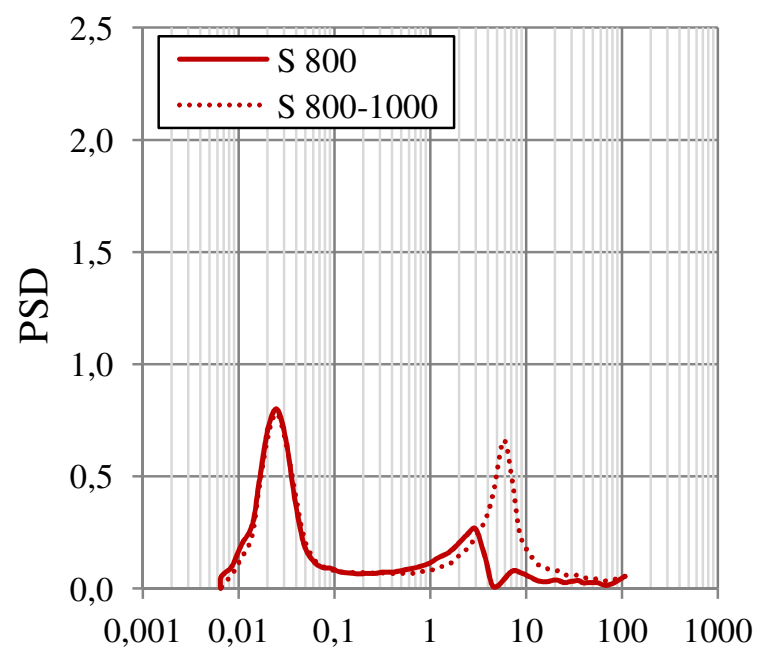

Diâmetro equivalente $(\mu \mathrm{m})$

(a)

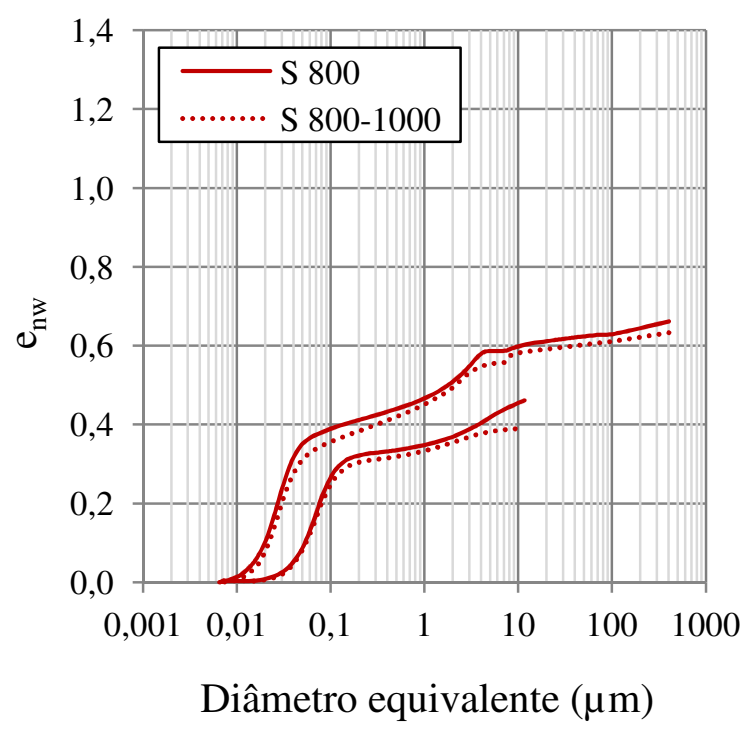

(b)

Figura 4.39 - Argila porosa de Brasília, solo em estado de Lama com tensão vertical de 800 kPa de tensão vertical em diferentes estados, para diferentes sucções: (a) Distribuição do tamanho dos poros; (b) Densidade do tamanho dos poros. 


\section{5 - MODELAGEM E DISCUSSÕES}

Este capítulo apresenta a modelagem e a análise dos resultados apresentados no capítulo anterior, com ênfase nos resultados relacionados à microestrutura e a curva de retenção. $\mathrm{O}$ processo de calibração dos parâmetros para os modelos constitutivos requer que os ensaios sejam analisados conjuntamente, de modo a verificar, por exemplo, a relação entre o comportamento mecânico, hidráulico e microestrutural.

\section{1 - ANÁLISE MICROESTRUTURAL DA CURVA DE RETENÇÃO}

Para a realização da análise microestrutural da curva de retenção, os resultados obtidos pelas técnicas de papel filtro, placa de pressão e WP4 apresentados no Capítulo 4 foram modelados. Estes resultados apresentaram curvas de retenção bimodais, ou seja, possuem dois valores de entrada de ar: um nos microporos e outro nos macroporos. Com as técnicas utilizadas, podem ser medida uma faixa de sucção entre $1 \mathrm{kPa}$ e $50 \mathrm{MPa}$. O efeito da histerese, devido à diferença de trajetórias (secagem e umedecimento), foi considerado pequeno, e para as análises, pode ser desprezados. Esta análise é baseada em resultados apresentados por Otálvaro (2013), nos quais foi observado que as curvas de secagem e umedecimento são muito próximas e têm forma semelhante.

Para a representação matemática dos dados experimentais das curvas de retenção, foi utilizada a proposta de Durner (1994), que é uma versão multimodal da equação de van Genuchten (1990). A equação utilizada tem a seguinte forma:

$w=\frac{w_{M}}{\left[1+\left(a_{M} \cdot s\right)^{n_{M}}\right]^{1-1 / n_{M}}}+\frac{w_{m}}{\left[1+\left(a_{m} \cdot s\right)^{n_{m}}\right]^{1-1 / n_{m}}}$

Onde, os índices $M$ e $m$ são utilizados para diferenciarem a macro e a microestrutura, respectivamente; $a$ e $n$ são parâmetros de ajuste; $w_{M}$ e $w_{m}$ também são parâmetros de ajuste, que são relacionados à umidade que fica retida no macroporo e no microporo; $s$ é a sucção. $\mathrm{O}$ parâmetro $n$ está ligado à distribuição do tamanho dos poros, enquanto $a$ está relacionado ao valor de entrada de ar.

A Tabela 5.1 apresenta os parâmetros de ajuste. São apresentados os valores de ajuste para o solo Natural, Compactado, Lama e os resultados de solo compactado apresentados por Silva 
(2009). De modo geral, a equação permite um bom ajuste da curva de retenção para os diferentes estados (Natural, Lama e Compactado) e diferentes índices de vazios.

Tabela 5.1 - Parâmetros utilizados para ajuste matemático das curvas de retenção do solo.

\begin{tabular}{|c|c|c|c|c|c|c|}
\hline Parâmetros & $\begin{array}{c}\text { Natural } \\
(\mathrm{e}=1,63)\end{array}$ & $\begin{array}{c}\text { Lama } \\
(\mathrm{e}=1,33)\end{array}$ & $\begin{array}{c}\text { Compactada } \\
(\mathrm{e}=1,20)\end{array}$ & $\begin{array}{c}\text { Silva, 2009 } \\
(\mathrm{e}=1,10)\end{array}$ & $\begin{array}{c}\text { Silva, 2009 } \\
(\mathrm{e}=0,92)\end{array}$ & $\begin{array}{c}\text { Silva, 2009 } \\
(\mathrm{e}=0,70)\end{array}$ \\
\hline$w_{M}$ & 39,0 & 28,5 & 27,5 & 25,0 & 18,0 & 14,5 \\
\hline$\alpha_{M}$ & 0,40 & 0,03 & 0,60 & 0,50 & 0,35 & 0,20 \\
\hline$n_{M}$ & 1,8 & 1,7 & 1,8 & 1,6 & 1,5 & 1,5 \\
\hline$m_{M}$ & 0,44 & 0,41 & 0,44 & 0,38 & 0,33 & 0,33 \\
\hline$w_{m}$ & 19 & 19 & 16 & 16 & 16 & 16 \\
\hline$\alpha_{m}$ & 0,0001 & 0,0001 & 0,0002 & 0,0002 & 0,0002 & 0,0002 \\
\hline$n_{m}$ & 2,5 & 2,8 & 2,1 & 2,1 & 2,1 & 2,1 \\
\hline$m_{m}$ & 0,60 & 0,64 & 0,52 & 0,52 & 0,52 & 0,52 \\
\hline $\mathrm{R}^{2}$ & 0,982 & 0,993 & 0,973 & 0,994 & 0,977 & 0,987 \\
\hline
\end{tabular}

Na Figura 5.1 estão apresentados os resultados de curvas de retenção do solo Compactado, obtidos por Silva (2009), e os resultados do solo Compactado obtidos nesta pesquisa. Existe uma variação nos valores de entrada de ar, correspondente aos macroporos. Foi observado que, mesmo que o solo possua índice de vazios diferentes, devido a processo de compactação ou carregamento, não ocorre variação na microestrutura, como pode ser constatado visualmente na figura e pelos valores relacionados à microestrutura apresentados na Tabela 5.1. É possível observar também que a variação do índice de vazios produz um aumento do valor de entrada de ar dos macroporos que se reflete na redução do parâmetro $\mathrm{a}_{\mathrm{M}}$.

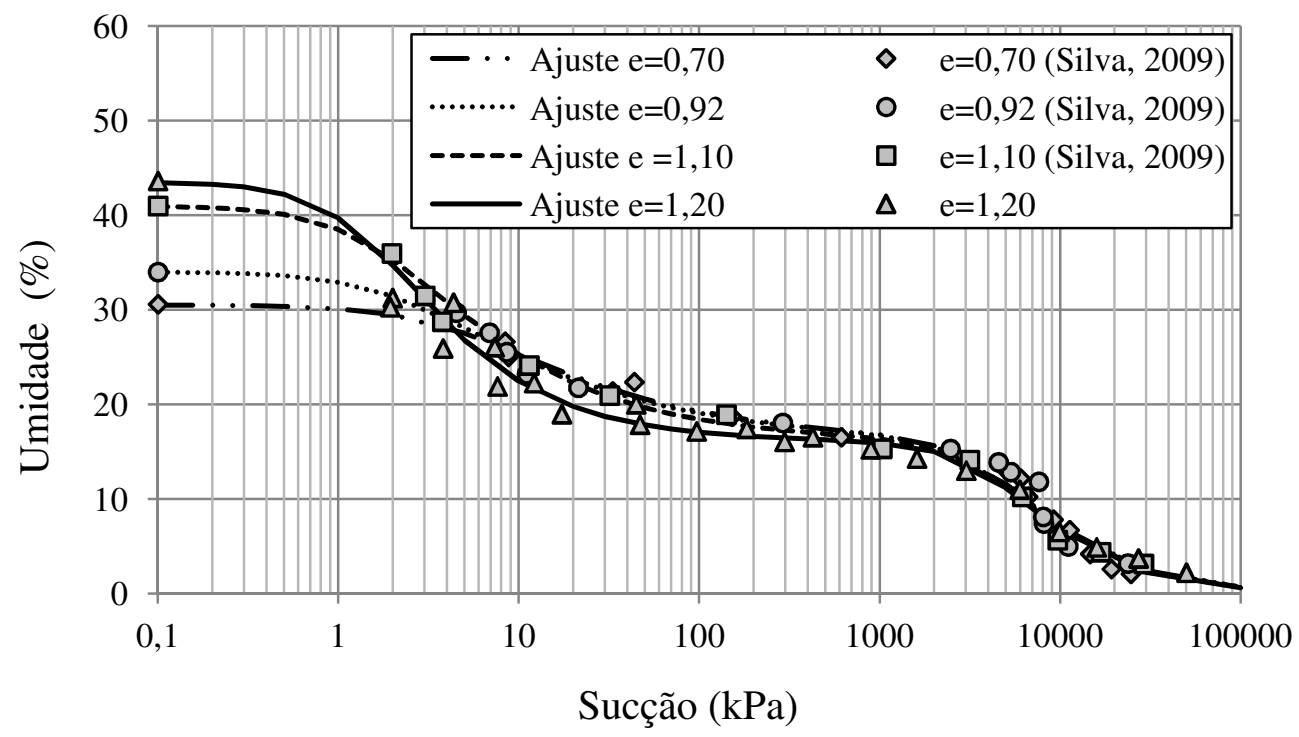

Figura 5.1 - Curva de retenção do solo do compactado de Brasília. 
Na Figura 5.2 são apresentadas as curvas de retenção do solo obtidas para as amostras Compactada, da Lama e Natural. Observe que há mudanças significativas nas curvas devido a diferentes estruturas existentes. As curvas de retenção das amostras Compactada e Natural possuem formas semelhantes. Os valores de entrada de ar dos micro e macroporos são iguais, porém, as curvas encontram-se transladadas.

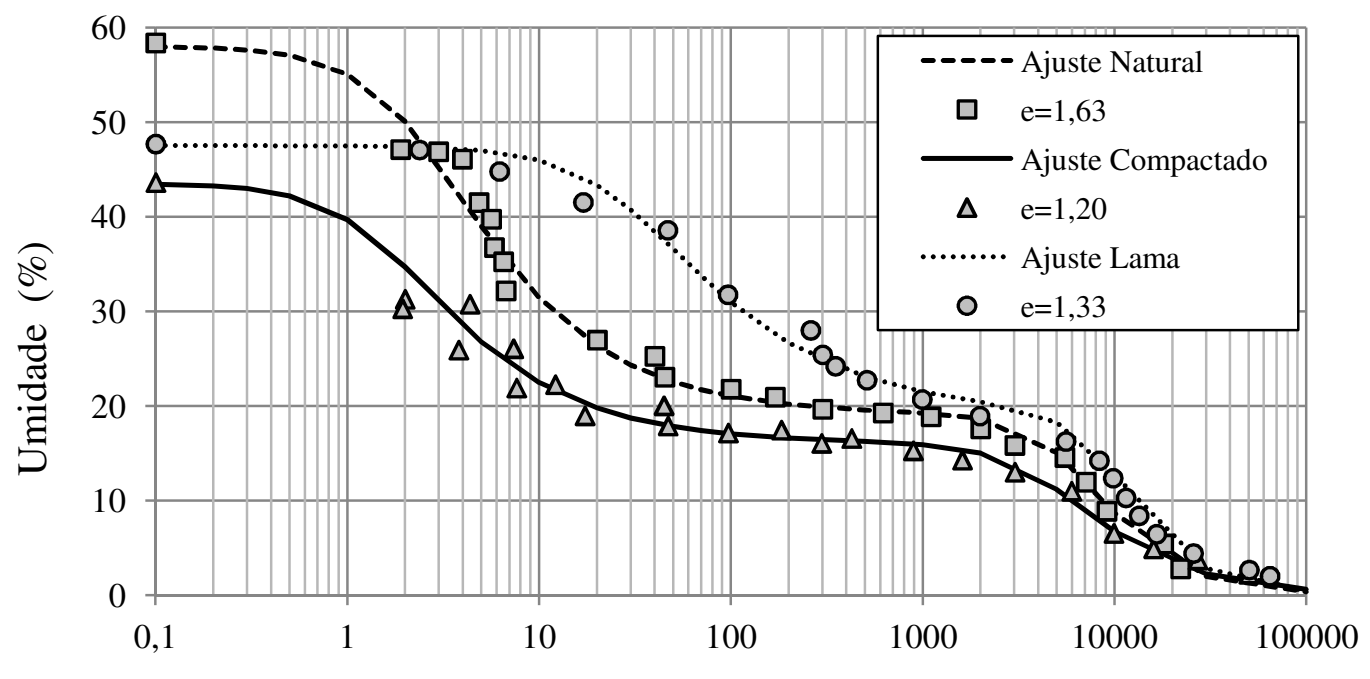

Sucção $(\mathrm{kPa})$

Figura 5.2 - Curva de retenção do solo de Brasília no estado Natural, Compactado e Lama.

A inclinação da curva retenção do solo, relacionada ao parâmetro $n$, está associada à distribuição do tamanho dos poros. Curvas mais inclinadas indicam distribuições de poros relativamente uniformes. Neste caso, as amostras Compactadas e Naturais teriam uma distribuição mais uniforme que a Lama. Porém, isso não se reflete no valor do parâmetro $n_{M}$ apresentado na Tabela 5.1.

Comparado o valor de entrada de ar nos macroporos obtidos para as diferentes amostras (Figura 5.2), observe que a amostra Compactada tem o menor valor $(1,0 \mathrm{kPa})$, seguido da amostra Natural $(1,5 \mathrm{kPa})$ e da Lama $(20,0 \mathrm{kPa})$. O fato de a amostra Natural ficar numa posição intermediária entre a lama e o solo compactado pode ser explicado pela existência de agregações que permitem ao solo ter uma estrutura mais aberta do que o solo compactado.

Segundo Marinho (2005), o formato S da curva de retenção de água do solo é o reflexo da distribuição do tamanho dos poros do material. Assim, um material poroso rígido, com uma distribuição do tamanho dos poros uniforme, apresentará uma transição abrupta entre a saturação e o teor de umidade residual (Figura 5.3), enquanto o material com diferentes tamanhos de poros apresentará uma transição gradual entre o estado saturado e o teor de umidade residual. 


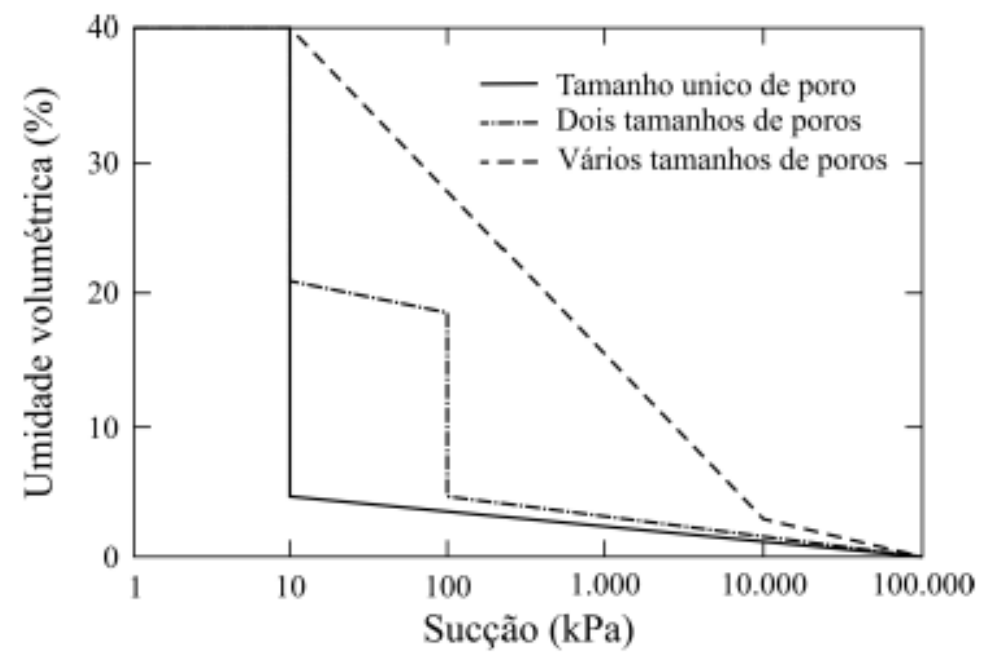

Figura 5.3 - Forma da curva de retenção de água do solo, segundo a distribuição do tamanho dos poros (Marinho, 2005).

Pode-se concluir que a amostra Compactada e a Natural devem ter curvas de distribuição do tamanho dos poros semelhantes, enquanto a Lama deve possuir uma distribuição levemente diferente (Figura 5.2). Além disso, o processo de carregamento tende a distribuir os poros de maneira menos uniforme. Esses resultados estão de acordo com o que foi observado nos resultados de porosimetria, apresentados no capitulo anterior, e com a modelagem que será apresentada no próximo item.

\section{2 - MODELAGEM DA DISTRIBUIÇÃO DO TAMANHO DOS POROS}

Devido à dificuldade de analisar apenas visualmente (ou qualitativamente) os efeitos de carregamentos na distribuição do tamanho dos poros, foi realizada uma modelagem dos resultados experimentais. A partir dos parâmetros obtidos foi possível realizar uma análise detalhada do que ocorre com a distribuição do tamanho dos poros. As curvas acumuladas de tamanho dos poros foram ajustadas utilizando a equação proposta por Durner (1994), que é uma modificação da equação de van Genutchen (1980), que permite separar e capturar os componentes micro e macro da estrutura do solo. Essa equação é a mesma utilizada na modelagem da curva de retenção, e, conforme será observado nos resultados permite analisar de maneira adequada aspectos da macro e da microestrutura. Para esse caso a equação do índice de vazios intrudido por mercúrio ajustado $\left(e_{n w}^{*}\right)$ pode ser apresentada como: 
$e_{n w}^{*}=e_{m}\left[\frac{1}{1+\left(\alpha_{m} \cdot D\right)^{n_{m}}}\right]^{\left(1-\frac{1}{n_{m}}\right)}+e_{M}\left[\frac{1}{1+\left(\alpha_{M} \cdot D\right)^{n_{M}}}\right]^{\left(1-\frac{1}{n_{M}}\right)}$

Onde, o subscrito $m$ está associado a microporos, e $M$ aos macroporos. O parâmetro $e_{n w}^{*}$ é o índice de vazios intrudido por mercúrio ajustado; $e_{m}$ e $e_{M}$ são os índices de vazios, $\alpha_{m}$ e $\alpha_{M}$ são a relação com tamanho de poro dominante; e $n_{m}$ e $n_{M}$ são os parâmetros de ajuste associados com a uniformidade do tamanho dos poros.

O ajuste foi realizado em duas etapas. Na primeira, os seis parâmetros da equação (5.2) foram calculados de modo a minimizar o erro e melhorar o ajuste das curvas. Numa segunda etapa os parâmetros de ajuste relacionados com os macroporos $\left(e_{M}, \alpha_{M}\right.$, e $\left.n_{M}\right)$ foram ajustados, enquanto os parâmetros associados aos microporos $\left(e_{m}, \alpha_{m}\right.$, e $\left.n_{m}\right)$ foram mantidos constantes e iguais à média dos valores encontrados no ajuste anterior.

Os resultados para o solo Natural na condição saturada com diferentes carregamentos são apresentados na Tabela 5.2. Os dados apresentados são denominados de ajuste completo, ou seja, todos os parâmetros foram modificados de modo a minimizar o erro. Como pode ser observado na Tabela 5.2, o coeficiente $\mathrm{R}^{2}$ é maior que $98 \%$ para todas as amostras, o que significa que o processo de modelagem foi capaz de capturar as principais características dos dados. Na Figura 5.4 está apresentado o pior e o melhor resultado de ajuste. Mesmo no pior resultado, as principais características da curva podem ser capturadas pelo ajuste.

Tabela 5.2 - Parâmetros de ajuste completos da densidade dos poros para o solo Natural.

\begin{tabular}{cccccccc}
\hline \multirow{2}{*}{ Amostras } & \multicolumn{3}{c}{ Parâmetros da Micro } & \multicolumn{3}{c}{ Parâmetros da Macro } & $\mathrm{R}^{2}$ \\
\cline { 2 - 7 } & $e_{m}$ & $\alpha_{m}$ & $n_{m}$ & $e_{M}$ & $\alpha_{M}$ & $n_{M}$ & - \\
\hline $\mathrm{N}$ & 0,42 & 0,034 & 3,29 & 1,07 & 61,64 & 2,16 & 0,987 \\
$\mathrm{~N}-50$ & 0,31 & 0,026 & 5,18 & 0,95 & 51,11 & 1,66 & 0,989 \\
$\mathrm{~N}-100$ & 0,30 & 0,026 & 5,82 & 0,75 & 26,67 & 1,54 & 0,997 \\
$\mathrm{~N}-200$ & 0,30 & 0,026 & 5,44 & 0,76 & 21,36 & 1,62 & 0,996 \\
$\mathrm{~N}-400$ & 0,27 & 0,026 & 6,27 & 0,67 & 16,31 & 1,48 & 0,996 \\
N-800 & 0,25 & 0,026 & 6,62 & 0,56 & 12,99 & 1,40 & 0,985 \\
\hline
\end{tabular}




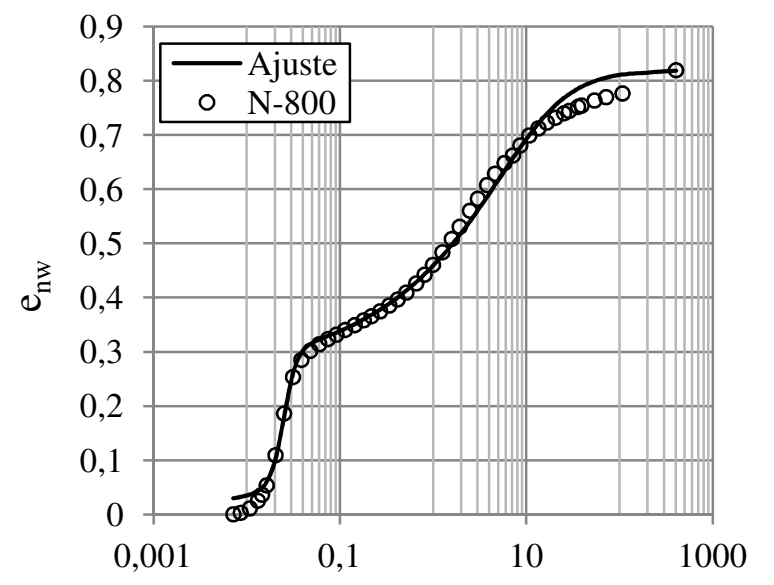

Diâmetro aparente dos poros $(\mu \mathrm{m})$

(a)

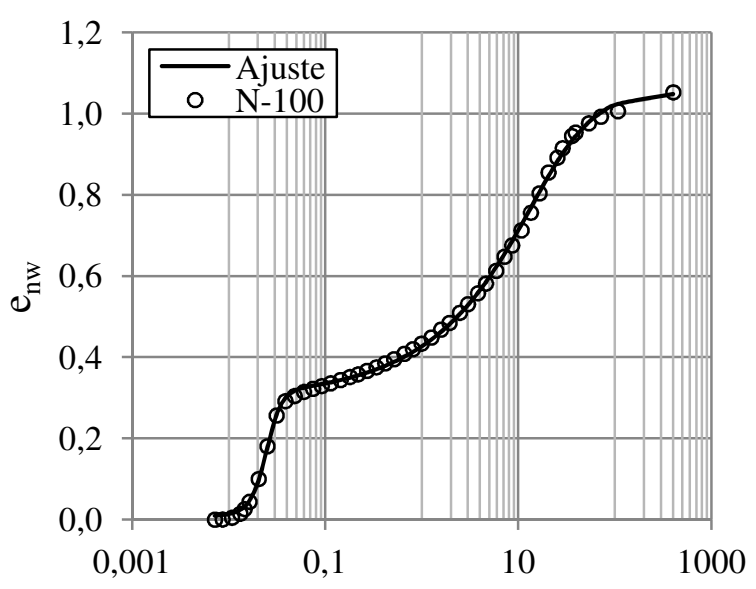

Diâmetro aparente dos poros $(\mu \mathrm{m})$

(b)

Figura 5.4 - Ajuste completo das curvas para o solo saturado: (a) Natural, com carregamento de $800 \mathrm{kPa}\left(\mathrm{R}^{2}=0,985\right)$; (b) Natural, com carregamento de $100 \mathrm{kPa}\left(\mathrm{R}^{2}=0,997\right)$.

Da mesma forma que para a amostra Natural, o ajuste completo foi realizado para o solo Compactado, na condição saturada e não saturada com sucção de $50 \mathrm{kPa}$ e $1000 \mathrm{kPa}$. Os dados obtidos são denominados de ajuste completo e são apresentados na Tabela 5.3. Do mesmo modo que no caso anterior, coeficiente $\mathrm{R}^{2}$ demonstra que a equação é capaz de captura as principais características do ensaio. Para uma melhor visualização desses ajustes, a Figura 5.5 apresenta os resultados com o melhor e o pior ajuste do solo Compactado.

Tabela 5.3 - Parâmetros de ajuste completos da densidade dos poros para o solo Compactado.

\begin{tabular}{cccccccc}
\hline \multirow{2}{*}{ Amostras } & \multicolumn{3}{c}{ Parâmetros da Micro } & \multicolumn{3}{c}{ Parâmetros da Macro } & $\mathrm{R}^{2}$ \\
\cline { 2 - 7 } & $e_{m}$ & $\alpha_{m}$ & $n_{m}$ & $e_{M}$ & $\alpha_{M}$ & - \\
\hline C & 0,43 & 0,038 & 2,94 & 0,43 & 33,79 & 2,52 & 0,989 \\
C-50 & 0,40 & 0,033 & 3,56 & 0,59 & 36,86 & 2,18 & 0,981 \\
C-100 & 0,33 & 0,032 & 4,04 & 0,68 & 35,18 & 1,81 & 0,976 \\
C-200 & 0,36 & 0,029 & 3,95 & 0,57 & 24,30 & 1,75 & 0,998 \\
C-400 & 0,34 & 0,030 & 4,11 & 0,60 & 24,35 & 1,65 & 0,987 \\
C-800 & 0,36 & 0,029 & 4,49 & 0,57 & 20,57 & 1,53 & 0,998 \\
\hline C-50-50 & 0,42 & 0,036 & 3,17 & 0,59 & 30,71 & 2,18 & 0,991 \\
C-100-50 & 0,40 & 0,035 & 3,34 & 0,57 & 30,18 & 2,38 & 0,992 \\
C-200-50 & 0,38 & 0,032 & 3,61 & 0,63 & 41,88 & 1,65 & 0,995 \\
C-400-50 & 0,38 & 0,034 & 3,50 & 0,54 & 27,67 & 1,93 & 0,993 \\
\hline C-50-1000 & 0,40 & 0,035 & 3,37 & 0,70 & 40,12 & 2,84 & 0,990 \\
C-100-1000 & 0,41 & 0,037 & 3,18 & 0,64 & 34,65 & 3,01 & 0,989 \\
C-200-1000 & 0,40 & 0,034 & 3,48 & 0,61 & 32,29 & 2,82 & 0,990 \\
C-400-1000 & 0,40 & 0,032 & 3,62 & 0,56 & 29,71 & 2,66 & 0,991 \\
C-800-1000 & 0,38 & 0,031 & 3,87 & 0,44 & 23,22 & 2,28 & 0,995 \\
\hline
\end{tabular}




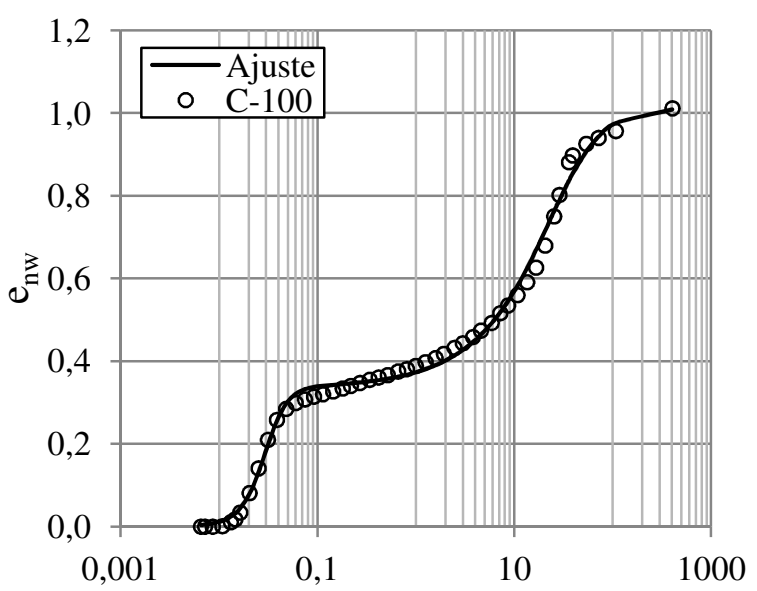

Diâmetro aparente dos poros $(\mu \mathrm{m})$

(a)

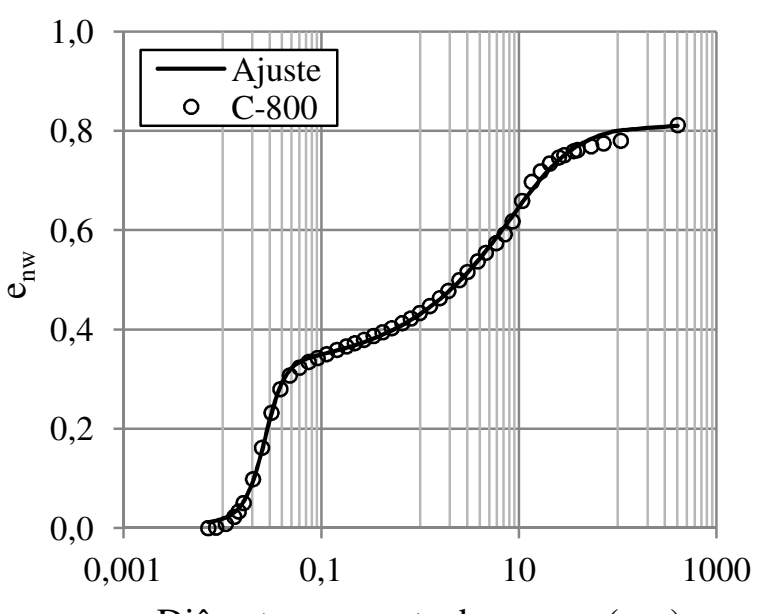

Diâmetro aparente dos poros $(\mu \mathrm{m})$

(b)

Figura 5.5 - Ajuste completo das curvas do solo Compactado: (a) Saturado, com carregamento de $100 \mathrm{kPa}\left(\mathrm{R}^{2}=0,976\right)$; (b) Saturado, com carregamento de $800 \mathrm{kPa}\left(\mathrm{R}^{2}=\right.$ 0,998).

Do mesmo modo que para os outros dois casos, a Tabela 5.4 apresenta o ajuste completo da Lama na condição saturada e não saturada, com sucções de $50 \mathrm{kPa}$ e $1.000 \mathrm{kPa}$. Todos os comentários anteriores, sobre a capacidade de a equação utilizada ser capaz de capturar as principais características dos dados, são verdadeiros, e na Figura 5.6 são apresentados os ajustes para o pior e melhor caso.

Tabela 5.4 - Parâmetros de ajuste completos da densidade dos poros para a Lama.

\begin{tabular}{cccccccc}
\hline \multirow{2}{*}{ Amostras } & \multicolumn{3}{c}{ Parâmetros da Micro } & \multicolumn{3}{c}{ Parâmetros da Macro } & $\mathrm{R}^{2}$ \\
\cline { 2 - 7 } & $\mathrm{e}_{\mathrm{m}}$ & $\alpha_{\mathrm{m}}$ & $\mathrm{n}_{\mathrm{m}}$ & $\mathrm{e}_{\mathrm{M}}$ & $\alpha_{\mathrm{M}}$ & $\mathrm{n}_{\mathrm{M}}$ & - \\
\hline $\mathrm{S}$ & 0,37 & 0,034 & 3,90 & 0,60 & 20,55 & 2,15 & 0,995 \\
$\mathrm{~S}-50$ & 0,37 & 0,030 & 4,19 & 0,50 & 24,88 & 1,60 & 0,996 \\
$\mathrm{~S}-100$ & 0,37 & 0,030 & 4,19 & 0,45 & 27,05 & 1,55 & 0,997 \\
$\mathrm{~S}-200$ & 0,34 & 0,031 & 4,36 & 0,41 & 12,94 & 1,56 & 0,990 \\
$\mathrm{~S}-400$ & 0,32 & 0,031 & 4,77 & 0,36 & 8,413 & 1,53 & 0,998 \\
$\mathrm{~S}-800$ & 0,35 & 0,030 & 4,50 & 0,31 & 10,56 & 1,40 & 0,996 \\
\hline $\mathrm{S}-50-50$ & 0,35 & 0,033 & 4,10 & 0,39 & 18,37 & 1,48 & 0,997 \\
$\mathrm{~S}-100-50$ & 0,34 & 0,031 & 4,35 & 0,38 & 12,45 & 1,51 & 0,999 \\
$\mathrm{~S}-200-50$ & 0,34 & 0,031 & 4,23 & 0,37 & 9,45 & 1,56 & 0,998 \\
$\mathrm{~S}-400-50$ & 0,32 & 0,031 & 4,67 & 0,37 & 10,95 & 1,43 & 0,997 \\
\hline $\mathrm{S}-50-1000$ & 0,37 & 0,032 & 4,09 & 0,45 & 12,18 & 1,75 & 0,996 \\
$\mathrm{~S}-100-1000$ & 0,33 & 0,031 & 4,47 & 0,46 & 12,27 & 1,61 & 0,999 \\
S-200-1000 & 0,33 & 0,031 & 4,68 & 0,42 & 12,75 & 1,48 & 0,996 \\
$\mathrm{~S}-400-1000$ & 0,39 & 0,035 & 3,56 & 0,31 & 17,99 & 1,74 & 0,995 \\
$\mathrm{~S}-800-1000$ & 0,31 & 0,032 & 4,65 & 0,32 & 7,85 & 1,42 & 0,996 \\
\hline
\end{tabular}




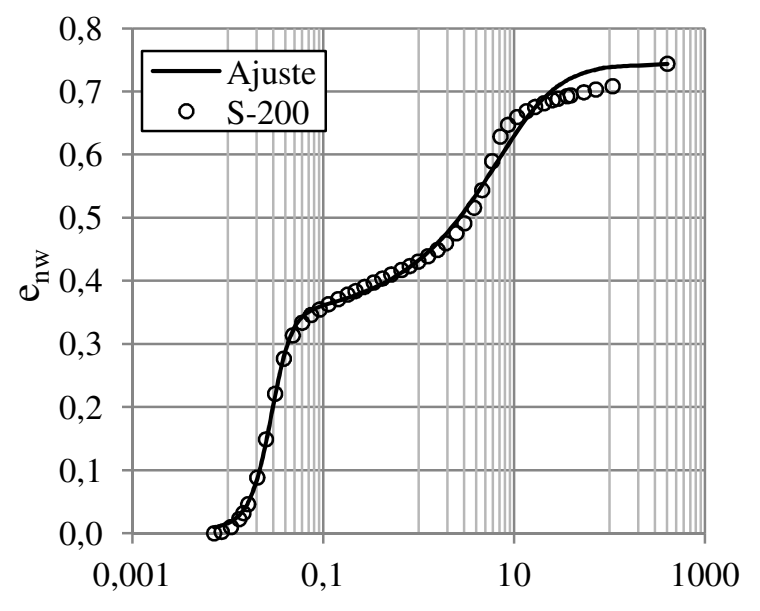

Diâmetro de poros aparente $(\mu \mathrm{m})$

(a)

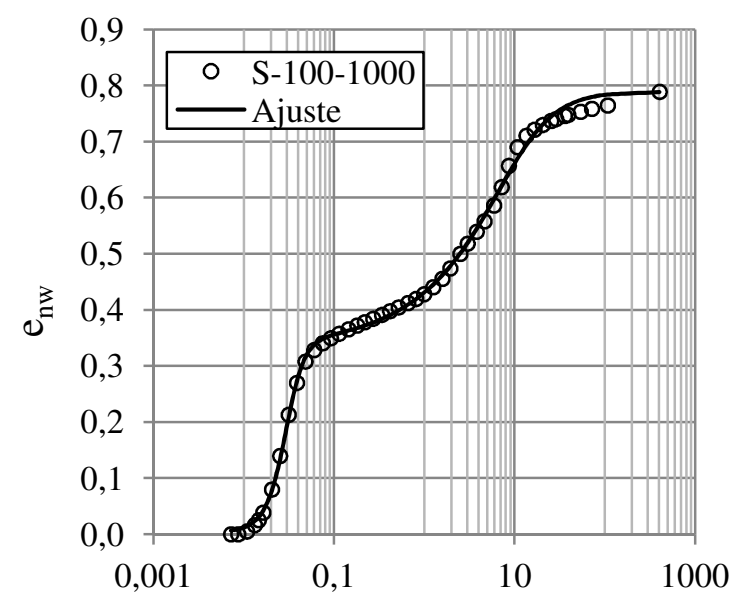

Diâmetro de poros aparente $(\mu \mathrm{m})$

(b)

Figura 5.6 - Ajuste completo das curvas para a Lama: (a) Saturado, com carregamento de 100 $\mathrm{kPa}(\mathrm{R} 2=0,990)$; (b) Sucção de $1.000 \mathrm{kPa}$, com carregamento de $100 \mathrm{kPa}(\mathrm{R} 2=0,999)$.

Conforme descrito no início do capítulo, na etapa seguinte de modelagem os parâmetros de ajuste relacionados com os microporos $\left(e_{m}, \alpha_{m}\right.$, e $\left.n_{m}\right)$ foram mantidos constantes e iguais para todas as amostras. Para determinar o valor dos parâmetros dos microporos fixados, foi realizada a média dos valores encontrados no ajuste do completo. Com os parâmetros da microestrutura fixados, os parâmetros relacionados aos macroporos $\left(e_{M}, \alpha_{M}\right.$, e $\left.n_{M}\right)$ foram ajustados.

As Tabelas 5.5, 5.6 e 5.7 apresentam os parâmetros de ajuste da macroestrutura para as amostras Natural, Compactada e Lama. Além disso, é possível observar que, em todos os casos os parâmetros da microestrutura são os mesmos. Em todos os casos o coeficiente $\mathrm{R}^{2}$ é maior que $97 \%$, o que significa que, mesmo fixando os parâmetros dos microporos, o processo de modelagem foi capaz de capturar as principais características dos dados.

Tabela 5.5 - Parâmetros de ajuste da macro da densidade dos poros do solo Natural.

\begin{tabular}{cccccccc}
\hline \multirow{2}{*}{ Amostras } & \multicolumn{3}{c}{ Parâmetros da Micro } & \multicolumn{3}{c}{ Parâmetros da Macro } & $\mathrm{R}^{2}$ \\
\cline { 2 - 8 } & $e_{m}$ & $\alpha_{m}$ & $n_{m}$ & $e_{M}$ & $\alpha_{M}$ & $n_{M}$ & - \\
\hline N & 0,34 & 0,029 & 4,65 & 1,11 & 87,02 & 1,67 & 0,978 \\
N-50 & 0,34 & 0,029 & 4,65 & 0,92 & 46,97 & 1,77 & 0,996 \\
N-100 & 0,34 & 0,029 & 4,65 & 0,71 & 24,51 & 1,65 & 0,998 \\
N-200 & 0,34 & 0,029 & 4,65 & 0,72 & 19,78 & 1,75 & 0,998 \\
N-400 & 0,34 & 0,029 & 4,65 & 0,60 & 14,34 & 1,65 & 0,997 \\
N-800 & 0,34 & 0,029 & 4,65 & 0,48 & 12,05 & 1,56 & 0,999 \\
\hline
\end{tabular}


Tabela 5.6 - Parâmetros de ajuste da macro da densidade dos poros do solo Compactado.

\begin{tabular}{cccccccc}
\hline \multirow{2}{*}{ Amostras } & \multicolumn{3}{c}{ Parâmetros da Micro } & \multicolumn{3}{c}{ Parâmetros da Macro } & $\mathrm{R}^{2}$ \\
\cline { 2 - 7 } & $e_{m}$ & $\alpha_{m}$ & $n_{m}$ & $e_{M}$ & $\alpha_{M}$ & $n_{M}$ & - \\
\hline C & 0,34 & 0,029 & 4,65 & 0,71 & 50,52 & 1,61 & 0,975 \\
C-50 & 0,34 & 0,029 & 4,65 & 0,65 & 50,52 & 1,65 & 0,987 \\
C-100 & 0,34 & 0,029 & 4,65 & 0,67 & 34,62 & 1,84 & 0,995 \\
C-200 & 0,34 & 0,029 & 4,65 & 0,59 & 27,33 & 1,61 & 0,997 \\
C-400 & 0,34 & 0,029 & 4,65 & 0,60 & 24,63 & 1,64 & 0,997 \\
C-800 & 0,34 & 0,029 & 4,65 & 0,47 & 16,30 & 1,59 & 0,998 \\
\hline C-50-50 & 0,34 & 0,029 & 4,65 & 0,67 & 44,16 & 1,58 & 0,983 \\
C-100-50 & 0,34 & 0,029 & 4,65 & 0,64 & 39,58 & 1,71 & 0,984 \\
C-200-50 & 0,34 & 0,029 & 4,65 & 0,67 & 50,61 & 1,49 & 0,994 \\
C-400-50 & 0,34 & 0,029 & 4,65 & 0,59 & 33,03 & 1,64 & 0,991 \\
\hline C-50-1000 & 0,34 & 0,029 & 4,65 & 0,77 & 48,26 & 2,01 & 0,980 \\
C-100-1000 & 0,34 & 0,029 & 4,65 & 0,71 & 45,42 & 1,86 & 0,975 \\
C-200-1000 & 0,34 & 0,029 & 4,65 & 0,67 & 39,48 & 1,92 & 0,980 \\
C-400-1000 & 0,34 & 0,029 & 4,65 & 0,62 & 36,92 & 1,85 & 0,982 \\
C-800-1000 & 0,34 & 0,029 & 4,65 & 0,48 & 27,80 & 1,78 & 0,991 \\
\hline
\end{tabular}

Tabela 5.7 - Parâmetros de ajuste da macro da densidade dos poros do solo Lama.

\begin{tabular}{cccccccc}
\hline \multirow{2}{*}{ Amostras } & \multicolumn{3}{c}{ Parâmetros da Micro } & \multicolumn{3}{c}{ Parâmetros da Macro } & $\mathrm{R}^{2}$ \\
\cline { 2 - 7 } & $e_{m}$ & $\alpha_{m}$ & $n_{m}$ & $e_{M}$ & $\alpha_{M}$ & $n_{M}$ & - \\
\hline S & 0,34 & 0,029 & 4,65 & 0,63 & 22,18 & 1,92 & 0,992 \\
S-50 & 0,34 & 0,029 & 4,65 & 0,60 & 34,82 & 1,34 & 0,996 \\
S-100 & 0,34 & 0,029 & 4,65 & 0,54 & 36,92 & 1,32 & 0,998 \\
S-200 & 0,34 & 0,029 & 4,65 & 0,47 & 14,59 & 1,40 & 0,996 \\
S-400 & 0,34 & 0,029 & 4,65 & 0,41 & 8,299 & 1,43 & 0,996 \\
S-800 & 0,34 & 0,029 & 4,65 & 0,39 & 8,056 & 1,33 & 0,996 \\
\hline S-50-50 & 0,34 & 0,029 & 4,65 & 0,40 & 17,72 & 1,47 & 0,996 \\
S-100-50 & 0,34 & 0,029 & 4,65 & 0,38 & 12,03 & 1,52 & 0,998 \\
S-200-50 & 0,34 & 0,029 & 4,65 & 0,37 & 9,18 & 1,57 & 0,998 \\
S-400-50 & 0,34 & 0,029 & 4,65 & 0,35 & 9,85 & 1,51 & 0,996 \\
\hline S-50-1000 & 0,34 & 0,029 & 4,65 & 0,47 & 13,46 & 1,60 & 0,996 \\
S-100-1000 & 0,34 & 0,029 & 4,65 & 0,45 & 11,75 & 1,65 & 0,998 \\
S-200-1000 & 0,34 & 0,029 & 4,65 & 0,41 & 11,83 & 1,53 & 0,996 \\
S-400-1000 & 0,34 & 0,029 & 4,65 & 0,36 & 22,63 & 1,45 & 0,992 \\
S-800-1000 & 0,34 & 0,029 & 4,65 & 0,29 & 6,70 & 1,54 & 0,995 \\
\hline
\end{tabular}

Nas Figuras 5.7, 5.8 e 5.9 são apresentados exemplos de ajustes em que os parâmetros da microestrutura permanecem constantes, sendo possível observar que para todos os casos há uma boa concordância entre o modelo e os dados. 
Tudo isso confirma as análises realizadas no Capítulo 4, em que foi observado que nenhum dos processos de obtenção das amostras (carregamentos, ciclos de umedecimento e secagem, compactação e obtenção da lama) foi capaz de afetar de maneira significativa os microporos.

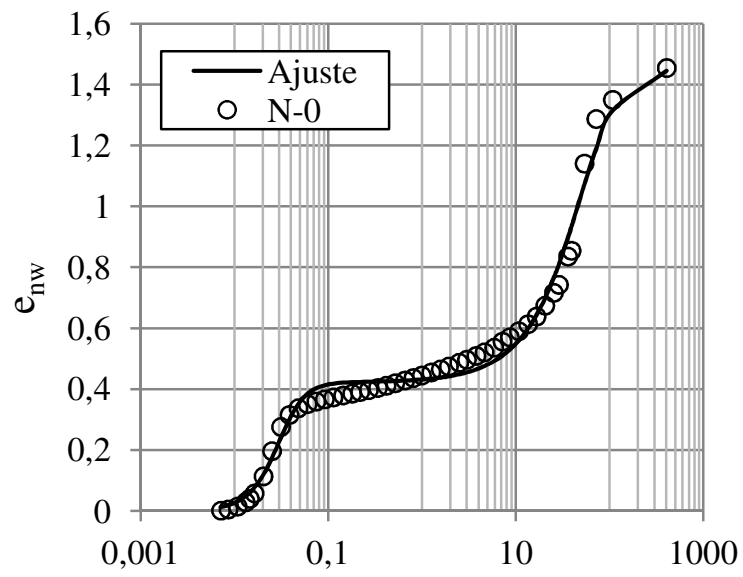

Diâmetro aparente dos poros $(\mu \mathrm{m})$ (a)

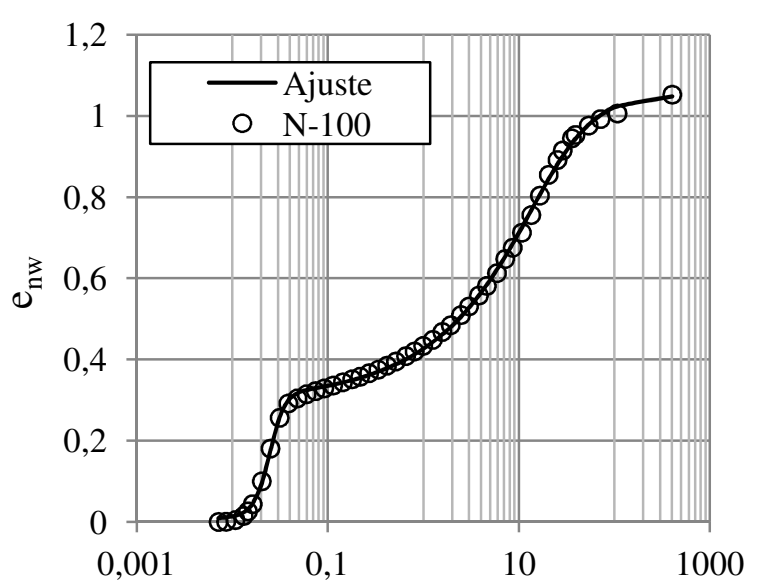

Diâmetro aparente dos poros $(\mu \mathrm{m})$ (b)

Figura 5.7 - Ajuste da macro das curvas para o solo Compactado: (a) saturado, sem carregamento $\left(\mathrm{R}^{2}=0,978\right)$; (b) saturado, com carregamento de $800 \mathrm{kPa}\left(\mathrm{R}^{2}=0,999\right)$.

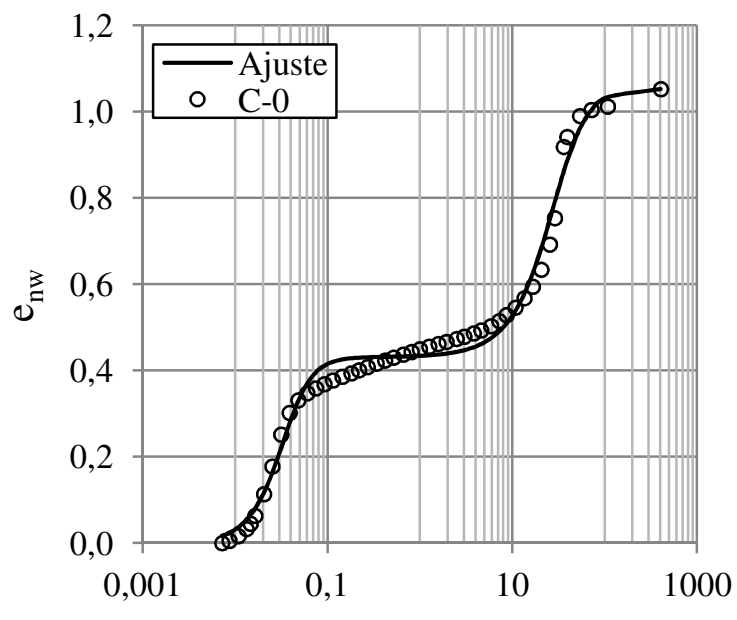

Diâmetro aparente dos poros $(\mu \mathrm{m})$

(a)

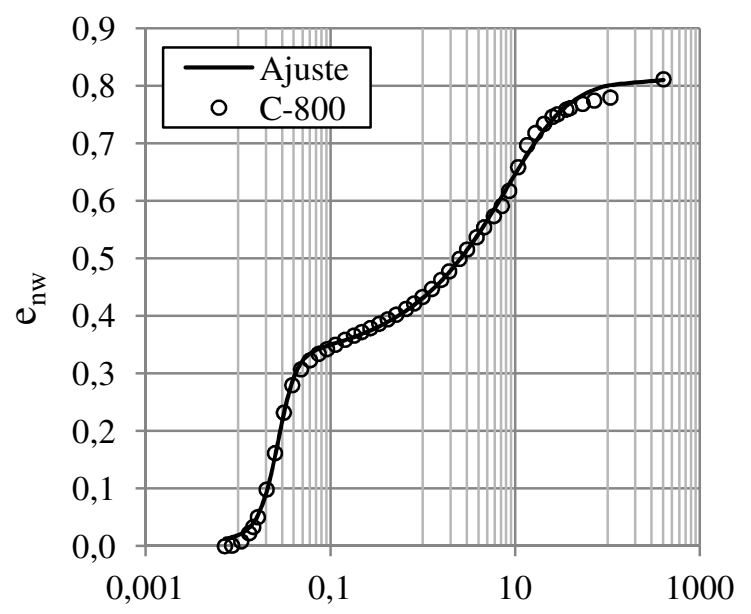

Diâmetro aparente dos poros $(\mu \mathrm{m})$

(b)

Figura 5.8 - Ajuste da macro das curvas para o solo Compactado: (a) saturado, sem carregamento $\left(\mathrm{R}^{2}=0,975\right)$; (b) Saturado, com carregamento de $800 \mathrm{kPa}\left(\mathrm{R}^{2}=0,998\right)$. 


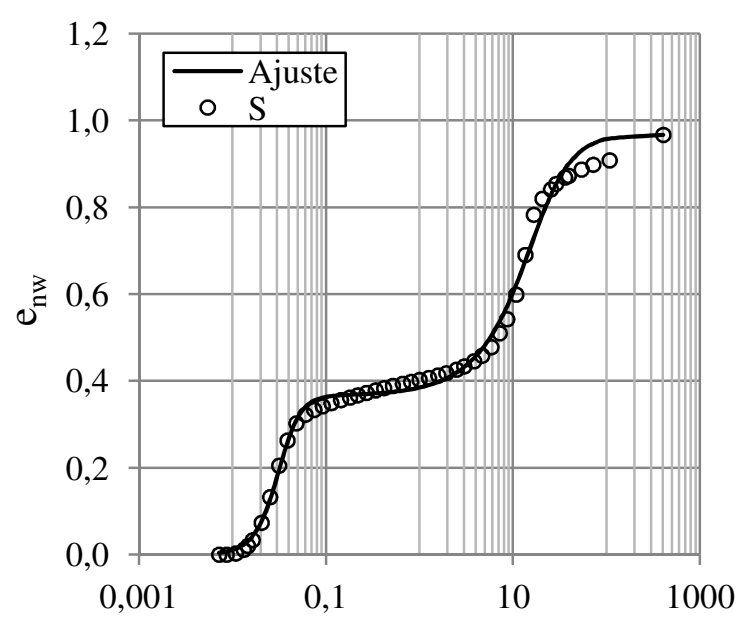

Diâmetro aparente dos poros $(\mu \mathrm{m})$

(a)

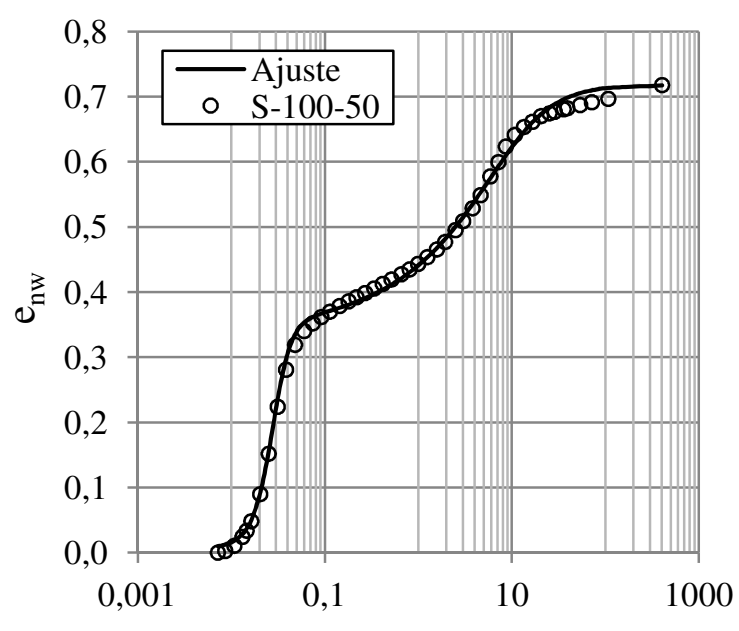

Diâmetro aparente dos poros $(\mu \mathrm{m})$

(b)

Figura 5.9 - Ajuste da macro das curvas para a Lama(a) saturada, sem carregamento $\left(\mathrm{R}^{2}=\right.$ 0,992) (b) sucção de $50 \mathrm{kPa}$, com carregamento de $100 \mathrm{kPa}\left(\mathrm{R}^{2}=0,998\right)$.

A Tabela 5.8 apresenta o índice de vazios dos microporos $\left(e_{m}\right)$ para o solo saturado, no estado Natural, Compactado e Lama. O parâmetro de ajuste $e_{m}$ é o valor do ponto de inflexão dos microporos. A sugestão de Delage \& Lefebvre (1984) foi utilizada para determinar os valores de $e_{m}$, a partir dos dados, que os autores definiram pela curva de extrusão. Em geral, os valores obtidos pela modelagem estão próximos, mas menores do que os valores da curva de extrusão. Cabe destacar que, se for utilizado o critério de Delage \& Lefebvre (1984), a variação do índice de vazio da microestrutura é pequeno, sendo mais uma vez confirmada a hipótese de que a microestrutura permanece quase inalterada.

Tabela 5.8 - Valores de índice de vazios microestrutural da curva de extrusão. Ponto de máxima curvatura e ponto final. Para o solo na condição saturada.

\begin{tabular}{c|cc|cc|cc}
\hline & \multicolumn{2}{|c|}{ Natural } & \multicolumn{2}{c}{ Lama } & \multicolumn{2}{c}{ Compactado } \\
\hline $\begin{array}{c}\text { Carga de } \\
\text { consolidação }\end{array}$ & $\begin{array}{c}\text { Delage \& } \\
\text { Lefebvre } \\
(1984)\end{array}$ & $\begin{array}{c}\text { Parâmetro } \\
\text { de ajuste }\end{array}$ & $\begin{array}{c}\text { Delage \& } \\
\text { Lefebvre } \\
(1984)\end{array}$ & $\begin{array}{c}\text { Parâmetro } \\
\text { de ajuste }\end{array}$ & $\begin{array}{c}\text { Delage \& } \\
\text { Lefebvre } \\
(1984)\end{array}$ & $\begin{array}{c}\text { Parâmetro } \\
\text { de ajuste }\end{array}$ \\
\hline 0 & 0,42 & 0,44 & 0,38 & 0,37 & 0,38 & 0,43 \\
50 & 0,39 & 0,31 & 0,46 & 0,37 & 0,38 & 0,40 \\
100 & 0,45 & 0,30 & 0,46 & 0,37 & 0,38 & 0,33 \\
200 & 0,48 & 0,30 & 0,46 & 0,34 & 0,45 & 0,36 \\
400 & 0,52 & 0,27 & 0,43 & 0,32 & 0,45 & 0,34 \\
800 & 0,48 & 0,26 & 0,46 & 0,35 & 0,49 & 0,36 \\
\hline
\end{tabular}


A Tabela 5.9 apresenta o índice de vazios dos microporos $\left(e_{m}\right)$ para o solo não saturado, no estado Compactado e Lama, seguindo o mesmo procedimento calculado para a Tabela 5.8. Apesar de haver uma pequena divergência nos valores, nas duas maneiras de se obter o índice de vazios da micro, é possível observar que não há grandes mudanças nestes valores. $\mathrm{Na}$ Lama, os valores se mantêm menores do que os valores da curva de extrusão. Já para o solo Compactado, estes valores são muito próximos, variando, hora menor, hora maior do que os valores da curva de extrusão.

Tabela 5.9 - Valores de índice de vazios microestrutural da curva de extrusão. Ponto de máxima curvatura e ponto final. Para o solo na condição não saturada, com sucção de $50 \mathrm{kPa}$.

\begin{tabular}{c|cc|cc}
\hline & \multicolumn{2}{|c|}{ Lama } & \multicolumn{2}{c}{ Compactado } \\
\hline $\begin{array}{c}\text { Carga de } \\
\text { consolidação }\end{array}$ & $\begin{array}{c}\text { Delage \& } \\
\text { Lefebvre } \\
(1984)\end{array}$ & $\begin{array}{c}\text { Parâmetro de } \\
\text { ajuste }\end{array}$ & $\begin{array}{c}\text { Delage \& } \\
\text { Lefebvre } \\
(1984)\end{array}$ & $\begin{array}{c}\text { Parâmetro de } \\
\text { ajuste }\end{array}$ \\
\hline 50 & 0,41 & 0,35 & 0,41 & 0,42 \\
100 & 0,43 & 0,34 & 0,37 & 0,40 \\
200 & 0,42 & 0,34 & 0,43 & 0,38 \\
400 & 0,43 & 0,32 & 0,39 & 0,38 \\
\hline
\end{tabular}

A Tabela 5.10 apresenta o índice de vazios dos microporos $\left(e_{m}\right)$ para o solo não saturado, no estado Compactado e Lama, seguindo o mesmo procedimento calculado para Tabela 5.8 e Tabela 5.9, para solo com sucção de $1.000 \mathrm{kPa}$. Os valores obtidos por modelagem ainda estão próximos, sendo que para a Lama se mantêm menores do que os valores da curva de extrusão, enquanto que para o solo Compactado, são maiores do que os valores da curva de extrusão. Nos dois casos, a micro teve pouca variação, independente do método que foi utilizado para obter o índice de vazio da microestrutura.

Tabela 5.10 - Valores de índice de vazios microestrutural da curva de extrusão. Ponto de máxima curvatura e ponto final. Para o solo na condição não saturada, com sucção de 1.000

\begin{tabular}{c|cc|cc}
\multicolumn{5}{c|}{$\mathrm{kPa}}$. \\
\hline $\begin{array}{c}\text { Carga de } \\
\text { consolidação }\end{array}$ & $\begin{array}{c}\text { Delage \& } \\
\text { Lefebvre } \\
(1984)\end{array}$ & $\begin{array}{c}\text { Parâmetro de } \\
\text { ajuste }\end{array}$ & $\begin{array}{c}\text { Delage \& } \\
\text { Lefebvre } \\
(1984)\end{array}$ & $\begin{array}{c}\text { Parâmetro de } \\
\text { ajuste }\end{array}$ \\
\hline 50 & 0,47 & 0,37 & 0,34 & 0,40 \\
100 & 0,49 & 0,33 & 0,35 & 0,41 \\
200 & 0,49 & 0,33 & 0,33 & 0,40 \\
400 & 0,36 & 0,39 & 0,35 & 0,40 \\
800 & 0,39 & 0,31 & 0,35 & 0,38 \\
\hline
\end{tabular}


Considerando que a micro estrutura não varia, ou que pelo menos a sua variação é pequena, é necessária uma análise do que acontece com a macroestrutura. Nas Figuras 5.10 a 5.16 é apresentada a variação dos parâmetros relacionados com a macroestrutura, sendo que os itens (a) estão associados ao parâmetro $\alpha_{M}$ e os itens (b) estão associados ao $\left(n_{M}\right)$. Em todos os casos foram apresentadas as evoluções dos parâmetros relacionados aos ajustes denominados de completo e somente da macroestrutura.

Nas Figuras 5.10a, 5.11a e 5.12a são apresentadas as evoluções dos parâmetros associados ao diâmetro dominante $\left(\alpha_{M}\right)$ para as amostras saturadas nos diferentes estados: Natural, Compactado e Lama.

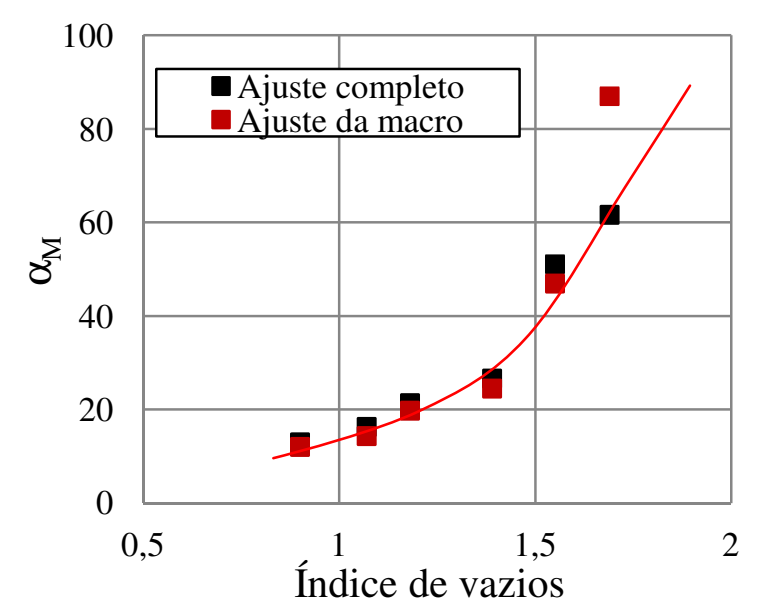

(a)

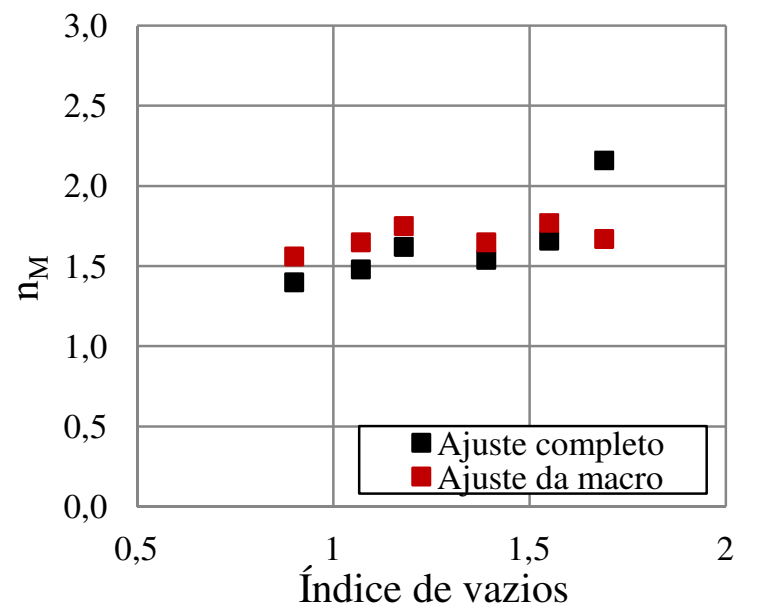

(b)

Figura 5.10 - Variação dos parâmetros de ajuste do solo saturado no estado Natural: (a) Poro dominante $-\alpha_{M}$; (b) Coeficiente de uniformidade - $n_{M}$.

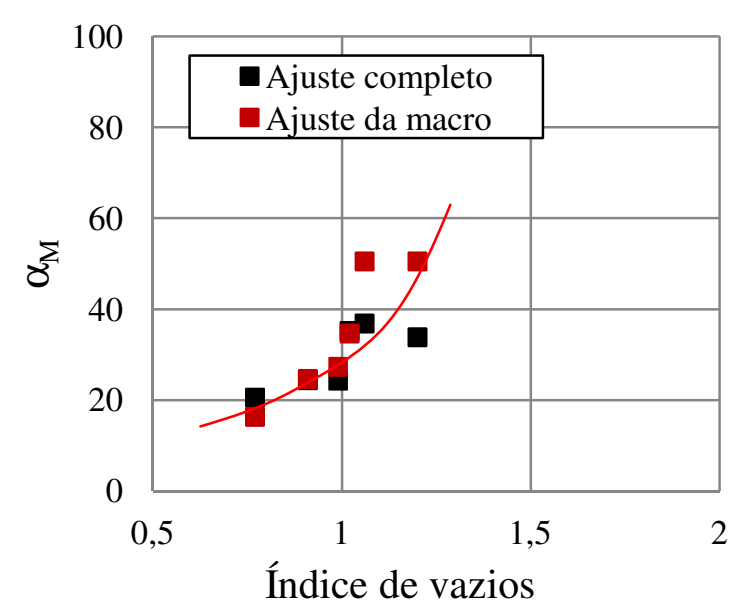

(a)

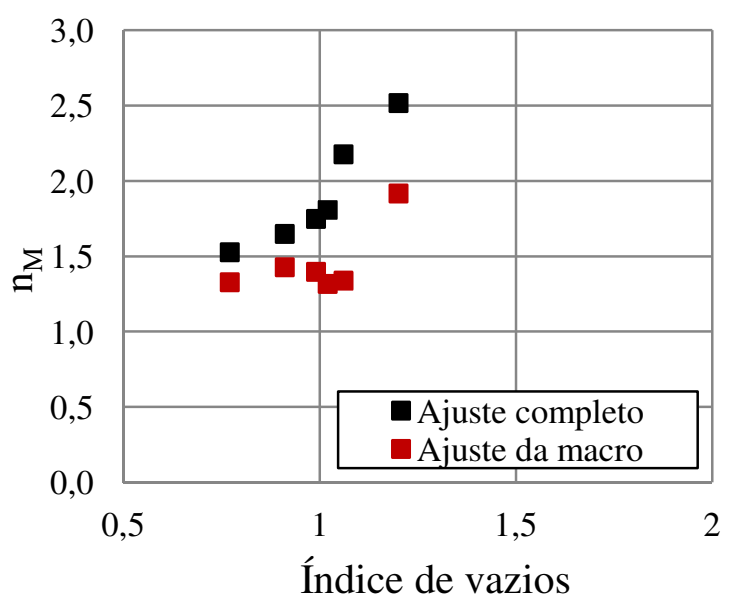

(b)

Figura 5.11 - Variação dos parâmetros de ajuste do solo saturado no estado Compactado: (a) Poro dominante - $\alpha_{M}$; (b) Coeficiente de uniformidade - $n_{M}$. 


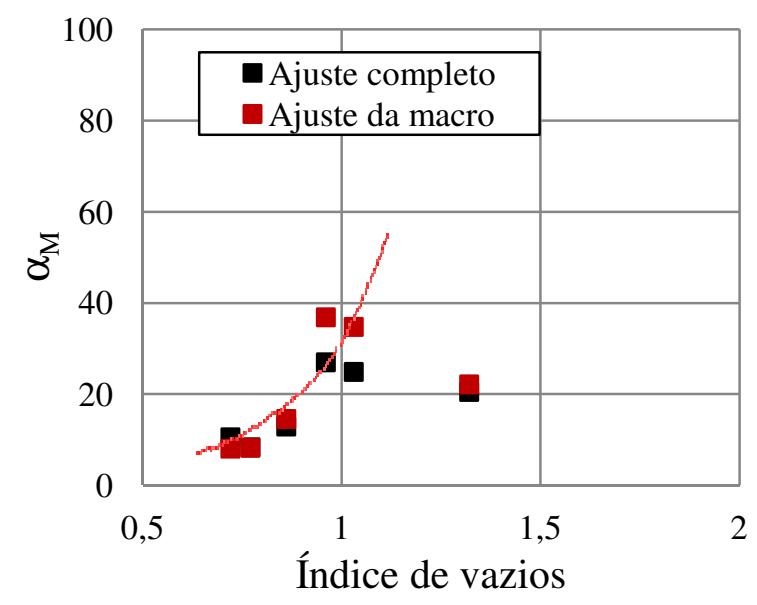

(a)

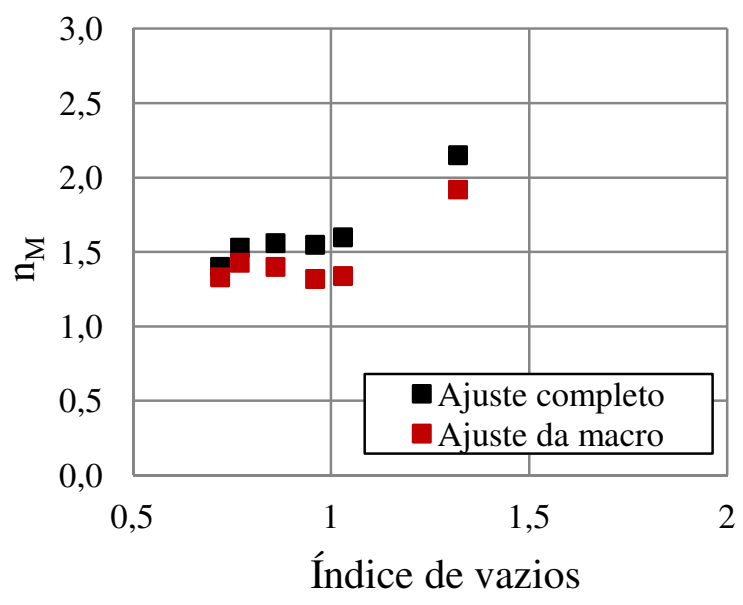

(b)

Figura 5.12 - Variação dos parâmetros de ajuste do solo saturado no estado de Lama: (a) Poro dominante - $\alpha_{M}$; (b) Coeficiente de uniformidade - $\mathrm{n}_{M}$.

De modo geral, os parâmetros dos macroporos evoluem como esperado. A velocidade do decréscimo de $\alpha_{M}$ é maior para a amostra Natural do que para as amostras Compactadas e Lama, podendo estar relacionada com a existência de uma fraca ligação entre agregados (provavelmente óxido de ferro) que não estão presentes nas outras amostras. Após esta ligação ser destruída, a amostra Natural passa a ter um comportamento semelhante aos outros casos. Apesar de as estruturas iniciais serem diferentes, os valores de $\alpha_{M}$ tendem para zero, o que significa que todas as amostras evoluiriam para um comportamento unimodal, caso as cargas verticais continuassem a crescer.

Para as amostras compactadas (Figura 5.11b) os valores de $n_{M}$ induzem a conclusão de que o carregamento pode levar a uma distribuição dos macroporos mais uniforme, sendo seu valor em torno de 1,5, existe uma a variação pequena e também pode ser resultado do processo de amostragem, ou seja, fenômeno estatístico. Caso a hipótese de que $n_{M}$ seja pouco influenciado pela estrutura e pelos carregamentos, é possível supor que este parâmetro não está relacionado com a estrutura, mas com uma propriedade intrínseca do solo associada com o tamanho dos grãos, a forma dos grãos, a interação entre minerais, argila e água, etc.

O número de ensaios realizados neste estudo não é suficiente para ser conclusivo, porém, foi possível relacionar o comportamento mecânico e hidráulico com os resultados de microestrutura advindos do MIP.

Na Figura 5.13 e na Figura 5.14 são apresentados os resultados dos parâmetros $\alpha_{M}$ e $n_{M}$ do solo na condição não saturada ( $\mathrm{s}=50 \mathrm{kPa}$ ), para o solo Compactado e Lama, respectivamente. É possível observar que no solo Compactado há uma diminuição do $\alpha_{M}$, mas este não sofre 
grandes alterações durante o carregamento. Por outro lado, observando-se os resultados da Lama, os valores de $\alpha_{M}$ são baixos e não apresentam grandes variações.

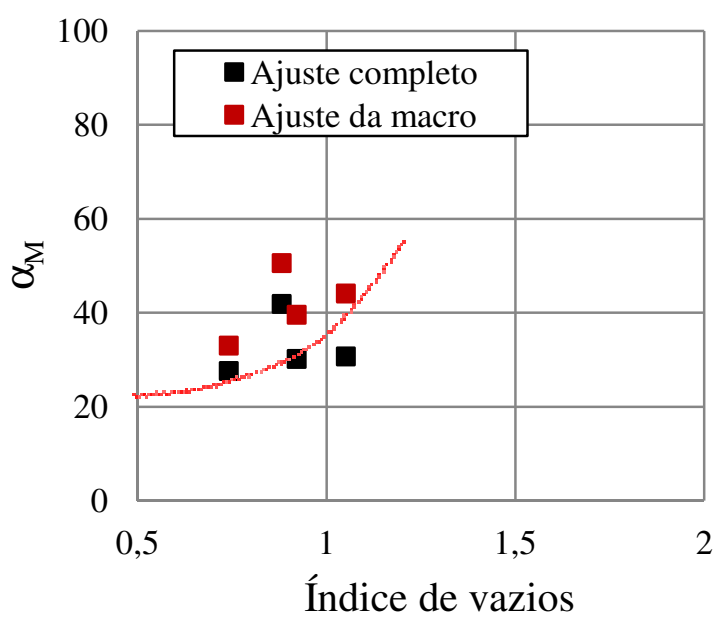

(a)

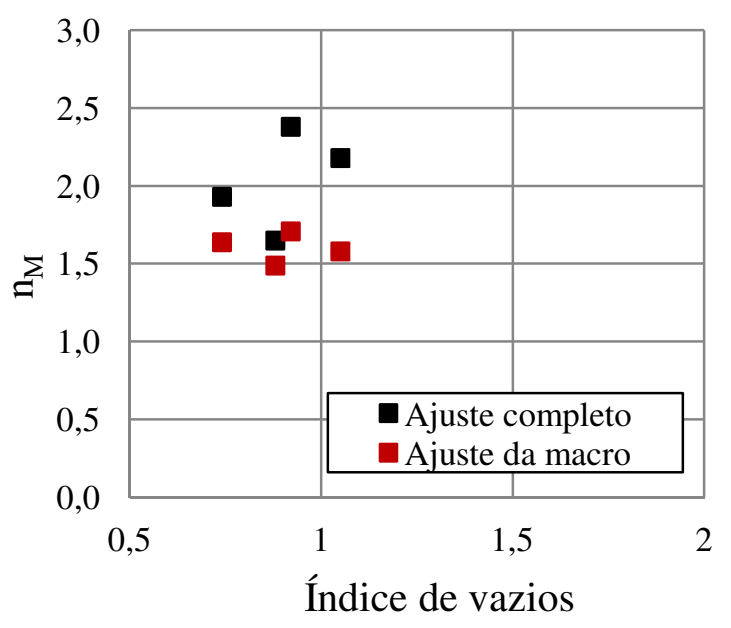

(b)

Figura 5.13 - Variação dos parâmetros de ajuste do solo não saturado com sucção de $50 \mathrm{kPa}$ no estado Compactado: (a) Poro dominante - $\alpha_{M}$; (b) Coeficiente de uniformidade - $\mathrm{n}_{M}$.

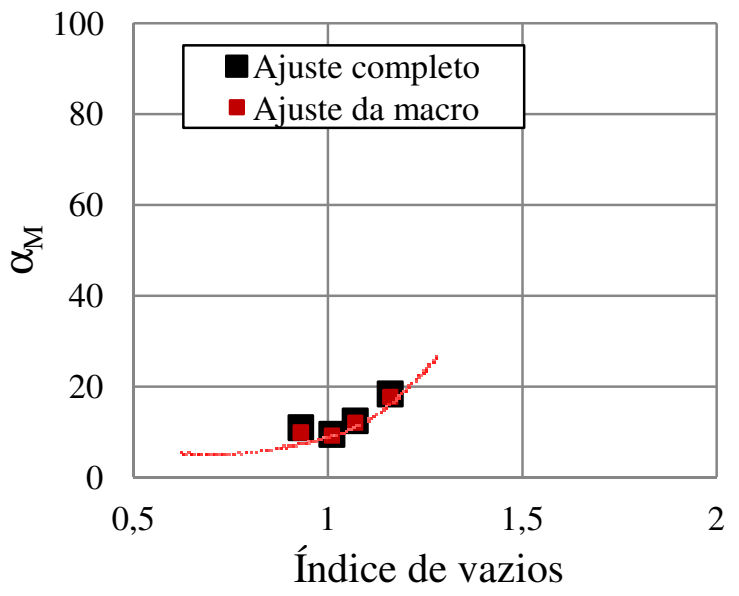

(a)

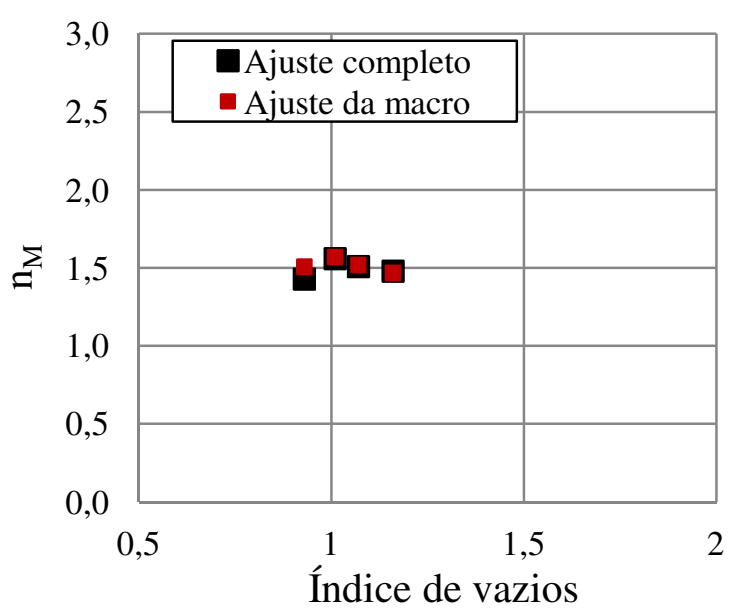

(b)

Figura 5.14 - Variação dos parâmetros de ajuste do solo não saturado com sucção de $50 \mathrm{kPa}$ no estado de Lama: (a) Poro dominante - $\alpha_{M}$; (b) Coeficiente de uniformidade - $\mathrm{n}_{M}$.

O parâmetro uniformidade dos macroporos $\left(n_{M}\right)$ não se altera com o processo de carregamento e com a imposição da sucção, sendo seu valor em torno de 1,5. No caso do solo Compactado há uma dispersão muito grande nos valores de modo que é impossível avaliar qualquer tendência, como foi feito para as amostras saturadas.

Na Figura 5.15 e na Figura 5.16 são apresentados os resultados dos parâmetros $\alpha_{M}$ e $n_{M}$ do solo na condição não saturada $(\mathrm{s}=1.000 \mathrm{kPa})$, para o solo Compactado e Lama, respectivamente. Como foi observado para os outros casos, no solo Compactado e na Lama há 
uma redução do $\alpha_{M}$. A sucção age reduzindo a velocidade com que isso ocorre com o carregamento.

O parâmetro de uniformidade dos macroporos $\left(n_{M}\right)$ não se altera de forma significativa com o processo de carregamento e com a imposição da sucção. Nas amostras em diferentes estruturas, o valor de $n_{M}$ se mantém próximo de 1,5. A exceção disso são os resultados da amostra Compactada quando é realizado o ajuste completo (Figura 5.15b) e os valores do mesmo parâmetro, para o caso do ajuste, só da macroestrutura são superiores a 1,5.

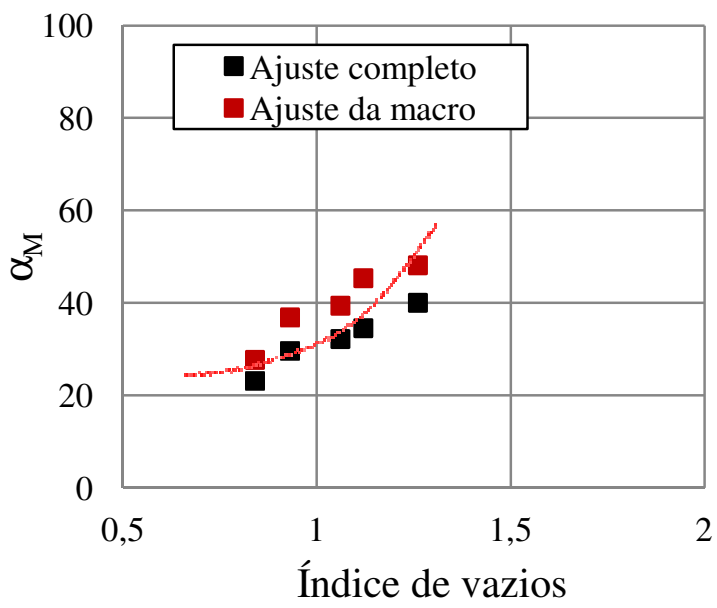

(a)

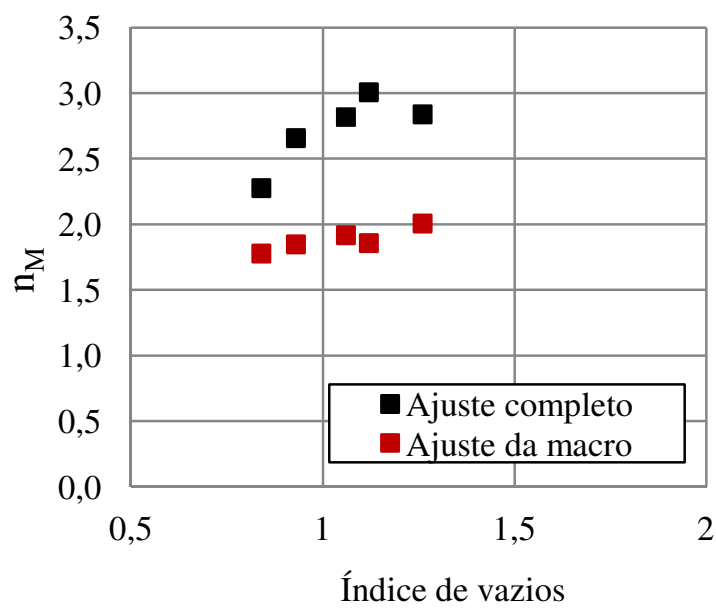

(b)

Figura 5.15 - Variação dos parâmetros de ajuste do solo não saturado com sucção de 1.000 kPa no estado Compactado: (a) Poro dominante - $\alpha_{M}$; (b) Coeficiente de uniformidade $-\mathrm{n}_{M}$.

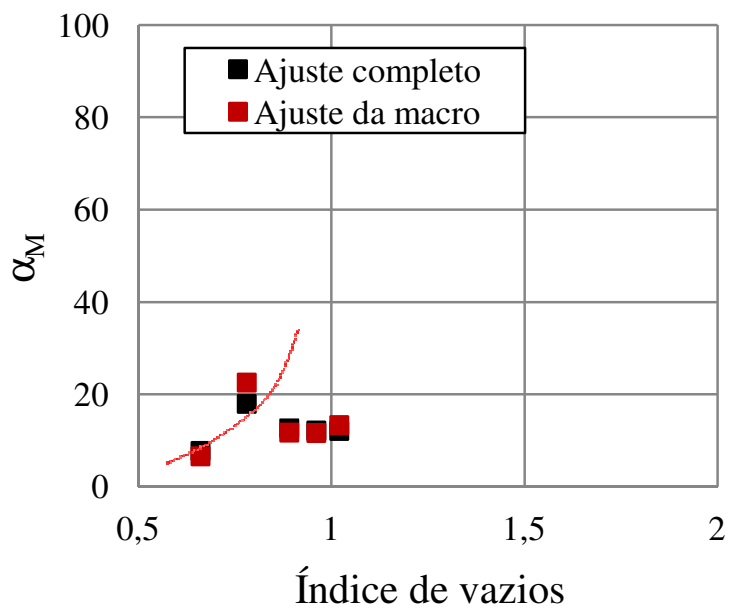

(a)

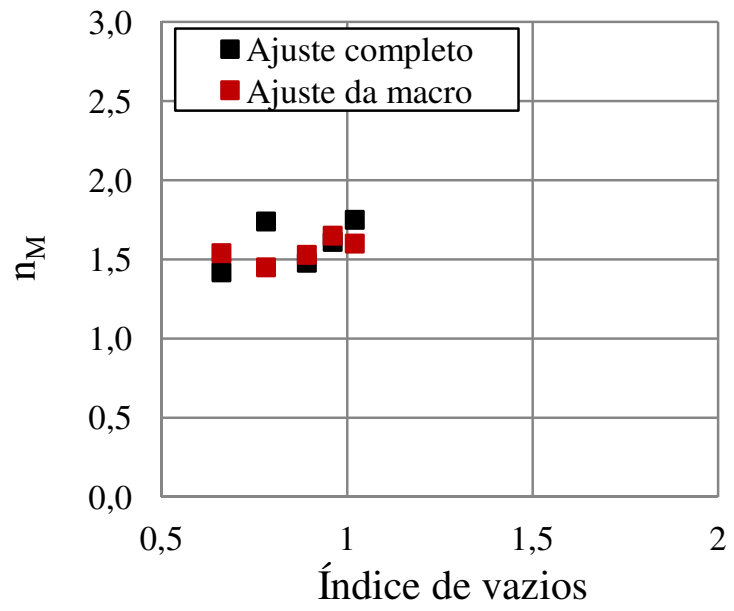

(b)

Figura 5.16 - Variação dos parâmetros de ajuste do solo não saturado com sucção de 1.000 kPa no estado de Lama: (a) Poro dominante $-\alpha_{M}$; (b) Coeficiente de uniformidade $-\mathrm{n}_{M}$. 


\section{3 - ANÁLISE QUALITATIVA DA DISTRIBUIÇÃO DO TAMANHO DOS POROS}

Após a realização da modelagem das curvas de distribuição do tamanho dos poros apresentadas no item anterior, foi possível concluir que para o solo estudado a microestrutura pode ser considerada como constante ou, pelo menos, que sua variação não é significativa.

Desta forma, é possível realizar uma segunda análise associada à variação dos poros efetivos por meio de um índice de vazio relativo ou efetivo, definido pela equação:

$e_{r}=\left(e_{n w}-e_{\min }\right) /\left(e_{\max }-e_{\min }\right)$

sendo: $e_{n w}$ o índice de vazios preenchido por mercúrio; $e_{\max } \mathrm{o}$ maior índice de vazios calculado no ajuste; $\mathrm{e}_{\min }$ é o índice de vazios da micro $\left(\mathrm{e}_{\mathrm{m}}\right)$ calculado no ajuste, obtido pela equação (5.2).

A partir destes resultados, foi feita uma análise da curva de distribuição do tamanho dos poros efetivos, muito semelhante à curva de distribuição de grãos, ou curva granulométrica. A título de comparação, foram calculados índices e coeficientes semelhantes aos utilizados na análise das curvas granulométricas, tais como: coeficiente de não uniformidade (CNU) e de curvatura (CC). Além desses, foi definido um novo índice (I), e que corresponde à inclinação do trecho reto da curva de distribuição do tamanho dos poros do solo. Cada um dos índices citado anteriormente é definido como:

$$
\begin{aligned}
& C N U=D_{60} / D_{10} \\
& C C=\left(D_{30}\right)^{2} /\left(D_{10} \cdot D_{60}\right) \\
& I=0,8 * \log \left(D_{10} / D_{90}\right)
\end{aligned}
$$

Na Tabela 5.11 são apresentados os coeficientes, de não uniformidade e de curvatura, e inclinação para o solo Natural na condição saturada, enquanto na Figura 5.17 é apresentada as curvas. Observe que há um aumento do coeficiente de não uniformidade (CNU), dando aos poros uma distribuição bem graduada. Os valores obtidos para o coeficiente de curvatura (CC) não variam muito, o que significa que não há grandes alterações na forma da curva. Os resultados de inclinação da curva diminuem com o aumento do carregamento. Na Figura 5.17 é possível observar que com o aumento do carregamento este material torna-se menos uniforme. 
Tabela 5.11 - Coeficiente, de não uniformidade e de curvatura, e inclinação para o solo Natural na condição saturada.

\begin{tabular}{|c|c|c|c|c|c|c|c|}
\hline Amostras & $\mathrm{D}_{10}$ & $\mathrm{D}_{30}$ & $\mathrm{D}_{60}$ & $\mathrm{D}_{90}$ & $\mathrm{I}$ & $\mathrm{CNU}$ & $\mathrm{CC}$ \\
\hline $\mathrm{N}-0-0$ & 8,3 & 22,8 & 50,1 & 172,9 & 0,61 & 6,1 & 1,3 \\
\hline N-50-0 & 1,5 & 8,3 & 27,9 & 99,7 & 0,44 & 18,2 & 1,6 \\
\hline N-100-0 & 0,4 & 2,9 & 12,2 & 51,5 & 0,37 & 33,0 & 1,9 \\
\hline N-200-0 & 0,5 & 3,1 & 11,3 & 43,5 & 0,42 & 21,9 & 1,7 \\
\hline N-400-0 & 0,1 & 1,3 & 6,5 & 30,9 & 0,33 & 52,2 & 2,1 \\
\hline N-800-0 & 0,0 & 0,6 & 4,1 & 23,1 & 0,30 & 87,6 & 2,0 \\
\hline
\end{tabular}

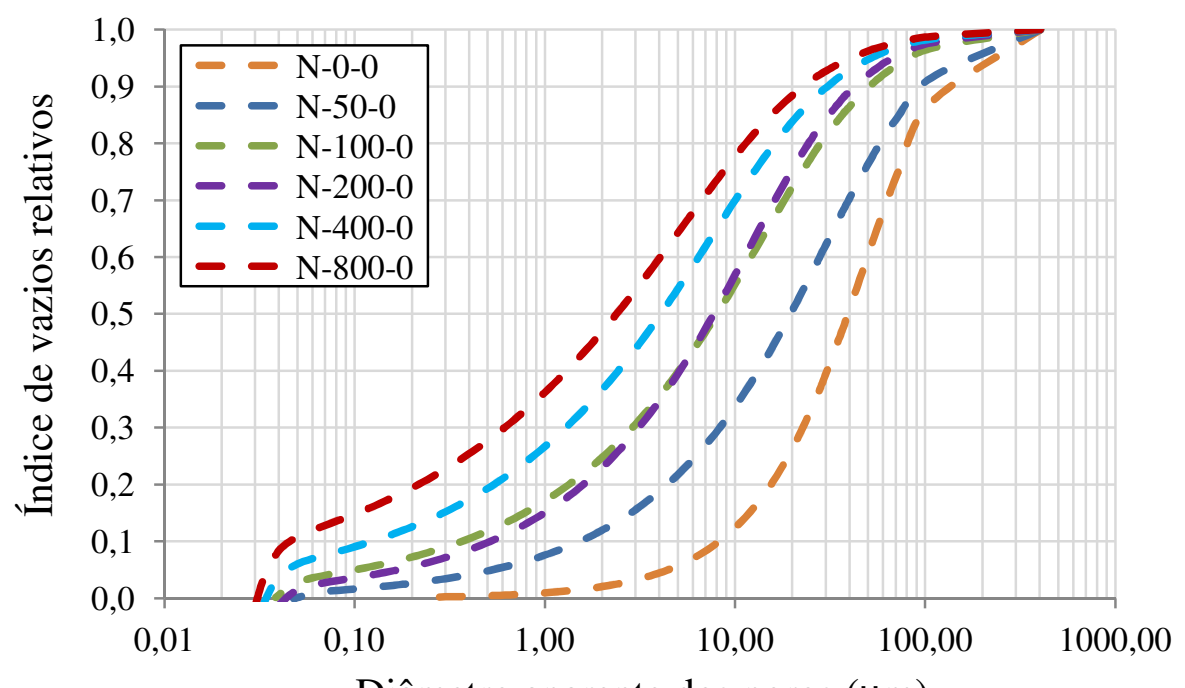

Diâmetro aparente dos poros $(\mu \mathrm{m})$

Figura 5.17 - Relação do índice de vazios relativo versus Diâmetro aparente dos poros para o solo Natural na condição saturada.

Na Tabela 5.12 são apresentados os coeficientes, de não uniformidade e de curvatura, e inclinação para o solo Compactado na condição saturada. É possível notar que os mesmos comentários apresentados para o solo natural na condição saturada são validos neste caso, ou seja, ocorre uma diminuição da inclinação e aumento do coeficiente de não uniformidade (CNU). O coeficiente de curvatura quase não varia. Isso ainda pode ser visualizado na Figura 5.18. Por outro lado, comparando a Figura 5.17 e a Figura 5.18, é possível observar que apesar de efeitos serem semelhantes, o mesmo carregamento final $(800 \mathrm{kPa})$ produziu na amostra natural uma curva melhor graduada $(\mathrm{CNU}=87,6)$ que na amostra compactada $(\mathrm{CNU}=42,1)$. 
Tabela 5.12 - Coeficiente, de não uniformidade e de curvatura, e inclinação para o solo Compactado na condição saturada.

\begin{tabular}{|c|c|c|c|c|c|c|c|}
\hline Amostras & $\mathrm{D}_{10}$ & $\mathrm{D}_{30}$ & $\mathrm{D}_{60}$ & $\mathrm{D}_{90}$ & $\mathrm{I}$ & $\mathrm{CNU}$ & $\mathrm{CC}$ \\
\hline C-50-0 & 5,2 & 14,0 & 30,0 & 74,8 & 0,69 & 5,7 & 1,2 \\
\hline C-100-0 & 2,0 & 8,2 & 23,1 & 71,2 & 0,52 & 11,3 & 1,4 \\
\hline C-200-0 & 1,1 & 5,0 & 15,1 & 50,5 & 0,48 & 13,4 & 1,5 \\
\hline C-400-0 & 0,7 & 4,0 & 13,4 & 49,8 & 0,43 & 18,8 & 1,6 \\
\hline C-800-0 & 0,2 & 1,6 & 7,4 & 33,7 & 0,35 & 42,1 & 2,0 \\
\hline
\end{tabular}

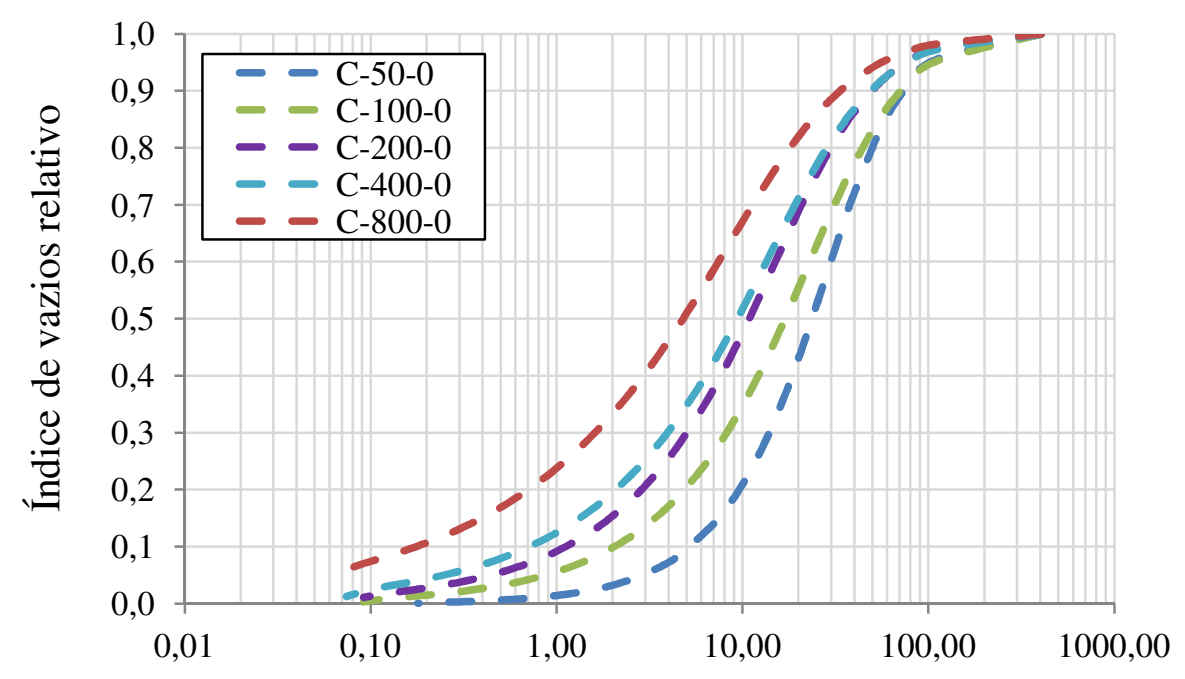

Diâmetro aparente dos poros $(\mu \mathrm{m})$

Figura 5.18 - Relação do índice de vazios relativo versus Diâmetro aparente dos poros para o solo Compactado na condição saturada.

Finalmente, na Tabela 5.13 são apresentados os coeficientes, de não uniformidade e de curvatura, e inclinação para a Lama na condição saturada. Os resultados obtidos para a inclinação da curva tem uma variação inferior aos outros dois casos. A mesma explicação é válida para o coeficiente de não uniformidade (CNU). Estes resultados podem ser observados nas Figuras 5.17 até 5.21. Em todos os casos a amostra de Lama (Figura 5.19) tinha uma distribuição de macroporos melhor graduada (ou "mais" não uniforme) que as outras duas. O carregamento tornou as outras duas amostras melhor graduadas. É interessantes notar que à medida que as amostras tornam-se melhor graduadas, estas passam a ter uma resposta mecânica também semelhante. 
Tabela 5.13 - Coeficiente, de não uniformidade e de curvatura, e inclinação para a Lama na condição saturada.

\begin{tabular}{|c|c|c|c|c|c|c|c|}
\hline Amostras & $\mathrm{D}_{10}$ & $\mathrm{D}_{30}$ & $\mathrm{D}_{60}$ & $\mathrm{D}_{90}$ & $\mathrm{I}$ & $\mathrm{CNU}$ & $\mathrm{CC}$ \\
\hline S-50-0 & 0,5 & 3,4 & 12,7 & 49,9 & 0,40 & 24,1 & 1,7 \\
\hline S-100-0 & 0,4 & 3,1 & 12,6 & 52,3 & 0,38 & 31,3 & 1,8 \\
\hline S-200-0 & 0,2 & 1,5 & 6,2 & 25,6 & 0,38 & 30,0 & 1,8 \\
\hline S-400-0 & 0,1 & 0,9 & 3,8 & 16,5 & 0,37 & 34,7 & 1,8 \\
\hline S-800-0 & 0,1 & 0,5 & 3,3 & 18,9 & 0,32 & 53,7 & 1,2 \\
\hline
\end{tabular}

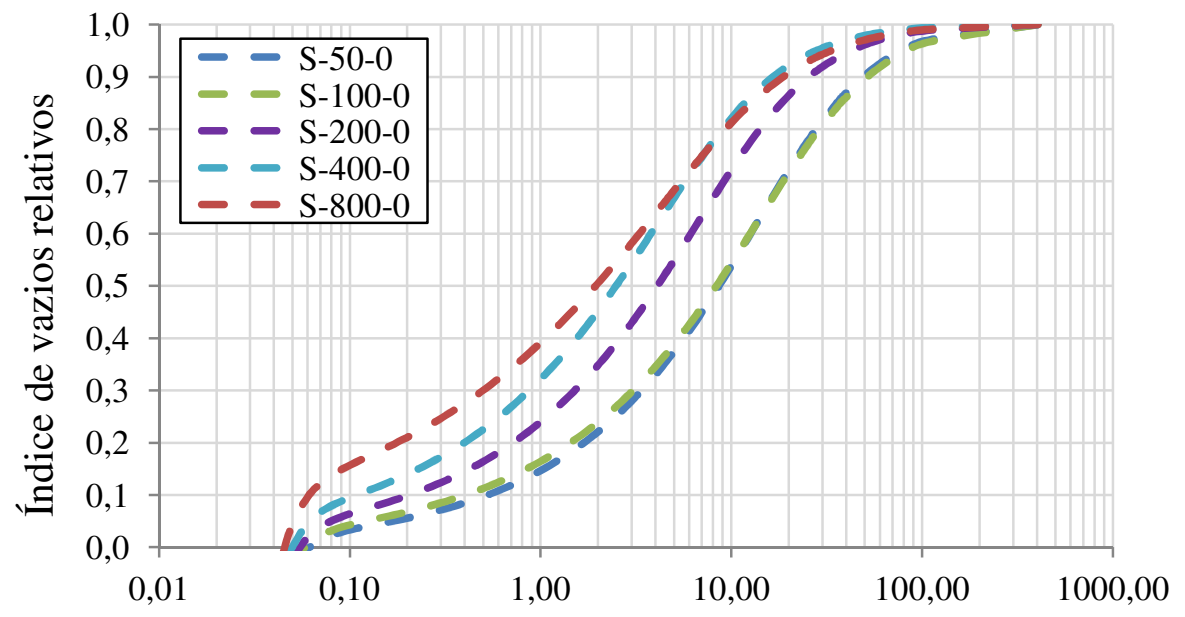

Diâmetro aparente dos poros $(\mu \mathrm{m})$

Figura 5.19 - Relação do índice de vazios relativo versus Diâmetro aparente dos poros para a Lama na condição saturada.

$\mathrm{Na}$ Tabela 5.14 são apresentados os coeficientes de não uniformidade e de curvatura e inclinação para o solo Compactado com sucção de $1.000 \mathrm{kPa}$. Os resultados obtidos para o coeficiente de curvatura (CC) são praticamente iguais, ou seja, não há variação na forma da curva. $\mathrm{O}$ coeficiente de não uniformidade (CNU) apresenta valores muito próximos, não ocorrendo mudanças significativas com o aumento do carregamento. O mesmo é válido para a inclinação. É possível observar todos esses aspectos na Figura 5.20.

Aparentemente, a sucção impede que haja uma redistribuição dos poros, ou seja, que poros de um tamanho sejam destruídos ou reduzam de tamanho. Esse é exatamente o efeito que é esperado da sucção, que ela mantenha a estrutura do solo intacta para cargas maiores. 
Tabela 5.14 - Coeficiente, de não uniformidade e de curvatura, e inclinação para o solo Compactado com sucção de $1.000 \mathrm{kPa}$.

\begin{tabular}{|c|c|c|c|c|c|c|c|}
\hline Amostras & $\mathrm{D}_{10}$ & $\mathrm{D}_{30}$ & $\mathrm{D}_{60}$ & $\mathrm{D}_{90}$ & $\mathrm{I}$ & $\mathrm{CNU}$ & $\mathrm{CC}$ \\
\hline $\mathrm{C}-50-1000$ & 11,6 & 22,1 & 37,6 & 75,1 & 0,98 & 3,3 & 1,1 \\
\hline C-100-1000 & 11,1 & 20,2 & 33,3 & 64,3 & 1,05 & 3,0 & 1,1 \\
\hline C-200-1000 & 9,2 & 17,7 & 30,4 & 61,4 & 0,97 & 3,3 & 1,1 \\
\hline C-400-1000 & 7,5 & 15,3 & 27,2 & 57,0 & 0,91 & 3,6 & 1,1 \\
\hline C-800-1000 & 3,9 & 9,6 & 19,6 & 47,8 & 0,73 & 5,1 & 1,2 \\
\hline
\end{tabular}

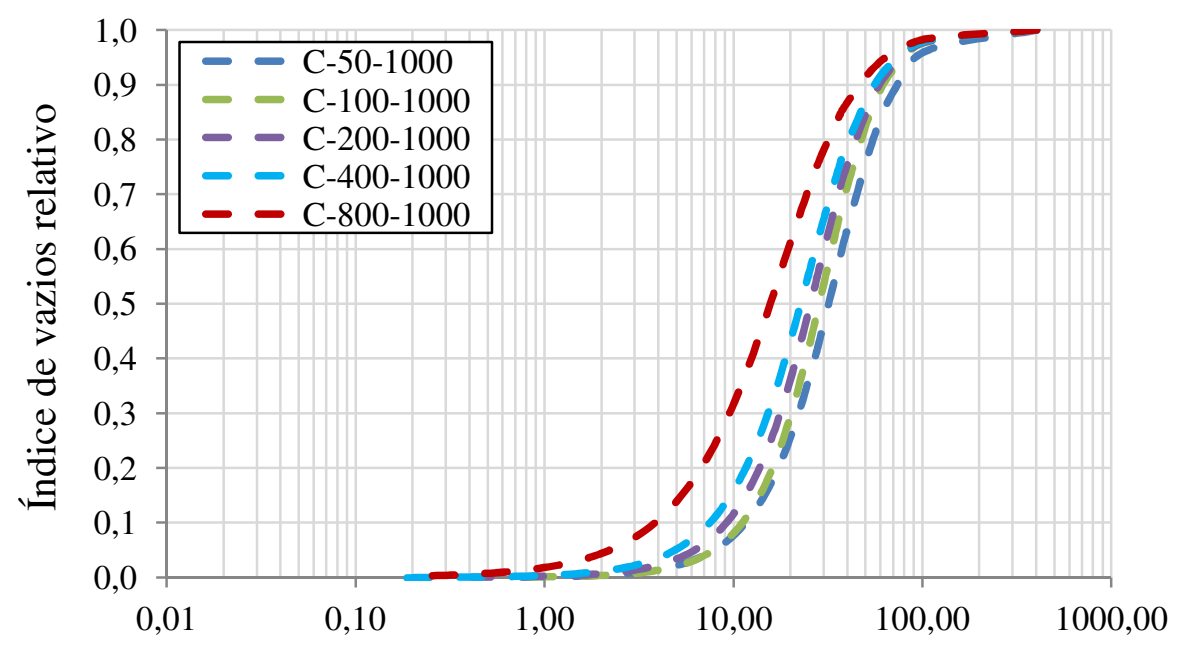

Diâmetro aparente de poros $(\mu \mathrm{m})$

Figura 5.20 - Relação do índice de vazios relativo versus Diâmetro aparente dos poros para o solo Compactado com sucção de $1.000 \mathrm{kPa}$.

Por outro lado, a sucção não teve o mesmo efeito nas amostras de Lama. Na Tabela 5.15 são apresentados os coeficientes, de não uniformidade e de curvatura, e inclinação para a Lama com sucção de $1.000 \mathrm{kPa}$. Os resultados obtidos para o coeficiente de curvatura (CC) são muito próximos, já o coeficiente de não uniformidade (CNU) aumenta com o carregamento, o que não foi observado nas amostras compactadas. A inclinação desta distribuição também tem valores muito próximos, não ocorrendo mudanças significativas com o aumento do carregamento.

Tabela 5.15 - Coeficiente, de não uniformidade e de curvatura, e inclinação para a Lama com sucção de $1.000 \mathrm{kPa}$

\begin{tabular}{|c|c|c|c|c|c|c|c|}
\hline Amostras & $\mathrm{D}_{10}$ & $\mathrm{D}_{30}$ & $\mathrm{D}_{60}$ & $\mathrm{D}_{90}$ & $\mathrm{I}\left(\mathrm{D}_{90}-\mathrm{D}_{10}\right)$ & $\mathrm{CNU}$ & $\mathrm{CC}$ \\
\hline S-50-1000 & 0,6 & 2,5 & 7,6 & 25,2 & 0,48 & 13,5 & 1,5 \\
\hline S-100-1000 & 0,3 & 1,8 & 6,4 & 24,8 & 0,41 & 22,7 & 1,7 \\
\hline S-200-1000 & 0,1 & 1,0 & 5,1 & 24,2 & 0,34 & 47,5 & 2,0 \\
\hline S-400-1000 & 0,8 & 3,6 & 11,1 & 36,9 & 0,48 & 13,9 & 1,5 \\
\hline S-800-1000 & 0,1 & 0,4 & 2,7 & 14,2 & 0,34 & 41,2 & 1,2 \\
\hline
\end{tabular}


A Figura 5.21 apresenta os resultados obtidos pela Lama na condição não saturada com 1.000 $\mathrm{kPa}$ de sucção e mostra que com o aumento do carregamento tornou a curva mais bem distribuída. Além desses resultados, é possível notar na Figura 5.21 que o carregamento praticamente destrói a macroestrutura da amostra de Lama, o que não foi observado na amostra Compactada na Figura 5.20.

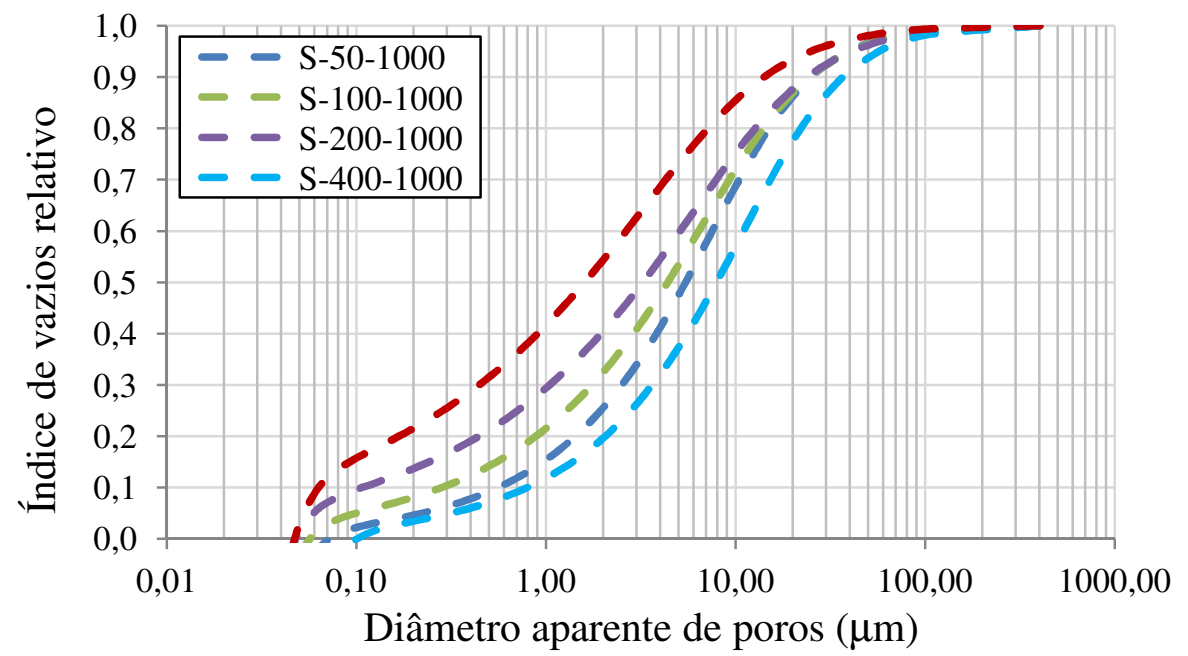

Figura 5.21 - Relação do índice de vazios relativo versus Diâmetro aparente dos poros para a Lama com sucção de $1.000 \mathrm{kPa}$.

Apesar de não ser conclusivo, é possível afirmar que a sucção teria efeitos diferentes em amostras do mesmo solo, com estruturas diferentes. Nas amostras compactadas, a condição saturada faz com que a destruição da macroestrutura ocorra de forma mais acelerada do que nas amostras que possuem alguma sucção. Por outro lado, na amostra de lama, o mesmo nível de sucção não foi capaz de enrijecer a estrutura do solo, e os carregamentos afetaram de maneira mais significativa os macroporos. Aparentemente, o coeficiente de não uniformidade dos poros foi capaz de capturar isso de maneira precisa. 


\section{6 - CONSIDERAÇÕES FINAIS}

Este capítulo apresenta as conclusões obtidas a partir dos resultados dos ensaios laboratoriais, a modelagem e a análise microestrutural realizadas em amostras Naturais, Compactadas e Lama do solo do Campo Experimental do Programa de Pós-Graduação em Geotecnia da Universidade de Brasília e sugestões para trabalhos futuros.

\section{1 - CONCLUSÃO}

O trabalho de pesquisa realizado neste solo teve seu enfoque dividido em três partes principais: comportamento hidráulico, mecânico e estrutural do solo na condição saturada e não saturada. A partir da análise e discussão dos resultados, algumas observações e hipóteses, válidas dentro dos limites deste estudo, puderam ser levantadas.

A partir dos resultados obtidos a respeito do comportamento hidráulico conclui-se que:

- a curva de retenção apresenta comportamento bimodal;

- é possível observar que a variação do índice de vazios, devido a carregamentos, produz um aumento do valor de entrada de ar dos macroporos;

- a variação do índice de vazios, devido a carregamentos, não afeta o valor de entrada de ar dos microporos;

- é possível observar a influência da estrutura do solo na curva retenção. Dois efeitos são observados: a translação das curvas e uma mudança no formato e na inclinação, decorrentes das diferentes estruturas utilizadas. Esta diferença é mais evidente na amostra de Lama;

- a modelagem da curva de retenção a partir da versão multimodal da equação de van Genuchten apresentou resultados satisfatórios.

A respeito da influência do comportamento mecânico pode-se dizer que:

- para carregamentos mais elevados, haveria uma tendência de convergências das curvas para todas as amostras estudadas (Natural, Compactada e Lama);

- a diferença entre o índice de vazios inicial das amostras Naturais, Compactada e Lama se deve à variabilidade do processo de amostragem e não à expansão e/ou contração 
das amostras, no entanto esta diferença não influenciou significativamente nos resultados;

- há diferença no valor da tensão de pré-adensamento entre as amostras Compactada e Natural. Por limitações do procedimento utilizado não foi possível obterem-se os valores de pré-adensamento da amostra de Lama;

- os valores de carga atingidos não foram suficientes para definir de forma conclusiva a inclinação dos trechos virgens da amostra Compactada;

- os resultados demonstraram que a estrutura tem um efeito maior sobre $\mathrm{o}$ comportamento do solo para os carregamentos iniciais e que, após atingido um certo nível de carregamento as diferentes amostras tendem a ter comportamento mecânico semelhantes.

A respeito da influência da estrutura no comportamento do solo constatou-se que:

- a obtenção das amostras para realização do MIP, a partir da metodologia proposta neste trabalho, pode ser considerada como representativa em relação à curva de adensamento. Vale destacar que a amostra Natural é muito heterogênea, porém não há muita diferença entre as amostras do MIP e a curva de adensamento;

- os valores obtidos no MIP foram subestimados quando comparados aos obtidos na curva de consolidação, no entanto este é um problema comum, devido às limitações do equipamento;

- todas as amostras apresentaram um comportamento bimodal;

- o segmento da curva associado com os microporos, nos três estados do solo, é o mesmo, isto significa que a diferença da estrutura do solo não afeta o nível de microporos;

- a partir dos resultados do MIP, as amostras de solo (Natural, Compactada e Lama) têm estruturas diferentes, sendo a microestrutura das amostras muito semelhante enquanto há variação tanto do diâmetro de poros dominantes como da densidade do tamanho de poros da macroestrutura;

- para todas as amostras (Natural, Compactada e Lama) na condição saturada há uma redução do índice de vazios da macroestrutura com o aumento do carregamento, enquanto o índice de vazios da microestrutura permanece praticamente inalterado. $\mathrm{O}$ 
mesmo acontece com as amostras na condição não saturada; no entanto, a existência da sucção desacelera a destruição dos macroporos com o carregamento;

- a modificação estrutural do solo em estudo, devido ao carregamento mecânico e/ou hidráulico, leva a alterações na estrutura dos macroporos e não afeta os microporos. Quanto maior é o carregamento na amostra compactada menor será o efeito da sucção;

- a modelagem da curva de distribuição do tamanho dos poros, a partir da uma versão multimodal modificada da equação de van Genuchten, apresentou resultados satisfatórios;

- mesmo fixando os parâmetros relacionados à microestrutura no ajuste da macro, os resultados são semelhantes ao ajuste completo de todos os parâmetros. Isto se justifica pelo fato de a microestrutura de todas as amostras serem muito semelhantes;

- de maneira geral a metodologia proposta neste trabalho para separação entre micro e macro se mostrou semelhante ao método proposto por Delage \& Lefebvre (1984) para todas as amostras de solo estudadas;

- tendo em vista que $n_{M}$ seja pouco influenciado pela estrutura e pelos carregamentos, é possível supor que este parâmetro não está relacionado com a estrutura, mas com uma propriedade intrínseca do solo associada com tamanho dos grãos, a forma dos grãos, a interação entre minerais, argila e água, etc.;

- a velocidade do decréscimo de $\alpha_{M}$ é maior para a amostra Natural do que para as amostras Compactadas e Lama. Isto pode estar associado à existência de uma fraca ligação entre agregados (provavelmente óxido de ferro) que não estão presentes nas outras amostras. Apesar de as estruturas iniciais serem diferentes, os valores de $\alpha_{M}$ tendem para zero, o que significa que todas as amostras evoluiriam para um comportamento unimodal, caso as cargas verticais continuassem a crescer;

- a análise da curva de distribuição dos poros efetivos, proposta nesta pesquisa, simplifica a compreensão da evolução da macroestrutura, inclusive sendo possível perceber com mais nitidez o efeito da sucção na desaceleração da destruição da estrutura. E aparentemente, o coeficiente de não uniformidade dos poros é capaz de capturar isso de maneira precisa. 


\section{2 - SUGESTÕES A TRABALHOS FUTUROS}

A partir dos resultados obtidos nesta tese, assim como o conhecimento adquirido no desenvolvimento desta pesquisa, são apresentadas algumas sugestões para pesquisas futuras:

- construir um equipamento que permita avaliar a influência do cisalhamento na distribuição de poros;

- estudar como diferentes tipos de trajetória de cisalhamento e deformabilidade afetam a distribuição dos poros;

- estudar a evolução da estrutura de amostras de solo (reconstituída e compactada) preparadas com diferentes umidades iniciais;

- estudar a estrutura de outros solos submetidos a trajetórias hidromecânicas;

- estudar a relação dos parâmetros $n_{M}$ e $\alpha_{M}$ com a estrutura do solo. 


\section{REFERÊNCIAS}

ABNT - ASSOCIAÇÃO BRASILEIRA DE NORMAS TÉCNICAS. NBR 6458: Solo Grãos de pedregulhos retidos na peneira de 4,8mm - Determinação da massa específica, da massa específica aparente e absorção de água. São Paulo, SP, 1984, 6 p.

ABNT __ NBR 6459: Solo - Determinação do limite de liquidez. São Paulo, SP, 1984, $6 \mathrm{p}$.

ABNT _ _ NBR 7180: Solo - Determinação do limite de plasticidade. São Paulo, SP, $1984,3 \mathrm{p}$.

ABNT _ _ NBR 7181: Solo - Análise granulométrica. São Paulo, SP, 1984, 13 p.

ABNT _. NBR 7182: Solo - Ensaio de compactação - Método de ensaio. São Paulo, SP, 1986, $10 \mathrm{p}$.

ABNT $1990,13 p$.

. NBR 12007: Solo - Ensaio de adensamento unidimensional. São Paulo, SP,

Ahmed, S., Lovell, C. W., Diamond, S. (1974). Pore sizes and strength of compacted clay. Journal Geotechnical Engineering Div. GT4, 407-425.

Al-Mukhtar, M., Balanteur, N., Tessier, D., Vanapalli, S. K. (1996). The fabric of a clay soil under controlled mechanical and hydraulic stress states. Applied Clay Science. 11:99-115.

Alonso, E. E., Gens, A., Josa, A. (1990). A constitutive model for partially saturated soils. Géotechnique, 40 (3): 405-430.

Alonso, E. E., Lloret, A., Gens, A. (1995). Experimental behaviour of highly expansive double-structure clay. Proc. 1st Int. Conf. Unsaturated Soils, Paris, 1: 11-16.

Alonso, E. E., Pereira, J. M., Vaunat, J., Olivella, S. (2010). A microstructurally based effective stress for unsaturated soils. Géotechnique, 60 (12), 913-925.

Alonso, E. E., Pinyol, N. M., Gens, A. (2013). Compacted soil behaviour: initial state, structure and constitutive modelling. Géotechnique, 63 (6): 463-478.

Alonso, E. E.; Romero, E., Hoffmann, C. (2011). Hydromechanical behaviour of compacted granular expansive mixtures: experimental and constitutive study. Géotechnique 61 (4): 329-344.

Alonso, E. E., Vaunat, J., Gens, A. (1999). Modelling the mechanical behavior of expansive clays. Engineering Geology, 54: 173-183.

Aung, K. K., Rahardjo, H., Leong, E. C., Toll, D. G. (2001). Relationship between porosimetry measurement and soil-water characteristic curve for an unsaturated residual soil. Geotechnical and Geological Engineering, 19: 401-416. 
Barrera, M. B. (2002). Estudio Experimental del Comportamiento Hidro-mecánico de Suelos Colapsables. Tese de doutorado, Departamento de Engenharia de Terreno e Cartografia, Universidade Politécnica da Catalunia, Barcelona, 480 p.

Borges, C. R. (2010). Comportamento hidráulico de um perfil de solo não saturado de Aparecida de Goiânia-GO. Dissertação (Mestrado), Universidade Federal de Goiás, Escola de Engenharia Civil, Goiânia, GO, 2 v, 257p.

Brutsaert, W. (1996). Probability laws for pore-size distributions. Soil Science, 101: 85-92.

Buenfil, C.M.B. (2007). Caracterización Experimental del Comportamiento Hidromecánico de uma Arcilla Compactada. Tese de doutorado, Departamento de Engenharia de Terreno e Cartografia, Universidade Politécnica da Catalunia, Barcelona, 466 p.

Camapum de Carvalho, J., Mortari, D., Araki, M. S., Palmeira, E. M. (1994). Aspectos relativos à colapsividade da argila porosa de Brasília, Distrito Federal. X Congresso Brasileiro de Mecânica dos Solos e Engenharia de Fundações, Foz do Iguaçu, 3: 11571163.

Chandler, R. J., Crilly, M. S., Montgomery-Smith, G. (1992). "A Low-cost Method of Assessing Clay Desiccation for Lowrise Buildings". Proceedings, Institute of Civil Engineering, 1992, 92 (2): 82-89.

Chandler, R. J., Gutierrez, C. I. (1986). "The Filter-paper Method of Suction Measurement," Géotechnique, 36 (2): 265-268.

Cui, Y. ., Yahia-Aissa, M., Delage, P. (2002). A model for the volume change behavior of heavily compacted swelling clays. Engineering Geology, 64 (2-3), 233-250.

Cuisinier, O., Masrouri, F. (2004). Testing the hydromechanical behavior of a compacted swelling soil. Geotechnical Testing Journal, 27 (6): 598-606.

Decagon Devices, Inc. (2014). WP4 Water Dewpoint Potentiometer. Operator's Manual Version. Decagon Devices, Inc., Pullman, USA (www.decagon.com).

Delage, P. (2002). Experimental unsaturaed soils mechanics. Proc. 3rd Int. Conf. on Unsaturated Soils, UNSAT' 2002, Juca JFT, De Campos TMP, Marino FAM, Recife, Brazil, Balkema, 3: 973-996.

Delage, P., Audiguier M., Cui, Y. J., Howatt, M. D. (1996). Microstructure of a compacted silt. Canadian Geotechnique Journal, 33: 150-158.

Delage, P., Cui, Y. J. (2008). An evaluation of the osmotic method of controlling suction. Geomechanics and Geoengineering, 3 (1): 1-11.

Delage, P., Lefebvre, G. (1984). Study of the structure of a sensitive champlain clay and of its evolution during consolidation. Canadian Geotechnique Journal, 21: 21-35.

Della Vecchia, G., Jommi, C., Romero, E. (2013). A fully coupled elastic-plastic hydromechanical model for compacted soils accounting for clay activity. Int. J. Numer. Anal. Meth. Geomech. 37: 503-535. 
Durner, W. (1994). Hydraulic conductivity estimation for soils with heterogeneous pore structure. Water Resourses Res., 30: 211-223.

Fredlund, D. G., Rahardjo, H. (1993). Soil Mechanics for Unsaturated Soil. John Wiley \& Sons, Inc. New York, USA, 517p.

Fredlund, D. G., Xing, A., Fredlund, M. D., Barbour, S. L. (1995). The relationship of the unsaturated soil shear strength to the soil-water characteristic curve. Canadian Geotechnical Journal, 32: 440-448.

Futai, M. M., Almeida, M. S. S. (2005). An experimental investigation of the mechanical behaviour of an unsaturated gneiss residual soil. Géotechnique, 55 (3): 201-213. doi:10.1680/geot.2005.55.3.201

Gallipoli, D., Wheeler, S.J., Karstunen, M. (2003). Modelling the variation of degree of saturation in a deformable unsaturated soil. Géotechnique, 53 (1): 105-112.

Garcia-Bengochea, I., Lovell, C. W., Altschaeffl, A. G. (1979). Pore distribution and permeability of silty clays. Journal of Geotechnical and Engeneering Division, 105(GT7), 839-856.

Grau, E. D. A. (2014). Efeito da Variação de Umidade no Empuxo em Solos Tropicais. Dissertação de Mestrado, Publicação G.DM-240/2014, Departamento de Engenharia Civil e Ambiental, Universidade de Brasília, Brasília, DF, 105p.

Griffiths, F. J., Joshi, R. C. (1989). Changes in pore size distribution due to consolidation of clays. Géotechnique, 39 (1): 159-167.

Guimarães, R. C. (2002). Análise das Propriedades e Comportamento de um Perfil de Solo Laterítico Aplicada ao Estudo do Desempenho de Estacas Escavadas. Dissertação de Mestrado, Publicação G.DM-090A/02, Departamento de Engenharia Civil e Ambiental, Universidade de Brasília, Brasília, DF, 183p.

Hamblin, A. P. (1981). "Filter Paper Method for Routine Measurement of Field Water Potential”. Journal Hydrology. 53: 355-360.

Hoffmann, C., Alonso, E. E., Romero, E. (2007). Hydro-mechanical behaviour of bentonite pellet mixtures. Physics and Chemistry of the Earth, 32: 832-849.

Juang, C. H., Holtz, R. D. (1986). Fabric, pore size distribution and permeability of sandy soils. Journal of Geotechnical Engineering, ASCE, 112 (9): 855-868.

Koliji, A., Laloui,L., Cuisinier, O., Vulliet, L. (2006). Suction induced effects on the fabric of a structured soil, Transport in Porous Media, 64 (2): 261-278.

Koliji, A., Vulliet, L., Laloui L. (2010). Structural characterization of unsatured aggregated soil. Canadian Geotechnique Journal, 47: 297-311.

Kosugi, K., Hopmans, J. W. (1998). Scaling Water Retention Curves for Soils with Lognormal Pore-Size Distribution. Soil Science Soc. Am. Journal, 62: 1496-1505.

Lambe, T. W., Whitman, R. V. (1969). Soil Mechanics. Wiley. New York. 
Lapierre, C., Leroueil, S., Locat, J. (1990). Mercury intrusión and permeability of Louisville clay. Canadian Geotechnique Journal, 27: 761-773.

Leong, E. C., He., L., Rahardjo, H. (2002). Factors affecting the filter paper method for total and matric suction measurements. Journal Geotechnical Testing, 25 (3).

Leroueil, S., Vaughan, P. R., (1990). The general and congruent effects of structure in natural soils and weak rocks. Géotechnique, 40(3), 467-488.

Li, X., Zhang, L. M. (2009). Characterization of dual-structure pore-size distribution of soil. Canadian Geotechnique Journal, 46: 129-141.

Lima, M. C., Souza, N. M., Camapum de Carvalho, J.; Santos, P. M. Jr. (2002). Obtenção da curva granulométrica utilizando o granulômetro a laser. In: XII Congresso Brasileiro de Mecânica dos Solos e Engenharia de Fundações. São Paulo-SP. XII COBRAMSEG, 1: 457-465.

Lloret, A., Villar, M. V. (2007). Advances on the knowledge of the thermo-hydro-mechanical behaviour of heavily compacted 'FEBEX' bentonite. Physics and Chemistry of the Earth, 32: $701-715$.

Loret, B., Khalili, N., (2000). A three-phase model for unsaturated soils. International Journal for Numerical Analytical Methods Geomechanics, 24: 893-927.

Marinho, F. A. M.(2005). Nature of the soil-water characteristic curves for plastic soils. Journal of Geotechnical and Geoenvironmental Engineering, USA, 131 (5): 654-661.

Marinho, F. A. M. (1994). Medição de Sucção com o Método do Papel Filtro. In: X Congresso Brasileiro de Mecânica dos Solos e Engenharia de Fundações, 1994. Anais... Foz do Iguaçu-PR, 9 p.

Marinho, F. A. M.; Oliveira, O. M. (2006). The filter paper method revisited. Geotechnical Testing Journal, 29 (3): 1-9.

Marshall, T. J. (1958). A relation between permeability and size distribution of pores. Journal of Soil Science, 9 (1): 1-8.

Mascarenha, M. M. A. (2008). Influencia da microestrutura no comportamento hidromecânico de uma argila siltoso não saturada incluindo pequenas deformações. Tese de Doutorado, Departamento de Engenharia Civil, Universidade de Brasília, Brasília, DF, 158p.

Mascarenha, M. M. A., Cordão Neto, M. P., Silva, M. T. M. G (2014). Alternative method for analysing hidromechanical behaviour of unsaturated soils. (submetido e aceito para publicação em: Soils and Rocks).

Miguel, M. G., Bonder, B. H. (2012). Soil-Water Characteristic Curves Obtained for a Colluvial and Lateritic Soil Profile Considering the Macro and Micro Porosity. Geotechnical and Geological Engineering, 30 (6): 1405-1420.

Mitchell, J. K., Soga, K. (2005). Fundamentals of soil behavior (Third). New Jersey: John Wiley \& Sons, INC., 577p. 
Musso, G., Romero, E., Gens, A., Castellanos, E. (2003). The role of structure in the chemicalyy induced deformations of Febex bentonita. Applied Clay Science, 23: 229-237.

Otálvaro, C. I. F. (2013). Comportamento hidromecânico de um solo tropical compactado.. Tese de Doutorado - Universidade de Brasília. Faculdade de Tecnologia. Departamento de Engenharia Civil e Ambiental, Brasília, DF, 122p.

Otálvaro, I. F. C., Cordão Neto, M.P. (2011). Características de la curva de retención de agua en un suelo tropical compactado Characteristics of the water retention curve in a compacted tropical soil. Pan-Am CGS, Geotechnical Conference.

Penumadu, D., Dean, J. (2000). Compressibility effect in evaluating the pore-size distribution of kaolin clay using mercury intrusion porosimetry. Canadian Geotechnical Journal, 37: 393-405.

Prapaharan, S., Altschaeffl, A. G., Dempsey, B. J. (1985). Moisture curve of a compacted clay: mercury intrusion method. Journal of Geotechnical Engineering, 111 (9): 1139-1143.

Prapaharan, S., White, D. M., Altschaeffl, A. G. (1991). Fabric of field- and laboratorycompacted clay. Journal of Geotechnical Engineering, ASCE, 117 (12): 1934-1940.

Romero, E. (1999). Characterisation and Thermo Hydro-mechanical Behaviour of Unsaturated Boom Clay: An Experimental Study. Tese de Doutorado, Departamento de Engenharia de Terreno e Cartografia, Universidade Politécnica da Catalunia, Barcelona. 405p.

Romero, E. (2013). A microstructural insight into clayey soils and their hydraulic properties. Engineering Geology 165: 3-19.

Romero, E., Hoffmann, C., Castellanos, E., Suriol, J., Lloret, A. (2005). Microstructural changes of compacted bentonite induced by hydro-mechanical actions. Advances in 157 Understanding Engineered Clay Barriers, E.E., Alonso \& A. Ledesma (eds.), Taylor \& Francis Group, London: 193-202.

Romero, E., Simms, P. H. (2008). Microstructure investigation in unsaturated soils: A review with special attention to contribution of mercury intrusion porosimetry and environmental scanning electron microscopy. Geotechnical Geol. Engineering. DOI 10.1007/s10706-0089204-5.

Romero, E., Vaunat, J. (2000). Retention curves of deformable clays. Experimental Evidence and Theoretical Approaches in Unsaturated Soils, Tarantino \& Mancuso (eds.), Balkema, Rotterdam: 91-106.

Romero, E., Vecchia, G. D., Jommi, C. (2011). An insight into the water retention properties of compacted clayey soils. Géotechnique 61 (4): 313-328.

Roseno, J. L., Camapum de Carvalho, J. (2007). Avaliação granulométrica de um perfil de solo tropical usando o granulômetro a laser. In: III Simpósio sobre solos tropicais e processos erosivos no Centro-Oeste. Cuiabá, MT: 137-147. 
Sasanian, S., Newson, T. (2013). Use of mercury intrusion porosimetry for microstructural investigation of reconstituted clays at high water contents. Engineering Geology, 158: 1522.

Sheng, D. (2011). Review of fundamental principles in modelling unsaturated soil behaviour. Computers and Geotechnics 38:757-776.

Silva, J. (2007). Estudos preliminares para implantação de trincheiras de infiltração. Dissertação de Mestrado, Departamento de Engenharia Civil e Ambiental, Universidade de Brasília, Brasília, DF, 155 p.

Silva, M. T. M. G. (2009). Metologia para Determinação de Parâmetros para Solos não Saturados Utilizando Ensaios com Umidade Conhecida. Dissertação de Mestrado, Departamento de Engenharia Civil, Universidade de Brasília, Brasília, DF, 98 p.

Simms, P. H., Yanful, E. K. (2001). Measurement and estimation of pore shrinkage and pore distribution in a clayey till during soil-water characteristic curve tests. Canadian Geotechnical Journal, 38: 741-754.

Simms, P. H., Yanful, E. K. (2002). Predicting soil-water characteristic curves of compacted plastic soils from measured pore-size distributions. Géotechnique 52 (4): 269-278.

Simms, P. H., Yanful, E. K. (2004). A discussion of the application of mercury intrusion porosimetry for the investigation of soils, including an evaluation of its use to estimate volume change in compacted clayey soils. Géotechnique 54 (6): 421-426.

Simms P. H.,Yanful, E. K. (2005). A pore-network model for hydromechanical coupling in unsaturated compacted clayey soils. Canadian Geotechnical Journal, 42: 499-514.

Sivakumar, R., Sivakumar, V., Blatz, J., Vimalan, J. (2006). Twincell stress path apparatus for testing unsaturated soils. Geotechnical Testing Journal, 29 (2): 1-5.

Sivakumar, V., Sivakumar, R., Boyd, J., Mackinnon, P. (2010). Mechanical behaviour of unsaturated kaolin (with isotropic and anisotropic stress history). Part 1: wetting and compression behaviour. Géotechnique 60 (8): 581-594.

Sivakumar, V., Wheeler, S.J. (2000). Influence of compaction procedure on the mechanical behaviour of an unsaturated compacted clay. Part 1: wetting and isotropic compression. Géotechnique, 50 (4): 359-368.

Soto, M. A. A. (2004). Comparação entre métodos de imposição e controle de sucção. Universidade de São Paulo.

Tarantino, A., De Col, E. (2008). Compaction behaviour of clay. Geotechnique, 58: 199-213.

Thom, R., Sivakumar, R., Murray, E. J., Mackinnon, P. (2007). Pore size distribution of unsaturated compacted kaolin: the initial states and final states following saturation. Géotechnique, 57 (5): 469-474.

van Genutchen, M. (1980). A closed form equation for predicting the hydraulic conductivity of unsaturated soils. Soil Sci. Soc. Am. J., 44: 892-898. 
Vaunat, J., Romero, E., Jommi, C. (2000). An elastoplastic hydro-mechanical model for unsaturated soils. Experimental Evidence and Theoretical Approaches in Unsaturated Soils, Tarantino \& Mancuso (eds), Balkema, Rotterdam, ISBN 9058091864.

Vazquez, E. V., Moreno R. G., Tarquis A. M., Requejo A. S., Mirás-Avalos, J. M., PazFerreiro, J. (2010). Multifractal characterization of pore size distributions measured by mercury intrusion porosimetry. 19th World Congress of Soil Science, Soil Solutions for a Changing World, 6 August 2010, Brisbane, Australia. Published on DVD.

Vecchia, G. D. Jommi, C., Romero, E. (2012). A fully coupled elastic-plastic hydromechanical model for compacted soils accounting for clay activity. International Journal for Numerical Analytical Methods Geomechanics, Published online in Wiley Online Library (wileyonlinelibrary.com).

Wheeler, S. J., Sharma, R. S., Buisson, M. S. R. (2003). Coupling of hydraulic hysteresis and stress-strain behaviour inunsaturated soils. Géotechnique, 53 (1): 41-54.

Wheeler, S. J., Sivakumar, V. (1995). An elasto-plastic critical state framework for unsaturated soil. Géotechnique, 45 (1): 35-53.

Zhang, B., Liu, W. I., Liu, X. (2006). Scale-dependent nature of the surface fractal dimension for bi- and multi-disperse porous solids by mercury porosimetry. Applied Surface Science. 253:1349-1355. 